\title{
How do different sources of evidence contribute to European policy making in the field of food and nutrition?
}

Citation for published version (APA):

Lafranconi, A. (2021). How do different sources of evidence contribute to European policy making in the field of food and nutrition? [Doctoral Thesis, Maastricht University]. Maastricht University. https://doi.org/10.26481/dis.20210423al

Document status and date:

Published: 01/01/2021

DOI:

10.26481/dis.20210423al

Document Version:

Publisher's PDF, also known as Version of record

Please check the document version of this publication:

- A submitted manuscript is the version of the article upon submission and before peer-review. There can be important differences between the submitted version and the official published version of record.

People interested in the research are advised to contact the author for the final version of the publication, or visit the DOI to the publisher's website.

- The final author version and the galley proof are versions of the publication after peer review.

- The final published version features the final layout of the paper including the volume, issue and page numbers.

Link to publication

\footnotetext{
General rights rights.

- You may freely distribute the URL identifying the publication in the public portal. please follow below link for the End User Agreement:

www.umlib.nl/taverne-license

Take down policy

If you believe that this document breaches copyright please contact us at:

repository@maastrichtuniversity.nl

providing details and we will investigate your claim.
}

Copyright and moral rights for the publications made accessible in the public portal are retained by the authors and/or other copyright owners and it is a condition of accessing publications that users recognise and abide by the legal requirements associated with these

- Users may download and print one copy of any publication from the public portal for the purpose of private study or research.

- You may not further distribute the material or use it for any profit-making activity or commercial gain

If the publication is distributed under the terms of Article $25 \mathrm{fa}$ of the Dutch Copyright Act, indicated by the "Taverne" license above, 
How do different sources of evidence contribute to European policy making in the field of food and nutrition? 
The research for this dissertation was performed at the Department of International Health within CAPHRI, the Care and Public Health Research Institute, Faculty of Health, Medicine and Life Sciences, Maastricht University, in close collaboration with the Joint Research Centre of the European Commission, Directorate Health and Consumer Protection and with the University of Milano Bicocca, Research Centre on Public Health.

Dissertation: How do different sources of evidence contribute to European policy making in the field of food and nutrition?

Author: Alessandra Lafranconi

Cover design, layout design and typesetting: Lorenzo Maria Boldorini

Copyright: Alessandra Lafranconi, Maastricht, 2021

All rights reserved. No part of this publication may be reproduced without permission of the copyright owner.

ISBN: 978-94-6419-180-6

Printed by Gildeprint, Enschede 


\section{How do different sources of evidence contribute to European policy making in the field of food and nutrition?}

\section{Dissertation}

To obtain the degree of Doctor at the Maastricht University, on the authority of the Rector Magnificus Prof. dr. Rianne M. Letschert, in accordance with the decision of the Board of Deans,

to be defended in public on Friday, 23 April 2021, at 16:00 hrs

by Alessandra Lafranconi 


\section{Supervisor}

Dr. Katarzyna Czabanowska

\section{Co-supervisor}

Prof. Dr. Suzanne Babich

\section{Assessment Committee}

Prof. Dr. Helmut Brand (chair)

Prof. Dr. Genc Burazeri,

Prof. Dr. Milena Pavlova

Dr. Paola Palestini, University Milano Bicocca, Italy

Dr. Costas Christophi, Cyprus University of Technology, Cyprus

\section{Funding}

This work was partially supported by the Jean Monnet Erasmus + Grant, 574376-EPP-1-20161-IT-EPPJMO-MODULE 


\section{Table of Contents}

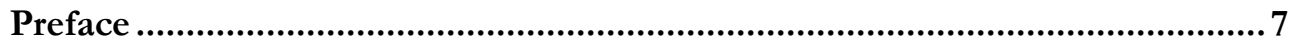

Chapter 1 ...........................................................................................11

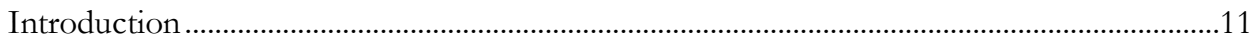

Chapter 2 ........................................................................................ 33

Burden of disease related to current dietary patterns and costs of non-communicable

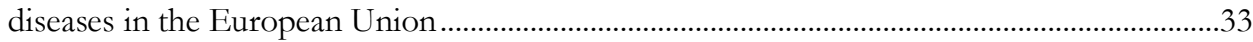

Chapter 3 .................................................................................................. 45

How best to use the EXPO momentum to improve our food environment? ..........................45

Chapter 4 ..................................................................................... 53

Health inequalities in nutrition-related determinants, in the European Union.........................53

Chapter 5 .................................................................................... 71

Facilitators and barriers to the use of economic evaluations in nutrition and public health.71

Chapter 6 ........................................................................................ 89

'Du bist was du isst': challenges in European nutrition policy .................................................89

Chapter 7 .....................................................................................107

Coffee decreases risk of endometrial cancer: a dose-response meta-analysis on prospective

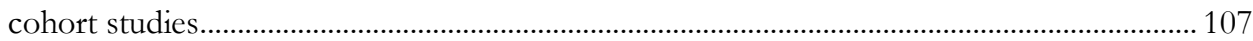

Chapter 8 ...................................................................................127

Coffee intake decreases risk of postmenopausal breast cancer: a dose-response meta-analysis

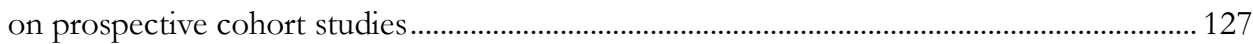

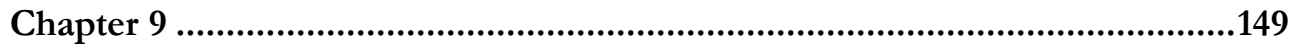

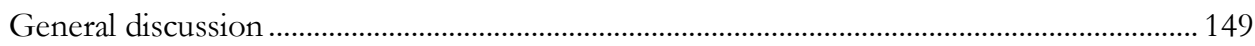

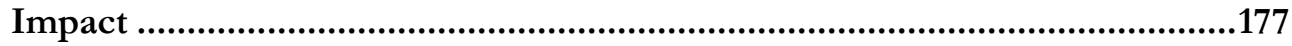

Summary $(E N$, IT, NL) ...............................................................181

List of abbreviations .....................................................................187

Acknowledgments .............................................................................189

Curriculum Vitae ...................................................................................191

List of publications.......................................................................193 

Preface 

The inspiration and foundation for this research was my participation in the Universal Exposition EXPO, "Feeding the planet, energy for life"1, held in Milan in 2015. During that year, I participated in numerous initiatives that revealed how complex and fascinating was the food-related world, and that helped me in shaping my research interests. In the editorial "How best to use the EXPO momentum to improve our food environment?" (1), which I consider the starting stone of my $\mathrm{PhD}$, I reflected on two main themes:

A. A broad variety of policy options influence and guide public health nutrition: price (e.g. food subsidies and taxes) and labelling (e.g. nutritional labels) are two key examples.

B. Huge economic interests are related to environment, health and agriculture; the interplay can be tricky and even science can give different answers, depending on the angle that researchers are prioritizing.

Such themes were then translated into my research interests, for the years to come:

A. If policy options are many, how can we know what works best and for whom? Can we describe the status quo, quantifying the burden of diseases related to poor nutrition? Can we quantify the impacts of different policy options? And, once we have done it, can we allocate scarce resources in a way to maximize impacts and reduce health inequalities at the same time? Would economic analyses, such as costeffectiveness analyses, prove to be effective tools for evaluation of nutritional policies and their impacts?

B. Coffee is food and also a tradable commodity; its production has enormous environmental, social and political impacts, and the scientific evidence related to coffee consumption and health is not obvious. What is its effect on health, particularly on chronic diseases?

Most of my original findings have been published in peer-reviewed journals (European Journal of Public Health, South Eastern European Journal of Public Health and Nutrients) and form separate chapters of this thesis. Moreover, I have used some of my published material (a book chapter (2), an editorial (3) and a commentary (4); a workshop report (5), a scientific society report (6) and few articles I coauthored (7-10) ) in the introduction and discussion, respectively.

In truth, I could not have achieved my current level of success without a strong support group. First of all, my family, who supported me with love and understanding. And secondly, my committee members, each of whom has provided patient advice and guidance throughout the research process. Thank you all for your unwavering support.

\footnotetext{
${ }^{1}$ Expo Milano "Feeding the Planet, Energy for Life" took place in 2015 (May-October) and represented a unique platform for dialogue on nutrition; 21 million people visited the Universal Exposition. Universal Expositions take place every five years; a theme is proposed, and people from virtually all countries meet up around the physical places of the exposition to reflect on the theme. Main thematic areas of Expo Milano were: agricultural policy, food security and nutrition, rural development, sustainability, territorial governance and well-being.
} 


\section{References}

1. Lafranconi A, Birt C. How best to use the EXPO momentum to improve our food environment? European Journal of Public Health. 2015;25(5):751-2.

2. Sironi V, Morini G. Le declinazioni del cibo. Nutrizione, salute, cultura (Italiano). Capitolo 5: Cibo e nutrizione, dai numeri alla pratica, di Alessandra Lafranconi ISBN-10: 8858123352. ISBN-13: 9788858123355 .

3. Lafranconi A, Ray S, Grosso G. Editorial: Public Health Nutrition: Assessing Evidence to Determine Policy and Practice. Front Public Health. 2019;7:21.

4. Lafranconi A, Gomes B, Stankunas M, Babich SM, Rethmeier KA, Czabanowska K, et al. Medical leadership--from inspiration to education. Lancet. 2015;386(10003):1531-2.

5. Lafranconi A, Wollgast J, Caldeira S. Public health and nutrition economics: the numbers behind prevention (2017)

https://ec.europa.eu/jrc/sites/jrcsh/files/phe_ws_report_020517_online.pdf

6. EUPHA Food and Nutrition Working group. Healthy and Sustainable Diets for European Countries. Report of a Working Group.

https://eupha.org/repository/advocacy/EUPHA_report_on_healthy_and_sustainable_diets_20-052017.pdf

7. Collaborators GHAaQ. Measuring performance on the Healthcare Access and Quality Index for 195 countries and territories and selected subnational locations: a systematic analysis from the Global Burden of Disease Study 2016. Lancet. 2018;391(10136):2236-71.

8. Collaborators GS. Measuring progress from 1990 to 2017 and projecting attainment to 2030 of the health-related Sustainable Development Goals for 195 countries and territories: a systematic analysis for the Global Burden of Disease Study 2017. Lancet. 2018;392(10159):2091-138.

9. Collaborators GDaH. Global, regional, and national disability-adjusted life-years (DALYs) for 359 diseases and injuries and healthy life expectancy (HALE) for 195 countries and territories, 1990-2017: a systematic analysis for the Global Burden of Disease Study 2017. Lancet. 2018;392(10159):1859-922. 10. Collaborators GRF. Global, regional, and national comparative risk assessment of 84 behavioural, environmental and occupational, and metabolic risks or clusters of risks for 195 countries and territories, 1990-2017: a systematic analysis for the Global Burden of Disease Study 2017. Lancet.

2018;392(10159):1923-94.

All links contained in this reference section have been checked on 3 September 2020 


\section{Chapter 1}

Introduction 



\section{Presentation of the investigated field}

Nutrition has received significant public health attention in the last few years due to research on its impact on non-communicable chronic and degenerative diseases $(1,2)$. In the European Union (EU), the prevalence of non-communicable diseases (NCDs) is high and public budgets to finance health and wellbeing are constrained (3).

In the EU, the estimated healthcare costs for cardiovascular diseases (CVDs) and cancers were around $€ 111$ billion a year (2015) and $€ 51$ billion a year (2009), respectively (4, 5); in the European Region ${ }^{1}$, around $€ 145$ billion were spent on healthcare for diabetes, in 2015 (6).

Beyond the obvious aspiration to build healthier societies where wellbeing goes hand in hand with productivity and growth (7), there is a financial argument that cannot be overlooked. The relationship between obesity and economic burden on health systems provides a clear example: patients who are obese use more healthcare services and incur more costs to healthcare systems than patients of a normal weight ( $8 \%$ and $12 \%$ more in US and EU, respectively) (8-11). Along with ageing, obesity will play a key role in shaping the future use of healthcare services (12-16).

Non-healthcare costs further increase the economic burden of nutrition-related diseases: in the EU, CVDs were responsible for over 45 billion in productivity losses and over 43 billion in informal/family care spending (4), while cancers cost over $€ 50$ billion in productivity losses and $€ 20$ billion in informal/family care spending (5), in 2009. The problem is not limited to Europe and it is expected to worsen; according to the World Economic Forum, "over the next 20 years, NCDs will cost more than US\$ 30 trillion, representing 48\% of global GDP in 2010" (17).

The distribution of the burden of chronic diseases is uneven across societies: social and economic conditions have a role in shaping people's lives, and in shaping their health too. Such conditions are called social determinants of health, and lead to vast health inequalities ${ }^{2}$ both within and between countries (18). With regards to food and nutrition, obesity has been clearly linked to social determinants: in the WHO European Region, about $20-25 \%$ of the risk of obesity among men and 40-50\% among women can be attributed to differences in the socioeconomic status (19-21). In order to address the issue, disparities in food habits according to the socioeconomic status have been studied in depth (22-26).

${ }^{1}$ IDF members of the European Region: Albania, Armenia, Austria, Azerbaijan, Belarus, Belgium, Bulgaria, Croatia, Cyprus, Czech Republic, Estonia, Faroe Islands, Finland, France, Georgia, Germany, Greece, Hungary, Iceland, Israel, Italy, Kazakhstan, Kyrgyzstan, Latvia, Lithuania, Luxembourg, Malta, Moldova, North Macedonia, Norway, Poland, Portugal, Romania, Russia, Serbia, Slovakia, Slovenia, Spain, Sweden, Switzerland, Turkey, Ukraine, Uzbekistan.

${ }^{2}$ Health inequalities are unjust and avoidable differences in health status across the population and between different population groups. Many European cities are victims of the so-called Glasgow effect, defined as the extreme difference of more than 30 years in life expectancy in a physical distance of few kilometers, when comparing people between the most deprived and the most affluent communities. 
Prevention is key in counteracting the increasing burden of chronic diseases. In particular, primary prevention has been repeatedly shown to be cost effective, yet health expenditure is seldom allocated to prevention policies: according to OECD data, spending on disease prevention accounts for only 3\% of total health spending, and between 2009 and 2014 spending on preventive care shrunk by $1.9 \%$ on an annual basis (27). Health promotion and health protection policies are crucial in addressing the burden of disease (28); yet, similarly to disease prevention, health promotion and health protection suffer from little political and financial attention. A self-assessment carried out in the WHO European Region found that health promotion is underdeveloped, particularly for policies on NCDs and lifestyle risk factors; moreover, inclusion of equity in legislation and policy-making was reported by only half of EU countries (29).

Public health policies may have a vertical (one disease or risk factor or exposure, only) or a horizontal (holistic, community-based) orientation ${ }^{3}$. Moreover, they can be allocative policies, with redistributive effects, or regulatory policies, meant to influence behaviors. A useful way to classify regulatory policies has been proposed by the Nuffield Council on Bioethics (30): the Nuffield intervention ladder groups health policies according to the way they can affect peoples' choices, through behavioral changes. Policies and programs that are higher up the ladder have a more intrusive effect, and a strong public health rationale should justify their use:

- Eliminate choice;

- $\quad$ Restrict choice;

- $\quad$ Guide choice by disincentives;

- Guide choice by incentives;

- $\quad$ Guide choice by changing the default policy;

- Enable choice;

- Provide information;

- Do nothing.

With regards to food and nutritional policies, a wide variety of options are available, from education and counselling to regulation and fiscal measures (31-38).

Despite their abundance, it is yet not clear which policies work best in improving people lives and in reducing national healthcare expenditures (39-41). Progress in global, national and local public health policies has been made: for example, at the EU level, the Impact Assessment (IA) has been introduced as a key evaluation tool for policies across sectors that are "likely to have significant economic, environmental or social impacts". According to the 2015 European

\footnotetext{
${ }^{3}$ Health policies are those interventions that affect health, either having or not having health as the main policy objective. Examples of policy interventions and social programs that have important ancillary health effects are social housing, early childhood education, food provision, and the various forms of income support. In this thesis, only health policies having health as the main policy objective will be treated.
} 
Commission Better Regulation Agenda, an IA is required to identify viable policy options, to assess their economic, social and environmental impacts, to stratify such impacts across subpopulations, to compare policy alternatives in terms of effectiveness, efficiency and coherence, and to monitor and retrospectively evaluate the implemented ones (42).

With regards to nutrition, the recent European Commission's report on trans-fatty acid (TFA) is an example of how an Impact Assessment can be used as a reference guide in policy making. The report, which builds upon literature reviews, data analyses and extensive consultation with national authorities and relevant stakeholders, summarizes the presence of TFA in foods and in the overall diet of the EU population, presents the already in-place policy options to limit TFA consumption worldwide and their effectiveness (i.e. legal TFA limits, mandatory TFA labelling, and voluntary reformulation), and outlines some of the possible consequences of such approaches in the EU, with a focus on economic and social impacts $(43,44)$. The case on TFA culminated in the 2019 EU Regulation, that strictly limits the amount of industrially produced TFA in all foods sold to EU consumers (45). Such case, to which the 2017 Council Conclusions of Maltese presidency paved the way (46), should be read as a good practice example on how robust and scientifically sound economic evaluations have influenced and guided health policy decision making.

Economic evaluation of prevention and public health interventions remain largely unaddressed for reasons such as low funding, low interest from the community and the difficulties in performing it (47). Yet, economic evaluations can assist decision makers in assessing whether public health interventions are "good value for money", through the comparison of two or more courses of action in terms of both costs (or "inputs") and consequences (or “outcomes") $4(48,49)$.

Economic evaluations of public health policies and interventions could inform decision-making and facilitate an optimum allocation of scarce health resources (50). In this context, nutrition-economic evaluation studies are very promising: the majority of public health economic evaluations conducted so far show that nutrition-based interventions aimed at reducing incidence of chronic disease are cost-saving or cost-effective, with salt-related interventions being particularly cost-effective and even cost-saving $(50,51)$. Yet, the economic evidence in this area is scarce, and methodological issues challenge the robustness of results (5254). Moreover, the decision criteria are purely economic and don't take into account other common policy principles such as equity, thus further hampering the applicability of economic evidence $(55,56)$.

\footnotetext{
${ }_{4}^{4}$ Different techniques are used to perform economic evaluations, and the most popular ones are: costeffectiveness analysis (CEA), cost-utility analysis (CUA, which is a subtype of CEA), and cost-benefit analysis (CBA). The main difference lays in the way to quantify outcomes: in CEA and CUA, the outcome is measured in physical units or utility, respectively (e.g. years of survival, Quality Adjusted Life Years, QALYs, or Disability Adjusted Life Years, DALYs); in CBA, both input and outcome are measured in economic costs.
} 
In recent years, nutrition policies have been evaluated through environmental lenses, too (57, 58): current patterns of consumption have been proven to be unsustainable, due to their multiple environmental impacts on climate change, food waste, water stress and resource exploitation (59-62). In turn, these environmental effects have detrimental repercussions on economic activities and human health, for example in the field of food production and food security (63, 64). Food safety and nutrition security have also profound links with environmental aspects (6567).

The EU enjoys a prominent position in the field of environment and public health: very early in its history, the EU has endorsed two fundamental principles, namely the precautionary principle and the high level of human health and environmental protection principle. Despite the fact that their origins are related to environmental policies, in practice, the scope of these principles is far wider. Nowadays, they cover consumer policy, food policy and policies in the field of human, animal and plant health. Further referral to such principles is presented in Box 1.

Box 1. Precautionary principle and high level of protection principle.

The precautionary principle is detailed in Article $191(1,2,3)$ of the Treaty on the Functioning of the European Union (TFEU)

191 (1). Union policy on the environment shall contribute to pursuit of the following objectives: preserving, protecting and improving the quality of the environment, protecting human health, prudent and rational utilization of natural resources, promoting measures at international level to deal with regional or worldwide environmental problems, and in particular combating climate change. (2). Union policy on the environment shall aim at a high level of protection taking into account the diversity of situations in the various regions of the Union. It shall be based on the precautionary principle and on the principles that preventive action should be taken, that environmental damage should as a priority be rectified at source and that the polluter should pay. In this context, harmonization measures answering environmental protection requirements shall include, where appropriate, a safeguard clause allowing Member States to take provisional measures, for non-economic environmental reasons, subject to a procedure of inspection by the Union. (3). In preparing its policy on the environment, the Union shall take account of: available scientific and technical data, environmental conditions in the various regions of the Union, the potential benefits and costs of action or lack of action, the economic and social development of the Union as a whole and the balanced development of its regions.

According to the European Commission, the precautionary principle may be invoked when a phenomenon, product or process may have a dangerous effect, identified by a scientifically solid and objective evaluation, if a certain degree of uncertainty is entailed in the results of this evaluation.

The precautionary principle may only be called upon in the event of a potential risk, thus ensuring a high level of protection through preventative decision-taking in case of risk. It can never justify arbitrary decisions, and three preliminary conditions are necessary to have recourse to the principle: identification of potentially adverse effects; availability of scientific evaluations; presence of scientific uncertainty. If these conditions are met, potential benefits and costs can be identified. Moreover, the diversity of situations in the various regions of the Union is considered, in order to limit unbalanced economic and social development and related inequalities.

The high level of human health and environmental protection principle is detailed in Article 114 (3) and in Article 168 (1) of the Treaty on the Functioning of the European Union (TFEU).

114 (3). The Commission, in its proposals envisaged in paragraph 1 concerning health, safety, environmental protection and consumer protection, will take as a base a high level of protection, taking account in particular of any new development based on scientific facts. Within their respective powers, the European Parliament and the Council will also seek to achieve this objective.

168 (1). A high level of human health protection shall be ensured in the definition and implementation of all Union policies and activities.

A high level of human health protection and of environmental protection is enshrined in the Charter of Fundamental Rights of the European Union, article 35 and article 37, respectively.

Art. 35. Everyone has the right of access to preventive health care and the right to benefit from medical treatment under the conditions established by national laws and practices. A high level of human health protection shall be ensured in the definition and implementation of all Union policies and activities. 
With regards to nutrition and food system, a considerable landmark in EU policy making is the 2020 publication of the EU's "Farm to Fork" strategy for sustainable food. Such strategy is part of the European Green Deal for the EU and its citizens and contains a list of key actions in the field of: climate change; clean energy; industrial strategy and circular economy; mobility; Common Agricultural Policy (CAP); biodiversity; chemical pollution; sustainability in all policies (68).

Concerted actions at the global level are led by the United Nation 2030 Agenda for Sustainable Development: the 17 Sustainable Development Goals (SDGs), which lay at the heart of the Agenda, are an urgent call for action by all countries, to adopt strategies to improve health and education, reduce inequality and spur economic growth, while tackling environmental challenges(69).

In summary, food and nutrition policies are powerful instruments are an important tool to address population health through action on health determinants and their unequal distribution (70-73). Moreover, if properly evaluated through the use of economic evaluations, food and nutrition policies that are cost-effective or even cost-saving can maximize health and economic costs simultaneously (74-76). Lastly, food and nutrition policies are key levers for improving food systems and to promote planetary health, meaning "the health of human civilization and the state of the natural systems on which it depends" $(77,78)$. 


\section{Gaps in knowledge}

Based on the scholarly evidence in the field of public health nutrition policy-making, we can identify consensus on a variety of topics, listed in Figure 1. Various gaps in knowledge deserve to be further investigated, and such gaps can be grouped into three main themes: equalityoriented approaches, economic analyses, and collection of systematic data. These three elements constitute the core of my $\mathrm{PhD}$ thesis.

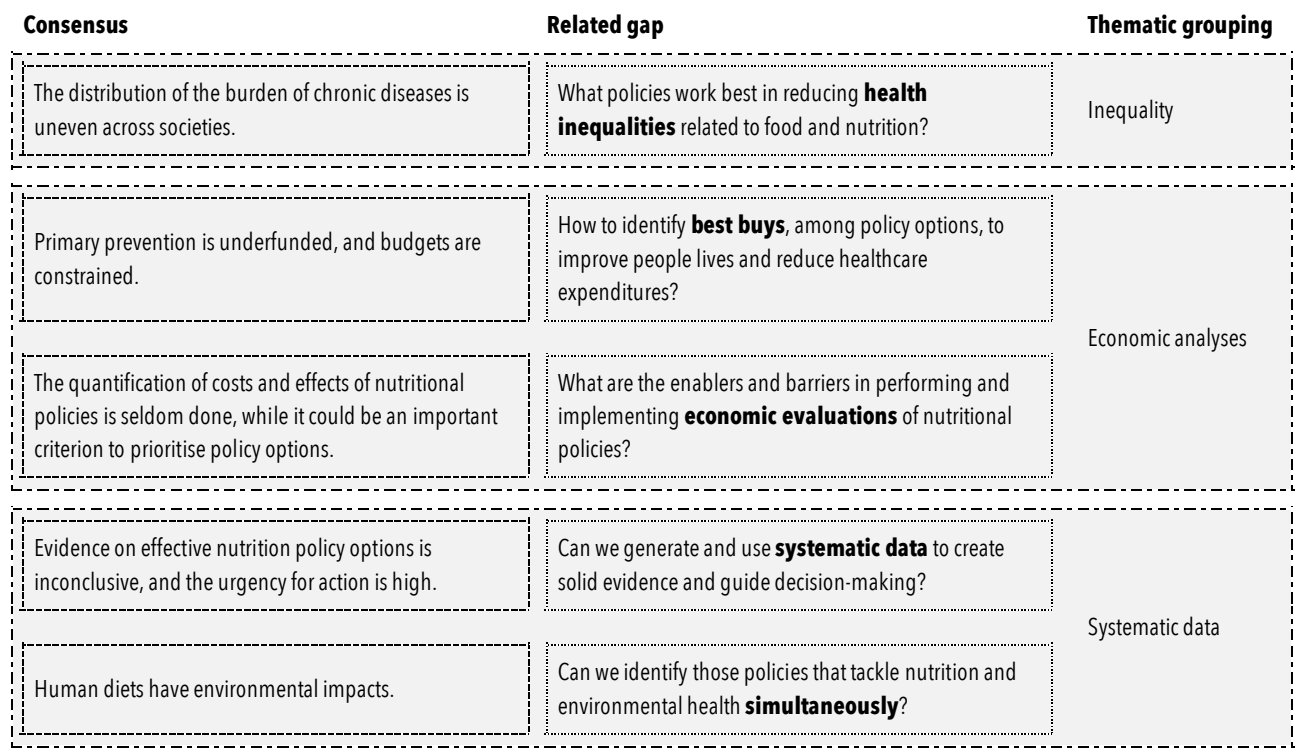

Figure 1. Research gaps and thematic grouping. Source: compiled by the author. 


\section{Research questions}

The present dissertation aims to explore the following overarching research question: How can equality-oriented approaches, economic analyses and systematic data collection contribute to informing food and nutrition policies in Europe, to improve public health?

The overarching research question will be addressed through the following, more granular questions:

- Food and nutrition policy in Europe: How to address nutrition-related health inequalities (chapter 4)? What is the role of economic analyses in evaluating food and nutrition policies (chapter 5)?

- European nutrition policy on healthy and sustainable diets: What are the practical implications for public health policy makers when addressing health and environment simultaneously (chapter 6)?

- Coffee is a case example of a food and tradable good, a link between health and economics: How systematically collected data inform our knowledge on chronic diseases, using the case of coffee in relation to breast and endometrial cancers (chapter $7-8) ?$

The research questions give rise to the chapters' structures summarized in Table 1. The table gives an overview of the main research question, the five research sub-questions and the general structure. The sub-questions are analyzed within this thesis, and collectively answer the main research question.

Table 1: Research question, sub-questions, and structure of the PhD thesis. Source: compiled by the author.

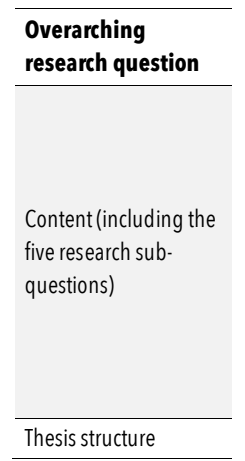

$\begin{aligned} & \text { How such factors as equality-oriented approaches, economic analyses and systematic data collection can } \\
& \text { contribute to informing food and nutrition policies in Europe, to improve public health? }\end{aligned}$
\begin{tabular}{lllll} 
Food and nutrition & Food and nutrition & European nutrition & Case study: & Case study: \\
policy in Europe: & policy in Europe: & policy on healthy and & How systematic & How systematically \\
How to address & What is the role of & sustainable diets: & collected data inform & collected data inform \\
nutrition-related & economic analyses in & What are the practical & our knowledge on & our knowledge on \\
health inequalities? & evaluating food and & implications for & chronic diseases, & chronic diseases, \\
& nutrition policies? & public health policy & using the case of & using the case of \\
& & makers when & coffee in relation to & coffee in relation to \\
& & considering health & endometrial cancer? & breast cancer? \\
& & and environment & & \\
\hline Chapter 4 & simultaneously? & & Chapter 7 & Chapter 8
\end{tabular}




\section{Methodology}

This thesis deals at its core with public health nutrition in a European public health perspective, and is designed around the main research question: How can equality-oriented approaches, economic analyses and systematic data collection contribute to informing food and nutrition policies in Europe, to improve public health?

This question indicates the three investigated perspectives: a health policy perspective, an economic perspective and a data and information perspective. The variety of applied methods in this thesis underline the different research foci.

The health policy perspective has been studied through the use of a policy brief and a scoping review, to identify nutrition policy options with positive effects in reducing health inequalities (policy brief), and to detect those policies having synergies on health and environment (scoping review).

The economic perspective has been explored through content analysis, to explore expert perceptions on the use of economic analyses to evaluate public health nutrition interventions, and to identify facilitators and barriers in the implementation of such analyses.

The data and information perspective have been examined through systematic reviews and metaanalyses, to assess and quantify the effect of coffee consumption on breast and endometrial cancers.

In Table 2, the methodological approaches are summarized.

Table 2: Methodological approaches used to address the research question and sub-questions. Source: compiled by the author.

\begin{tabular}{|c|c|c|c|c|c|}
\hline $\begin{array}{l}\text { Overarching } \\
\text { research question }\end{array}$ & \multicolumn{5}{|c|}{$\begin{array}{l}\text { How such factors as equality-oriented approaches, economic analyses and systematic data collection can } \\
\text { contribute to informing food and nutrition policies in Europe, to improve public health? }\end{array}$} \\
\hline $\begin{array}{l}\text { Content (including the } \\
\text { five research sub- } \\
\text { questions) }\end{array}$ & $\begin{array}{l}\text { Food and nutrition } \\
\text { policy in Europe: } \\
\text { How to address } \\
\text { nutrition-related } \\
\text { health inequalities? }\end{array}$ & $\begin{array}{l}\text { Food and nutrition } \\
\text { policy in Europe: } \\
\text { What is the role of } \\
\text { economic analyses in } \\
\text { evaluating food and } \\
\text { nutrition policies? }\end{array}$ & $\begin{array}{l}\text { European nutrition } \\
\text { policy on healthy and } \\
\text { sustainable diets: } \\
\text { What are the practical } \\
\text { implications for } \\
\text { public health policy } \\
\text { makers when } \\
\text { considering health } \\
\text { and environment } \\
\text { simultaneously? }\end{array}$ & $\begin{array}{l}\text { Case study: } \\
\text { How systematic } \\
\text { collected data inform } \\
\text { our knowledge on } \\
\text { chronic diseases, } \\
\text { using the case of } \\
\text { coffee in relation to } \\
\text { endometrial cancer? }\end{array}$ & $\begin{array}{l}\text { Case study: } \\
\text { How systematically } \\
\text { collected data inform } \\
\text { our knowledge on } \\
\text { chronic diseases, } \\
\text { using the case of } \\
\text { coffee in relation to } \\
\text { breast cancer? }\end{array}$ \\
\hline Thesis structure & Chapter 4 & Chapter 5 & Chapter 6 & Chapter 7 & Chapter 8 \\
\hline Methodology & Policy brief & Content analysis & Scoping review & Meta-analysis & Meta-analysis \\
\hline
\end{tabular}




\section{Conceptual framework}

According to the World Health Organization (WHO), there are 10 Essential Public Health Operations (EPHOs) that "countries can adapt and work on together, to assess and plan for stronger public health services and capacities" 5 . At the core of these operations, there are the three service-delivery EPHOs: Health Protection, Disease Prevention and Health Promotion.

The research questions, generated by the evidence and gaps in knowledge described above, are relevant to public health because they address nutrition and policy issues falling in the domain of health promotion, health protection and disease prevention, as reflected by EPHOs. The conceptual framework is sketched in Figure 2.

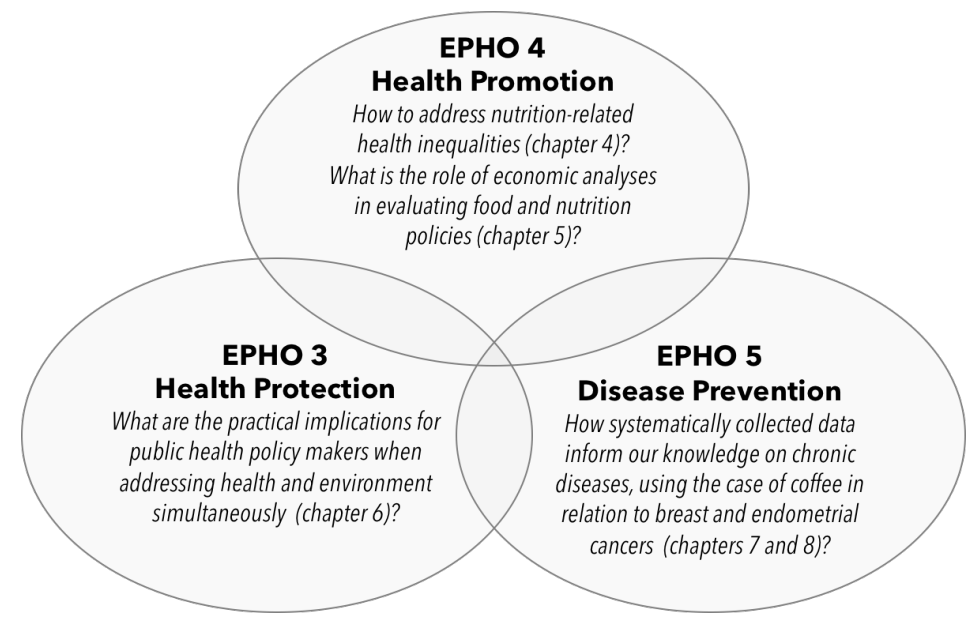

Figure 2. Conceptual framework of the thesis. Source: compiled by the author, based on the WHO Essential Public Health Operations (EPHOs).

5 EPHO1: Surveillance of population health and wellbeing; EPHO2: Monitoring and response to health hazards and emergencies; EPHO3: Health protection including environmental occupational, food safety and others; EPHO4: Health Promotion including action to address social determinants and health inequity; EPHO5: Disease prevention, including early detection of illness; EPHO6: Assuring governance for health and wellbeing; EPHO7: Assuring a sufficient and competent public health workforce; EPHO8: Assuring sustainable organizational structures and financing; EPHO9: Advocacy communication and social mobilization for health; EPHO10: Advancing public health research to inform policy and practice. 


\section{EPHO 4: Health Promotion including action to address social determinants and health inequity}

Health promotion comes to light in 1986, with the Ottawa Charter (79), as a response to the growing demand for public health, which had already led to the drafting of the Declaration of Alma Ata in 1978, and to the document Health for All in the same year, as well as the debate on intersectoral actions for health, which occurred during the WHO World Health Assembly. The Ottawa Charter clearly states that to achieve a state of complete physical, mental and social wellbeing, an individual or group must be able to identify and to realize aspirations, to satisfy needs, and to change or cope with the environment. Central to this process is the strengthening of the community, which draws on existing human and material resources. The concept of health develops then a further sense: health is no longer a goal, but a resource, which benefits the entire community. Hence, the promotion of health, which is the process that allows individuals or groups to increase control over (and improve) their own health, deeply relies on empowerment. The health sector is asked to orient the prevention and treatment of diseases to health promotion. Health promotion involves not only the health sector but any other dimension that affects the life of the individual. Only coordinated actions will lead to equitable health policy, fair income policies and meaningful social policies.

Health promotion interventions act on healthy and sick patients, and try to influence individual behaviors, encouraging the ones believed to produce positive health effects and discouraging the others. Health promotion interventions frequently take the form of public information campaigns (low-intensity program), but high-intensity programs are not uncommon either. While the decision to undertake the health action is ultimately up to the individual, delivery of health promotion programs is targeted at a group or population.

According to the WHO, the purpose of EPHO 4, Health Promotion, is "to promote population health and well-being by addressing inequalities and the broader social and environmental determinants of health. Supportive environments need to be created and community assets strengthened to empower individuals and populations to have healthier lifestyles and behaviors across the life course. Multisectoral action is needed to create healthy environments and to reduce inequalities and risk factors in social and environmental determinants of health."

With regards to nutrition, physical activity and obesity, WHO explicitly points to the importance of developing, implementing and evaluating policies to promote healthy diets and to prevent overweight and obesity (29).

In the current thesis, EPHO 4 gives origin to Chapter 4 (health inequalities in nutrition-related determinants and policies to reduce them in the EU countries) and Chapter 5 (economic analyses of nutrition interventions to promote healthy diets). 


\section{EPHO 3: Health protection including environmental, occupational, food safety and others}

Health protection aims to reduce health risks by changing the physical or social environment in which people live. The role of individual beneficiaries of health protection interventions is either passive or limited to compliance with laws or regulations (80). A familiar example in the context of food and nutrition would be the adherence to the HACCP (Hazard Analysis and Critical Control Point) regulation, to minimize the risks of ingesting contaminated or, more generally, unhealthy food (81).

According to the WHO, "the purpose of this essential public health operation (EPHO) is to use intelligence from surveillance and monitoring in developing services that are meant to protect health from communicable diseases and environmental risks and hazards".

With regards to nutrition and food systems, WHO gives emphasis to cross-sectoral impacts on climate change, green health services and sustainable development: the environmental impact of the current food patterns, from production to delivery and consumption, are not trivial, and numerous calls for healthy and sustainable diets have been made $(82,83)$.

In the current thesis, EPHO 3 gives foundation to Chapter 6 (healthy and sustainable diets, with practical implications for public health policy making in Europe).

\section{EPHO 5: Disease prevention, including early detection of illness}

Disease prevention consists of all the activities undertaken to minimize a risk, either its magnitude or in its likelihood (84). Disease prevention services are usually provided to groups of individuals which face high clinical risks (for example: analysis of blood in feces for people older than 50 years). The example is a form of secondary prevention, because the action is on an already-present disease, and the objective is to detect it early enough to have a better prognosis. Primary prevention, on the contrary, implies the absence of a disease (the action is therefore on healthy subjects); a classic example is immunization (for instance, with regards to nutrition, a relevant example is HAV vaccine to avoid food-borne hepatitis).

According to the WHO, "the purpose of this essential public health operation (EPHO) is to prevent disease through actions at primary, secondary and tertiary levels", and the three levels of prevention are defined as it follows:

- improving the overall health of the population (primary prevention)

- improving health of those already having a health-condition (secondary prevention)

- improving treatment and recovery (tertiary prevention).

With regards to nutrition, WHO addresses the importance of obesity prevention as a form of primary prevention, and of screening programmes and health checks as a form of secondary prevention to fight cancers and cardiorespiratory diseases (39). 
In the current thesis, EPHO 5 gives structure to Chapters 7 and 8 (analyses of the role of coffee in preventing the occurrence of breast and endometrial cancers in developed populations).

Table 3 is a summary of the main research question and sub-questions, the methodological approaches used to address each question, and the conceptual framework.

Table 3: Conceptual framework of the PhD thesis and the related research question and sub-questions. Source: compiled by the author.

\begin{tabular}{|c|c|c|c|c|c|}
\hline $\begin{array}{l}\text { Overarching } \\
\text { research question }\end{array}$ & \multicolumn{5}{|c|}{$\begin{array}{l}\text { How such factors as equality-oriented approaches, economic analyses and systematic data collection can } \\
\text { contribute to informing food and nutrition policies in Europe, to improve public health? }\end{array}$} \\
\hline $\begin{array}{l}\text { Content (including the } \\
\text { five research sub- } \\
\text { questions) }\end{array}$ & $\begin{array}{l}\text { Food and nutrition } \\
\text { policy in Europe: } \\
\text { How to address } \\
\text { nutrition-related } \\
\text { health inequalities? }\end{array}$ & $\begin{array}{l}\text { Food and nutrition } \\
\text { policy in Europe: } \\
\text { What is the role of } \\
\text { economic analyses in } \\
\text { evaluating food and } \\
\text { nutrition policies? }\end{array}$ & $\begin{array}{l}\text { European nutrition } \\
\text { policy on healthy and } \\
\text { sustainable diets: } \\
\text { What are the } \\
\text { practical implications } \\
\text { for public health } \\
\text { policy makers when } \\
\text { considering health } \\
\text { and environment } \\
\text { simultaneously? }\end{array}$ & $\begin{array}{l}\text { Case study: } \\
\text { How systematic } \\
\text { collected data inform } \\
\text { our knowledge on } \\
\text { chronic diseases, } \\
\text { using the case of } \\
\text { coffee in relation to } \\
\text { endometrial cancer? }\end{array}$ & $\begin{array}{l}\text { Case study: } \\
\text { How systematically } \\
\text { collected data inform } \\
\text { our knowledge on } \\
\text { chronic diseases, } \\
\text { using the case of } \\
\text { coffee in relation to } \\
\text { breast cancer? }\end{array}$ \\
\hline Thesis structure & Chapter 4 & Chapter 5 & Chapter 6 & Chapter 7 & Chapter 8 \\
\hline Methodology & Policy brief & Content analysis & Scoping review & Meta-analysis & Meta-analysis \\
\hline Conceptual framework & \multicolumn{2}{|c|}{ Health promotion } & Health protection & \multicolumn{2}{|c|}{ Disease prevention } \\
\hline
\end{tabular}




\section{Outline of the PhD thesis}

The present dissertation is articulated in nine chapters. The introductory chapter (Chapter 1) gave an overview of the investigated field and its related gaps in knowledge. Furthermore, the chapter presented the research questions, the methodology deployed to develop them, the conceptual framework related to the thesis structure, and culminated with the outline.

As a starting point, Chapter 2 describes the burden of disease related to current dietary patterns and costs of non-communicable diseases in the European Union. In this chapter, social and economic burdens of chronic diseases in Europe are quantified, with a focus on determinants related to lifestyle and in particular to nutrition, thus making a case for European nutrition policy making.

Chapter 3 assesses the status quo in public health nutrition in Europe, and it should be intended as a call for action: the abundance of policy options in nutrition public health and the interplay of economic interests should prompt scientists to be careful in posing the right research questions, to improve our food environment.

Chapter 4 focuses on nutrition-related health inequalities. It investigates the role of socioeconomic drivers in generating unequal exposure to nutrition-related determinants in Europe and identifies key policies to reduce nutrition-related inequalities. As the chapter aims to summarize consolidated facts on which the public health community has already expressed a consensus, the primary source is represented by gray literature, such as official documents and reports produced by governments, academics, and international organizations.

Chapter 5 further reflects on public health policies, and it elaborates on the paucity of economic evaluations of such policies and interventions. It consists of a qualitative study aimed at exploring facilitators and barriers in conducting and using economic analysis to inform decision makers in the field of public health nutrition, in the European Region.

Chapter 6 describes current dietary patterns in Europe, and the key challenges they pose, following an approach "from field to fork". A scoping review sketches existing patterns of farming and food production, and their effects on both health and the environment, with a focus on the association of 'unhealthy' nutrition and detrimental environmental impacts. Evidence on current European diets is summarized, costs and benefits in transitioning to healthy and sustainable diets are detailed, and sustainable dietary guidelines are identified as the way forward to protect our environment and our health.

Chapters 7 and 8 contain secondary data on coffee in relation to cancer outcomes (endometrial and breast cancers) in developed countries. Two systematic reviews and dose-response metaanalyses explore the relationship between coffee consumption and endometrial and breast cancer, respectively.

Finally, the concluding Chapter 9, the General Discussion, provides a synthesis of the main findings from this research. It reflects on health inequalities in nutrition, suggesting to opt for policies associated to reduction in health inequalities (e.g. reformulation initiatives, school 
interventions, interventions aimed to change the physical environment and the default options); it elaborates on the asymmetries between health economists and policy makers with regards to economic analyses to evaluate public health policies; it enlarges the focus to environment, and it calls for sustainable dietary guidelines as suitable tools to take into account human health and environment together. Lastly, the chapter addresses the limitations of this thesis and devises implications for policy and future research. 


\section{References}

1. Mozaffarian D, Rosenberg I, Uauy R. History of modern nutrition science-implications for current research, dietary guidelines, and food policy. BMJ. 2018;361:k2392.

2. Afshin A, Sur PJ, Fay KA, Cornaby L, Ferrara G, Salama JS, et al. Health effects of dietary risks in 195 countries, 1990-2017: a systematic analysis for the Global Burden of Disease Study 2017. The Lancet. 2019;393(10184):1958-72.

3. Reeves A, McKee M, Stuckler D. The attack on universal health coverage in Europe: recession, austerity and unmet needs. Eur J Public Health. 2015;25(3):364-5.

4. EHN. European Cardiovascular Disease Statistics (2017)

http://www.ehnheart.org/cvd-statistics/cvd-statistics-2017.html

5. Luengo-Fernandez R, Leal J, Gray A, Sullivan R. Economic burden of cancer across the European Union: a population-based cost analysis. The LancetOncology. 2013;14(12):1165-74.

6. IDF. Diabetes Atlas - 9th edition (2019)

https://diabetesatlas.org/en/

7. Kumar A, Chen W. Health, education and the dynamics of cross-country productivity differences.

Applied Economics Letters. 2013;20(12):1160-4.

8. Cecchini M, Sassi F. Preventing Obesity in the USA: Impact on Health Service Utilization and Costs. PharmacoEconomics. 2015;33(7):765-76.

9. Cawley J, Meyerhoefer C, Biener A, Hammer M, Wintfeld N. Savings in Medical Expenditures Associated with Reductions in Body Mass Index Among US Adults with Obesity, by Diabetes Status. PharmacoEconomics. 2015;33(7):707-22.

10. Dee A, Kearns K, O'Neill C, Sharp L, Staines A, O'Dwyer V, et al. The direct and indirect costs of both overweight and obesity: a systematic review. BMC research notes. 2014;7:242-0500-7-242.

11. Tremmel M, Gerdtham UG, Nilsson PM, Saha S. Economic Burden of Obesity: A Systematic Literature Review. International journal of environmental research and public health.

2017;14(4):10.3390/ijerph14040435.

12. Sassi F, Cecchini M, Lauer J, Chisholm D. Improving Lifestyles, Tackling Obesity: The Health and Economic Impact of Prevention Strategies. OECD Health Working Paper. OECD Publishing; 2009 2009/11/20/. Report No.: 48.

13. Berghofer A, Pischon T, Reinhold T, Apovian CM, Sharma AM, Willich SN. Obesity prevalence from a European perspective: a systematic review. BMC public health. 2008;8:200-2458-8-200.

14. Kelly T, Yang W, Chen CS, Reynolds K, He J. Global burden of obesity in 2005 and projections to 2030. International journal of obesity (2005). 2008;32(9):1431-7.

15. Lehnert T, Sonntag D, Konnopka A, Riedel-Heller S, Konig HH. Economic costs of overweight and obesity. Best practice \& researchClinical endocrinology \& metabolism. 2013;27(2):105-15.

16. Webber L, Divajeva D, Marsh T, McPherson K, Brown M, Galea G, et al. The future burden of obesity-related diseases in the 53 WHO European-Region countries and the impact of effective interventions: a modelling study. BMJ open. 2014;4(7):e004787-2014-.

17. WEF. The Global Economic Burden of NCDs

http://www3.weforum.org/docs/WEF_Harvard_HE_GlobalEconomicBurdenNonCommunicableDise ases_2011.pdf

18. Marmot M. The Health Gap: The Challenge of an Unequal World: the argument. International journal of epidemiology. 2017;46(4):1312-8.

19. WHO. Review of social determinants and the health divide in the WHO European Region ISBN 9789289000307 
http://www.euro.who.int/en/publications/abstracts/review-of-social-determinants-and-the-healthdivide-in-the-who-european-region.-final-report

20. Devaux M, Sassi F. Social inequalities in obesity and overweight in 11 OECD countries. European journal of public health. 2013;23(3):464-9.

21. Hruby A, Hu FB. The Epidemiology of Obesity: A Big Picture. PharmacoEconomics. 2015;33(7):673-89.

22. Fernández-Alvira JM, Bammann K, Pala V, Krogh V, Barba G, Eiben G, et al. Country-specific dietary patterns and associations with socioeconomic status in European children: the IDEFICS study. European Journal of Clinical Nutrition. 2014;68(7):811-21.

23. Mullie P, Clarys P, Hulens M, Vansant G. Dietary patterns and socioeconomic position. European Journal of Clinical Nutrition. 2010;64(3):231-8.

24. López-Azpiazu I, Sánchez-Villegas A, Johansson L, Petkeviciene J, Prättälä R, Martínez-González MA, et al. Disparities in food habits in Europe: systematic review of educational and occupational differences in the intake of fat. Journal of Human Nutrition and Dietetics. 2003;16(5):349-64.

25. Sanchez-Villegas A, Martínez JA, Prättälä R, Toledo E, Roos G, Martínez-González MA. A systematic review of socioeconomic differences in food habits in Europe: consumption of cheese and milk. European Journal of Clinical Nutrition. 2003;57(8):917-29.

26. Naska A, Fouskakis D, Oikonomou E, Almeida MDV, Berg MA, Gedrich K, et al. Dietary patterns and their socio-demographic determinants in 10 European countries: data from the DAFNE databank. European Journal of Clinical Nutrition. 2005;60(2):181-90.

27. OECD. Health at a glance 2016

http://www.oecd-ilibrary.org/social-issues-migration-health/health-at-a-glance-europe2016_9789264265592-en

28. Goldsmith LJ, Hutchison B, Hurley FJ. Economic evaluation across the four faces of prevention: a Canadian perspective

http://www.ncchpp.ca/docs/Economic_Prevention_Paper_May_2004.pdf

29. WHO. Review of public heath capacities and services in the European Region

http://www.euro.who.int/_data/assets/pdf_file/0010/172729/Review-of-public-health-capacities-andservices-in-the-European-Region.pdf?ua=1

30. Nuffield Council on Bioethics. Public health: ethical issues. Chapter 3: policy process and practice https://nuffieldbioethics.org/assets/pdfs/Public-health-ethical-issues.pdf

31. Binks M, Chin SH. What are the challenges in developing effective health policies for obesity? International journal of obesity (2005). 2017.

32. Cuschieri S, Mamo J. Getting to grips with the obesity epidemic in Europe. SAGE open medicine. 2016;4:2050312116670406.

33. Drewnowski A, Kawachi I. Diets and Health: How Food Decisions Are Shaped by Biology, Economics, Geography, and Social Interactions. Big data. 2015;3(3):193-7.

34. Recanati F, Maughan C, Pedrotti M, Dembska K, Antonelli M. Assessing the role of CAP for more sustainable and healthier food systems in Europe: A literature review. Sci Total Environ. 2019;653:908-19 35. Aiking H. Protein production: planet, profit, plus people? The American Journal of Clinical Nutrition. 2014;100(Supplement 1):483S-9S.

36. Akkerman R, Farahani P, Grunow M. Quality, safety and sustainability in food distribution: a review of quantitative operations management approaches and challenges. OR Spectrum. 2010;32(4):863-904. 
37. Afshin A, Penalvo J, Del Gobbo L, Kashaf M, Micha R, Morrish K, et al. CVD Prevention Through Policy: a Review of Mass Media, Food/Menu Labeling, Taxation/Subsidies, Built Environment, School Procurement, Worksite Wellness, and Marketing Standards to Improve Diet. Curr Cardiol Rep.

2015;17(11):98.

38. Afshin A, Micha R, Khatibzadeh S, Schmidt LA, Mozaffarian D. Dietary Policies to Reduce NonCommunicable Diseases. In: Brown GW, Yamey G, Wamala S, editors. The Handbook of Global Health Policy: John Wiley \& Sons, Ltd; 2014. p. 175-93.

39. Brownson RC, Fielding JE, Maylahn CM. Evidence-based public health: a fundamental concept for public health practice. Annual Review of Public Health. 2009;30:175-201.

40. Knorpp L, Kroke A. Evidence-based public health nutrition: What constitutes good evidence? CAB Reviews: Perspectives in Agriculture, Veterinary Science, Nutrition and Natural Resources. 2012;7:1-22.

41. Capacci S, Mazzocchi M, Shankar B, Brambila Macias J, Verbeke W, Pérez-Cueto FJA, et al. Policies to promote healthy eating in Europe: a structured review of policies and their effectiveness. Nutrition Reviews. 2012;70(3):188-200.

42. European Commission. Impact Assessments

https://ec.europa.eu/info/law/law-making-process/planning-and-proposing-law/impactassessments_en

43. European Commission. Report from the Commission to the European Parliament and the Council regarding trans fats in foods and in the overall diet of the Union population

https://ec.europa.eu/food/sites/food/files/safety/docs/fs_labelling-nutrition_trans-fats-report_en.pdf 44. Martin-Saborido C, Mouratidou T, Livaniou A, Caldeira S, Wollgast J. Public health economic evaluation of different European Union-level policy options aimed at reducing population dietary trans fat intake. The American Journal of Clinical Nutrition. 2016;104(5):1218-26.

45. Commission Regulation (EU) 2019/649 of 24 April 2019 amending Annex III to Regulation (EC) No 1925/2006 of the European Parliament and of the Council as regards trans fat, other than trans fat naturally occurring in fat of animal origin.

46. Council conclusions to contribute towards halting the rise in Childhood Overweight and Obesity. OJ C 205, 29.6.2017, p. 46-52.

47. Wanless D. Securing Good Health for the Whole Population http://www.nhshistory.net/wanless_health_trends203.pdf

48. Musgrove P, Fox-Rushby J. Cost-Effectiveness Analysis for Priority Setting. In: Jamison DT, Breman JG, Measham AR, Alleyne G, Claeson M, Evans DB, et al., editors. Disease Control Priorities in Developing Countries. 2nd ed. Washington (DC): The International Bank for Reconstruction and Development/The World Bank Group; 2006.

49. Rabarison KM, Bish CL, Massoudi MS, Giles WH. Economic Evaluation Enhances Public Health Decision Making. Front Public Health. 2015;3:164.

50. Lenoir-Wijnkoop I, Dapoigny M, Dubois D, van Ganse E, Gutierrez-Ibarluzea I, Hutton J, et al. Nutrition economics - characterising the economic and health impact of nutrition. The British journal of nutrition. 2011;105(1):157-66.

51. Cobiac LJ, Veerman L, Vos T. The role of cost-effectiveness analysis in developing nutrition policy. Annual Review of Nutrition. 2013;33:373-93.

52. Weatherly H, Drummond M, Claxton K, Cookson R, Ferguson B, Godfrey C, et al. Methods for assessing the cost-effectiveness of public health interventions: key challenges and recommendations. Health policy (Amsterdam, Netherlands). 2009;93(2-3):85-92.

53. Fattore G, Ferre F, Meregaglia M, Fattore E, Agostoni C. Critical review of economic evaluation studies of interventions promoting low-fat diets. Nutrition reviews. 2014;72(11):691-706. 
54. Gyles CL, Lenoir-Wijnkoop I, Carlberg JG, Senanayake V, Gutierrez-Ibarluzea I, Poley MJ, et al. Health economics and nutrition: a review of published evidence. Nutrition reviews. 2012;70(12):693-708. 55. Stone D. Policy Paradox: The Art of Political Decision Making. ISBN 10: 0393912728 ISBN 13: 9780393912722. W W Norton \& Co Inc , 2012.

56. Squires H, Chilcott J, Akehurst R, Burr J, Kelly MP. A systematic literature review of the key challenges for developing the structure of public health economic models. International Journal of Public Health. 2016;61(3):289-98.

57. EUPHA Food and Nutrition Working group. Healthy and Sustainable Diets for European Countries. Report of a Working Group.

https://eupha.org/repository/advocacy/EUPHA_report_on_healthy_and_sustainable_diets_20-052017.pdf

58. Lang T, Mason P. Sustainable diet policy development: implications of multi-criteria and other approaches, 2008-2017. Proc Nutr Soc. 2018;77(3):331-46.

59. Johnston JL, Fanzo JC, Cogill B. Understanding Sustainable Diets: A Descriptive Analysis of the Determinants and Processes That Influence Diets and Their Impact on Health, Food Security, and Environmental Sustainability. Advances in Nutrition: An International Review Journal. 2014;5(4):418-29. 60. Joyce A, Dixon S, Comfort J, Hallett J. Reducing the Environmental Impact of Dietary Choice: Perspectives from a Behavioural and Social Change Approach. Journal of Environmental and Public Health, Journal of Environmental and Public Health. 2012;2012, 2012:e978672.

61. Fazeni K, Steinmüller H. Impact of changes in diet on the availability of land, energy demand, and greenhouse gas emissions of agriculture. Energy, Sustainability and Society. 2011;1(1):6.

62. Buttriss. Feeding the planet: an unprecedented confluence of pressures anticipated. Nutrition Bulletin. 2011;36(2):235-41.

63. Berry EM, Dernini S, Burlingame B, Meybeck A, Conforti P. Food security and sustainability: can one exist without the other? Public Health Nutrition. 2015;18(13):2293-302.

64. Lake, Hooper, Abdelhamid, Bentham, Boxall, Draper, et al. Climate change and food security: health impacts in developed countries. Environmental health perspectives. 2012;120(11):1520-6.

65. Alsaffar AA. Sustainable diets: The interaction between food industry, nutrition, health and the environment. Food Science and Technology International = Ciencia Y Tecnologia De Los Alimentos Internacional. 2016;22(2):102-11.

66. Garcia JM, Teixeira P. Organic versus conventional food: A comparison regarding food safety. Food Reviews International. 2017;33(4):424-46.

67. Auestad N, Fulgoni VL. What Current Literature Tells Us about Sustainable Diets: Emerging

Research Linking Dietary Patterns, Environmental Sustainability, and Economics. Advances in Nutrition: An International Review Journal. 2015;6(1):19-36.

68. Communication From The Commission To The European Parliament, The European Council, The Council, The European Economic And Social Committee And The Committee Of The Regions. The European Green Deal COM/2019/640 final.

69. United Nations General A. Transforming our world: the 2030 Agenda for Sustainable Development: Sustainable Development Knowledge Platform. 2015.

70. Mackenbach JD, Nelissen KGM, Dijkstra SC, Poelman MP, Daams JG, Leijssen JB, et al. A Systematic Review on Socioeconomic Differences in the Association between the Food Environment and Dietary Behaviors. Nutrients. 2019;11(9):2215.

71. Lago S, Cantarero D, Rivera B, Pascual M, Blázquez-Fernández C, Casal B, et al. Socioeconomic status, health inequalities and non-communicable diseases: a systematic review. Zeitschrift fur Gesundheitswissenschaften = Journal of public health. 2018;26(1):1-14. 
72. McGill R, Anwar E, Orton L, Bromley H, Lloyd-Williams F, O’Flaherty M, et al. Are interventions to promote healthy eating equally effective for all? Systematic review of socioeconomic inequalities in impact. BMC Public Health. 2015;15:457.

73. Allen K, Pearson-Stuttard J, Hooton W, Diggle P, Capewell S, O'Flaherty M. Potential of trans fats policies to reduce socioeconomic inequalities in mortality from coronary heart disease in England: cost effectiveness modelling study. Bmj. 2015;351:h4583.

74. Owen L, Morgan A, Fischer A, Ellis S, Hoy A, Kelly MP. The cost-effectiveness of public health interventions. Journal of Public Health. 2012;34(1):37-45.

75. Van Cauwenberghe E, Maes L, Spittaels H, van Lenthe FJ, Brug J, Oppert J-M, et al. Effectiveness of school-based interventions in Europe to promote healthy nutrition in children and adolescents:

systematic review of published and 'grey' literature. The British Journal of Nutrition. 2010;103(6):781-97.

76. Garnett T, Mathewson S, Angelides P, Borthwich F. Policies and actions to shift eating patterns:

What works? A review of the evidence of the effectiveness of interventions aimed at shifting diets in more sustainable and healthy directions. Oxford, UK: Food Climate Research Network (FCRN), University of Oxford.; 20152015.

77. Whitmee S, Haines A, Beyrer C, Boltz F, Capon AG, Dias BFdS, et al. Safeguarding human health in the Anthropocene epoch: report of The Rockefeller Foundation-Lancet Commission on planetary health. The Lancet. 2015;386(10007):1973-2028.

78. The Lancet Planetary Health. The bigger picture of planetary health. Lancet Planet Health. 2019;3(1):e1.

79. Potvin L, Jones CM. Twenty-five years after the Ottawa Charter: the critical role of health promotion for public health. Canadian Journal of Public Health. 2011;102(4):244-8.

80. Echols MA. Food safety regulation in the European Union and the United States: different cultures, different laws. Colum J Eur L. 1998;4:525.

81. Motarjemi Y. Ch. 31 - Hazard Analysis and Critical Control Point System (HACCP). In: Motarjemi Y, Lelieveld H, editors. Food Safety Management. San Diego: Academic Press; 2014. p. 845-72.

82. WHO. Healthy diet

https://www.who.int/nutrition/publications/nutrientrequirements/healthydiet_factsheet/en/

83. WHO. Protecting health in an environment challenged by climate change: European Regional

Framework for Action

http://www.euro.who.int/en/media-centre/events/events/2010/03/fifth-ministerial-conference-on-

environment-and-health/documentation/protecting-health-in-an-environment-challenged-by-climate-

change-european-regional-framework-for-action

84. Gordon RS, Jr. An operational classification of disease prevention. Public health reports (Washington, DC : 1974). 1983;98(2):107-9. 



\section{Burden of disease related to current dietary} patterns and costs of non-communicable diseases in the European Union

Authorship:

During her time as UVS (Unpaid Visiting Scientist) at the Joint Research Centre, Dr. Alessandra Lafranconi has contributed to the Health Promotion and Disease Prevention Knowledge Gateway.

She was the lead author of three peer reviewed "briefs" published in 2018:

EU Burden from Non-Communicable Diseases and key risk factors in the EU, Health Inequalities: Dietary and Physical Activity Related Determinants and Cost of Non-Communicable Diseases in the EU

Published as:

https://ec.europa.eu/jrc/en/health-knowledge-gateway/societal-impacts/burden https://ec.europa.eu/jrc/en/health-knowledge-gateway/societal-impacts/costs 



\section{The Disease Burden of current dietary patterns in the European Union: the GBD Study}

Dietary habits and diet-related risk factors contribute to a considerable fraction of the burden of disease worldwide. This burden can be measured and is often expressed in Disability Adjusted Life Years (DALYs) which are the sum of the Years of Life Lost (YLL) due to premature mortality and the Years Lost due to Disability (YLD) for people living with the health condition or its consequences. YLLs are obtained as difference between age at premature death and life expectancy, and YLDs result from multiplying the average duration of any disease or disability by its corresponding weighting factor (where $0=$ perfect health and $1=$ death). A DALY therefore provides a single figure for the "healthy years" lost due to disability and to premature mortality (1).

The DALYs attributable to dietary related risk factors in the EU have been estimated by the Global Burden Disease (GBD) Study (2) and amounted to about 16 million DALYs in 2017 (3). The individual member state estimates of these DALYS (expressed per 100,000 population) are shown in Table 1 (3); it should be said that such estimates are summary measures, and the differences between the countries could be affected by the different age structure of the populations. Dietary risk factors that have been considered in this context include: diet high in processed meat, diet high in red meat, diet high in sodium, diet high in sugar-sweetened beverages, diet high in trans fatty acids, diet low in calcium, diet low in fiber, diet low in fruits, diet low in legumes, diet low in milk, diet low in nuts and seeds, diet low in polyunsaturated fatty acids, diet low in seafood omega-3 fatty acids, diet low in vegetables, diet low in whole grains (4).

Table 1. Disability-Adjusted Life Years (DALYs)/100,000 attributable to dietary risk factors in the EU-28 countries, for the year 2017. Source: IMHE.

\begin{tabular}{lc}
\hline & DALYs per $\mathbf{1 0 0 , 0 0 0}$ \\
\hline Belgium & 2,338 \\
Bulgaria & 9,193 \\
Czech Republic & 4,921 \\
Denmark & 2,275 \\
Germany & 3,307 \\
Estonia & 4,933 \\
Ireland & 1,908 \\
Greece & 3,563 \\
Spain & 1,932 \\
France & 1,834 \\
Croatia & 5,300 \\
Italy & 2,424 \\
Cyprus & 2,470 \\
Latvia & 7,834 \\
Lithuania & 7,525 \\
Luxembourg & 1,910 \\
Hungary & 6,421 \\
Malta & 3,516 \\
Netherlands & 2,105 \\
\hline
\end{tabular}




\begin{tabular}{ll}
\hline Austria & 2,581 \\
Poland & 4,650 \\
Portugal & 2,800 \\
Romania & 6,603 \\
Slovenia & 3,110 \\
Slovakia & 5,380 \\
Finland & 3,268 \\
Sweden & 2,651 \\
United Kingdom & 2,395 \\
EU28 & $\mathbf{3 , 1 3 1}$ \\
\hline
\end{tabular}

An attempt to depict the relative contribution of the different dietary risk factors to each of the diseases they are associated with is shown in Table 2. Its analysis highlights that the DALYs attributable to diet -related risk factors are mostly caused by cardiovascular diseases (CVDs) and other non-communicable diseases such as diabetes, cancers and chronic kidney disease.

Table 2. Disability-Adjusted Life Years (DALYs)/100,000 attributable to the GBD diet-related risk factors, EU28, year 2017. Source: IMHE.

\begin{tabular}{llll}
\hline & $\begin{array}{l}\text { DALYs per } \\
\mathbf{1 0 0 , 0 0 0}\end{array}$ & $\begin{array}{l}\text { \% of dietary } \\
\text { risk }\end{array}$ & Associated diseases \\
\hline Diet low in whole grains & 985 & 20.9 & Cardiovascular diseases, stroke, diabetes \\
Diet low in fruits & 668 & 14.2 & Cancers, cardiovascular diseases, stroke, diabetes \\
Diet low in nuts and seeds & 593 & 12.6 & Cardiovascular diseases, diabetes \\
Diet high in sodium & 576 & 12.2 & Cancers, cardiovascular diseases, stroke, chronic kidney disease \\
Diet low in seafood omega-3 fatty acids & 351 & 7.5 & Cardiovascular diseases \\
Diet low in vegetables & 343 & 7.3 & Cardiovascular diseases, stroke \\
Diet low in fiber & 282 & 6.0 & Cancers, cardiovascular diseases \\
Diet low in legumes & 240 & 5.1 & Cardiovascular diseases \\
Diet low in polyunsaturated fatty acids & 195 & 4.1 & Cardiovascular diseases \\
Diet high in processed meat & 124 & 2.6 & Cancer, cardiovascular diseases, diabetes \\
Diet high in sugar-sweetened beverages & 103 & 2.2 & Cardiovascular diseases, diabetes \\
Diet low in calcium & 89 & 1.9 & Cancers \\
Diet low in milk & 61 & 1.3 & Cancers \\
Diet high in trans fatty acids & 49 & 1.0 & Cardiovascular diseases \\
Diet high in red meat & 49 & 1.0 & Cancer, diabetes \\
\hline
\end{tabular}

DALYs attributable to dietary risk factors can be further broken down into the main disease categories to which they relate (3):

- Cardiovascular diseases (CVDs), mainly in the form of Ischaemic Heart Disease (IHD) and stroke;

- Metabolic conditions, such as diabetes, obesity and metabolic syndrome;

- Cancers, such as gastrointestinal cancers, but also cancers affecting the respiratory system.

Figure 1 represents as a whole all DALYs in the EU, the DALYs attributable to each disease and the fraction of these that are attributable to dietary risk factors for each disease: for example, in the EU 8.6\% of all DALYs are attributable to ischemic heart disease (IHD) and about two thirds of this IHD burden is related to dietary risk factors (3). 
Figure 1. Representation of the fraction of Disability-Adjusted Life Years (DALYs) attributable to dietary risks, for each disease in the EU-28. Light-colored boxes represent diseases and the internal darker segments correspond to the fraction of that particular disease due to dietary risks. Source: IHME.

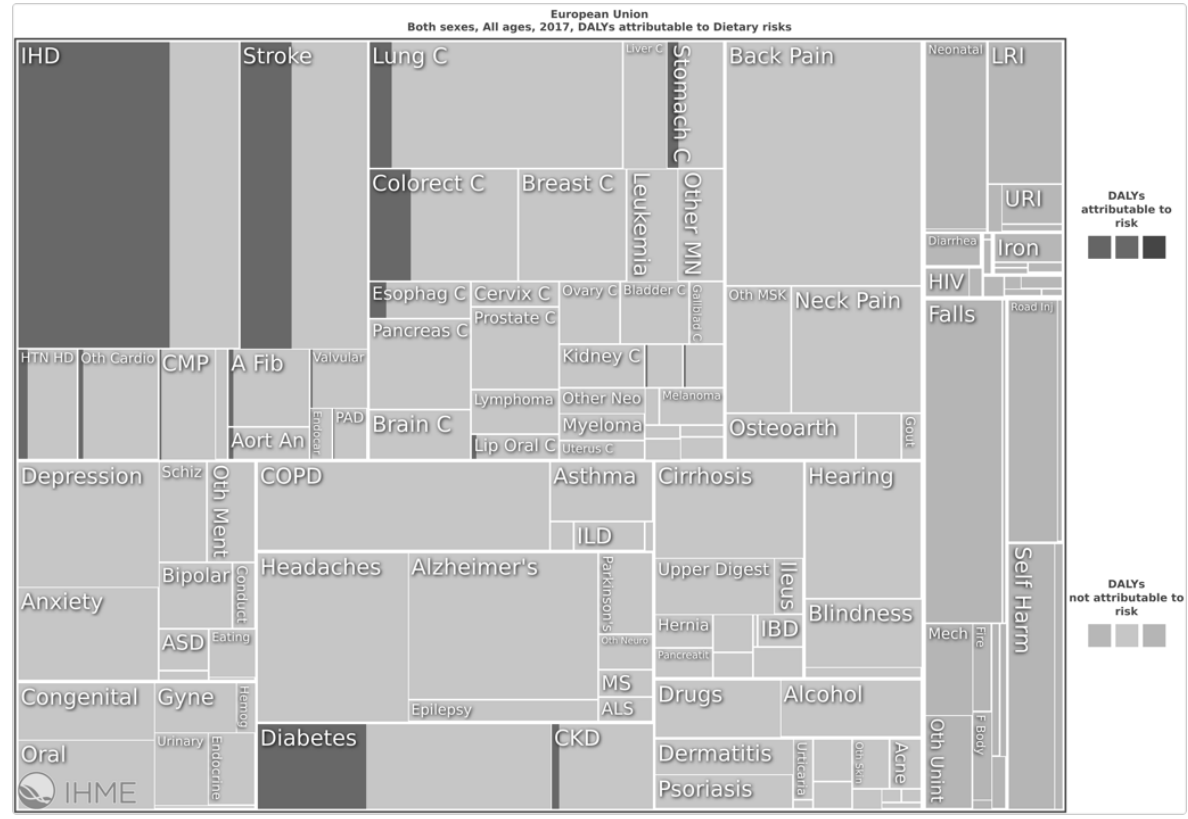

For cardiovascular outcomes, the relationship has been studied for a long time. The American Heart Association defines ideal cardiovascular health as: "The presence of both ideal health behaviors (non-smoking, body mass index lower than $25 \mathrm{~kg} / \mathrm{m} 2$, physical activity at goal levels, and pursuit of a diet consistent with current guideline recommendations) and ideal health factors (untreated total cholesterol lower than $200 \mathrm{mg} / \mathrm{dL}$, untreated blood pressure lower than 120/80 $\mathrm{mm} \mathrm{Hg}$, and fasting blood glucose lower than $100 \mathrm{mg} / \mathrm{dL}$ )" (5). Out of seven indicators, five are strongly related to diet.

Other health outcomes, such as neuro-psychological disorders (ranging from disturbance of cognitive function to mood disturbances and depression) have also been related to diet, but their quantification is still quite challenging, especially because scientific methods traditionally applied to the medical sciences (e.g. randomized controlled trials in clinical settings, or time-series analysis in environmental epidemiology) describe the complex relationship between nutrition and health only incompletely (6)

While the GBD Study aims to provide worldwide reliable and comparable estimates, it has several limitations (7). For instance, while the number of studied risk factors is increasing in each edition of the GBD Study, some important risk factors might still be unaddressed; moreover, the number of avoided DALYs is highly hypothetical, because the reference exposure is the 
minimum level of risk, that in most cases is well below actual exposure, and also below usually recommended thresholds. Table 3 defines reference exposure levels for dietary risk factors (4).

Table 3. Definitions of dietary risk factors used in the Global Burden of Disease study, 2017. Source: IHME.

\begin{tabular}{|c|c|}
\hline Risk factor & Definition \\
\hline Diet low in whole grains & $\begin{array}{l}\text { Average daily consumption of less than } 125 \text { grams per day of whole grains (bran, germ, and endosperm in their } \\
\text { natural proportion) from breakfast cereals, bread, rice, pasta, biscuits, muffins, tortillas, pancakes, and other } \\
\text { sources. }\end{array}$ \\
\hline Diet low in fruits & $\begin{array}{l}\text { Average daily consumption of less than } 250 \text { grams per day of fruits (fresh, frozen, cooked, canned, or dried, } \\
\text { excluding fruit juices and salted or pickled fruits). }\end{array}$ \\
\hline Diet low in nuts and seeds & Average daily consumption of less than 20.5 grams per day of nuts and seeds. \\
\hline Diet high in sodium & Average 24 hour urinary sodium greater than 3 grams per day. \\
\hline Diet low in seafood omega-3 & $\begin{array}{l}\text { Average daily consumption of less than } 250 \text { milligrams per day of eicosapentaenoic acid (EPA) and } \\
\text { docosahexaenoic acid (DHA). }\end{array}$ \\
\hline Diet low in vegetables & $\begin{array}{l}\text { Average daily consumption of less than } 360 \text { grams per day of vegetables (fresh, frozen, cooked, canned or dried } \\
\text { vegetables excluding legumes and salted or pickled vegetables, juices, nuts and seeds, and starchy vegetables } \\
\text { such as potatoes or corn). }\end{array}$ \\
\hline Diet low in fibre & $\begin{array}{l}\text { Average daily consumption of less than } 23.5 \text { grams of fibre per day from all sources including fruits, vegetables, } \\
\text { grains, legumes, and pulses. }\end{array}$ \\
\hline Diet low in legumes & Average daily consumption of less than 60 grams per day of legumes. \\
\hline Diet low in PUFA & $\begin{array}{l}\text { Average daily consumption of less than } 11 \% \text { of total energy intake from polyunsaturated fatty acids as a } \\
\text { replacement for high intake of saturated fatty acids ( }>7 \% \text { of total energy intake). }\end{array}$ \\
\hline Diet high in processed meat & $\begin{array}{l}\text { Average daily consumption of greater than } 2 \text { grams of meat preserved by smoking, curing, salting, or addition } \\
\text { of chemical preservatives. }\end{array}$ \\
\hline Diet high in SSBS & $\begin{array}{l}\text { Average daily consumption of greater than } 2.5 \text { grams per day of beverages with } \geq 50 \mathrm{kcal} \text { per } 226.8 \mathrm{gram} \\
\text { serving, including carbonated beverages, sodas, energy drinks, fruit drinks, but excluding } 100 \% \text { fruit and } \\
\text { vegetable juices. }\end{array}$ \\
\hline Diet low in calcium & $\begin{array}{l}\text { Average daily consumption of less than } 1.15 \text { grams of calcium per day from all sources, including milk, yogurt, } \\
\text { and cheese. }\end{array}$ \\
\hline Diet low in milk & $\begin{array}{l}\text { Average daily consumption of less than } 435 \text { grams per day of milk including non-fat, low-fat, and full-fat milk } \\
\text { but excluding soy milk and other plant derivatives. }\end{array}$ \\
\hline Diet high in TFA & $\begin{array}{l}\text { Average daily consumption of greater than } 0.5 \% \text { of total energy intake from trans fatty acids from all sources, } \\
\text { mainly partially hydrogenated vegetable } 0 \text { ils and ruminant products. }\end{array}$ \\
\hline Diet high in red meat & $\begin{array}{l}\text { Average daily consumption of greater than } 22.5 \text { grams per day of red meat (includes beef, pork, lamb, and goat } \\
\text { but excludes poultry, fish, eggs, and all processed meats). }\end{array}$ \\
\hline
\end{tabular}

Abbreviations: PUFAs: polyunsaturated fatty acids; SSBs: sugar-sweetened beverages; TFA: trans fatty acids

Lastly, diet has far broader impacts on population health and health of the planet, including threats to climate, biodiversity and ecosystem resilience (8). While there have been substantial improvements in some aspects of European diets over the past decades, concern has been expressed that health agencies, including the World Health Organization Regional Office for Europe (WHO Europe), have not included sustainability as an integral part of multi-sectoral food policy (9). 


\section{The Economic Costs of Non-Communicable Diseases in the European Union}

Depending on the perspective adopted in an economic evaluation, e.g. the payer perspective or the wider societal perspective, the costs of disease can be estimated using measures of direct medical costs (that correspond to healthcare costs), other direct costs (for example, the cost of transportation to receive medical care), and indirect costs (which reflect productivity losses due to morbidity or mortality and also costs of informal care, for example). The economic burden of NCDs is on the rise and is projected to show steeper increases in the future, especially in less developed economies and among the poor in middle- and high-income countries. The key drivers associated with these costs are detailed below at 3 different levels (10-12):

- Costs at the level of individuals and households: reduced well-being (also with potential impairment in mental health, stigma and discrimination for the ones affected by chronic illnesses), increased disabilities and premature deaths, decreased household income, increased expenditures (including out of pocket and catastrophic spending, especially in countries where out-of-pocket expenditures cover a high share of total healthcare and healthcare-related expenditures) and loss in savings and assets, and reduced opportunities (for instance, effects on education: performance can be impaired in those with ill-health, but also in those having a sick person in the household, such as children with sick parents);

- Costs to health systems (i.e. healthcare delivery costs): increased use of NCD-related healthcare services, high medical treatment costs per episode, demand for more expensive treatments (including the cost of technology and innovation), and health system adaptation needs and costs, for instance in introducing new organization and financing aspects;

- Costs to national economies: reduced labor supply, reduced labor outputs including absenteeism and presentism (that is, a worker being present, but unable to effectively do the work), lower tax revenues, lower returns on human capital investments, increased public health and social welfare expenditures, and increased cost to employers, for instance as productivity loss or as increased health costs.

\section{Healthcare Costs}

Healthcare costs are substantial. In 2015, governmental expenditure on health in the EU28 was $7.8 \%$ of GDP, on average, with more than $70 \%$ of expenditure funded by the public sector in two thirds of Member States (13). Due to population aging, chronic diseases and the diffusion of new diagnostic and therapeutic technologies, the share of GDP spending on health is projected to increase in the coming years.

In most high and middle-income countries, non-communicable diseases are responsible for the biggest share of such healthcare costs: for example, in the European Union, "70 to 80\% of health care budgets, an estimated $€ 700$ billion per year are spent on chronic diseases" (14).

More specifically the healthcare costs for CVD, diabetes and various types of cancers have been estimated at: 
- $\quad$ around $€ 111$ billion a year for CVDs, in 2015, in the EU; of such expenditure, approximately $€ 19$ billion are due to IHD and $€ 20$ billion are due to stroke (15);

- $\quad$ around $€ 51$ billion for cancers, in 2009, in the EU (16);

- $\quad$ around US\$156 billion, in 2015, for diabetes, in the European Region (17).

Country-based healthcare costs have also been estimated and are reported in Table 4.

Table 4. Country-based healthcare expenditure of CVDs (total, IHD and stroke), cancer and diabetes. CVD = cardiovascular disease; $I H D=i$ schemic heart disease; $n a=$ not assessed. Sources: European Heart Network, the Lancet, and International Diabetes Federation. Estimates are derived from different sources and can't be directly compared.

\begin{tabular}{|c|c|c|c|c|c|c|c|c|}
\hline \multirow[b]{3}{*}{ Belgium } & \multicolumn{4}{|c|}{$\begin{array}{l}\text { Healthcare expenditure } \\
\text { (in million } € \text { ) }\end{array}$} & \multicolumn{4}{|c|}{$\begin{array}{l}\text { Healthcare expenditure } \\
\text { (in million US\$) }\end{array}$} \\
\hline & \multirow{2}{*}{$\begin{array}{l}\begin{array}{l}\text { CVD } \\
\text { estimate } \\
\text { (2015) }\end{array} \\
2,421\end{array}$} & \multirow{2}{*}{$\begin{array}{l}\begin{array}{l}\text { IHD } \\
\text { estimate } \\
\text { (2015) }\end{array} \\
399\end{array}$} & \multirow{2}{*}{ 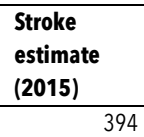 } & \multirow{2}{*}{$\begin{array}{r}\begin{array}{l}\text { Cancers } \\
\text { estimate } \\
(\mathbf{2 0 0 9 )}\end{array} \\
1,010\end{array}$} & \multicolumn{2}{|c|}{$\begin{array}{c}\text { Diabetes, range } \\
(2010)\end{array}$} & \multicolumn{2}{|c|}{$\begin{array}{c}\text { Diabetes, range } \\
(2030)\end{array}$} \\
\hline & & & & & 2,295 & 4,386 & 2,810 & 5,434 \\
\hline Bulgaria & 344 & 57 & 48 & 124 & 156 & 290 & 153 & 287 \\
\hline Czech Republic & 1,481 & 212 & 366 & 598 & 102 & 179 & 140 & 252 \\
\hline Denmark & 962 & 180 & 136 & 574 & 1,486 & 2,780 & 1,622 & 3,108 \\
\hline Germany & 28,306 & 4,776 & 5,651 & 14893 & 663 & 1228 & 769 & 1455 \\
\hline Estonia & 178 & 31 & 43 & 61 & 57 & 104 & 58 & 107 \\
\hline Ireland & 857 & 158 & 144 & 619 & 11,023 & 20,883 & 12,614 & 23,933 \\
\hline Greece & 1,948 & 369 & 356 & 1244 & 2,067 & 3,941 & 2,403 & 4,578 \\
\hline Spain & 9,243 & 1,517 & 1,245 & 4,114 & 1,009 & 1,904 & 1,122 & 2,187 \\
\hline France & 15,195 & 2,048 & 1,973 & 7051 & 28,109 & 51,319 & 30,288 & 56,013 \\
\hline Croatia & 242 & 46 & 37 & na & 641 & 1,188 & 699 & 1,317 \\
\hline Italy & 15,708 & 2,726 & 3,196 & 6,854 & 84 & 153 & 86 & 157 \\
\hline Cyprus & 80 & 21 & 8 & 36 & 233 & 438 & 242 & 462 \\
\hline Latvia & 130 & 28 & 21 & 60 & 43 & 77 & 52 & 97 \\
\hline Lithuania & 226 & 54 & 42 & 59 & 125 & 227 & 136 & 248 \\
\hline Luxembourg & 162 & 27 & 24 & 91 & 177 & 335 & 252 & 480 \\
\hline Hungary & 1,512 & 247 & 276 & 393 & 908 & 1,710 & 1307 & 2,507 \\
\hline Malta & 48 & 9 & 9 & 16 & 3,794 & 7,159 & 4,816 & 9,308 \\
\hline Netherlands & 5,527 & 1,339 & 844 & 2,143 & 1,588 & 2,872 & 1,869 & 3,486 \\
\hline Austria & 2,522 & 510 & 508 & 1,202 & 2,839 & 5,113 & 3,383 & 6,205 \\
\hline Poland & 4,352 & 836 & 561 & 1399 & 1557 & 2,853 & 1792 & 3,309 \\
\hline Portugal & 1,174 & 202 & 160 & 564 & 398 & 744 & 435 & 820 \\
\hline Romania & 1,274 & 164 & 163 & 421 & 245 & 451 & 320 & 603 \\
\hline Slovenia & 247 & 40 & 36 & 145 & 6,694 & 12,449 & 8,838 & 16,501 \\
\hline Slovakia & 657 & 139 & 110 & 306 & 1,987 & 3,798 & 2,270 & 4,417 \\
\hline Finland & 1,999 & 303 & 721 & 804 & 17,242 & 32,082 & 21,362 & 40,479 \\
\hline Sweden & 1,664 & 272 & 336 & 971 & 249 & 449 & 282 & 524 \\
\hline United Kingdom & 12,348 & 2,166 & 2,652 & 5,241 & 7,648 & 15,097 & 9,131 & 18,282 \\
\hline EU27* or EU28 & 110,809 & 18,876 & 20,058 & $50,994^{*}$ & 93,418 & 174,209 & 109,252 & 206,556 \\
\hline
\end{tabular}

\section{Non-Healthcare Costs}

Non-communicable diseases also result in other, non-healthcare costs, for example productivity losses due to morbidity or mortality and costs of informal care. In the European Union, it has been estimated that: 
- production losses due to mortality and morbidity associated with CVD cost the EU €54 billion in 2015 and the total cost of providing informal care for people with CVD was $€ 45$ billion (15);

- cancer cost over $€ 50$ billion in productivity losses due to mortality and morbidity in 2009 and over $€ 20$ billion in informal/family care spending (16).

These country-based non health-care costs are reported in Table 5.

Table 5. Estimated country-based non-healthcare costs (in billions $€$ ) of CVDs (total, IHD and stroke) and cancer. CVD $=$ cardiovascular disease; $I H D=$ ischemic heart disease; $n a=$ not assessed. Sources: European Heart Network, and the Lancet.

\begin{tabular}{|c|c|c|c|c|}
\hline & \multicolumn{4}{|c|}{ Non health-care costs (production losses and informal care), in $€$ millions } \\
\hline & CVD (2015) & IHD (2015) & Stroke (2015) & Cancers (2009) \\
\hline Belgium & 2,247 & 819 & 567 & 2,204 \\
\hline Bulgaria & 605 & 186 & 150 & 176 \\
\hline Czech Republic & 1,300 & 483 & 284 & 734 \\
\hline Denmark & 1,193 & 404 & 298 & 1,667 \\
\hline Germany & 29,201 & 10,966 & 7,185 & 20,234 \\
\hline Estonia & 311 & 117 & 74 & 112 \\
\hline Ireland & 951 & 451 & 199 & 828 \\
\hline Greece & 1,242 & 640 & 250 & 1,351 \\
\hline Spain & 7,607 & 3,003 & 1,659 & 4,901 \\
\hline France & 8,407 & 3,835 & 2,321 & 9,832 \\
\hline Croatia & 535 & 231 & 128 & na \\
\hline Italy & 12,507 & 4,858 & 3,553 & 9,600 \\
\hline Cyprus & 132 & 64 & 24 & 73 \\
\hline Latvia & 338 & 142 & 81 & 131 \\
\hline Lithuania & 411 & 187 & 99 & 169 \\
\hline Luxembourg & 96 & 43 & 21 & 101 \\
\hline Hungary & 1,059 & 524 & 337 & 586 \\
\hline Malta & 63 & 28 & 14 & 22 \\
\hline Netherlands & 3,426 & 1,342 & 905 & 4,208 \\
\hline Austria & 2,218 & 987 & 687 & 1,436 \\
\hline Poland & 4,315 & 1,628 & 1,113 & 2242 \\
\hline Portugal & 1,654 & 641 & 572 & 1,484 \\
\hline Romania & 1,560 & 640 & 423 & 836 \\
\hline Slovenia & 294 & 116 & 65 & 261 \\
\hline Slovakia & 615 & 240 & 133 & 321 \\
\hline Finland & 925 & 331 & 293 & 707 \\
\hline Sweden & 1,824 & 659 & 526 & 1798 \\
\hline United Kingdom & 14,318 & 6,889 & 3,318 & 9,202 \\
\hline EU27* or EU28 & 99,355 & 40,452 & 25,280 & $75,212 *$ \\
\hline
\end{tabular}

\section{From Evidence to Policy: The Economic Rationale for Action}

Health and consumer protection has been enshrined in the EU Treaties since 1957, and article 168 of the Treaty of Lisbon represents a moral imperative for action towards " $a$ bigh level of human bealth protection". Yet, the quantification of direct and indirect costs related to NCDs is helpful in raising awareness and gaining the interest of those stakeholders that are focused more on the economic than the social aspects: health is determined to a large extent by factors outside the 
health area, and the ability to involve as many relevant policy areas as possible, following a "Health in all policies approach" (HiAP), is therefore crucial in ensuring health-minded policies.

Moreover, the quantification of NCD costs, together with the quantification of NCD burden, allows comparisons between the status quo and possible policy alternatives in reducing the burden of NCDs for given costs: economic evaluations in public health are useful tools in assessing whether a policy works, and in providing a rank of different policy options. Economic evaluations are becoming increasingly important in informing policy-making: for example, any European Commission Impact assessment has to answer the question of "What are the impacts of the different policy options and who will be affected?" which involves a robust assessment out of the economic, social and environmental impacts of the different policy options and who they will affect. The policy decisions that deliver the best balance between benefits and costs and the analysis assessed all the advantages and disadvantages of the policy options against the reference of the baseline. The procedure calls for all relevant impacts to be assessed quantitatively ${ }^{1}$, if possible, as well as qualitatively.

1 As detailed in the Impact assessment guidelines (http:/ / ec.europa.eu/smartregulation/guidelines/ug_chap3_en.htm) "When quantifying, spurious precision should be avoided and ranges provided, complemented by qualitative comments. In many cases, quantification will rely on a given set of assumptions. These should be clearly presented. Whenever an assumption is particularly important or uncertain, sensitivity analysis should be used to check whether changing it would lead to significantly different results. 


\section{References}

1. WHO. Metrics: Disability-Adjusted Life Year (DALY). Available at:

http://www.who.int/healthinfo/global_burden_disease/metrics_daly/en/.

2. WHO. Global Burden of Disease. Available at:

http://www.who.int/topics/global_burden_of_disease/en/.

3. IHME. VizHub - GBD Compare. Available at:

http://vizhub.healthdata.org/gbd-compare/.

4. GBD 2017. Stanaway JD, Afshin A, Gakidou E, Lim SS, Abate D, Abate KH, et al. Global, regional, and national comparative risk assessment of 84 behavioural, environmental and occupational, and metabolic risks or clusters of risks for 195 countries and territories, 1990-2017: a systematic analysis for the Global Burden of Disease Study 2017. The Lancet. 2018;392(10159):1923-94.

5. Lloyd-Jones DM, Hong Y, Labarthe D, Mozaffarian D, Appel LJ, Van Horn L, et al. Defining and Setting National Goals for Cardiovascular Health Promotion and Disease Reduction. Circulation 2010 Lippincott Williams \& Wilkins;121(4):586-613.

6. JRC. Public Health and Nutrition Economics: the numbers behind prevention?. Available at: https://ec.europa.eu/jrc/en/event/workshop/public-health-and-nutrition-economics-numbers-behindprevention.

7. GBD 2017. James SL, Abate D, Abate KH, Abay SM, Abbafati C, Abbasi N, et al. Global, regional, and national incidence, prevalence, and years lived with disability for 354 diseases and injuries for 195 countries and territories, 1990-2017: a systematic analysis for the Global Burden of Disease Study 2017. The Lancet. 2018;392(10159):1789-858.

8. FAO. Plates, pyramids, planet Developments in national healthy and sustainable dietary guidelines: a state of play assessment. Available at: http://www.fao.org/3/a-i5640e.pdf.

9. EUPHA Food and Nutrition Working group. Healthy and Sustainable Diets for European Countries. Report of a Working Group. EUPHA. Utrecht, 2017. Available at:

https://eupha.org/repository/advocacy/EUPHA_report_on_healthy_and_sustainable_diets_20-052017.pdf.

10. World Bank. Chronic Emergency: Why NCDs Matter. Available at: https://openknowledge.worldbank.org/bitstream/handle/10986/13591/639270WP0Chron0Box036153 3B00PUBLIC0.pdf? sequence $=1$ \&isAllowed $=\mathrm{y}$.

11. WHO on behalf of the European Observatory. Tackling chronic disease in Europe. Available at: http://www.euro.who.int/_data/assets/pdf_file/0008/96632/E93736.pdf.

12. World Economic Forum. The Global Economic Burden of NCDs. Available at: http://apps.who.int/medicinedocs/documents/s18806en/s18806en.pdf.

13. European Commission. European Semester thematic fiche. Health and health systems. Available at: https://ec.europa.eu/info/sites/info/files/file_import/european-semester_thematic-factsheet_healthsystems_en_0.pdf.

14. European Commission. The 2014 EU Summit on Chronic Diseases Conclusions. Available at: http://ec.europa.eu/health//sites/health/files/major_chronic_diseases/docs/ev_20140403_mi_en.pdf. 15. European Heart Network. European Cardiovascular Disease Statistics (2017). Available at: http://www.ehnheart.org/images/CVD-statistics-report-August-2017.pdf.

16. Luengo-Fernandez R, Leal J, Gray A, Sullivan R. Economic burden of cancer across the European Union: a population-based cost analysis. Lancet Oncol 2013 Nov;14(12):1165-1174.

17. International Diabetes Federation. IDF Diabetes Atlas - 7th edition (2015). Available at: http://www.diabetesatlas.org/. 



\section{Chapter 3}

\section{How best to use the EXPO momentum to improve our food environment?}

Published as:

Alessandra Lafranconi and Christopher A. Birt (2015) How best to use the EXPO momentum to improve our food environment? European Journal of Public Health, 25(5):751-2, doi: 0.1093/eurpub/ckv130 [IF (2015): 2,75] 



\section{Editorial}

If you were about to choose a place to go in May-October 2015, you might opt for Milan: the opening of EXPO exhibition "Feeding the Planet, Energy for Life" adds to the already vibrant atmosphere in the Italian capital of fashion and makes it nearly irresistible.

The European Commission, recognizing this, brought together at the EXPO EU Pavilion those with an interest in food, hosting the "Grand debate on Nutrition Security - a whole system approach": a joint initiative of various initiatives, which gathered agricultural (Joint Research Programming Initiative on Agriculture, Food Security and Climate Change, FACCE) and health stakeholders (Joint Research Programming Initiative "A healthy diet for a healthy life", HDHL).

Is this so impressive? Definitely, because a joint initiative confronts the dangerous risk (and apparent current practice) of keeping agriculture and health distinctly separate.

As Pamela Byrne, chair of HDHL, pointed out, there are good signals: in Brussels, May started off with the approval of a Research Agenda for Global Food and Nutrition Security; meanwhile, at the EXPO EU Pavilion experts are working on the role of research in global food and nutrition security (1).

Nutrition security is, for the European Union, a more interesting and challenging indicator than is food security: thanks to the Common Agricultural Policy, we do not experience lack of access to food. Instead, we suffer nowadays from over-consumption of calories and saturated fat: in the EU 20\% of people are obese, and one in three European children is overweight or obese (2). These data clearly indicate that our nutrition environment is insecure.

Addressing nutrition security means to place public health at the center of a complex debate, where environmental and economic concerns interact with those of health. And this is the second element (the first being the incentive to agriculture and health interests to talk to each other) which made us, researchers in public health, absolutely thrilled to attend the event. Was it up to our expectations?

Yes and no. Yes in the words of Joao Breda (WHO Programme Manager nutrition, physical activity and obesity), who reinforced the concept of an insecure food environment ("the obese are indeed living in a food insecure environment"), and who called for a holistic definition of food security. Food insecurity, he added, exists in developing countries where the population is simultaneously suffering from undernutrition and dying of cardiovascular diseases (mainly attributable to inappropriate overnutrition) at the highest rate worldwide. His two-fold conclusions appeared obvious: it is wrong to use sugar and fat to fight undernutrition; and it is crucial to use price to influence behaviors.

The price policy argument was addressed during the wider discussion, when all conference participants were invited to express their votes on real-life questions, simulating a parliamentary debate. Unexpectedly (because it was revealed that roughly $70 \%$ of participants classified themselves as "researchers"), the vast majority agreed on the controversial statement that "consumers should pay the real price of food". 
Another controversial issue was the front of pack labelling system (in this debate limited only to packaged food), known as the "traffic lights system". One conspicuous group affirmed that labelling, which might constitute a competitive advantage for those selling healthier products, should not be enforced in a mandatory form, but rather as a voluntary measure; moreover (so they argued), as the food industry has anyway a (presumed) economic interest in utilization of nutrition labelling, it might follow that the government should regulate something more urgent and meaningful than food labelling. Is this a valid position? Not really: back in 2010, the food and drink industry was active in blocking, at the European Parliament, a proposal for EU-wide "traffic lights" nutrition labelling, spending over $€ 1$ billion on lobbying to this end, as according to Corporate Europe Observatory (3). Probably researchers, at least the ones participating to the Grand Debate, under-estimate the power of the private sector!

Last but not least: there was no consensus on whether meat consumption can be classified as "unsustainable". While all agreed with Leslie Lipper (FAO, agriculture and development economics) in advocating for climate smart agriculture (4), there was disagreement on livestock and its impacts on environment. A vocal, but isolated, minority of those present based their observations on another FAO report (5), which defined important reductions in emissions "within reach", thanks to technologies and practices already existing, but not widely used; therefore, so they argued, it is possible to reduce emissions without cutting meat consumption.

In the end, we have to ask ourselves: "How do we raise nutritional standards?"

FACCE and HDHL JPIs should promote a joint transparent research agenda that includes analysis of the food environment in Europe and the exploration of possible basic reforms (including, for example, the withdrawal of subsidies directly or indirectly still used to support production of meat and dairy products).

Researchers should be a bit more suspicious when massive economic interests are at stake. And, maybe, eat less meat! 


\section{References}

1. Expo 2015 EU Scientific Steering Committee, The role of research in global food and nutrition security: http://www.europa.eu/expo2015/sites/default/files/files/FINAL_Expo-Discussionpaper_lowQ $\% 281 \% 29$.pdf

Accessed [May 2015]

2. Wijnhoven T MA et al, WHO European Childhood Obesity Surveillance Initiative: body mass index and level of overweight among 6-9-year-old children from school year 2007/2008 to school year 2009/2010, BMC Public Health 2014;14:806

3. Corporate Europe Observatory, A red light for consumer information http://www.corporateeurope.org/news/red-light-consumer-information Accessed [May 2015]

4. Lipper L et al, "Climate-smart" agriculture - Policies, practices and financing for food security, adaptation and mitigation:

http://www.fao.org/docrep/013/i1881e/i1881e00.pdf

Accessed [May 2015]

5. Gerber PI et al, Tackling climate change through livestock - A global assessment of emissions and mitigation opportunities:

http://www.fao.ord/docrep/018/i3437e/i3437e.pdf

Accessed [May 2015] 



\section{PART 1 \\ Health Promotion: nutritional policies and evaluation of their impacts}





\section{Health inequalities in nutrition-related determinants, in the European Union}

Authorship:

During her time as UVS (Unpaid Visiting Scientist) at the Joint Research Centre, Dr. Alessandra Lafranconi has contributed to the Health Promotion and Disease Prevention Knowledge Gateway.

She was the lead author of three peer reviewed "briefs" published in 2018:

EU Burden from Non-Communicable Diseases and key risk factors in the EU, Health Inequalities: Dietary and Physical Activity Related Determinants and Cost of Non-Communicable Diseases in the EU

Published as:

https://ec.europa.eu/jrc/en/health-knowledge-gateway/societal-impacts/inequalities 



\section{Understanding and Measuring Health Inequalities in the European Union}

Health inequalities have been defined as "differences in health status or in the distribution of health determinants between different population groups" (1). When avoidable, these inequalities are termed health inequities (2). In this manuscript, the term "health inequalities" will be used in its broader sense, which includes (but is not limited to) health inequities.

In the European Union, health inequalities exist both between and within countries. Within countries, vulnerable (and often socially excluded) population groups are characterized by one or more of the following conditions: low household income, low educational level, unemployment (especially long-term unemployment), low socio-economic status (SES, which often includes one or more of the already mentioned conditions), poverty (or at risk of poverty) 1 , migrant background, and ethnic minority background (3). Health tends to worsen from society's richest to poorest, often referred to as social gradient in health (health is progressively better the higher the socioeconomic position of people and communities). Age and gender differences can also worsen health inequalities.

Common indicators of health status - part of the European Core Health Indicators (ECHI) - are life expectancy at birth, healthy life expectancy at birth, infant mortality rate and standardized cause-specific mortalities. Table 1 shows how these indicators perform in the European countries. It illustrates several differences between countries such as:

- Life expectancy at birth - in 2014 life expectancy at birth differed by almost 9 years between countries with the highest and lowest records $(4,5)$ (albeit life expectancy has increased in most EU countries since 1990) (6); similar inequalities (gaps of 10 years and more, e.g. 67.5 vs 81.7 ) can be seen within some countries between people with different education levels $(4,5)$.

- Healthy life expectancy - in 2014, healthy life expectancy at birth in both men and women, ranged from approximately 50 to 70 years, meaning that depending on their country of birth Europeans could expect to have 20 more (or less!) years of healthy life $(4,5)$. Moreover, the mismatch between life expectancy at birth and healthy life expectancy varied across the EU, from the lowest difference of 10 years to the highest one of 23.6 years.

- Infant mortality rate per 1,000 ranged from 1.4 to 8.4 in 2014, indicating a 6-fold variation across EU countries (5).

- Standardized mortality for ischemic heart disease, the leading cause of death in the EU, ranged from below 100/100,000 deaths in some Northern and Southern European countries to over 350/100,000 deaths in Eastern European ones in 2013 (5).

\footnotetext{
${ }_{1}$ People in poverty or at risk of poverty meet at least one of the three following conditions: 1 . at-risk-ofpoverty after social transfers (income poverty); 2 . severely materially deprived; 3 . living in households with very low work intensity.
} 
Table 1. Life expectancy at birth, infant mortality rate and standardized ischemic heart disease (IHD) mortality rate in EU Countries. EU-28 average is represented at the bottom of the table. Flags signal issues in data quality (b: break in time series; e: estimated; p: provisional). For some countries, estimates of life expectancy stratified by education level are available. Sources: ECHI, Eurostat.

\begin{tabular}{|c|c|c|c|c|c|c|c|c|}
\hline \multirow[b]{2}{*}{ Country } & \multirow{2}{*}{$\begin{array}{l}\text { Life } \\
\text { expectancy } \\
\text { at birth, } \\
2014\end{array}$} & \multicolumn{3}{|c|}{ Life expectancy at birth, 2013} & \multicolumn{2}{|c|}{$\begin{array}{l}\text { Healthy life } \\
\text { expectancy, } 2014\end{array}$} & \multirow{2}{*}{$\begin{array}{l}\text { Infant } \\
\text { mortality } \\
\text { rate } \\
(1.000) \text {, } \\
2014 \\
\end{array}$} & \multirow{2}{*}{$\begin{array}{l}\text { Standard } \\
\text { mortality } \\
\text { rate IHD } \\
(100.000) \\
2013\end{array}$} \\
\hline & & $\begin{array}{l}\text { Low } \\
\text { education } \\
\text { (ISCED 0-2) }\end{array}$ & $\begin{array}{l}\text { Middle } \\
\text { education } \\
\text { (ISCED 3-4) }\end{array}$ & $\begin{array}{l}\text { Higher } \\
\text { Education } \\
\text { (ISCED 5-8) }\end{array}$ & Men & Women & & \\
\hline Belgium & 81.4 & & & & 64.5 & 63.7 & 3.4 & 78.4 \\
\hline Bulgaria & 74.5 & 68.7 & 76.3 & 78.7 & 62 & 66.1 & 7.6 & 199.5 \\
\hline Czech Republic & 78.9 & 73 & 78.6 & 79.6 & 63.4 & 65 & 2.4 & 364.4 \\
\hline Denmark & 80.7 & 77.6 & 80.6 & 82.5 & 60.3 & 61.4 & 4 & 86.8 \\
\hline Germany & $81.2 b$ & & & & 56.4 & 56.5 & 3.2 & 155 \\
\hline Estonia & 77.4 & 67.5 & 77.5 & 81.7 & 53.2 & 57.1 & 2.7 & 311.1 \\
\hline Ireland & $81.4 p$ & & & & 66.3 & 67.5 & 3.3 & 166.5 \\
\hline Greece & 81.5 & 79.4 & 82.5 & 83.6 & 64.1 & 64.8 & 3.8 & 97.9 \\
\hline Spain & 83.3 & & & & 65 & 65 & 2.8 & 72.1 \\
\hline France & $82.8 b$ & & & & 63.4 & 64.2 & 3.5 & 51.8 \\
\hline Croatia & 77.9 & 76.9 & 76.9 & 80.1 & 58.6 & 60 & 5 & 310.3 \\
\hline Italy & 83.2 & 80.9 & 85 & 84.9 & 62.5 & 62.3 & 2.8 & 104.2 \\
\hline Cyprus & 82.8 & & & & 66.1 & 66.3 & 1.4 & 104.2 \\
\hline Latvia & 74.5 & & & & 51.5 & 55.3 & 3.8 & 462.2 \\
\hline Lithuania & 74.7 & & & & 57.6 & 61.7 & 3.9 & 589.3 \\
\hline Luxembourg & 82.3 & & & & 64 & 63.5 & 2.8 & 89.7 \\
\hline Hungary & 76 & 71 & 77.1 & 79.4 & 58.9 & 60.8 & 4.5 & 396.6 \\
\hline Malta & 82.1 & & & & 72.3 & 74.3 & 5 & 214.2 \\
\hline Netherlands & 81.8 & & & & 63.3 & 59 & 3.6 & 66.5 \\
\hline Austria & 81.7 & & & & 57.6 & 57.8 & 3 & 191.7 \\
\hline Poland & 77.8 & 71.8 & 76.9 & 81.5 & 59.8 & 62.7 & 4.2 & 140.1 \\
\hline Portugal & $81.3 e$ & 80.1 & 82.3 & 84.1 & 58.3 & 55.4 & 2.9 & 65.6 \\
\hline Romania & $75 e$ & 71.1 & 76.7 & 77.5 & 59 & 59 & 8.4 & 323.9 \\
\hline Slovenia & 81.2 & 76.7 & 80.6 & 83.6 & 57.8 & 59.6 & 1.8 & 111.2 \\
\hline Slovakia & 77 & 70.1 & 77 & 80.1 & 55.5 & 54.6 & 5.8 & 433.3 \\
\hline Finland & 81.3 & 77.9 & 81.1 & 83.4 & 58.7 & 57.5 & 2.2 & 208.5 \\
\hline Sweden & 82.3 & 79.1 & 82.3 & 83.8 & $73.6 b$ & $73.6 n$ & 2.2 & 139.2 \\
\hline United Kingdom & $81.4 \mathrm{e}$ & & & & 63.4 & 64.2 & 3.9 & 126.1 \\
\hline EU28a & 80.9 bep & & & & 61.4 & 61.8 & 3.7 & 131.9 \\
\hline
\end{tabular}

For most EU countries, Eurostat population data and ECHI offer estimates of the fraction and the number of people belonging to specific vulnerable groups. The available data are presented in Table 2 and can be summarized as follows:

- Among an estimated 507 million people in the EU-28 in 2014, around 41 million were unemployed (half of which were long-term unemployed, with continuous periods of unemployment extending for a year), at least 74 million people had a low education level 
(ISCED2 0,1 or 2, year 2010), and around 124 million people lived in poverty or at risk of poverty; there were 34 million EU resident non-citizens (which includes neither illegal migrants nor migrants with EU citizenship already acquired, year 2013), and 6 million Roma (year 2012) $(4,5,7)$;

- Among the 124 million people defined as in poverty or at risk of poverty (mainly women, children, young people, people living in single-parent households, lower educated people and migrants) (8), 43 million have been estimated to also be at risk of food poverty ${ }^{3}$ (9). Food poverty, in affluent societies, has not been linked with dramatic energy intake deficiencies, but with some nutrient/micronutrient deficiencies and, importantly, with energy-dense diets, overweight and obesity (10).

2 According to the International standard classification of education (ISCED), the level of education usually presented for three main categories: less than primary, primary and lower secondary education (ISCED 2011 levels 0-2); upper secondary and post-secondary non-tertiary education (ISCED 2011 levels 3 and 4); tertiary education (ISCED 2011 levels 5-8).

${ }_{3}^{3}$ Food poverty has been defined as individual or household inability to purchase healthy and nutritious food"; factors influencing access to healthy and nutritious food include affordability and availability of food items, but also knowledge and skills to create a healthy meal. 
Table 2. Total population size, and numbers and percentages of people in vulnerable categories in EU countries. EU-28 average is represented at the bottom of the table. Flags signal issues in data quality (b: break in time series; p: provisional). Sources: ECHI, Eurostat, Council of Europe.

\begin{tabular}{|c|c|c|c|c|c|c|c|}
\hline & $\begin{array}{l}\text { Population } \\
\text { 1st Jan } 2014\end{array}$ & $\begin{array}{l}\% \\
\text { unemployed, } \\
\text { age 15-74, } \\
2014\end{array}$ & $\begin{array}{l}\% \text { long-term } \\
\text { unemployed, } \\
\text { age 15-74, } \\
2014\end{array}$ & $\begin{array}{l}\% \text { at risk of } \\
\text { poverty, } \\
2014\end{array}$ & $\begin{array}{l}\text { \% with low } \\
\text { education } \\
\text { (ISCED 0, 1, } \\
\text { 2), age 25- } \\
64,2010\end{array}$ & $\begin{array}{l}\% \text { resident } \\
\text { non- } \\
\text { citizens, } \\
2013\end{array}$ & $\begin{array}{l}\text { \% Roma } \\
\text { minority, } \\
2012\end{array}$ \\
\hline Belgium & $11,203,992$ & 8.5 & 4.3 & 21.2 & 29.63 & 11.17 & 0.27 \\
\hline Bulgaria & $7,245,677$ & 11.4 & 6.9 & $40.1 b$ & 19.79 & 0.62 & 10.35 \\
\hline Czech Republic & $10,512,419$ & 6.1 & 2.7 & 14.8 & 8.06 & 4.03 & 1.9 \\
\hline Denmark & $5,627,235$ & 6.6 & 1.7 & $17.8 b$ & 22.48 & 6.62 & 0.04 \\
\hline Germany & $80,767,463$ & 5 & 2.2 & 20.6 & 14.13 & $9.56 b$ & 0.13 \\
\hline Estonia & $1,315,819$ & 7.4 & 3.3 & $26 b$ & 10.74 & 15.09 & 0.08 \\
\hline Ireland & $4,605,501$ & 11.3 & 6.7 & 27.4 & 25.66 & $11.81 p$ & 0.81 \\
\hline Greece & $10,903,704$ & 26.5 & 19.5 & 36 & 36.2 & 8.14 & 1.6 \\
\hline Spain & $46,512,199$ & 24.5 & 12.9 & 29.2 & 47.29 & $10.91 b$ & 1.61 \\
\hline France & $65,835,579$ & 10.3 & 4.4 & 18.5 & 28.09 & 6.21 & 0.61 \\
\hline Croatia & $4,246,809$ & 17.3 & 10.1 & 29.3 & 21.37 & 0.66 & 0.82 \\
\hline Italy & $60,782,668$ & 12.7 & 7.8 & 28.3 & 44.7 & 7.2 & 0.25 \\
\hline Cyprus & 858,000 & 16.1 & 7.7 & 27.4 & 25.76 & 19.8 & 0.15 \\
\hline Latvia & $2,001,468$ & 10.8 & 4.7 & 32.7 & 11.52 & & 0.62 \\
\hline Lithuania & $2,943,472$ & 10.7 & 4.8 & 27.3 & 7.93 & 0.76 & 0.1 \\
\hline Luxembourg & 549,680 & 6 & 1.6 & 19 & 21.03 & 43.59 & 0.05 \\
\hline Hungary & $9,877,365$ & 7.7 & 3.7 & 31.1 & 18.55 & 1.43 & 7.59 \\
\hline Malta & 425,384 & 5.9 & 2.7 & 23.8 & 71.4 & 5.28 & \\
\hline Netherlands & $16,829,289$ & 7.4 & 3 & 16.5 & 27.23 & 4.25 & 0.24 \\
\hline Austria & $8,506,889$ & 5.6 & 1.5 & 19.2 & 17.45 & 11.68 & 0.41 \\
\hline Poland & $38,017,856$ & 9 & 3.8 & 24.7 & 11.19 & 0.25 & 0.09 \\
\hline Portugal & $10,427,301$ & 14.1 & 8.4 & 27.5 & 68.23 & 4 & 0.5 \\
\hline Romania & $19,947,311$ & 6.8 & 2.8 & 40.2 & 25.76 & $0.35 b$ & 9.27 \\
\hline Slovenia & $2,061,085$ & 9.7 & 5.3 & 20.4 & 16.67 & 4.43 & 0.41 \\
\hline Slovakia & $5,415,949$ & 13.2 & 9.3 & 18.4 & 9.01 & 1.37 & 9.05 \\
\hline Finland & $5,451,270$ & 8.7 & 1.9 & 17.3 & 17.03 & 3.56 & 0.2 \\
\hline Sweden & $9,644,864$ & 7.9 & 1.5 & 16.9 & 18.39 & 6.83 & 0.52 \\
\hline United Kingdom & $64,308,261$ & 6.1 & 2.2 & 24.1 & 23.59 & 7.74 & 0.35 \\
\hline EU28 & $506,824,509$ & $\begin{array}{l}\mathbf{1 0 . 2} \% \\
40,972,445\end{array}$ & $\begin{array}{l}\mathbf{5 . 1} \% \\
20,486,223\end{array}$ & $\begin{array}{l}\mathbf{2 4 . 4 \%} \\
123,665,180\end{array}$ & $>74,300,000$ & $34,202,384$ & $6,197,100$ \\
\hline
\end{tabular}

\section{Differences in Diet-related Determinants as Drivers of Health Inequalities}

Differences in several health determinants and behaviors underlie the health inequalities observed within and between EU countries, such as in smoking, alcohol consumption, diets or physical activity levels. With regards to diet, despite limited data availability on the quality of diets per population group, there is a considerable amount of information contained in more aggregated data.

Table 3 presents an example of data on fruit and vegetable intake, stratified by educational level. Self-reported daily consumption of fruit and vegetables is higher in groups with higher education levels in northern and central European countries, but not necessarily in southern countries (11). 
Table 3. Proportion of people reporting daily eating of vegetables or fruits by levels of education/ educational attainment in several EU countries. Source: Eurostat.

\begin{tabular}{|c|c|c|c|c|c|c|c|c|}
\hline \multirow[b]{2}{*}{ Country } & \multicolumn{4}{|c|}{$\begin{array}{l}\text { \% of people aged 15+ reporting to eat fruits at least } \\
\text { once a day, } 2014\end{array}$} & \multicolumn{4}{|c|}{$\begin{array}{l}\% \text { of people aged } 15+\text { reporting to eat vegetables at } \\
\text { least once a day, } 2014\end{array}$} \\
\hline & Overall & $\begin{array}{l}\text { ISCED } \\
\text { class } 0.2\end{array}$ & $\begin{array}{l}\text { ISCED } \\
\text { class 3-4 }\end{array}$ & $\begin{array}{l}\text { ISCED } \\
\text { class 5-8 }\end{array}$ & Overall & $\begin{array}{l}\text { ISCED class } \\
0-2\end{array}$ & $\begin{array}{l}\text { ISCED class } \\
3-4\end{array}$ & $\begin{array}{l}\text { ISCED class } \\
5-8\end{array}$ \\
\hline Belgium & 54.0 & 50.4 & 50.8 & 61.0 & 78.5 & 76.1 & 78.1 & 82.3 \\
\hline Bulgaria & 35.4 & 24.8 & 36.5 & 48.2 & 38.4 & 26.0 & 41.0 & 50.7 \\
\hline Czech Republic & 46.8 & 38.1 & 46.2 & 55.4 & 41.4 & 32.1 & 40.4 & 52.2 \\
\hline Denmark & 53.0 & 48.2 & 48.3 & 59.4 & 44.1 & 31.2 & 37.9 & 56.4 \\
\hline Germany & 47.3 & 49.5 & 45.1 & 49.4 & 34.1 & 33.2 & 31.1 & 39.0 \\
\hline Estonia & 52.2 & 44.3 & 50.8 & 59.8 & 54.8 & 47.9 & 53.7 & 61.3 \\
\hline Greece & 55.0 & 54.8 & 52.9 & 58.5 & 62.2 & 69.0 & 55.8 & 59.3 \\
\hline Spain & 66.7 & 66.5 & 63.4 & 69.6 & 44.6 & 42.6 & 46.7 & 46.9 \\
\hline France & 55.1 & 58.4 & 51.4 & 57.5 & 57.6 & 58.5 & 54.2 & 62.5 \\
\hline Croatia & 58.1 & 51.4 & 57.3 & 68.0 & 62.4 & 58.4 & 62.3 & 68.1 \\
\hline Italy & 70.9 & 71.6 & 68.5 & 74.6 & 61.9 & 59.3 & 62.1 & 70.5 \\
\hline Cyprus & 58.1 & 60.6 & 53.7 & 61.2 & 52.7 & 48.0 & 49.7 & 60.7 \\
\hline Latvia & 39.8 & 32.5 & 39.3 & 45.6 & 42.6 & 33.2 & 42.3 & 49.6 \\
\hline Lithuania & 47.9 & 40.7 & 46.2 & 55.8 & 54.5 & 44.6 & 53.0 & 63.5 \\
\hline Luxembourg & 49.8 & 54.6 & 47.2 & 49.0 & 52.2 & 53.8 & 49.7 & 55.0 \\
\hline Hungary & 59.2 & 53.2 & 58.7 & 66.4 & 46.3 & 40.2 & 45.3 & 54.8 \\
\hline Malta & 57.6 & 57.2 & 54.9 & 61.5 & 40.0 & 37.5 & 40.4 & 47.8 \\
\hline Netherlands & 41.0 & 42.3 & 39.1 & 42.5 & 31.3 & 30.4 & 28.2 & 37.1 \\
\hline Austria & 56.0 & 58.6 & 54.2 & 57.3 & 47.6 & 44.7 & 46.1 & 53.5 \\
\hline Poland & 58.5 & 52.1 & 57.9 & 65.7 & 55.7 & 47.4 & 54.2 & 66.2 \\
\hline Portugal & 70.9 & 70.0 & 67.9 & 77.4 & 55.2 & 51.9 & 55.5 & 66.8 \\
\hline Romania & 28.8 & 21.4 & 28.8 & 48.4 & 29.6 & 23.4 & 29.9 & 44.5 \\
\hline Slovenia & 60.7 & 63.5 & 58.8 & 58.7 & 60.9 & 61.0 & 60.4 & 61.8 \\
\hline Slovakia & 47.4 & 43.7 & 46.6 & 52.9 & 44.0 & 38.6 & 43.7 & 49.2 \\
\hline Finland & 44.0 & 44.8 & 38.2 & 48.8 & 45.4 & 35.6 & 37.0 & 57.1 \\
\hline Sweden & 46.8 & 49.9 & 42.7 & 52.2 & 52.1 & 48.5 & 47.6 & 62.3 \\
\hline United Kingdom & 62.8 & 57.1 & 60.7 & 68.4 & 65.5 & 54.2 & 62.3 & 75.7 \\
\hline EU28 & 55.7 & 57.5 & 52.0 & 59.7 & 50.1 & 48.2 & 47.3 & 56.9 \\
\hline
\end{tabular}

Table 4 summarizes the evidence reported so far on these and other nutrition-related health determinants and their relation to health inequalities.

Table 4. Nutrition -related health behaviors and inequalities. The summaries in this table are based on the evidence and discussions presented in the original references.

\begin{tabular}{|c|c|c|}
\hline Behavior & Evidence on inequality & Source \\
\hline Breast- & Mothers from lower socioeconomic groups are less likely to breastfeed than mothers from higher & WHO Europe (2014) (12) \\
\hline feeding & SES (evidence from many EU countries, and from the WHO European Region) & $\mathrm{EC}(2007)(13)$ \\
\hline \multirow[b]{2}{*}{$\begin{array}{l}\text { Breakfast } \\
\text { habits }\end{array}$} & $\begin{array}{l}\text { Young people from higher-affluence families (especially boys) show higher rates of breakfast } \\
\text { consumption in most countries compared to the general population (evidence from most EU } \\
\text { countries, from the WHO European Region and elsewhere) }\end{array}$ & WHO Europe (2016)(14) \\
\hline & $\begin{array}{l}\text { Children from families of low affluence are more likely to skip breakfast than their more affluent } \\
\text { counterparts, especially in northern and central Europe; exceptions are some countries in southern } \\
\text { and eastern Europe such as Bulgaria (evidence from many EU countries, and from WHO European } \\
\text { Region) }\end{array}$ & WHO Europe (2014) (9) \\
\hline Family dinner & $\begin{array}{l}\text { Children from high-affluence families are more likely to eat daily evening meals than children from } \\
\text { lower affluent households (evidence from most EU countries, from the WHO European Region, and } \\
\text { elsewhere) }\end{array}$ & WHO Europe (2016)(14) \\
\hline
\end{tabular}




\begin{tabular}{|c|c|c|}
\hline \multirow{7}{*}{$\begin{array}{l}\text { Fruit and } \\
\text { vegetable } \\
\text { consumption }\end{array}$} & $\begin{array}{l}\text { Low-income households have the lowest fruit and vegetable consumption in the EU (evidence from } \\
\text { many EU countries, and from the WHO European Region) }\end{array}$ & WHO Europe (2014) (9) \\
\hline & $\begin{array}{l}\text { Fruit consumption is more common in adolescents with higher parental occupational status and } \\
\text { with family material wealth than in adolescents from less wealthy households (evidence from many } \\
\text { EU countries, and from the WHO European Region) }\end{array}$ & WHO Europe (2014) (9) \\
\hline & $\begin{array}{l}\text { Families with children are more likely to cut on fresh fruit and vegetables than families without } \\
\text { children; similarly, single-parent households are more likely to cut on fresh fruit and vegetables } \\
\text { than families with two parents (evidence from many EU countries, and from the WHO European } \\
\text { Region) }\end{array}$ & WHO Europe (2014) (12) \\
\hline & $\begin{array}{l}\text { In children, low fruit and vegetable consumption is associated with parents' low education, low } \\
\text { income and unemployment (evidence from most EU countries, from the WHO European Region, } \\
\text { and elsewhere) }\end{array}$ & WHO Europe (2016)(14) \\
\hline & $\begin{array}{l}\text { Fruit consumption is generally higher among persons with higher educational levels, especially in } \\
\text { Bulgaria, Latvia and Romania; exceptions are some southern European countries such as Cyprus, } \\
\text { Greece, and Malta (evidence from most EU countries and from the WHO European Region) }\end{array}$ & $\operatorname{OECD}(2016)(6)$ \\
\hline & $\begin{array}{l}\text { Highly educated people tend to eat vegetables more often than their less educated counterparts. } \\
\text { The differences are fairly small in countries such as Belgium, Cyprus, Greece and the Slovak } \\
\text { Republic (evidence from most EU countries and from the WHO European Region) }\end{array}$ & OECD (2016) (6) \\
\hline & $\begin{array}{l}\text { In England, adults with higher income are significantly more likely than those with lower income } \\
\text { to report eating the recommended five or more portions per day }\end{array}$ & PHE (2013) (15) \\
\hline \multirow[t]{2}{*}{$\begin{array}{l}\text { Soft-drinks } \\
\text { consumption }\end{array}$} & $\begin{array}{l}\text { Adolescents with higher parental occupational status have lower soft-drink consumption in } \\
\text { northern, southern and western European countries than their counterparts from households with } \\
\text { lower occupational status. Exceptions are central and eastern countries, where consumption } \\
\text { increases with family affluence (evidence from most EU countries and from the WHO European } \\
\text { Region) }\end{array}$ & WHO Europe (2014) (9) \\
\hline & $\begin{array}{l}\text { Family affluence and soft-drink consumption do not show a consistent pattern across countries } \\
\text { (evidence from most EU countries, from the WHO European Region, and elsewhere) }\end{array}$ & WHO Europe (2016) (14) \\
\hline TV watching & $\begin{array}{l}\text { Children from low-affluence families are more likely to watch at least } 2 \text { hours of TV per day } \\
\text { compared to more affluent children; the difference is limited (evidence from most EU countries, } \\
\text { from countries from the WHO European Region and elsewhere) }\end{array}$ & WHO Europe (2016)(14) \\
\hline
\end{tabular}

A recent analysis (16) that explored how inequality trends are changing over time in children and adolescents of various countries, including EU countries, reports that inequality in unbealthy eating (based on 2002 - 2014 data on self-reported consumption of "sweets (candy or chocolate)" and "coke or other soft drinks that contain sugar"), in most EU countries was reduced (with the exception of Hungary, Poland, Estonia and Lithuania with no change, and Romania, Slovakia and Belgium, with increased inequalities). This reduction appears to be driven by improvements on the unhealthy eating behaviors of the lower SES population groups.

Among various minority groups living in the EU, it appears that dietary habits have been recorded systematically only for Roma (17). The data indicate that Roma minorities tend to have a diet characterized by fewer vegetables and more fats, compared to the general population.

\section{Obesity and other Conditions related to Diet-related Determinants}

Obesity is the most described health outcome associated with health inequalities related to diets. Data from 2014 (or latest year) indicate that the prevalence of self-reported adult obesity in the EU varies from 9\% in Romania to $26 \%$ in Malta (6). In the EU, measured overweight (including obesity) among children at various ages is about $23 \%$ for boys and $21 \%$ for girls (2010 or latest year, evidence from 22 countries) (6); self-reported overweight (including obesity) among 15- 
year-olds is about $22 \%$ in boys and $13 \%$ in girls (2013-14, evidence from 27 countries) (6). Many socio-economic variables are associated with obesity and these are summarized in Table 5.

Table 5. Proposed relations between overweight/obesity and socioeconomic status, educational level and ethnicity. The summaries in this table are based on the evidence and discussions presented in the original references.

\begin{tabular}{|c|c|c|}
\hline Determinant & Evidence & Source \\
\hline \multirow{25}{*}{$\begin{array}{l}\text { Socioeconomic } \\
\text { status }\end{array}$} & \multirow{6}{*}{$\begin{array}{l}\text { There is a strong social gradient in obesity: lower socioeconomic (SE) strata have higher } \\
\text { levels of obesity compared with the rest; this is particularly true for women and children }\end{array}$} & WHO Europe (2014) (9) \\
\hline & & WHO Europe (2014) (12) \\
\hline & & OECD (2016) (6) \\
\hline & & PHEIAC (2013) (18) \\
\hline & & Equity Action (2013) (19) \\
\hline & & European Commission (2007) (13) \\
\hline & \multirow{2}{*}{$\begin{array}{l}\text { In Eastern Europe, the social gradient in obesity is less pronounced than in other parts of } \\
\text { Europe }\end{array}$} & WHO Europe (2014) (9) \\
\hline & & European Commission (2007) (13) \\
\hline & \multirow{4}{*}{$\begin{array}{l}\text { Countries with higher levels of social inequality tend to have the highest prevalence of } \\
\text { obesity, especially among adolescents and children }\end{array}$} & WHO Europe (2014) (9) \\
\hline & & WHO Europe (2014) (12) \\
\hline & & Equity Action (2013)(19) \\
\hline & & European Commission (2007) (13) \\
\hline & $\begin{array}{l}\text { Social disparities in obesity also exist among children, but there are no significant } \\
\text { gender differences in the social gradient of child obesity }\end{array}$ & PHEIAC (2013) (18) \\
\hline & \multirow{5}{*}{$\begin{array}{l}\text { Obesity and overweight among children is associated with the socio-economic status of } \\
\text { their parents, especially their mothers }\end{array}$} & WHO Europe (2017) (20) \\
\hline & & WHO Europe (2014) (9) \\
\hline & & WHO Europe (2014) (12) \\
\hline & & Equity Action (2013) (19) \\
\hline & & European Commission (2007) (13) \\
\hline & \multirow{2}{*}{$\begin{array}{l}\text { In the European Region, about } 20-25 \% \text { of the risk of obesity among men and } 40-50 \% \\
\text { among women can be attributed to differences in SES }\end{array}$} & WHO Europe (2014) (9) \\
\hline & & European Commission (2007) (13) \\
\hline & \multirow{4}{*}{$\begin{array}{l}\text { The difference in overweight and obesity between socioeconomic groups is widening, } \\
\text { with faster growth among disadvantaged groups resulting in a steepening gradient }\end{array}$} & WHO Europe (2014) (9) \\
\hline & & WHO Europe (2014) (12) \\
\hline & & Equity Action (2013) (19) \\
\hline & & European Commission (2007) (13) \\
\hline & NCD burden falls more heavily on those in lower socioeconomic groups & WHO (2017) (21) \\
\hline \multirow{5}{*}{$\begin{array}{l}\text { Educational } \\
\text { level }\end{array}$} & \multirow{5}{*}{$\begin{array}{l}\text { In most countries, the higher the level of education, the lower the prevalence of obesity; } \\
\text { the obesity gradient is stronger in women than in men }\end{array}$} & WHO Europe (2014) (9) \\
\hline & & OECD (2016) (6) \\
\hline & & PHEIAC (2013) (18) \\
\hline & & Equity Action (2013) (19) \\
\hline & & European Commission (2007) (13) \\
\hline \multirow{5}{*}{ Ethnicity } & \multirow{2}{*}{$\begin{array}{l}\text { Some ethnic minority groups (e.g. African migrants in the UK, Turkish migrants) have } \\
\text { substantially higher obesity rates than others }\end{array}$} & PHEIAC (2013) (18) \\
\hline & & European Commission (2007) (13) \\
\hline & $\begin{array}{l}\text { In some of ethnic groups (e.g. African migrants in the UK), women appeared to be } \\
\text { significantly more vulnerable to higher obesity rates than men }\end{array}$ & PHEIAC (2013) (18) \\
\hline & $\begin{array}{l}\text { The gap in obesity between children from ethnic minorities and Caucasian children is } \\
\text { larger than that observed in adults (UK and US) }\end{array}$ & PHEIAC (2013) (18) \\
\hline & $\begin{array}{l}\text { There is a need to distinguish income, education and occupation differences from ethnic } \\
\text { differences before assuming one or the other is solely responsible for the raised risk of } \\
\text { obesity }\end{array}$ & Equity Action (2013) (19) \\
\hline
\end{tabular}

Among SES-related predictors of overweight and obesity, education is the one that has received the most attention from the scientific community. Yet little is known about the relative importance of causation (that is, the influence of parental education or of one's own education 
on the risk of developing overweight and obesity) and selection (that is, the influence of high BMI on the likelihood to attain education, adjusted for SES variables) (22).

A strong gender gap, defined as the difference between women and men in attainments and attitudes, is present in the distribution of obesity according to socio-economic variables. In most countries, obesity rates have grown more rapidly in low SES groups than in high SES groups (23), thus widening health inequalities. The link between obesity and socio-economic disadvantage appears to be perpetuated in a vicious cycle (12), and, over the life course, different types of inequality can contribute to diminished nutritional status, thus perpetuating the cycle. For instance, obesity in women, especially during pregnancy and lactation, contributes to the health risks of their children, amplifying health inequities across generations. Impacts can be long-lasting. For example, the association between the BMIs of parents and their children has been shown to persist from birth up to 45 years of age (19).

SES effects on health can also be seen in medical conditions other than obesity (24). National data from across Europe show an inverse association between the level of education and the proportion of population reporting any long-standing chronic illness or long-standing health problem (i.e. the higher the education level, the fewer the reported long-standing health concerns). In fact, obesity itself often clusters with metabolic risk factors, such as high blood pressure, high fasting glucose and dyslipidaemia in the so-called metabolic syndrome, and acts as a risk factor for the development of other non-communicable diseases. Data on reported BMI and reported recent diagnosis of diabetes and high blood pressure, stratified by education level, are presented in Table 6. 
Table 6. Percentage of people reporting BMI above 30 according to educational level, and percentage of people reporting a new diagnosis of diabetes or high blood pressure (HBP) according to educational level, in EU countries, in 2014. EU-28 average is represented at the bottom of the table. Sources: Eurostat.

\begin{tabular}{|c|c|c|c|c|c|c|c|c|c|}
\hline \multirow{2}{*}{ Country } & \multicolumn{3}{|c|}{$\begin{array}{l}\% \text { of people reporting BMI } \\
\text { above } 30\end{array}$} & \multicolumn{3}{|c|}{$\begin{array}{l}\% \text { of persons reporting diagnosed } \\
\text { diabetes in the past } 12 \text { months }\end{array}$} & \multicolumn{3}{|c|}{$\begin{array}{l}\% \text { of persons reporting diagnosed } \\
\text { HBP in the past } 12 \text { months }\end{array}$} \\
\hline & $\begin{array}{l}\text { ISCED } \\
\text { class } 0-2\end{array}$ & $\begin{array}{l}\text { ISCED } \\
\text { class 3-4 }\end{array}$ & $\begin{array}{l}\text { ISCED } \\
\text { class 5-8 }\end{array}$ & $\begin{array}{l}\text { ISCED } \\
\text { class } 0-2\end{array}$ & $\begin{array}{l}\text { ISCED } \\
\text { class 3-4 }\end{array}$ & $\begin{array}{l}\text { ISCED } \\
\text { class 5-8 }\end{array}$ & $\begin{array}{l}\text { ISCED } \\
\text { class } 0-2\end{array}$ & $\begin{array}{l}\text { ISCED } \\
\text { class 3-4 }\end{array}$ & $\begin{array}{l}\text { ISCED } \\
\text { class 5-8 }\end{array}$ \\
\hline Belgium & 17.6 & 13.4 & 9.8 & 7.8 & 5.1 & 2.6 & 21.6 & 14.1 & 12.2 \\
\hline Bulgaria & 15.7 & 15.3 & 10.4 & 8.0 & 6.2 & 4.2 & 35.0 & 27.9 & 25.1 \\
\hline Czech Republic & 18.0 & 20.4 & 12.5 & 12.9 & 7.5 & 4.2 & 27.6 & 24.9 & 16.1 \\
\hline Denmark & 18.3 & 15.9 & 11.3 & 7.8 & 4.7 & 2.9 & 24.0 & 18.4 & 13.6 \\
\hline Germany & 18.3 & 17.9 & 13.1 & 11.2 & 6.6 & 5.6 & 34.3 & 28.5 & 25.1 \\
\hline Estonia & 21.8 & 21.3 & 17.6 & 7.1 & 6.0 & 4.3 & 29.1 & 22.6 & 20.8 \\
\hline Greece & 21.0 & 14.4 & 13.4 & 15.8 & 4.9 & 3.9 & 34.2 & 11.7 & 10.7 \\
\hline Spain & 21.2 & 12.2 & 9.6 & 10.1 & 3.2 & 2.9 & 25.5 & 11.4 & 10.5 \\
\hline France & 18.4 & 15.2 & 8.8 & 14.7 & 8.4 & 6.1 & 19.7 & 13.5 & 8.6 \\
\hline Croatia & 21.4 & 18.8 & 12.6 & 11.1 & 6.1 & 5.1 & 33.9 & 22.2 & 19.7 \\
\hline Italy & 13.8 & 7.9 & 6.0 & 10.3 & 3.1 & 3.0 & 28.5 & 13.2 & 12.0 \\
\hline Cyprus & 17.9 & 14.6 & 9.3 & 12.2 & 3.5 & 3.6 & 32.6 & 11.8 & 10.1 \\
\hline Latvia & 19.7 & 22.6 & 17.6 & 6.1 & 5.0 & 2.8 & 33.0 & 31.2 & 23.1 \\
\hline Lithuania & 15.5 & 18.9 & 13.3 & 5.8 & 4.6 & 3.1 & 39.7 & 28.2 & 20.0 \\
\hline Luxembourg & 20.8 & 17.4 & 8.3 & 9.3 & 5.3 & 2.8 & 24.6 & 16.8 & 9.5 \\
\hline Hungary & 22.6 & 21.8 & 15.8 & 12.0 & 7.7 & 5.0 & 40.4 & 31.5 & 24.6 \\
\hline Malta & 28.9 & 18.3 & 20.7 & 11.5 & 2.8 & 2.3 & 28.5 & 8.1 & 9.9 \\
\hline Netherlands & 15.3 & 13.7 & 8.6 & 8.2 & 4.5 & 2.8 & 21.2 & 16.0 & 12.4 \\
\hline Austria & 18.6 & 14.9 & 9.0 & 7.2 & 4.9 & 2.9 & 28.7 & 21.0 & 14.2 \\
\hline Poland & 18.3 & 18.5 & 10.7 & 9.9 & 6.7 & 3.7 & 30.5 & 23.9 & 14.3 \\
\hline Portugal & 20.0 & 10.6 & 8.6 & 13.3 & 2.6 & 2.3 & 33.9 & 10.5 & 10.9 \\
\hline Romania & 10.4 & 8.8 & 6.7 & 6.7 & 4.2 & 2.5 & 25.4 & 13.4 & 11.0 \\
\hline Slovenia & 24.0 & 16.8 & 9.2 & 10.0 & 4.9 & 3.7 & 34.4 & 20.6 & 11.1 \\
\hline Slovakia & 18.3 & 17.6 & 8.3 & 13.0 & 6.5 & 3.2 & 34.9 & 27.0 & 15.3 \\
\hline Finland & 20.0 & 20.0 & 14.8 & 14.8 & 7.2 & 5.0 & 41.1 & 22.6 & 19.4 \\
\hline Sweden & 15.2 & 15.6 & 9.9 & 7.2 & 4.7 & 2.8 & 23.7 & 15.8 & 12.3 \\
\hline United Kingdom & 24.5 & 21.0 & 15.9 & 9.8 & 5.2 & 4.0 & 25.2 & 14.8 & 12.3 \\
\hline EU28 & 18.1 & 15.9 & 11.5 & 10.8 & 5.7 & 4.2 & 27.6 & 19.6 & 15.3 \\
\hline
\end{tabular}

\section{Policies to Reduce Diet-related Inequalities}

The European Commission regards health inequalities as a challenge to the EU's commitment to solidarity, social and economic cohesion, human rights and equal opportunities (25). Reducing them is one of the greatest public health challenges in Europe (26). The concept of proportionate universalism must be considered in this regard, i.e. "to reduce the steepness of the social gradient in health, actions must be universal, but with a scale and intensity that is proportionate to the level of disadvantage" (9).

Whereas policies that aim to improve income distribution and raise income of the poorest groups (e.g. social protection, minimum wage, equal pay legislation, and redistributive taxation) are of great relevance to decreasing the inequality gap, the discussion that follows is focused on dietrelated policies that target health inequalities. Policies can reduce inequalities in absolute or relative terms (27), as shown in Table 7. 
Table 7. Analysis of three bypothetical interventions $A, B$ and $C$, with the following characteristics:

A) Larger absolute and relative declines in low SES groups -> reduction of absolute and relative inequalities (most desirable outcome);

B) Larger absolute but smaller relative declines in low SES groups -> reduction of absolute inequalities, increase in relative inequalities (less desirable, but still valuable);

C) Smaller absolute and relative declines in low SES groups -> increase in absolute and relative inequalities (even less desirable, but still valuable).

\begin{tabular}{|c|c|c|c|c|c|c|c|c|}
\hline \multicolumn{3}{|c|}{ Intervention A } & \multicolumn{3}{|c|}{ Intervention B } & \multicolumn{3}{|c|}{ Intervention C } \\
\hline & Mortality (pre) & Mortality (post) & & Mortality (pre) & Mortality (post) & & Mortality (pre) & Mortality (post) \\
\hline High SES & $10 / 100,000$ & $5 / 100,000$ & High SES & $10 / 100,000$ & $5 / 100,000$ & High SES & $10 / 100,000$ & $5 / 100,000$ \\
\hline Low SES & $30 / 100,000$ & $10 / 100,000$ & Low SES & $30 / 100,000$ & $20 / 100,000$ & Low SES & $30 / 100,000$ & $28 / 100,000$ \\
\hline \multicolumn{3}{|c|}{$\begin{array}{l}\text { Reduction in absolute inequalities } \\
{[+20 \text { pre vs }+5 \text { post }]}\end{array}$} & \multicolumn{3}{|c|}{$\begin{array}{l}\text { Reduction in absolute inequalities } \\
{[+20 \text { pre vs }+15 \text { post }]}\end{array}$} & \multicolumn{3}{|c|}{$\begin{array}{l}\text { Increase in absolute inequalities } \\
{[+20 \text { pre vs }+23 \text { post }]}\end{array}$} \\
\hline \multicolumn{3}{|c|}{$\begin{array}{l}\text { Reduction in relative inequalities } \\
\text { [ } x 3 \text { pre vs } x 2 \text { post ] }\end{array}$} & \multicolumn{3}{|c|}{$\begin{array}{l}\text { Increase in relative inequalities } \\
\text { [ } x 3 \text { pre vs } x 4 \text { post ] }\end{array}$} & \multicolumn{3}{|c|}{$\begin{array}{l}\text { Increase in relative inequalities } \\
{[\times 3 \text { pre vs } \times 5.6 \text { post }]}\end{array}$} \\
\hline
\end{tabular}

In the current European context, where baseline levels of obesity are greater in low- than highSES groups, EU countries may wish to directly target those more vulnerable. Table 8 summarizes several recommendations.

Table 8. Examples of policy recommendations addressing inequalities in diet.

\begin{tabular}{|c|c|c|c|}
\hline & Policy recommendation & Source & Year \\
\hline \multirow{3}{*}{$\begin{array}{l}\text { Restriction } \\
\text { or } \\
\text { elimination }\end{array}$} & $\begin{array}{l}\text { "Restrict access to less healthy foods and sweets on school premises" (universal intervention, } \\
\text { applied to all SES strata) }\end{array}$ & WHO Europe (9) & 2014 \\
\hline & \multirow{2}{*}{$\begin{array}{l}\text { Encourage urban policy-makers to limit the density of fast food outlets and restaurants in } \\
\text { disadvantaged areas and around schools }\end{array}$} & WH0 Europe (12) & 2014 \\
\hline & & $\operatorname{CDC}(28)$ & 2009 \\
\hline $\begin{array}{l}\text { Incentives or } \\
\text { disincentives }\end{array}$ & $\begin{array}{l}\text { "Ensure welfare payments in vouchers or in kind include healthy food (e.g. France's fruit and } \\
\text { vegetable vouchers)" }\end{array}$ & WHO Europe (12) & 2014 \\
\hline \multirow{7}{*}{$\begin{array}{l}\text { Changes in } \\
\text { default } \\
\text { options }\end{array}$} & $\begin{array}{l}\text { "Increasing antenatal care attendance for socially deprived and young women by using } \\
\text { participatory methods to address their needs and perceptions" to tackle inequalities in } \\
\text { obesity from early on }\end{array}$ & WHO Europe (9) & 2014 \\
\hline & $\begin{array}{l}\text { "Encourage production of vegetables and fruit, and allocate surplus to school schemes or low } \\
\text { income groups" }\end{array}$ & WHO Europe (12) & 2014 \\
\hline & $\begin{array}{l}\text { "Take into account that breastfeeding support programmes specially geared to obese women } \\
\text { can be effective in low-income groups, and cash payments can increase participation" }\end{array}$ & WHO Europe (12) & 2014 \\
\hline & $\begin{array}{l}\text { Provide free or subsidized nutritious meals (including breakfasts), along with vegetables and } \\
\text { fruit in schools and early childhood centres (universal intervention, applied to all SES strata) }\end{array}$ & $\begin{array}{l}\text { WHO Europe }(9, \\
12)\end{array}$ & 2014 \\
\hline & $\begin{array}{l}\text { Foster promotion of urban food initiatives, particularly in low-income areas (e.g. farmers' } \\
\text { markets, mobile vans selling fruit and vegetables, grocery collectives and community } \\
\text { gardens and cooperatives) }\end{array}$ & $\begin{array}{l}\text { WHO Europe }(9, \\
12)\end{array}$ & 2014 \\
\hline & $\begin{array}{l}\text { "Encourage food manufacturers to make healthier reformulated products available at same } \\
\text { price as energy-dense alternatives" }\end{array}$ & WHO Europe (12) & 2014 \\
\hline & $\begin{array}{l}\text { "Restrict marketing of high-fat, -sugar and -salt foods and sugar-sweetened beverages to } \\
\text { children" }\end{array}$ & WHO Europe (12) & 2014 \\
\hline \multirow{4}{*}{$\begin{array}{l}\text { Provide } \\
\text { information }\end{array}$} & \multirow{2}{*}{$\begin{array}{l}\text { Consider that consumers with low numeracy or literacy skills may be more receptive to } \\
\text { pictograms/pictures or traffic-light labelling, rather than to detailed numerical nutritional } \\
\text { information on food labels }\end{array}$} & WHO Europe (12) & 2014 \\
\hline & & Equity Action (19) & 2013 \\
\hline & $\begin{array}{l}\text { "Increase breastfeeding education, breastfeeding promotion packs, skilled professional } \\
\text { support and early mother-infant bonding in order to help to increase breastfeeding initiation } \\
\text { rates for low-income obese mothers" }\end{array}$ & WHO Europe (12) & 2014 \\
\hline & "Deliver services (including dietary counselling) in community settings (e.g. churches)" & WHO Europe (12) & 2014 \\
\hline
\end{tabular}




\begin{tabular}{llll}
\hline & $\begin{array}{l}\text { Employ peer mediators with diverse ethnic and socioeconomic backgrounds, to provide } \\
\text { counselling services and to facilitate mother-to-mother support groups }\end{array}$ & WHO Europe (12) & 2014 \\
\hline Monitor & $\begin{array}{l}\text { A system of monitoring and evaluation is needed to measure obesity levels in different SES } \\
\text { groups, social determinants of obesity, and relative success of policies and interventions }\end{array}$ & WHO Europe (12) & 2014 \\
\hline
\end{tabular}

The European policy-making process is increasingly sensitive to inequalities. For example, exante impact assessments should address health and inequalities. This means that, an assessment of potential direct and indirect effects on specific population sub-groups should be presented for any new initiative, including whether these sub-groups can be affected differently and disproportionately by the initiative (29).

Many of the implemented policies reviewed in other chapters that target diets, nutrients or specific food and drink products have the potential to reduce health inequalities related to these. As highlighted in the recommendations above, they can for example be delivered specifically to more vulnerable groups to reduce the inequality gap. Also, population measures that attempt a universal coverage have the potential to reduce inequalities as they will effectively limit exposure to or intake of unhealthier messages or food products (12). Some examples are the limitation on advertising to minors (see chapter on Food Marketing to Children), or on the use of industrial trans-fatty acids in foods as seen in Austria, Denmark, and Hungary (30). Food improvement and reformulation initiatives that aim to decrease overall intake of nutrients of concern by directly improving the food products in the market also have the potential to reach all consumers as long as prices are not affected. The EU salt reduction framework (31), or other efforts framed by the EU Framework for national initiatives on selected nutrients (32), or the Roadmap for Action on Food Product Improvement (33) are good examples, provided that reformulation efforts cover all market segments.

School initiatives are also crucial in targeting populations from all SES groups. Interventions at vocational schools, as carried out in Denmark, specifically reach young people with less education.

One other mechanism that deserves to be highlighted in the context of inequalities is the Fund for European Aid to the Most Deprived (FEAD) and similar national schemes. FEAD can be used to support vulnerable groups by providing (among others, food aid. For example, a total of 228707 tons of food were distributed in 2014. With a health-sensitive selection of food products, the measure has the potential to increase the healthiness of the recipients' diets. The BE food package is a case in point containing semi-skimmed milk, canned salmon, filets of mackerel in tomato sauce, beef, macaroni, potato flakes, peeled tomatoes, peas and carrots, mushrooms, fruit cocktail light syrup, peanut oil, jam, breakfast cereals, vanilla pudding powder (34). Nutrient criteria such as those applied in school food policies or marketing restrictions could be considered to ensure the nutritional quality of these baskets.

A recurring issue in addressing health inequalities and identifying measures and policies that effectively diminish them is lack of data. Monitoring schemes and data collection initiatives that allow for data stratification on the basis of socio-economic status, education levels, minorities or 
religious and migrant background, gender and age will not only allow a better assessment of the health gap between different population groups but also allow for better evaluation of policies and measures that try to address them. The Global Observatory for Physical Activity (35) and the UK National Child Measurement Programme (36) are two examples of surveillance schemes that are sensitive to these issues.

In an attempt to sensitize and involve other stakeholders in reducing nutrition-related inequalities, the European Commission has also urged the members of the EU Platform for Action on Diet, Physical Activity and Health to consider health inequalities in their commitments (37). Few stakeholders have built on this call for action and the 2016 annual monitoring report, whose evaluation is limited to what is declared by the commitment proponents, flags 13 out of the 109 commitments active in 2015 as relevant to health inequalities $(38,39)$. Some are listed in Table 9.

Table 9. Examples of implemented programs (EU Platform commitments) with relevance to inequalities in nutrition and physical activity. Source: ICF International.

\begin{tabular}{|c|c|c|}
\hline Area of action & $\begin{array}{l}\text { Commitments } \\
\text { addressing } \\
\text { inequalities }\end{array}$ & Examples \\
\hline Marketing and advertising & 1 out of 14 & $\begin{array}{l}1118 \text { - International standards for marketing food to children: monitoring standards for } \\
\text { marketing food and beverages to children, to evaluate evidence on the relationship between } \\
\text { promotional marketing and diet, and to support advocacy actions. }\end{array}$ \\
\hline Reformulation & 0 out of 18 & Not applicable. \\
\hline Consumer information* & 1 out of 12 & $\begin{array}{l}582 \text { - Consumer information: provision of information to the consumer through labelling of } \\
\text { non-alcoholic beverages, to empower consumers (especially the less educated ones) to make } \\
\text { appropriate choices for their nutrition needs. }\end{array}$ \\
\hline Education** & 7 out of 33 & $\begin{array}{l}1703 \text { - Diabetes Prevention Forum "Feel } 4 \text { Diabetes": creation of a more supportive social and } \\
\text { physical environment to promote lifestyle and behavior change to prevent type } 2 \text { diabetes in } \\
\text { families from vulnerable groups. }\end{array}$ \\
\hline Physical activity promotion & 2 out of 11 & $\begin{array}{l}1418 \text { - Danone Sport Schools: classes, tutoring, athletic training and championships in schools } \\
\text { located in economically vulnerable areas. }\end{array}$ \\
\hline Advocacy & 1 out of 21 & $\begin{array}{l}1608 \text { - Promote information exchange and innovation, including health and social equity: } \\
\text { promotion of examples of sustainable approaches to address healthy lifestyles across the } \\
\text { social gradient. }\end{array}$ \\
\hline
\end{tabular}

* including labelling; ${ }^{* \star}$ including lifestyle modification 


\section{References}

1. WHO. Health inequality and inequity. Available at:

http://www.who.int/hia/about/glos/en/index1.html.

2. WHO. Social determinants of health. Available at:

http://www.who.int/social_determinants/thecommission/finalreport/key_concepts/en/.

3. EUR-Lex. Communication from the Commission to the European Parliament, the Council, the

European Economic and Social Committee and the Committee of the Regions - Solidarity in health: reducing health inequalities in the EU \{SEC(2009) 1396\} \{SEC(2009) 1397\}. Available at: http://eurlex.europa.eu/legal-content/EN/TXT/?qid=1396946539740\&uri=CELEX:52009DC0567.

4. European Commission. Public Health ECHI Data Tool. Available at:

http://ec.europa.eu/health/dyna/echi/datatool/index.cfm?indlist $=8$.

5. European Commission. Population (Demography, Migration and Projections), Eurostat. Available at: http:/ /ec.europa.eu/eurostat/web/population-demography-migration-projections/deaths-life-

expectancy-data/database

6. OECD. Health at a glance 2016. Available at: http://www.oecd-ilibrary.org/social-issues-migrationhealth/health-at-a-glance-europe-2016_9789264265592-en.

7. Council of Europe. Estimates on Roma population in European countries. Available at: http://www.coe.int/en/web/portal/roma.

8. European Commission. Smarter, greener, more inclusive? Indicators to support the Europe 2020 strategy (2015), Eurostat. Available at: http://ec.europa.eu/eurostat/en/web/products-statisticalbooks/-/KS-EZ-14-001.

9. WHO Europe. Review of social determinants and the health divide in the WHO European Region: final report (2014). Available at:

http://www.euro.who.int/_data/assets/pdf_file/0004/251878/Review-of-social-determinants-and-thehealth-divide-in-the-WHO-European-Region-FINAL-REPORT.pdf.

10. Elmadfa Editor. European Nutrition and Health Report (2009). Available at: http://www.europeannutrition.org/images/uploads/pub-pdfs/European_Nutrition_and_Health_Report_2009.pdf.

11. European Commission. Population (Health status and determinants), Eurostat. Available at: http://ec.europa.eu/eurostat/web/health/health-status-determinants/data/database.

12. WHO Europe. Obesity and inequities - Guidance for addressing inequities in overweight and obesity. Available at: http://www.euro.who.int/_data/assets/pdf_file/0003/247638/obesity-090514.pdf.

13. Robertson, Lobstein and Knai for the European Commission. Obesity and socio-economic groups in Europe: evidence review and implications for action. Available at:

http://ec.europa.eu/health/ph_determinants/life_style/nutrition/documents/ev20081028_rep_en.pdf.

14. WHO Europe. Growing up unequal: gender and socioeconomic differences in young people's health and well-being. Health Behaviour in School-aged Children (HBSC) study: international report from the 2013/2014 survey. Available at: http://www.euro.who.int/en/publications/abstracts/growing-upunequal.-hbsc-2016-study-20132014-survey.

15. PHE. Social and economic inequalities in diet and physical activity. Available at: http://www.noo.org.uk/uploads/doc/vid_19253_Social_and_economic_inequalities_in_diet_and_physi cal_activity_04.11.13.pdf.

16. UNICEF. Innocenti Report Card 13, Fairness for Children A league table of inequality in child wellbeing in rich countries. Available at: https://www.unicef-irc.org/publications/pdf/RC13_eng.pdf. 
17. European Commission. Roma Health Report Health status of the Roma population. Data collection in the Member States of the European Union. Available at:

http://ec.europa.eu/health//sites/health/files/social_determinants/docs/2014_roma_health_report_en. pdf.

18. PHEIAC for the European Commission. Evaluation of the implementation of the Strategy for Europe on Nutrition, Overweight and Obesity related health issues. Available at:

http://ec.europa.eu/health//sites/health/files/nutrition_physical_activity/docs/pheiac_nutrition_strate gy_evaluation_en.pdf.

19. EquityAction. Papers produced from the Health Inequalities Audit Process. Diet, Nutrition and Obesity. Task 1: Evidence, Research and Economic Analysis of Nutrition, Obesity and Health Inequalities. Available at: http://www.health-inequalities.eu/wp-content/uploads/2016/05/Task-1Evidence-research-and-economic-analysis-of-nutrition-obesity-and-HI.pdf.

20. WHO Europe. Adolescent obesity and related behaviours: trends and inequalities in the WHO European Region, 2002-2014. Available at: http://www.euro.who.int/en/health-topics/diseaseprevention/nutrition/publications/2017/adolescent-obesity-and-related-behaviours-trends-andinequalities-in-the-who-european-region,-20022014.

21. WHO. Healthier, fairer, safer: the global health journey 2007-2017. Available at: http://www.who.int/publications/10-year-review/healthier-fairer-safer/en/.

22. Kim TJ, Roesler NM, von dem Knesebeck O. Causation or selection - examining the relation between education and overweight/obesity in prospective observational studies: a meta-analysis. Obesity Reviews 2017:n/a-n/a.

23. OECD. Obesity update. Available at: http://www.oecd.org/health/Obesity-Update-2014.pdf.

24. European Union. EU health policy forum. Available at:

http://ec.europa.eu/health//sites/health/files/major_chronic_diseases/docs/hpf_response_consultatio n_cd_en.pdf

25. European Commission. Reducing health inequalities in the European Union. Available at: http://bookshop.europa.eu/is-bin/INTERSHOP.enfinity/WFS/EU-Bookshop-Site/en_GB//EUR/ViewPublication-Start?PublicationKey=KE3010290.

26. WHO. Closing the gap in a generation - Health equity through action on the social determinants of health. Available at: http://www.who.int/social_determinants/final_report/csdh_finalreport_2008.pdf. 27. Masseria and Allin for the European Commission. Methodological note: Relative and absolute inequalities in health. Available at: http:/ / citeseerx.ist.psu.edu/viewdoc/download?doi=10.1.1.602.1989\&rep=rep1\&type=pdf.

28. CDC. Recommended Community Strategies and Measurements to Prevent Obesity in the United States. Available at: https://www.cdc.gov/mmwr/preview/mmwrhtml/rr5807a1.htm.

29. European Commission. Better regulation. Available at: http://ec.europa.eu/smartregulation/guidelines/tool_27_en.htm.

30. European Commission. Commission Staff Working Document: Results of the Commission's consultations on 'trans fatty acids in foodstuffs in Europe'. Available at: https://ec.europa.eu/food/sites/food/files/safety/docs/fs_labelling-nutrition_trans-fats-oswp_en.pdf. 31. European Commission. EU salt reduction framework. Available at: http://ec.europa.eu/health//sites/health/files/nutrition_physical_activity/docs/euframework_national_ salt_en.pdf.

32. European Commission. EU framework for national initiatives on selected nutrients. Available at: http://ec.europa.eu/health//sites/health/files/nutrition_physical_activity/docs/euframework_national_ nutrients_en.pdf. 
33. Dutch Presidency of the EU. Roadmap for Action on Food Product Improvement. Available at: https://www.rijksoverheid.nl/documenten/formulieren/2016/02/22/roadmap-for-action-on-foodproduct-improvement.

34. EUR-Lex. Report from the Commission to the Council and the European Parliament. Summary of the annual implementation reports for the operational programmes co-financed by the fund for European aid to the most deprived in 2014. COM/2016/0435 final. Available at: http://eurlex.europa.eu/legal-content/EN/TXT/?uri=COM:2016:435:FIN.

35. ISPAH \& UPFEL. Global Observatory for Physical Activity. Available at: http://www.globalphysicalactivityobservatory.com/.

36. HSCIC. National Child Measurement Programme: England, 2014/15 school year. Available at: http://content.digital.nhs.uk/catalogue/PUB19109/nati-chil-meas-prog-eng-2014-2015-rep.pdf.

37. EU Platform on Diet, Physical Activity and Health. Diet, Physical Activity and Health - a European Platform for action, 26 September 2013 Minutes. Available at:

https://ec.europa.eu/health/sites/health/files/nutrition_physical_activity/docs/ev20130926_mi_en.pdf. 38. ICF on behalf of the European Commission. Monitoring the activities of the EU Platform on Diet, Physical Activity and Health, Annual Report 2016. Available at:

http://ec.europa.eu/health//sites/health/files/nutrition_physical_activity/docs/2016_report_en.pdf. 39. ICF on behalf of the European Commission. Annex 1, Monitoring the activities of the EU Platform on Diet, Physical Activity and Health, Annual Report 2016. Available at:

http://ec.europa.eu/health/sites/health/files/nutrition_physical_activity/docs/2016_report_annex1_en. pdf. 



\section{Facilitators and barriers to the use of} economic evaluations in nutrition and public health

Alessandra Lafranconi, Vera Meusel, Sandra Caldeira, Suzanne Babich and Katarzyna Czabanowska (2020) Facilitators and barriers to the use of economic evaluations in nutrition and public health South Eastern European Journal of Public Health, doi.org/10.4119/seejph-3271

Acknowledgements:

We wish to thank all the interviewed experts. We are indebted to Jan Wollgast for critical reading of the manuscript and constructive suggestions. The work of AL is partially supported by a Jean Monnet Erasmus+ grant (574376-EPP-12016-1-IT-EPPJMO-MODULE).

Conflicts of interest:

None declared. 



\section{Abstract}

Aims: Interventions targeting diets have the potential to reduce a consistent fraction of the chronic disease burden. Economic evaluations of such interventions can be an important tool in guiding public health practitioners and decision makers at various levels, yet there are still not many economic evaluations in this area. This qualitative study explored facilitators and barriers in conducting and using economic analyses to inform decision makers in the field of public health nutrition.

Methods: Data were collected through written, open-ended questionnaires administered to twenty-three participants (13 from academia and 10 from government) using purposive sampling and analysed through a conventional content analysis.

Results: The analysis revealed two broad categories of barriers, which included: i) "Methodological challenges", and; ii) "Barriers related to application of economic evaluations." Two main categories of facilitators were also identified: i) "Facilitators to improving the methodology of economic evaluations", with subcategories further detailing frameworks and methods to be applied, and; ii) "Facilitators to broaden the use of economic evaluations", with most subcategories addressing science-into-policy translations. These barriers and facilitators to the use of economic evaluations in public health are perceived differently by researchers and policymakers, the former more focused on implementation aspects, the latter more concerned by methodological gaps.

Conclusion: Public health nutrition policies seldom take into account data from formal economic evaluations. Economic evaluation methodologies can be improved to ensure their broader application to decision making.

Keywords: economic evaluations, interviews, nutrition, public health, public policy 


\section{Introduction}

The social and economic burden of chronic diseases is a major source of concern for public health researchers and decision makers worldwide. According to the Global Burden of Disease (GBD) Study, over $91 \%$ of deaths and almost $87 \%$ of disability adjusted life years (DALYs) in the European Union are the result of non-communicable diseases (NCDs), mainly cardiovascular disease and cancers (1). With regards to dietary risk factors, the GBD Study group estimates that in the European Union over 950,000 deaths and over 16 million DALYs are attributable to dietary risks due to unhealthy diets, such as low whole grains, fruit and vegetables intake, low omega-3 intake and high sodium intake (2).

Along with an ageing population, obesity is a leading risk factor contributing to the burden of chronic diseases, and will play a key role in shaping the future use of healthcare services (3). Mean Body Mass Index (BMI) has increased worldwide over the last four decades (4). Already in 2008, the prevalence of adult obesity in European Countries reached "epidemic proportions", with some countries recording obesity rates higher than $25 \%$ (5). The prevalence of overweight or obesity is about $22 \%$ among 11 -years-olds in Europe, and in Southern and Eastern Europe such prevalence is as high as $38-39 \%(6,7)$. Inequalities have been documented not only between, but also within countries. For example, there is a gradient throughout the educational attainment spectrum, where those with lower levels are more likely to be overweight or have obesity; the inequality gap is particularly marked in women $(8,9)$. The future does not look brighter; according to projections modelled through 2030, on the basis of past and current BMI trends, obesity and obesity-related chronic diseases will continue increasing in almost all countries from the WHO European Region (10) and worldwide $(11,12)$.

Chronic disease risk factors associated with poor dietary habits are often modifiable and preventable. Actions to reduce the exposure to such risk factors have the potential to reduce the social and economic burden of overweight, obesity (13), and chronic diseases (14).

Economic evaluations can be used to estimate costs and benefits related to different interventions or policy options and help to guide the decision making processes (15). In the field of nutrition, economic evaluations have shown that most of nutrition-related interventions and policies are cost-effective, especially those applied at the population level, such as reformulation initiatives to lower salt intake (16) or a legal limit on industrial trans-fat use in the European Union (17). Yet, as stated by some authors who performed economic evaluations of interventions aimed at improving dietary factors: "Given the potential health gains related to such interventions, the paucity of such studies is alarming and indicates that additional evidence in this area is needed. It is difficult to design evidence-based policies with so little empirical evidence." (18).

Although methodological challenges of economic evaluations in public health, and specifically in the field of nutrition, have been identified by various authors (19-22), to our knowledge there is little research on challenges and facilitators in transferring economic evidence of public health and nutrition interventions into policy (23). 
The aim of this pilot study is to identify key barriers and facilitators to performing and applying data from economic evaluations in the decision making processes in nutrition and public health. We report on the perceptions of policymakers and academic experts in the field of nutrition, public health and economics, to better understand and encourage the use of economic evaluations in planning, implementing and evaluating future interventions and policies.

\section{Methods}

\section{Study design}

Open-ended written interview questions (two broad questions, each with three sub-questions, Box 1) were given to participants on a dedicated web platform. A link to the questionnaire was sent to each participant via e-mail. Conventional content analysis was applied to analyse the qualitative data (24), with the overall purpose of describing participants' experiences, field knowledge and views on a topic that has received little previous investigation (25).

\section{Participants}

Participants were recruited from a pool of 30 experts who participated in the 2015 workshop "Public Health and Nutrition Economics: the numbers behind prevention?", organized by the Joint Research Centre of the European Commission. Participants of the workshop were purposively chosen to ensure a range in expertise (public health, nutrition, and economics), representation (policymaking, academia, private sector, advocacy groups), and reach of action (local, national or international). Moreover, geographical criteria (EU and neighbouring countries) were taken into account. Inclusion criteria consisted of being a policymaker or an academic expert in any of the above-mentioned fields, and of having at least intermediate theoretical knowledge and/or work experience across all expertise domains (i.e. at least three years of study/experience in all domains: public health, nutrition and economics).

Twenty-seven people met the inclusion criteria, and 23 (13 from academia, 10 from government) participated in the study.

\section{Procedure}

The participants were selected between July and October 2015, the workshop took place on November 12-13, 2015, and the written interview was administered two weeks before the workshop, with a reminder sent after one week. The interview was sent via email, with the indication that the answers would be made available to all workshop participants, to foster discussion.

Oral or written consent of all participants was obtained. The study adhered to principles of ethical research practice (26). 


\section{Data analysis}

Data were analysed through conventional content analysis, according to which coding categories are derived directly from the text data, through an inductive process, in order to move from specific instances to general statements. The advantage of such technique is that information is obtained directly from study participants, without imposing preconceived categories or theoretical perspectives. An example of the process is illustrated in Box 1.

Box 1. Themes of the written interview and example of meaning unit, condensed meaning unit and codes from content. BAU $=$ business as usual. TF $A=$ trans-fatty acids. PHEE $=$ public health economic evaluations.

\section{Themes}

1: How have economic evaluations of policies/interventions informed decision making in public health?

- General observations on facilitators and barriers to the use of economic evaluations in public health, nutrition and prevention of chronic diseases

- Examples of success stories in public health

o from direct experience

o from literature

- Examples of success stories in nutrition and physical activity

- from direct experience

○ from literature

2: What are examples of possible or existing policies/interventions where economic evaluations are needed to help decision makers?

- General observations on facilitators and barriers to the use of economic evaluations in public health, nutrition and prevention of chronic diseases

- Examples of gaps in public health

○ from direct experience

- from literature

- Examples of gaps in nutrition and physical activity

o from direct experience

o from literature

\begin{tabular}{|c|c|c|c|}
\hline Meaning Unit (MU) & Condensed MUs & Codes & Categories \\
\hline \multirow{2}{*}{$\begin{array}{l}\text { "I think it was easy to argue in this case because there is } \\
\text { hardly any controversy in this case in what regards the } \\
\text { heart effects of TFA consumption and so there was/is no } \\
\text { opposition to the ban but the calculation of the health } \\
\text { effects and the costs saved are strong arguments to } \\
\text { those that are perhaps less health-minded to prioritise } \\
\text { and implement it." }\end{array}$} & $\begin{array}{l}\text { When there are no controversies } \\
\text { on health effects, it is possible to } \\
\text { implement policies. }\end{array}$ & Scepticism & $\begin{array}{l}\text { Barriers related to } \\
\text { the use of PHEE in } \\
\text { policy settings }\end{array}$ \\
\hline & $\begin{array}{l}\text { The calculation of health effects } \\
\text { and costs in case of inaction is a } \\
\text { strong argument to less health- } \\
\text { minded policy-makers. }\end{array}$ & $\begin{array}{l}\text { Inclusion of BAU } \\
\text { scenarios to reveal } \\
\text { costs of inaction }\end{array}$ & $\begin{array}{l}\text { Facilitators to } \\
\text { widen the use of } \\
\text { PHEE in policy } \\
\text { settings }\end{array}$ \\
\hline
\end{tabular}

Data were already in written format, and firstly two researchers (AL and VM) read all the texts consequently, to immerse themselves in the data, have a common understanding, and detect both manifest and latent content.

Secondly, AL and VM selected four interviews (two for each participant category, i.e. academia and government), and, for each interview, independently identified and condensed simple meaning units (words, sentences or paragraphs containing aspects related to each other through their content and context). Discussion and resolution of discrepancies by consensus followed this second stage.

Third, AL extracted the condensed meaning units of the remaining interviews; VM reviewed the extraction process, and discrepancies were again discussed and resolved by consensus. 
At a fourth stage, AL created and assigned codes to all condensed meaning units; subsequently, VM independently assigned the codes created by AL and added new codes as necessary. Subsequently, discussion between AL and VM took place to reach consensus on the coding procedure.

Finally, similar codes were grouped into comprehensive subcategories and categories, through an inductive process carried out by $\mathrm{AL}$, which consisted of comparison, reflection and interpretation.

The software QDA data miner was used to facilitate the above processes.

\section{Results}

Twenty-three participants (10 from policy-making bodies, and 13 from academia) were engaged in this study, for a total of 5,436 words (median: 161 words; interquartile range IQR 25-75: 79237 words). Their main characteristics (gender, expertise, reach of action and geographic coverage) are presented in Table 1.

Table 1. Participants characterization.

\begin{tabular}{|c|c|c|c|c|c|c|c|}
\hline \multicolumn{8}{|c|}{ Policymakers } \\
\hline \multicolumn{2}{|l|}{ Gender } & \multicolumn{2}{|l|}{ Expertise } & \multicolumn{2}{|l|}{ Area of action } & \multicolumn{2}{|c|}{ Geographic area } \\
\hline$M$ & 7 & Public health & 4 & EU & 4 & EU & 9 \\
\hline \multirow[t]{2}{*}{$\mathrm{F}$} & 3 & Economics & 4 & National or sub-national & 6 & Non-EU & 1 \\
\hline & & Nutrition & 2 & & & & \\
\hline \multicolumn{8}{|c|}{ Researchers } \\
\hline \multicolumn{2}{|l|}{ Gender } & \multicolumn{2}{|l|}{ Expertise } & \multicolumn{2}{|l|}{ Area of action } & \multicolumn{2}{|c|}{ Geographic area } \\
\hline$M$ & 6 & Public health & 3 & Non applicable & & EU & 8 \\
\hline \multirow[t]{2}{*}{$\mathrm{F}$} & 7 & Economics & 7 & & & Non-EU & 5 \\
\hline & & Nutrition & 3 & & & & \\
\hline
\end{tabular}

The participants identified two sets of barriers to performing PHEE, and two categories of facilitators: methodological challenges in performing PHEE, barriers related to the use of PHEE in policy settings, facilitators to improve the methodology of PHEE, facilitators to widen the use of PHEE in policy settings. These categories and their subcategories are summarized in Table 2. 
Table 2. Facilitators and barriers classified in categories and subcategories, with examples obtained from data analysis.

\begin{tabular}{|c|c|c|}
\hline \multicolumn{2}{|c|}{ Sub-categories } & \multirow[b]{2}{*}{$\begin{array}{l}\text { Examples } \\
\text { "Public health interventions [...] are supposed to have a substantial impact on health and health care systems, but the } \\
\text { assessment and the consequences on health are not sufficiently analysed, for multiple reasons [such as] difficulties to measure } \\
\text { the impact (indirect and/or direct consequences)". (Policymaker) } \\
\text { "Some questions arise: should we focus on health-related behaviours or on anthropometrics (weight, waist circumference,...)? } \\
\text { How long should the intervention last in order to have an impact?" (Researcher) } \\
\text { "Calculations for [long-term] cost-effectiveness should be [performed in] every project in the area of primary prevention. This } \\
\text { would enable reviewers/decision makers to decide which of the proposed actions would give the highest long-lasting (i.e. } \\
\text { longitudinal) impact for the money spent". (Researcher) }\end{array}$} \\
\hline \multirow{2}{*}{ 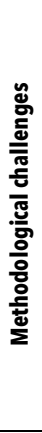 } & $\begin{array}{l}\text { Definition and } \\
\text { measurement } \\
\text { of outcomes }\end{array}$ & \\
\hline & $\begin{array}{l}\text { Lack of } \\
\text { adequate } \\
\text { frameworks }\end{array}$ & $\begin{array}{l}\text { "Methods to evaluate public health interventions are less well established than those for medical interventions" (Policymaker) } \\
\text { "Lack of standardised methodologies and evidence based approaches, and no special focus of HTA units and bodies [are } \\
\text { challenges encountered] in public health evaluations". (Policymaker) } \\
\text { "[In public health nutrition,] the magnitude of the association [between exposure and outcome] is relatively small. So, the case } \\
\text { for carefully designed cost-effectiveness analysis appears to be strong" (Researcher) }\end{array}$ \\
\hline \multirow{2}{*}{ 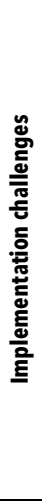 } & Scepticism & $\begin{array}{l}\text { eeling is that there is still some controversy around the real effect [of SSB taxation] on [SSB] consumption and eventually } \\
\text { h". (Policymaker) } \\
\text { uests for evaluations are happening in (and are a symptom of) a context in which policymakers are increasingly confronted } \\
\text { intractable problems to which science may not always be fully equipped to reply. Policymakers are flooded with scientific } \\
\text { ture (some of which of weak basis), institutional reports, lobbyists' papers and social media posts". (Policymaker) } \\
\text { uld highlight the decision of withdrawing the GRAS (generally recognized as safe) status to TFAs (trans-fatty acids) in the US } \\
\text { he ongoing EU considerations of setting a limit to its content in foods as a success story. In both cases there were economical } \\
\text { lations made that clearly demonstrated the added value of a "ban" on the industrially produced TFA both in health and } \\
\text { omic terms. I think it was easy to argue in this case because there is hardly any controversy in this case in what regards the } \\
\text { effects of TFA consumption and so there was/is no opposition to the ban". (Policymaker) }\end{array}$ \\
\hline & $\begin{array}{l}\text { Lack of strategy } \\
\text { for effective } \\
\text { budget } \\
\text { allocation }\end{array}$ & $\begin{array}{l}\text { Ision [from an economic evaluation] was that there was no need [for a new highly specialized hospital yard], but the } \\
\text { on was to open one any way". (Researcher) } \\
\text { d interventions [to promote healthy lifestyles and to reduce obesity] proposed in the national preventive program for } \\
\text { th [...] fall within budget planning, without any solid proofs for (cost) effectiveness of actions and interventions } \\
\text { ". (Researcher) }\end{array}$ \\
\hline \multirow{4}{*}{ 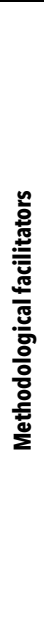 } & 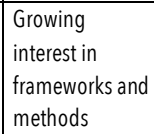 & $\begin{array}{l}\text { ate methodological frameworks and methods to assess } \\
\text { onized methodology, indicators and cut offs for different }\end{array}$ \\
\hline & $\begin{array}{l}\text { Multidimension } \\
\text { al evaluations } \\
\text { (whole-of- } \\
\text { society } \\
\text { approach) }\end{array}$ & $\begin{array}{l}\text { "Due to [its] complex nature and multiple causes, imp } \\
\text { agriculture, health, education, trade, environment, an } \\
\text { expert in the field of health economics when planning } \\
\text { "It would be good to (...) have a solid and as much a } \\
\text { mean } 360 \text { degrees, what effects did it have on con } \\
\text { finances, etc)".(Policymaker) }\end{array}$ \\
\hline & strat & $\begin{array}{l}\text { "There is lacking economic evaluation of [breast, cervical and colon cancer] screenings and it is necessary to introduce national } \\
\text { based evidence to support such interventions". (Researcher) } \\
\text { "A lot of evaluations of obesity prevention programs have been performed, but there is more research needed on obesity } \\
\text { prevention in the socially deprived families. [...] These people are the hardest to reach". (Researcher) } \\
\text { "Such programs [targeted to socially deprived families] will probably need more financial resources than prevention programs } \\
\text { for the general population, but the cost-savings in the long-term could be potentially higher in this subgroup." (Researcher) }\end{array}$ \\
\hline & $\begin{array}{l}\text { S } \\
\text { re }\end{array}$ & $\begin{array}{l}\text { n actions and their evaluations must be continuous and must have continuous financial support because once } \\
\text { most all effort is lost". (Researcher) }\end{array}$ \\
\hline
\end{tabular}




\begin{tabular}{|c|c|c|}
\hline \multirow{5}{*}{ 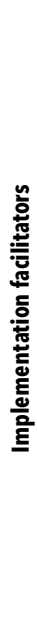 } & $\begin{array}{l}\text { Production of } \\
\text { comparative } \\
\text { analysis }\end{array}$ & $\begin{array}{l}\text { "Cost-effectiveness evaluations (...) may be crucial when deciding which actions from the same division are to be considered at } \\
\text { the top priority". (Researcher) } \\
\text { "Economic evaluation contributes to evidence-based decision making by helping the public health community identify, } \\
\text { measure, and compare activities". (Policymaker) }\end{array}$ \\
\hline & $\begin{array}{l}\text { Targeted } \\
\text { evaluations that } \\
\text { respond to } \\
\text { concrete needs }\end{array}$ & $\begin{array}{l}\text { "Evaluations on the efficacy and efficiency of tools are useful to guide policymakers (...). The evaluation [of implementation } \\
\text { processes], although not a full-fledged evaluation, [could be] important for political guidance." (Policymaker) } \\
\text { "PHE evaluations in general would support impact assessments for EU/national policies/initiatives (including repeals of existing } \\
\text { legislation) in the area of food and health. Examples are: measures addressing nutritional composition of foods; marketing (and } \\
\text { not only advertising to children) of products; school/public workplace policies aiming to improve diet/physical activity". } \\
\text { (Policymaker) }\end{array}$ \\
\hline & $\begin{array}{l}\text { Transposal of } \\
\text { good practices }\end{array}$ & $\begin{array}{l}\text { "Many countries are considering SSB taxes in differentforms and (...) a solid [economic evaluation] could inform other countries } \\
\text { and other potential taxes, too". (Policymaker) }\end{array}$ \\
\hline & $\begin{array}{l}\text { Inclusion of } \\
\text { BAU scenarios } \\
\text { to reveal costs } \\
\text { of inaction }\end{array}$ & $\begin{array}{l}\text { "Given the potentially sizeable benefits of healthier lifestyles for improved population health, understanding the costs and } \\
\text { impacts of lifestyle-focused health promotion interventions is an important policy priority" (Policymaker) } \\
\text { "The calculation of the health effects and the costs saved are strong arguments to those that are perhaps less health-minded to } \\
\text { prioritise and implement [a nutrition policy]". (Policymaker) }\end{array}$ \\
\hline & Transp & $\begin{array}{l}\text { "National governments should enhance the transparency and publicity of operation by disclosing all decisions and contracts" } \\
\text { (Researcher) } \\
\text { "It is crucial to have transparent decision making based on evidence, including [...] economic evidence". (Researcher) }\end{array}$ \\
\hline
\end{tabular}

\section{Methodological challenges in performing PHEE}

Participants considered issues related to definition and measurement of outcomes as fundamental barriers in performing PHEE. The choice and definition of the outcome to report on (from behaviours to biomarkers and the number of related diseases and deaths) are not trivial issues, as such choices can yield very different results in terms of cost-effectiveness and may challenge the validity of the analysis. Measurement difficulties identified pertained primarily to the assessment of exposures to dietary risk factors, outcomes related to such exposures, social and economic costs of diseases, and economic costs of policy interventions. Moreover, the long time lag (between implementing an intervention and seeing health benefits at the population level) requires use of modelling techniques to project possible benefits into the future, and to relate them to changes in disease patterns.

A second challenge, perceived by both researchers and policymakers, is the absence of adequate frameworks to guide a PHEE. The participants pointed out that adequate frameworks exist and are commonly used in clinical settings, and mentioned health technology assessment (HTA); on the contrary, there are no such frameworks and standardised methodologies for the evaluation of nutrition interventions. The need for carefully designed frameworks and methodologies suitable to public health nutrition is therefore high.

\section{Barriers related to the use of PHEE in policy settings}

Many participants noted that the background evidence, on which PHEE should be based, is at times controversial or scientifically weak, and other voices and stakeholders may easily discredit these efforts. There is therefore scepticism in using PHEE in policymaking settings, especially because of low quality evidence. When the level of scepticism towards a particular nutritionrelated issue is low, as in the case of the effects of trans-fatty acids consumption on 
cardiovascular disease, the economic evaluation is more likely to succeed in influencing such policy.

On the other hand, most of the interviewed researchers pointed out that the allocation of public budgets does not always reflect what is recommended by the evidence (economic evidence or, in more extreme cases, evidence of effect), and gave some examples of stakeholder influence in funding public health interventions. They considered this a barrier to the use of PHEE.

\section{Facilitators to improving the methodology of PHEE}

This category consists of four subcategories, identified mainly by the researcher participants: 1) growing interest in frameworks and methods, 2) multi-dimensional evaluations, following a whole-of-society approach, 3) data stratification at different levels, according to SES and geographic regions, and 4) sustainable research infrastructure.

Lack of a suitable framework has been previously identified as a major methodological barrier in PHEE. Researchers are optimistic that this issue will be addressed, as there is a growing interest in developing better frameworks and methods to perform economic evaluations in public health; for instance, the following areas have been mentioned: harmonized methodology, measurement of exposure and outcome, identification of indicators and sensitive cut-offs for such indicators.

A thorough identification of the stakeholders' perspectives, such as the healthcare perspective or the whole of society perspective, appeared to be crucial for well-suited economic evaluations, according to researchers and decision makers. Interventions and policies in the field of nutrition and obesity prevention have an impact not only on the targeted population groups, but also on various sectors of our societies. Economic analysis should therefore be multidimensional and address costs and benefits for all relevant stakeholders. Health economists should attempt to provide costs and benefits for each group of stakeholders.

In addition to assessing and reporting specific costs and benefits of interest to different stakeholders, there is also interest in disaggregating results according to geographic specificities, or to SES of populations. According to the researchers consulted, such stratifications, if available, would increase the credibility of PHEE. For example, estimates obtained using country-level data would be perceived as more reliable and more relevant than estimates obtained with regional or global data.

Last, a sustainable research infrastructure should be in place to ensure the production of methodologically sound PHEE. According to some researchers, such infrastructure should have a dedicated team or unit, and consistent financial support.

\section{Facilitators to widen the use of PHEE in policy settings}

This category includes facilitators of the demand for PHEE and consists of five subcategories: 1) production of comparative analyses; 2) targeted evaluations that respond to concrete needs; 3) transposal of good practices; 4) inclusion of BAU (business as usual) scenarios to reveal costs of inaction; 5) transparency in decision making. 
Acknowledging the limitations on both financial and human resources, researchers and policymakers agreed on the importance of economic evaluations in comparing different policy options targeting nutrition and, more broadly, public health. Comparative analysis enables the choice of the most cost-effective option and could increase the demand for PHEE.

Some of the policymakers interviewed have used economic evaluations "to guide" or influence colleagues in a decision-making process. There is the potential for demand for PHEE to rise if economic evaluations respond to concrete needs, thus having a direct impact on decision makers, and providing guidance in daily practices. Moreover, some of the policymakers interviewed, indicated that having more examples of legislation informed by economic evidence may in itself stimulate the greater demand for PHEE.

Economic evaluations can be useful also in evaluating transposal of good practices from their inception into different practice contexts; for instance, economic evaluations of taxation interventions can be carried out in those countries where sound public health taxation has been already implemented, to best inform countries in the process to design similar schemes. According to some of the policymakers interviewed, such cases can increase the demand for PHEE.

The costs of inaction need also to be known. This could be done, for example, by including BAU scenarios when performing comparative economic analyses. A case in point is to clarify the high costs of inaction in obesity and related chronic diseases, both in social and monetary terms, as noted by some policymakers. This could be a key driver for action but also for increasing the demand for PHEE.

Lastly, most researchers identify a desire for transparency in policy decision making as a very important rationale for economic evaluations.

\section{Discussion}

\section{Main findings and comparison to the literature}

This qualitative analysis aimed to identify key barriers and facilitators of performing public health economic evaluations and in including them in the development of policies in the area of nutrition and prevention of chronic diseases. We found that barriers (methodological challenges and barriers related to the use of PHEE) were symmetrical to facilitators (facilitators to improve the methodology and increase the use of PHEE), meaning that facilitators were those factors that reduced barriers in either performing or using PHEE.

Policymakers and researchers diverged in their opinions and perspectives. For instance, in the category "Barriers related to the use of PHEE", researchers identified "Lack of strategy for effective budget allocation." In contrast, policymakers mentioned "Scepticism" attributed largely to doubts about the quality of the data, conclusiveness of the findings, controversies and limitations of current PHEE practices. Nonetheless, both groups provided numerous insights about methodological challenges and data paucity. With regards to facilitators, only researcher 
participants identified the availability of stratified data for geographical and social conditions as a facilitator towards the production of methodologically sounder PHEE, and only policymaker participants highlighted the need for providing targeted evaluations responding to concrete needs as a facilitator of greater use of PHEE. Generally speaking, researchers focused on methodological facilitators, while policymakers stressed a need for more widespread use of PHEE (Figure 1).

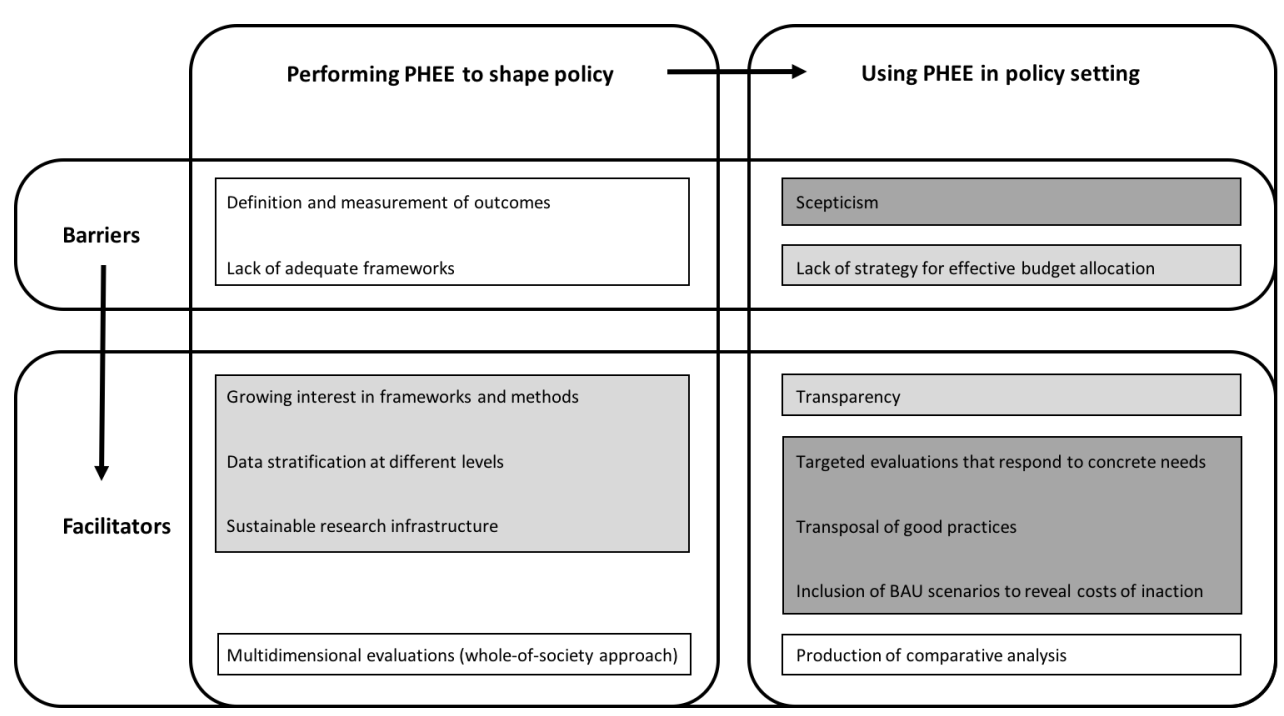

Figure 1. Main categories and subcategories of facilitators and barriers to PHEE identified by researchers only (light grey boxes), policymakers only (dark grey boxes) or both (white boxes)

Our findings on methodological barriers and facilitators resonate with previous literature, indicating that researchers performing economic evaluations need to improve their communication of the structure and results of their analyses to decision makers (27). For instance, Weatherly and colleagues (19) identified four main methodological challenges in assessing the cost-effectiveness of public health interventions: attribution of effect, measuring and valuing outcomes, identifying intersectoral costs and consequences, and incorporating equity considerations. They are similar to those identified in our study: definition and measurement of outcomes (where "definition" includes effect attribution and "measurement" includes measuring and valuing outcomes), multidimensional evaluations (whole-of-society approach), and data stratification at different levels (geographical and social determinants enable the inclusion of equity considerations in economic analyses). A wide variation in approaches and methodologies in economic studies on dietary factors, and the consequent call for an adequate framework, has also been documented $(20,22)$. 
An expert meeting on nutrition economics has also previously identified and commented on key features of economic evaluations in nutrition, such as: societal perspective and multi-stakeholder approach in identification of costs and benefits, comparison of alternatives, and generalisability of results (28).

\section{Strengths and limitations}

Despite existing discussions on generalisability of qualitative studies, nonetheless we consider our analysis as the first attempt to systematically collect perceptions on barriers and facilitators in translating economic evidence into policy from a broad, though small, sample of both researchers and policymakers from the European region.

While the general nature of the questions posed allowed for great freedom in responses and could accommodate the differences in the participants' expertise, more specific questions would have returned more concrete thoughts and examples. The fact that answers were made available to all workshop participants without anonymity could also have influenced the respondents and resulted in their more cautious expressions and examples.

Because of the limited number of questions asked and the relatively small number of participants, findings should be taken with caution; subsequent work might be done, including a larger number of participants with a more in-depth interview questionnaire.

\section{Implications for policy and research}

To our knowledge, there are no other studies addressing facilitators and barriers to the use of economic evidence in public health nutrition: so far studies have addressed only methodological gaps in economic evaluations of public health interventions $(19,21,22)$ and nutrition interventions (20).

The paucity of successful cases in which economic evaluations played a role in shaping policies should also be considered, as pointed out by most participants during in the questionnaire and during the workshop. Some expressions, such as "My feeling" or "Science may not always be fully equipped", may reflect this fact. Such observations may also reflect the difficulties in accounting for complex societal phenomena: changes in eating habits (29) or environmental sustainability (30) are two among numerous examples.

The results from our analysis show an increasing interest and unmet demand for public health policies informed by economic evaluations. Enablers of the use of economic evaluation should be further facilitated. Expanding the application of sound PHEE to policymaking will ensure a better informed process and, presumably, better outcomes in terms of the intended effects of the policies. 


\section{References}

1. James SL, Abate D, Abate KH, Abay SM, Abbafati C, Abbasi N, et al. Global, regional, and national incidence, prevalence, and years lived with disability for 354 diseases and injuries for 195 countries and territories, 1990-2017: a systematic analysis for the Global Burden of Disease Study 2017. Lancet 2018;392:1789-858.

2. Afshin A, Sur PJ, Fay KA, Cornaby L, Ferrara G, Salama JS, et al. Health effects of dietary risks in 195 countries, 1990-2017: a systematic analysis for the Global Burden of Disease Study 2017. The Lancet. 2019;393(10184):1958-72

3. Cecchini M, Sassi F. Preventing Obesity in the USA: Impact on Health Service Utilization and Costs. Pharmacoeconomics 2015;33:765-76.

4. Finucane MM, Stevens GA, Cowan MJ, Danaei G, Lin JK, Paciorek CJ, et al. National, regional, and global trends in body-mass index since 1980: systematic analysis of health examination surveys and epidemiological studies with 960 country-years and 9.1 million participants. Lancet 2011;377:557-67.

5. Berghofer A, Pischon T, Reinhold T, Apovian CM, Sharma AM, Willich SN. Obesity prevalence from a European perspective: a systematic review. BMC Public Health 2008;8:200.

6. Wijnhoven TM, van Raaij JM, Spinelli A, Starc G, Hassapidou M, Spiroski I, et al. WHO European Childhood Obesity Surveillance Initiative: body mass index and level of overweight among 6-9-year-old children from school year 2007/2008 to school year 2009/2010. BMC Public Health 2014;14:806.

7. WHO. Growing up unequal. HBSC 2016 study (2013/2014 survey). World Health Organization, Regional Office for Europe: Copenhagen, Denmark; 2016.

8. Devaux M, Sassi F. Social inequalities in obesity and overweight in 11 OECD countries. Eur J Public Health 2013;23:464-9.

9. Hruby A, Hu FB. The Epidemiology of Obesity: A Big Picture. Pharmacoeconomics 2015;33:673-89.

10. Webber L, Divajeva D, Marsh T, McPherson K, Brown M, Galea G, et al. The future burden of obesity-related diseases in the $53 \mathrm{WHO}$ European-Region countries and the impact of effective interventions: a modelling study. BMJ Open 2014;4:e004787.

11. Kelly T, Yang W, Chen CS, Reynolds K, He J. Global burden of obesity in 2005 and projections to 2030. Int J Obes 2008;32:1431-7.

12. Doytch N, Dave DM, Kelly IR. Global evidence on obesity and related outcomes: An overview of prevalence, trends, and determinants. East Econ J 2016;42:7-28.

13. Feigl AB, Goryakin Y, Devaux M, Lerouge A, Vuik S, Cecchini M. The short-term effect of BMI, alcohol use, and related chronic conditions on labour market outcomes: A time-lag panel analysis utilizing European SHARE dataset. PLoS One 2019;14:e0211940.

14. Peters R, Ee N, Peters J, Beckett N, Booth A, Rockwood K, et al. Common risk factors for major noncommunicable disease, a systematic overview of reviews and commentary: the implied potential for targeted risk reduction. Ther Adv Chronic Dis 2019;10:2040622319880392.

15. Musgrove P, Fox-Rushby J. Cost-Effectiveness Analysis for Priority Setting. In: Jamison DT, Breman JG, Measham AR, Alleyne G, Claeson M, Evans DB, et al., editors. Disease Control Priorities in Developing Countries. 2nd ed. Washington (DC): The International Bank for Reconstruction and Development/The World Bank Group; 2006.

16. Cobiac LJ, Veerman L, Vos T. The role of cost-effectiveness analysis in developing nutrition policy. Annu Rev Nutr 2013;33:373-93.

17. Martin-Saborido C, Mouratidou T, Livaniou A, Caldeira S, Wollgast J. Public health economic evaluation of different European Union-level policy options aimed at reducing population dietary trans fat intake. Am J Clin Nutr 2016;104:1218-26. 
18. Fattore G, Ferre F, Meregaglia M, Fattore E, Agostoni C. Critical review of economic evaluation studies of interventions promoting low-fat diets. Nutr Rev 2014;72:691-706.

19. Weatherly H, Drummond M, Claxton K, Cookson R, Ferguson B, Godfrey C, et al. Methods for assessing the cost-effectiveness of public health interventions: key challenges and recommendations. Health Policy 2009;93:85-92.

20. Gyles CL, Lenoir-Wijnkoop I, Carlberg JG, Senanayake V, Gutierrez-Ibarluzea I, Poley MJ, et al. Health economics and nutrition: a review of published evidence. Nutr Rev 2012;70:693-708.

21. Squires H, Chilcott J, Akehurst R, Burr J, Kelly MP. A systematic literature review of the key challenges for developing the structure of public health economic models. Int J Public Health 2016;61:289-98.

22. Lung TW, Muhunthan J, Laba TL, Shiell A, Milat A, Jan S. Making guidelines for economic evaluations relevant to public health in Australia. Aust N Z J Public Health 2017;41:115-7.

23. Margetts B, Warm D, Yngve A, Sjostrom M. Developing an evidence-based approach to Public Health Nutrition: translating evidence into policy. Public Health Nutr 2001;4:1393-7.

24. Hsieh HF, Shannon SE. Three approaches to qualitative content analysis. Qual Health Res 2005;15:1277-88.

25. Pope C, Mays N. Reaching the parts other methods cannot reach: an introduction to qualitative methods in health and health services research. Br Med J 1995;311:42-5.

26. Orb A, Eisenhauer L, Wynaden D. Ethics in qualitative research. J Nurs Scholarsh 2001;33:93-6.

27. Lo Piano S, Robinson M. Nutrition and public health economic evaluations under the lenses of post normal science. Futures 2019;112:102436.

28. Lenoir-Wijnkoop I, Dapoigny M, Dubois D, van Ganse E, Gutierrez-Ibarluzea I, Hutton J, et al. Nutrition economics - characterising the economic and health impact of nutrition. Br J Nutr 2011;105:157-66.

29. Diószegi J, Llanaj E, Ádány R. Genetic Background of Taste Perception, Taste Preferences, and Its Nutritional Implications: A Systematic Review. Frontiers in Genetics. 2019;10(1272).

30. Lafranconi A, Birt CA. 'Du bist was du isst': challenges in European nutrition policy. Eur J Public Health. 2017;27(suppl_4):26-31. 



\section{PART 2 \\ Health Protection: environmental aspects of nutritional policies in Europe}



'Du bist was du isst': challenges in European nutrition policy

Published as:

Alessandra Lafranconi and Christopher A. Birt (2017) 'Du bist was du isst': challenges in European nutrition policy European Journal of Public Health, 27(4):26-31, doi:10.1093/eurpub/ckx162

[IF (2017): 2,78]

Acknowledgements:

The authors acknowledge the contribution of the following: Tatjana Buzeti, Giuseppe Grosso, Lise Justesen, Carl Lachat, Enni Mertanen, Natalie Rangelov and Sirpa Sarlio-Lähteenkorva. The work of the author Alessandra Lafranconi is partially supported by a Jean Monnet Erasmus+ grant (574376-EPP-1-2016-1-IT-EPPJMO-MODULE).

Conflict of interest:

None declared. 



\section{Abstract}

Food cultures have developed in communities as according to the produce of local farms in the vicinity. The industrial revolution resulted in large cities and towns becoming reliant on farm produce from the neighbouring countryside; this stimulated development of farming, which itself became industrialised. However, although local diets in Europe differed markedly, the "healthiness" of all diets was unquestioned until recently.

Early in the twentieth century, academic departments studying nutrition were established, but it is only since the 1980s that much interest in the "healthiness" of our food began to be of concern within academia. At about this time it was becoming clear that existing patterns of farming and food production were having negative effects on the environment. Since the 1990s, environmental, farming, and nutritional sciences have each progressed, but in parallel, and there has been all too little effort to unite them. However, it is clear that, in general, production of foods associated with "unhealthy" nutrition are also the most damaging from an environmental viewpoint.

This article summarises the evidence on current European diets, analyses of costs and benefits in transitioning to healthy and sustainable diets, identifies sustainable dietary guidelines as the way forward and discusses the role of public health in achieving dietary reform in the interests of improved nutrition and environmental protection. 


\section{European agriculture, nutrition and related policies: historical background}

European agriculture grew out of the practice of subsistence farming. Families had grown their own food for many centuries; surpluses were sold at markets in local towns. The eighteenth century, with the industrial revolution, saw a rapid development of early industrial farming, as from around 1750 the developing large industrial cities came to rely for food upon farm produce brought in by farmers working in the surrounding countryside. Accordingly, as the industrial revolution spread across Europe, in the nineteenth century farming itself really became an industry. However, farms continued to produce what had been consumed traditionally in their own areas, and meals, whether based on olive oil and wine in southern Europe, or on animal fats and beer in northern Europe, were all considered to be "healthy" (1).

Nutrition was not studied as a scientific discipline until the early years of the twentieth century, and a number of specialist research institutes were established between then and 1939. One of these was the Rowett Research Institute in Aberdeen; the first Director of which, John Boyd Orr, later Lord Boyd Orr, was subsequently the first Director-General of the UN Food and Agriculture Organisation (FAO). His report "Food Health and Income", published in 1936, revealed for the first time the appalling levels of malnutrition among the peoples of the UK; on account of this publication, Winston Churchill asked Boyd Orr to lead the development of a scientifically-designed diet with the intention of keeping the British population healthy during World War 2, a diet based as much as possible on local farm produce (2).

Towards the end of World War 2, and during the first few years after this, hunger, severe starvation, and death from under-nutrition were still prevalent in Germany and other parts of western, central and eastern Europe, owing to the complete destruction of infrastructure, including farming, brought about by the War. In Germany and in Austria, the occupying powers were responsible for feeding the populations in their respective sectors. This was the reason why food rationing was maintained in UK for years after the War, so that there was surplus food which could be used to feed hungry Germans in the UK-occupied sector (3).

It is therefore not surprising that, as soon as the European Economic Community came into existence in 1957, the original six members, as according to Article 39 of their Treaty, agreed to: increase agricultural productivity; ensure a fair standard of living for the agricultural community; stabilise agricultural markets; provide certainty of food supplies; ensure that food supplies reached consumers at reasonable prices.

Various early initiatives were soon set up, and a fully-fledged Common Agricultural Policy (CAP) was established in 1962. To achieve the stated objectives, farmers were provided with generous production subsidies, guaranteed minimum prices, and tariffs on farm imports, to prevent price under-cutting. However, there was still no real conceptual link between agricultural production and nutrition, healthy or otherwise, even though agricultural research institutes, which worked on nutrition, had been established several decades earlier. Only in more recent years have aspects of poor nutrition been linked to the CAP $(4,5)$. Accordingly, overconsumption, as well as the intake of salt, saturated fats and sugar, are nowadays targeted by an increasing number of 
public health policies: for instance, the EU platform for action on diet, physical activity and health was launched in 2005 to use voluntary measures and achieve improvements in marketing and advertising, reformulation, consumer information (including labelling), education (including lifestyle modification), physical activity promotion and advocacy (6). The latest effort at EU level is represented by the commitment towards tackling childhood obesity, undertaken by the 2017 Maltese Presidency of the Council of the EU (7). Similarly, at WHO house, nutrition has been addressed for long: building on Scandinavian successes in the last few decades, the WHO Regional Office for Europe has been instrumental in providing guidance for food and nutrition policy in Europe, and three consecutive versions of the Action Plan for Food and Nutrition Policy have been prepared since 2000 (8). Yet, such actions, designed to improve human nutrition, fail to address the environmental implications of our current food consumption patterns.

Nevertheless, we live in a time when politicians give emphasis to food, nutrition, public health and environmental aspects. Both nutrition and sustainability are high on the global political agenda as reflected in the "2030 Agenda for Sustainable Development" resolution accepted by the United Nations (UN) General Assembly in 2015 (9), and the significance of food and diets in sustainable development can be further observed in the UN 17 Sustainable Development Goals (SDGs) document (9). Moreover, in late 2015, the United Nations Framework Convention on Climate Change adopted the Paris Agreement (10). Parties signing the Paris Agreement agreed to strengthen the global response to climate change, by "increasing the ability to adapt to the adverse impacts of climate change and foster climate resilience and low greenhouse gas emissions development, in a manner that does not threaten food production" (10). Lastly, in April 2016, from 2016 to 2025, a decade on nutrition was declared, which is an unprecedented window of opportunity to develop and to implement sustainable food systems that deliver the best possible health outcomes for all (11).

Despite convincing evidence of the very considerable impact that food systems and human diets exert on public and planetary health, efforts to incorporate sustainable development into food systems planning has been limited and fragmented (12-14); concerted guidelines and policy action that include sustainable aspects, in addition to healthy nutrition, are generally lacking in Europe $(15,16)$.

\section{Review by the Food and Nutrition Working Group: healthy and sustainable diets}

As a contribution to the academic and political debate on sustainable and healthy eating, a working group set up by the Food and Nutrition Section of EUPHA undertook a literature review, the primary aim of this being to summarise the scientific background related to health and environmental sustainability in the domains of diet and nutrition. The secondary aim was to provide evidence-based policy recommendations designed to address these issues, including 
by identifying specific ways forward for public health practitioners (17). The methods applied by the working group have been described elsewhere (17).

Sustainable diets are defined by the FAO as: "Those diets with low environmental impacts, which contribute to food and nutrition security and to healthy life for present and future generations. Sustainable diets are protective and respectful of biodiversity and ecosystems, culturally acceptable, accessible, economically fair and affordable; nutritionally adequate, safe and healthy; while optimising natural and human resources" (18). However, according to WHO, sustainable diets are: "High in vegetables, fruit and whole grains, with limited intake of saturated fat, trans fats, sugar and salt" (8); the WHO definition has been chosen as the reference definition in this article.

Despite the broad focus of the document produced by the working group (17), and of the current review, the following fundamental aspects are not addressed:

- The impact of current and potential new food production systems on agricultural workers and on rural communities generally;

- The various challenges related to the assurance of basic human rights to seasonal workers;

- Environmental, economic and social impacts of agriculture and food trade, both at local and global levels, according to the three-pillars definition of "sustainable development" (17);

- Food waste and the concept of a circular economy (i.e. zero waste economy), as applied to food.

\section{Results}

\section{Descriptions of current European diets, including trends, their determinants and social patterns}

Systematic data on the sustainability of European diets are not available; however, useful data come from: pan-EU projects that offer valuable insights on diets and facilitate comparison among EU countries (e.g. the EU Framework for National Salt Initiatives and the EU Framework for National Initiatives on Selected Nutrients); FAO Food Balance Sheets, containing data on total production, import and stocks of food; household budget surveys, which provide national data on food availability at the household level (17).

Despite economic and geographic differences between European countries, the direction of current dietary patterns seems to be towards a common European dietary platform, with local and regional variations. Over recent decades, a common European diet is becoming established across different parts of the continent, following a process of westernisation (for example, the supply of dairy products in South and East Europe is reaching levels equivalent to those observed previously in North and West Europe) (17). Meanwhile, more meat is becoming available, quantities of available poultry are growing, and, in parallel, the availability of vegan proteins is increasing, while eating out of the home is becoming increasingly common (17). Changes in eating environments (e.g. availability of fast food outlets) are themselves affecting 
diets, while a growing demand for and consumption of locally produced food may be supporting biodiversity and diverse diet patterns, as this usually values traditional plant and animal species (17).

Meat, fish and dairy products are primary sources of protein; in European countries, protein intake is higher than that recommended by WHO, and red meat consumption is twice as high as recommended by the World Cancer Research Fund. Consumption of livestock products, including eggs, has shown a modest rise, whereas consumption of milk is declining, with no changes being apparent in cheese or butter consumption (17). Although the supply of fish is increasing in most countries, Europeans consume only half of the recommended quantities of this (17). Similarly, the supply of fruit and vegetables is also increasing (17), but consumption of fruit and vegetables remains too low: more than half of Europeans eat less than $400 \mathrm{~g}$ per day as recommended by WHO (17). Such trends are shown in Table 1. 
Table 1. Food supply in European regions from 1961 to 2013. Based on FAOSTAT supply in kilograms per capita per years.

\begin{tabular}{|c|c|c|c|c|c|}
\hline & EU & Eastern Europe & Northern Europe & Southern Europe & Western Europe \\
\hline \multicolumn{6}{|l|}{ Meat } \\
\hline 1961 & 47.37 & 41.69 & 63.00 & 27.27 & 66.06 \\
\hline 2013 & 77.34 & 68.75 & 82.28 & 81.94 & 85.28 \\
\hline change & $+63 \%$ & $+65 \%$ & $+31 \%$ & $+201 \%$ & $+29 \%$ \\
\hline \multicolumn{6}{|l|}{ Poultry } \\
\hline 1961 & 4.61 & 3.71 & 5.39 & 3.74 & 6.65 \\
\hline 2013 & 23.35 & 25.27 & 27.94 & 21.28 & 19.64 \\
\hline change & $+407 \%$ & $+581 \%$ & $+418 \%$ & $+469 \%$ & $+195 \%$ \\
\hline \multicolumn{6}{|l|}{ Pig } \\
\hline 1961 & 21.63 & 20.34 & 24.62 & 9.79 & 31.74 \\
\hline 2013 & 34.61 & 28.92 & 28.38 & 39.54 & 42.57 \\
\hline change & $+60 \%$ & $+42 \%$ & $+15 \%$ & $+304 \%$ & $+34 \%$ \\
\hline \multicolumn{6}{|l|}{ Fish and seafood } \\
\hline 1961 & 13.91 & 11.51 & 20.71 & 17.30 & 12.59 \\
\hline 2013 & 21.85 & 17.02 & 25.34 & 29.07 & 21.45 \\
\hline change & $+57 \%$ & $+48 \%$ & $+22 \%$ & $+68 \%$ & $+70 \%$ \\
\hline \multicolumn{6}{|l|}{ Milk and butter } \\
\hline 1961 & 171.08 & 157.36 & 245.98 & 115.93 & 202.95 \\
\hline 2013 & 215.11 & 171.05 & 261.44 & 211.55 & 261.29 \\
\hline change & $+26 \%$ & $+9 \%$ & $+6 \%$ & $+82 \%$ & $+29 \%$ \\
\hline \multicolumn{6}{|l|}{ Pulses } \\
\hline 1961 & 3.54 & 3.28 & 2.38 & 7.20 & 1.80 \\
\hline 2013 & 2.56 & 1.78 & 3.12 & 5.19 & 1.34 \\
\hline change & $-28 \%$ & $-46 \%$ & $+31 \%$ & $-28 \%$ & $-26 \%$ \\
\hline \multicolumn{6}{|l|}{ Animal Fat } \\
\hline 1961 & 11.16 & 9.57 & 19.01 & 3.87 & 15.97 \\
\hline 2013 & 10.99 & 9.19 & 9.81 & 7.81 & 16.93 \\
\hline change & $-2 \%$ & $-4 \%$ & $-48 \%$ & $+102 \%$ & $+6 \%$ \\
\hline \multicolumn{6}{|l|}{ Vegetable Oil } \\
\hline 1961 & 8.00 & 5.12 & 9.37 & 11.25 & 10.13 \\
\hline 2013 & 17.65 & 14.24 & 15.82 & 24.08 & 18.64 \\
\hline change & $+121 \%$ & $+178 \%$ & $+69 \%$ & $+114 \%$ & $+84 \%$ \\
\hline \multicolumn{6}{|l|}{ Sugar \& Sweets } \\
\hline 1961 & 32.47 & 30.91 & 50.54 & 21.76 & 34.75 \\
\hline 2013 & 41.75 & 44.43 & 42.09 & 31.68 & 45.64 \\
\hline change & $+29 \%$ & $+44 \%$ & $-17 \%$ & $+46 \%$ & $+31 \%$ \\
\hline \multicolumn{6}{|l|}{ Fruits } \\
\hline 1961 & 49.42 & 23.66 & 54.00 & 80.30 & 73.35 \\
\hline 2013 & 94.93 & 67.79 & 122.67 & 112.62 & 107.64 \\
\hline change & $+92 \%$ & $+187 \%$ & $+127 \%$ & $+40 \%$ & $+47 \%$ \\
\hline \multicolumn{6}{|l|}{ Vegetables } \\
\hline 1961 & 85.39 & 78.61 & 51.96 & 123.82 & 85.56 \\
\hline 2013 & 115.10 & 67.79 & 96.46 & 136.75 & 97.50 \\
\hline change & $+35 \%$ & $-14 \%$ & $+86 \%$ & $+10 \%$ & $+14 \%$ \\
\hline
\end{tabular}

North-south as well the east-west gradients in vegetable availability are evident: in northern countries, the availability and supply of vegetables are lower than in the south and east (17). Geographical gradients are also observed for fruit, the availability and supply of which are at their lowest in eastern countries (17). 
Daily fruit and vegetable intake varies also by gender, with women more likely to report daily consumption of fruit and vegetables than men (19). There is also a clear difference in fruit and vegetable consumption by educational level, in favour of well-educated adults. However, in 2014, only 5\% and 33\% of highly-educated people in Romania and Denmark, respectively, ate the recommended amount of five portions of fruit and vegetables per day (19).

The observed influence of both regional preferences and urbanisation on diet quality highlights the importance of planning and implementing nutrition strategies at regional level. Regional diets, such as the Mediterranean Diet and New Nordic Diets (17) have been promoted as solutions to the demand for healthier and more sustainable nutrition: they include high intakes of olive oil, nuts, fruit, vegetables, pulses and cereals, and low consumption of meat and dairy products. In addition, diet should be an integral part of local lifestyles, which include traditional recipes, seasonality, socialisation, and regular physical activity.

\section{Costs and benefits of sustainable healthy eating}

To understand costs and benefits of a healthy and sustainable diet, the framework presented in Table 2 was proposed by the working group, so as to differentiate between actions that impact at the individual or societal levels; on the basis of this Table, costs and benefits of unsustainable diets can be assessed directly.

Table 2. Benefits and costs of a sustainable and bealthy diet, at individual and societal levels. Given the current status quo, a more bealthy and more sustainable diet will produce "bigher" costs (first column) and "lower" burden (in form of health burden, bealthcare expenditure, and environmental impact; second column). Costs and benefits of unbealthy and unhealthy diet can be derived from first column (it would be "benefits", with "lower" costs) and from second column (it would be "costs", with "bigher" individual and societal burden).

\begin{tabular}{|c|c|c|}
\hline & Costs of a sustainable and healthy diet & Benefits of a sustainable and healthy diet \\
\hline 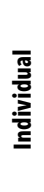 & $\begin{array}{l}\text { - Higher monetary and non-monetary costs of a healthy diet: it includes the } \\
\text { monetary cost of nutritious food (which often is higher than food of low } \\
\text { nutritional quality, especially in geographic areas where fresh food is } \\
\text { rarely available), and other related aspects (time and knowledge needed } \\
\text { to prepare such food, to make it enough palatable) }\end{array}$ & $\begin{array}{l}\text { - Lower incidence and prevalence rates for overweight, obesity } \\
\text { and non-communicable diseases }\end{array}$ \\
\hline 焉 & $\begin{array}{l}\text { - Higher costs related to policy making and to implementation of policy } \\
\text { designed to move dietary choices towards healthy and sustainable diets }\end{array}$ & $\begin{array}{l}\text { - Lower healthcare costs and lower economic losses related to } \\
\text { overweight, obesity and non-communicable diseases } \\
\text { - Lower environmental impacts (climate change, loss of } \\
\text { biodiversity, erosion, loss of soil fertility, salination of water } \\
\text { tables, unsustainable rates of water extraction, and reliance } \\
\text { on fossil fuel-derived energy) }\end{array}$ \\
\hline
\end{tabular}

In high income countries, the price difference between healthier and less healthy food-based diet patterns is around 1.5 US\$ per day; this difference is negligible, but it is likely to be unaffordable for low SES (socioeconomic status) households, which often opt for cheap and highly satiating energy-dense nutrient-poor processed food (20). While low-cost, nutrient-rich food items are available (e.g. carrots and apples), they are often neither palatable nor culturally acceptable (21). 
Therefore, nutrients, price, appeal, individual preferences and social norms should all be taken into account when considering monetary and non-monetary costs of healthy diets, the implications of which are likely to impact more on low SES households than high SES ones.

Similarly, individual benefits of healthy diets (meaning: benefits felt already at the individual level, not only at the societal level) are expected to be maximal in people of low SES, who face a high risk of developing chronic diseases and conditions: about $20-25 \%$ of the risk of obesity among men and 40-50\% among women in the European Region can be attributed to differences in SES (17). The complex link between SES (often "education level" is used as a proxy indicator for this, and it is usually the preferred indicator of SES, because it is much easier to assess education levels than occupation levels, poverty, migration background, or other vulnerabilities) and nutrition shows us that health benefits are not limited to the individual sphere, but act at the societal sphere as $(22,23)$. Other major societal implications of healthy eating are to be found in averted detrimental impacts on the environment and averted direct and indirect health costs(17). In light of our focus on "healthy and sustainable" diets, we presented positive environment and economic impacts as "benefits" (that is, costs avoided through healthy and sustainable diets), rather than "costs" (that is, costs related to unhealthy and unsustainable diets).

Dietary change toward more plant-based diets, in line with standard dietary guidelines promoting health, could reduce emissions by up to $50 \%$, as compared to those associated with current diets; such reductions would be still higher if more radical dietary changes (i.e. towards vegetarian or vegan diets) could be achieved (24). The reduction potential not only depends on the baseline amount and types of meat in the diet, but also on the environmental impact of the foods used to replace meat (24). An attempt to analyse the relationship between dietary impacts and greenhouse gas (GHG) emissions, land use and water use all together, has been achieved through a systematic review of 63 studies: this found a statistically significant association between restriction of consumption of animal-based foods and reduction in environmental footprints (25).

Similarly, the adoption of sustainable diets has been associated with reductions (up to 10\%) in all-cause mortality, increased quality of life, and with avoidable economic costs, including not only direct healthcare costs, but also indirect costs associated with unpaid informal care and productivity losses from lost labour time $(24,25)$.

\section{Sustainable dietary guidelines: the way forward}

According to FAO, whose definition of sustainable diets is "those diets with low environmental impacts which contribute to food and nutrition security and to healthy life for present and future generations. Sustainable diets are protective and respectful of biodiversity and ecosystems, culturally acceptable, accessible, economically fair and affordable; nutritionally adequate, safe and healthy; while optimizing natural and human resources." Yet, to date, only four countries have included sustainability within their Food Based Dietary Guidelines: Brazil, Sweden, Qatar and Germany (26). Quasi-official guidelines (that is, those guidelines that stem from government 
agencies or government funded entities) are to be found in the UK, France, Netherlands and Estonia, and in the Nordic countries (26).

Food Based Dietary Guidelines (or dietary guidelines), whose aim is to establish a regional or national basis for public food and nutrition policies (including health, agricultural policies and nutrition education), provide advice on foods, food groups and dietary patterns to promote health at the population level (26). Such guidelines provide important benchmarks for planned diets, and could take on a crucial role in enshrining sustainability into regional and national cultures.

Other dietary guidelines have attempted to incorporate sustainability into their visions of food consumption: the Double Pyramid Model, developed by the Barilla Centre for Food and Nutrition Foundation, is based on the principle that the foods recommended to be consumed most frequently (such as vegetables, grains, pulses, and fruit) are also those which are associated with reduced environmental impacts, and conversely, that the foods that should be consumed less frequently (meat and highly processed foods) are those associated with higher environmental impacts (27).

Sustainability issues in Food Based Dietary Guidelines are often incorporated, but are not always explicit. For instance, from a nutritional and public health perspective, the promotion of fruit and vegetable intake is a well-established strategy to improve diets around the world. Moreover, some authors argue that visual representations of guidelines, such as in the Eatwell Plate, are needed to promote the consumption of nutritious and sustainable foods (28).

\section{Discussion}

\section{The public health role in promoting healthy and sustainable diets}

Sustainable healthy diets have low environmental impact, contribute to food and nutrition security and to healthy lives, reducing risks of all forms of malnutrition - both under- and overnutrition, for present and future generations. In our view, public health professionals can represent a strong and independent voice in protecting and promoting health, through evidencebased analyses, advocacy, and political engagement, towards the promotion of healthy and sustainable diets. Unfortunately, we should also admit that there are significant public health competency deficits in Europe: it will be difficult to progress the high level recommendations set out in this review without addressing these capacity deficits in public health nutrition (29), public health advocacy and leadership (30), as pointed out in many occasions by our colleagues within ASPHER (Association of Schools of Public Health in the European Region).

\section{Key recommendations towards healthy and sustainable diets}

Significant changes in European food systems are required to promote healthy and sustainable diets. Food systems should take account of and include both healthy nutrition and sustainability, by linking both the population health and climate stabilisation agendas, through carefully 
designed interventions that can improve simultaneously agriculture, food security, human health, and planetary health.

Thus, redevelopment of agriculture and fisheries in ways that conserve the natural resources upon which production depends needs to be addressed. As widely discussed in our EUPHA report (17), it is essential that agriculture's dependence on fossil fuels, and the carbon footprints of all food systems, are reduced, and that control of pests and biosecurity is improved. In addition, inter-species diversity and the protection of neglected species and varieties, which can be essential to nutrition security, should be addressed. Similarly, local products should increasingly be invested in and made available; however, at the same time, damage to the economies of developing countries must be avoided.

By means of appropriate regulation, the food industry should be required to produce healthy, nutritious (minimally processed) foods in a sustainable manner, with low contents of sugars, salt and additives that could adversely affect health. Production and marketing should be bound legally to be honest and transparent, with consumer-friendly food labelling. These principles should apply consistently outside home environments, that is, for example, in restaurants, workplace cafeterias, vending machines, medical facilities (including hospitals), sports arenas, public spaces, schools and day-care centres. Advertising and marketing restrictions should apply to unhealthy food, such as most types of snacks and sweet beverages, especially if targeted to children. As a right, every citizen should have access to a wholesome, culturally appropriate and affordable food basket for a sustainable, heathy diet.

To this end, the European Commission and governments of non-member states of the EU should each establish a statutory Sustainable Nutrition Task Force, the responsibilities of which would be, in each jurisdiction:

- $\quad$ to identify essential key features of a healthy and sustainable complete food system from farm to fork;

- to formulate and to recommend a strategic plan for moving from current food systems towards healthy and sustainable alternatives, by adopting a multi-disciplinary approach to food and nutrition;

- to plan and to recommend a programme for implementation of the strategy for sustainable and healthy food systems;

- $\quad$ to monitor progress towards implementation of such policies;

- to supervise the evaluation of outcomes in relation to both healthy nutrition and environmental sustainability.

To achieve all of the above successfully, an appropriate fully-funded "from farm to fork" food research infrastructure will also be necessary, so that all decisions made are evidence -based, and scientific monitoring and evaluation of all projects is assured.

Each Sustainable Nutrition Task Force should include multidisciplinary representation of all relevant stakeholders, from government (for health, nutrition, agriculture, environment, education, finance, and justice), and from municipalities / local authorities (for urban planning), 
agriculture (farmers), environment, health professions, industry, the catering sector, academia, media, NGOs, civil society and consumer organisations. Such stakeholders include, for instance, food policy NGOs, social entrepreneurs and a wide range of community and other bottom-up movements focused on healthy and sustainable diets based on locally produced food with minimisation of food waste: one extraordinary example of integrated decision-making is described by Carey and colleagues, while one inspirational case of local actions is presented by Preuss, as layed out in our report (17).

Last, but not least, each Strategy for Sustainable Healthy Nutrition should be supported by overarching legislation, an institutional infrastructure, educational structures which include appropriate capacity building, and food security. Nutrition for all should be guaranteed both now and into the future. 


\section{References}

1. Lains P, Pinella V, (editors). Agriculture and Economic Development in Europe since 1870. London: Routledge; 2009.

2. Nobel Peace Prize 1949. Lord Boyd Orr - Biographical.

http://www.nobelprize.org/nobel_prizes/peace/laureates/1949/orr-bio.html. Last opened: 12 August 2017.

3. Garfield S. Our Hidden Lives. London: Ebury Press; 2004.

4. Birt C. A CAP on Health? The Impact of the EU Common Agricultural Policy on Public Health; a report by the Faculty of Public Health. London: Faculty of Public Health; 2007.

5. Lloyd-Williams F, O'Flaherty M, Mwatsama M, Birt C, Ireland R, Capewell S. Estimating the cardiovascular mortality burden attributable to the European Common Agricultural Policy on dietary saturated fats. Bull World Health Organ. 2008;86(7):535-41a.

6. European Commission. EU platform for action on diet, physical activity and health.

https://ec.europa.eu/health/nutrition_physical_activity/platform_en

Last opened: 12 August 2017.

7. European Union. Council conclusions to contribute towards halting the rise in Childhood Overweight and Obesity.

http://eur-lex.europa.eu/legal-content/IT/TXT/?uri=uriserv:OJ.C_.2017.205.01.0046.01.ENG

Last opened: 12 August 2017.

8. World Health Organization. European Food and Nutrition Action Plan 2015-2020. 2014.

9. United Nations General Assemply. Transforming our world: the 2030 Agenda for Sustainable

Development: Sustainable Development Knowledge Platform. 2015.

http://www.un.org/sustainabledevelopment/development-agenda/

Last opened: 12 August 2017.

10. United Nations Framework Convention on Climate Change. Adoption of the Paris Agreement. 2015. https://unfccc.int/resource/docs/2015/cop21/eng/109r01.pdf

Last opened: 12 August 2017.

11. United Nations General Assembly. United Nations Decade of Action on Nutrition (2016-2025).

2016. http://www.who.int/nutrition/decade-of-action/en/

Last opened: 12 August 2017.

12. Whitmee S, Haines A, Beyrer C, Boltz F, Capon AG, Dias BFdS, et al. Safeguarding human health in the Anthropocene epoch: report of The Rockefeller Foundation-Lancet Commission on planetary health. The Lancet. 2015;386(10007):1973-2028.

13. Perignon M, Vieux F, Soler L-G, Masset G, Darmon N. Improving diet sustainability through evolution of food choices: review of epidemiological studies on the environmental impact of diets. Nutrition Reviews. 2017;75(1):2-17.

14. Tilman D, Clark M. Global diets link environmental sustainability and human health. Nature. 2014;515(7528):518-22.

15. Lafranconi A, Birt C. How best to use the EXPO momentum to improve our food environment? Eur J Public Health. 2015;25(5):751-2.

16. Dernini S, Berry EM. Mediterranean Diet: From a Healthy Diet to a Sustainable Dietary Pattern. Frontiers in Nutrition. 2015;2.

17. EUPHA Food and Nutrition Working Group. Healthy and Sustainable Diets for European

Countries. Report of a Working Group. EUPHA. Utrecht, 2017. 
18. Food and Agriculture Organization of the United Nations, Biodiversity I, editors. Proceedings of the International Scientific Symposium: Biodiversity and Sustainable Diets United Against Hunger 2012.

Rome, Italy.

http://www.fao.org/docrep/016/i3004e/i3004e.pdf

Last opened: 12 August 2017.

19. Organization for Economic Co-operation and Development. Health at a Glance: Europe 2016.

http://www.oecd.org/health/health-at-a-glance-europe-23056088.htm

Last opened: 12 August 2017.

20. Rao M, Afshin A, Singh G, Mozaffarian D. Do healthier foods and diet patterns cost more than less healthy options? A systematic review and meta-analysis. BMJ Open. 2013;3(12):e004277.

21. Darmon N, Drewnowski A. Contribution of food prices and diet cost to socioeconomic disparities in diet quality and health: a systematic review and analysis. Nutr Rev. 2015;73(10):643-60.

22. Devaux M, Sassi F. Social inequalities in obesity and overweight in 11 OECD countries. European journal of public health. 2013;23(3):464-9.

23. World Health Organization. Fiscal policies for diet and the prevention of noncommunicable diseases. http://www.who.int/dietphysicalactivity/publications/fiscal-policies-diet-prevention/en/

Last opened: 12 August 2017.

24. Springmann M, Godfray HCJ, Rayner M, Scarborough P. Analysis and valuation of the health and climate change cobenefits of dietary change. Proceedings of the National Academy of Sciences. 2016;113(15):4146-51.

25. Aleksandrowicz L, Green R, Joy EJM, Smith P, Haines A. The Impacts of Dietary Change on Greenhouse Gas Emissions, Land Use, Water Use, and Health: A Systematic Review. PLOS ONE. 2016;11(11):e0165797.

26. Fischer CG, Garnett T. Plates, pyramids and planets - Developments in national healthy and sustainable dietary guidelines: a state of play assessment. Food and Agriculture Organization of the United nations and Food Climate Research Network (FCRN), University of Oxford.; 20162016.

27. Barilla Center for Food and Nutrition. Doppia Piramide 2016 - Un futuro più sostenibile dipende da noi. https://www.barillacfn.com/it/pubblicazioni/doppia-piramide-2016-un-futuro-piu-sostenibiledipende-da-noi/

Last opened: 12 August 2017.

28. Johnston JL, Fanzo JC, Cogill B. Understanding Sustainable Diets: A Descriptive Analysis of the Determinants and Processes That Influence Diets and Their Impact on Health, Food Security, and Environmental Sustainability. Advances in Nutrition: An International Review Journal. 2014;5(4):418-29. 29. Foldspang A, Otok R. Competences based Individual career and Workforce planning in Public health.

http://www.euro.who.int/_data/assets/pdf_file/0010/325945/Eurohealth-V22-N4-2016.pdf. Last opened: 12 August 2017.

30. Lafranconi A, Gomes B, Stankunas M, Babich SM, Rethmeier KA, Czabanowska K, et al. Medical leadership--from inspiration to education. Lancet. 2015;386(10003):1531-2. 



\section{PART 3 \\ Disease Prevention: \\ case study on coffee}





\section{Coffee decreases risk of endometrial cancer: a dose-response meta-analysis on prospective cohort studies}

Published as:

Alessandra Lafranconi, Agnieszka Micek, Fabio Galvano, Sabrina Rossetti, Lino Del Pup, Massimiliano Berretta and Gaetano Facchini (2017) Coffee Decreases the Risk of Endometrial Cancer: A Dose-Response Meta-Analysis of

Prospective Cohort Studies

Nutrients, 9(11):1223; doi:10.3390/nu9111223 [IF (2017): 2,80]

Acknowledgements:

The authors wish to acknowledge the contribution of Antonio Simone Laganà and Salvatore Giovanni Vitale, and to thank "LILT Sezione di Napoli". The work of Alessandra Lafranconi is partially supported by a Jean Monnet Erasmus + grant (574376-EPP-1-2016-1-IT-EPPJMO-MODULE).

Author Contributions:

A.L. and A.M. conceived the study; A.L. wrote introduction and discussion in consultation with F.G., S.R., L.D.P., M.B. and G.F.; A.M. carried out the statistical analysis and wrote methods and results.

Conflict of interest:

None declared. 



\section{Abstract}

Aim: The aim of this study was to perform a comprehensive meta-analysis of the association between coffee consumption and risk of endometrial cancer.

Methods: Eligible studies were identified by searching the PubMed and EMBASE databases. The dose-response relationship as well as the risk of endometrial cancer for the highest versus the lowest categories of coffee consumption were assessed. Subgroup analyses considering the menopausal and receptor statuses, the smoking status, and the BMI (Body Mass Index) were performed in order to identify potential confounders.

Results: We identified a total of 12 studies eligible for meta-analysis. A dose-response metaanalysis showed a decreased risk of endometrial cancer. Moreover, a subgroup analysis indicated that coffee consumption is significantly associated with a decreased risk of postmenopausal cancer. Increasing coffee consumption by four cups per day was associated with a $20 \%$ reduction in endometrial cancer risk (relative risk (RR) $0.80 ; 95 \%$ confidence interval (CI) 0.72 to 0.89 ) and with a $24 \%$ reduction in postmenopausal cancer risk (RR $0.76 ; 95 \%$ CI 0.69 to 0.83 ).

Conclusions: Our findings suggest that increased coffee consumption is associated with decreased risk of endometrial cancer, and this association is observed also for postmenopausal cancer.

Keywords: coffee; caffeine; postmenopausal; endometrial cancer; prospective cohort; metaanalysis. 


\section{Introduction}

Endometrial cancer is the third most common female cancer, after breast cancer and cervical cancer: in 2012, worldwide, there were over 1.2 million women with a diagnosis of endometrial cancer made in the previous 5 years. Similarly, in Europe there were 370,000 women with the same diagnosis [1]. The burden of non-communicable diseases, including cancers, has been associated with dietary habits, such as the consumption of fibers, sugar, saturated fatty acids, and trans fatty acids [2-4].

Among others, coffee consumption has also been shown to potentially affect human health [5]. Moderate coffee consumption has been suggested to improve metabolic health and to decrease the risk of mortality $[6,7]$. Regarding cancer risk, coffee consumption has been associated with decreased risk of liver [8], prostate [9], pancreatic [10], and colon cancer [11], suggesting a potential role of coffee in cancer prevention. Coffee is composed of a variety of compounds, including polyphenols, diterpenes and melanoidins, that have been reported to modulate antiinflammatory and anti-oxidant body responses, which may explain the potential beneficial effects of coffee in cancer prevention $[12,13]$.

A decreased risk of endometrial cancer in women who regularly drink coffee has been documented in retrospective and prospective studies: Je and Giovannucci performed a metaanalysis including 10 case-control and 6 cohort studies and found a significant inverse association of endometrial cancer with coffee consumption in the highest versus the lowest category of coffee intake [14]. The dose-response analysis showed a decrease of $8 \%$ in the risk of endometrial cancer for an increment of one cup of coffee per day [14]. Similar conclusions were reported by Zhou and colleagues in a meta-analysis of prospective studies: they found a significant reduction of endometrial cancer risk associated with increased coffee consumption, with a linear dose-response relationship [15]. Significant results were obtained also in the metaanalysis of Yang and colleagues, who estimated a decreased risk of endometrial cancer of about $10 \%$ for every additional daily cup of coffee [16].

Results are promising but evidence is not yet conclusive, especially regarding specific population subgroups (e.g., in relation to body mass index (BMI), age, geographic place of residence, and ethnicity); in light of the high worldwide consumption of coffee, further research is needed [17, 18]. Moreover, new cohort studies have been published, and some overlapping cohorts were not considered in the previous meta-analyses [19]. Thus, the aim of this study was to update the current evidence on the association between coffee intake and risk of endometrial cancer, providing insights on potential effect modifiers or confounding factors, including the BMI and the menopausal status.

\section{Methods}

We followed the Meta-Analysis of Observational Studies in Epidemiology (MOOSE) protocols throughout the design, execution, analysis, and reporting of the current meta-analysis (Supplementary Table S1) [20]. 


\section{Search Strategy}

We conducted a comprehensive literature search using two medical databases, namely, PubMed (http://www.ncbi.nlm.nih.gov/pubmed/) and EMBASE (http://www.embase.com); the databases were screened from the earliest available online indexing year up to March 2017, with English-language restriction. We included the following search terms: (coffee OR caffeine OR beverages OR diet Or dietary) AND (endometrial OR endometrium) AND (cancer OR carcinoma OR neoplasm) (Supplementary Table S2).

Two authors evaluated independently the pertinence of the retrieved studies and obtained full texts of the relevant ones. We limited our search to prospective cohort studies that evaluated the association between dietary coffee intake and the risk of endometrial cancer in the overall female population. Studies were included if they provided any of the following risk estimates: relative risks (RRs) or hazard ratios (HRs). We excluded studies that reported insufficient statistics or insufficient coffee consumption categories (less than three). Among the included manuscripts, all references were also examined in order to maximize the number of relevant studies through the addition of studies not previously identified. When duplicate publications from the same study were identified, we chose the report that provided the largest number of cases (or the entire cohort), or the longest follow-up for each endpoint of interest. Full texts of potentially relevant articles were assessed independently for eligibility by two different authors.

\section{Data Extraction}

A standardized extraction form was used to extract data from each study included in the metaanalysis. The following information was collected: (1) first author name; (2) year of publication; (3) study cohort name; (4) country; (5) number of participants; (6) sex of participants; (7) age range of the study population at baseline; (8) categories of consumption; (9) follow-up period; (10) endpoints and cases; (11) distributions of cases and person-years, RRs, HRs, and 95\% CIs (confidence interval) for all categories of exposure; (12) covariates used in adjustments. Two authors independently performed such process, and discrepancies were discussed and resolved by consensus. Each study was critically appraised through the use of a quality scale, namely, the Newcastle-Ottawa Quality Assessment Scale [21], which consists of three variables of quality as follows: selection (4 points), comparability ( 2 points), and outcome ( 3 points), for a total score of 9 points ( 9 representing the highest quality).

\section{Statistical Analysis}

In this meta-analysis, HRs were deemed equivalent to relative risks (RRs) [22]. For each study, extracted statistical estimates were RRs and HRs with 95\% CI for all categories of exposure. Random-effects models were used to calculate pooled RRs with 95\% CI for the highest versus the lowest categories of exposure (such analysis aimed to assess the presence of a relationship between coffee intake and risk of endometrial cancer). In performing such analysis, for each study, we used the risk estimate derived from the most fully adjusted models (analysis of the pooled RR). Heterogeneity was assessed using the Q test and $\mathrm{I}^{2}$ statistic. The level of significance was set equal to 0.10 for the $\mathrm{Q}$ test. The $\mathrm{I}^{2}$ statistic explains the amount of total variation that 
could be attributed to heterogeneity. $\mathrm{I}^{2}$ values $<25 \%, 25-50 \%, 50-75 \%$, and $>75 \%$ indicated no, small, moderate, and significant heterogeneity, respectively. To evaluate the stability of the results and potential sources of heterogeneity, a sensitivity analysis by exclusion of one study at a time was performed. Moreover, a subgroup analysis was performed in order to check for potential sources of heterogeneity according to the geographical area. To test for potential confounders and effect modifiers, other subgroup analyses were performed (by menopausal status, receptor status, BMI, smoking status, and coffee type). The publication bias was evaluated by a visual investigation of the funnel plots for potential asymmetry.

To better explore the relationship between exposure and outcome, a dose-response metaanalysis was performed (a dose-response analysis was preferred over other designs, e.g., metaregression, to better compare our results with previous studies and to better draft potential recommendations whether evidence would support the present findings). Extracted data were stratified by the level of coffee intake, and distributions of cases and person-years (when available), and RRs or HRs with 95\% CIs for 3 exposure categories were included. The median or mean intake of coffee in each category was assigned to the corresponding RR or HR with the 95\% CI for each study. If coffee consumption was reported in a range of intake, we used the midpoint of the range. Similarly, when the highest category was open-ended, we assumed that the width of the category would be the same as the adjacent category. In the case of an openended lowest category, we clearly set the lower boundary to zero. Two-stage random-effects dose-response meta-analysis was performed to examine linear and non-linear relationship between coffee intake and risk of endometrial cancer. In the first stage, the method of Greenland and Longnecker (generalized least-squares, GLS) was used to calculate study-specific coefficients on the basis of results across categories of coffee intake, taking into account the correlation within each set of retrieved RRs and HRs [23, 24]. Through the use of restricted cubic splines with three knots at fixed percentiles $(25 \%, 50 \%$, and $75 \%)$ of the distributions, non-linear doseresponse analyses were modelled [25], and the coefficients (that had been estimated within each study by performing random-effects meta-analysis) were combined. To estimate the relative risks, we used the method of DerSimonian and Laird in linear dose-response meta-analyses, and the multivariate extension of the method of moments in non-linear dose-response metaanalyses. We calculated a p-value for non-linearity by testing the coefficient of the second spline as equal to zero. We performed all analyses with $\mathrm{R}$ software version 3.0.3 (Development Core Team, Vienna, Austria).

\section{Results}

\section{Study Characteristics}

The search identified 598 studies, of which 511 were excluded after reviewing the title, and 70 on the basis of the abstract (Figure 1). Of the 17 publications selected, five were excluded for the following reasons: (1) the article did not provide risk measurements with confidence intervals; (2) the article did not have a prospective design; (3) the article provided data only on 
genetic polymorphism. For the analysis on the association between coffee consumption and endometrial cancer risk, 12 studies were eligible [16, 26-36]. Two cohorts, NOWAC and VIP $[27,33]$, were excluded from the main analysis because part of theirs cases are included in the multicenter study EPIC [32]. However, an alternative analysis was performed by including these cohorts and excluding the EPIC study. One article was used only for subgroup analysis [31]. Studies eligible for the main analysis comprised 1,404,541 participants and 10,548 endometrial cancer cases. The main characteristics of the studies included in the meta-analysis are described in Table 1. Seven studies provided relative risk measurements for the postmenopausal [26-31,35] status, and two for the premenopausal status [27,31]. Five studies were conducted in the USA [28-31, 35], five in Europe [16, 26, 27, 33, 36], one in Asia [34], and one on a cohort from Europe and North America [32]. The follow-up in prospective cohort studies ranged from about 6 to 26 years, and the age range at study baseline was between 25 and 74 years (with almost all studies covering the age range between 40 and 60 years).

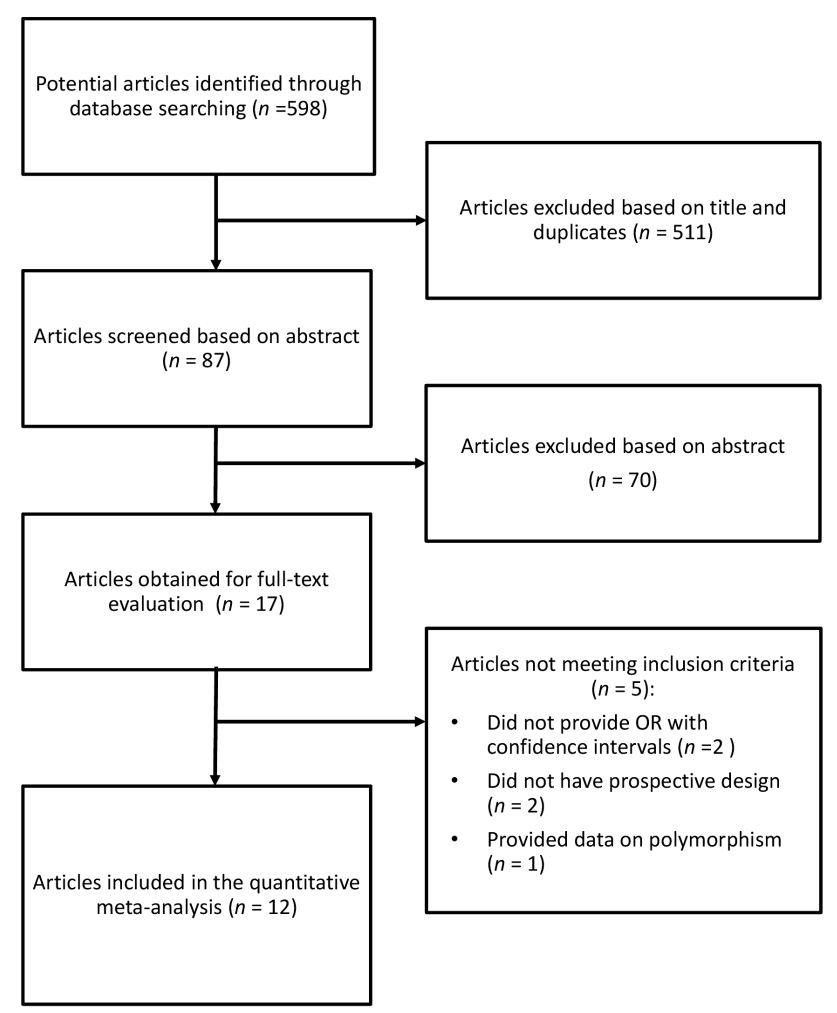

Figure 1. Selection process of relevant studies reporting on the association between coffee consumption and endometrial cancer risk. 
Table 1. Characteristics of the studies included in the meta-analysis.

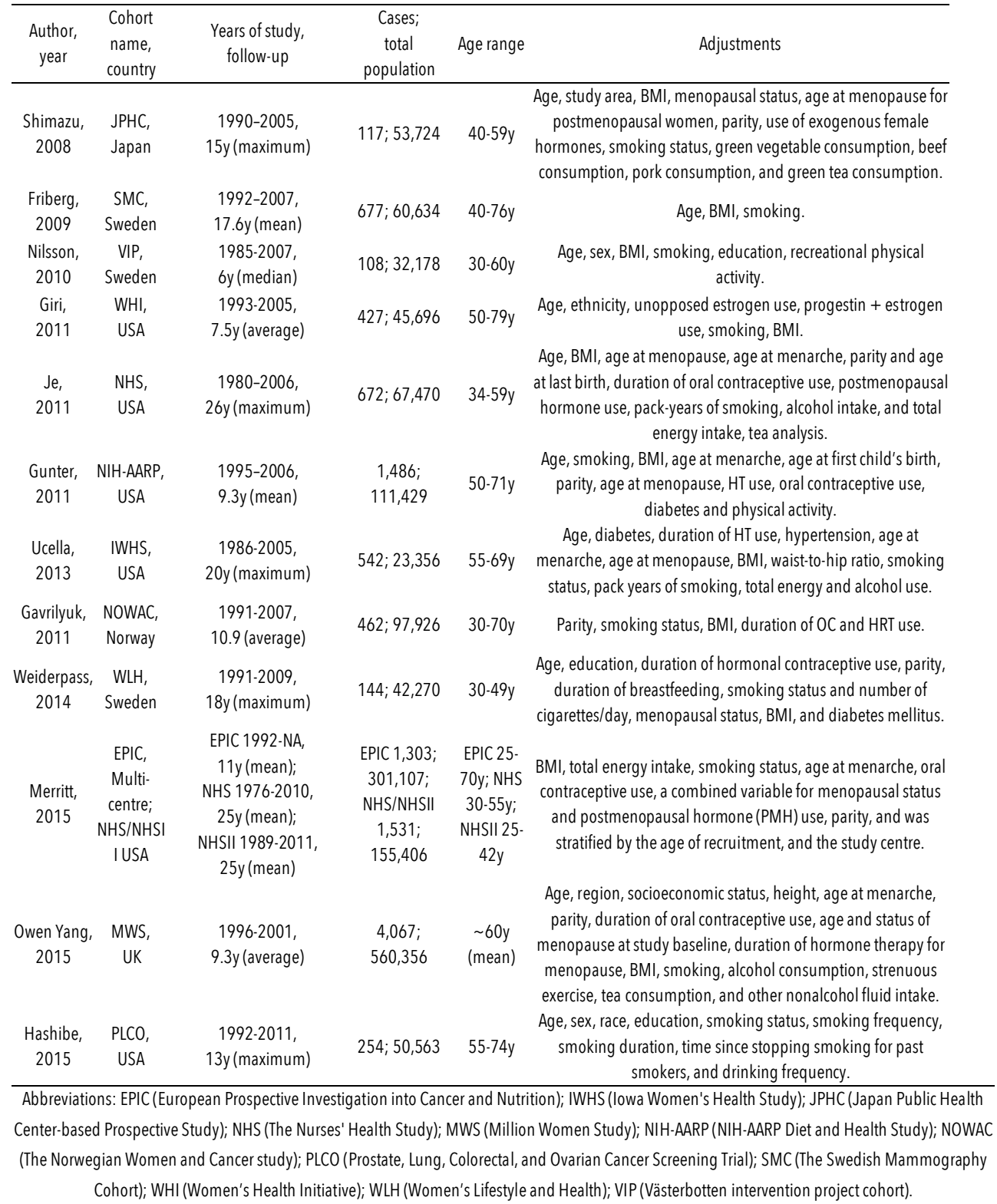




\section{Summary Relative Risk for Highest vs. Lowest Category of Coffee Consumption}

The summary Relative Risk (RR) of endometrial cancer for the highest versus the lowest category of coffee consumption was $\mathrm{RR}=0.79,95 \% \mathrm{CI}: 0.73,0.87$, with small heterogeneity $\mathrm{I}^{2}=28 \%$, $\mathrm{p}=0.19$, (Figure 2); no publication bias was found after a visual inspection of the funnel plot (Supplementary Figure S1).

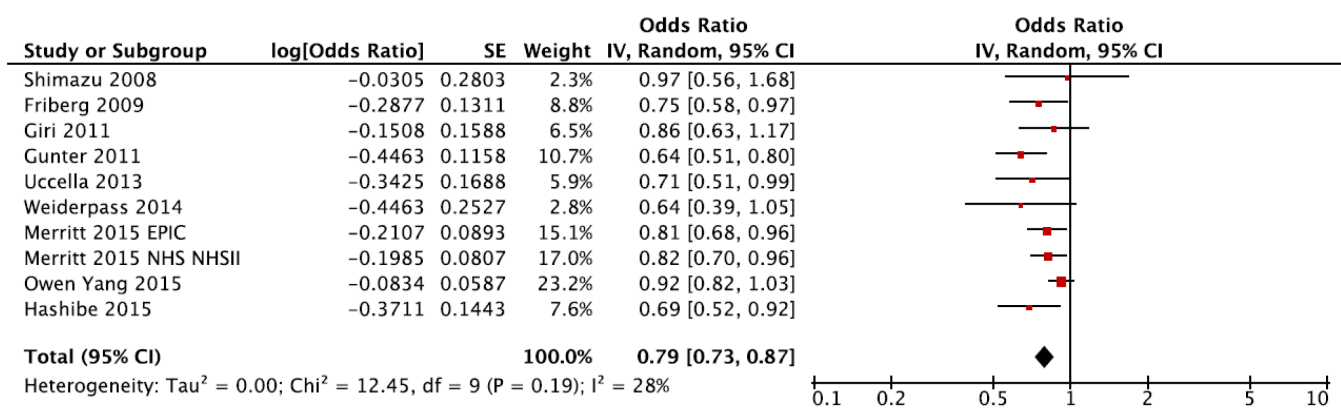

Figure 2. Forest plot of summary relative risks (RRs) of endometrial cancer for the bighest versus lowest (reference) category of coffee consumption. Exposure categories are reported as identified in the original studies; in the dose-response analysis they were harmonized (range: 0-9 cups).

When we performed the alternative analysis that included the NOWAC and VIP cohorts instead of the EPIC study (used in the main analysis), the RR was even lower and equal to 0.73 (95\% CI: $0.64,0.84)$, with moderate heterogeneity $\left(I^{2}=44 \%, p=0.0375\right)$. The associations for caffeinated and decaffeinated coffee were consistent with the aforementioned relationship (RR $=0.65,95 \%$ CI: 0.50, 0.85 for caffeinated coffee, and RR $=0.76,95 \%$ CI: $0.62,0.93$ for decaffeinated. When taking into account the menopausal status, a significant decrease in the risk of endometrial cancer $(\mathrm{RR}=0.70,95 \% \mathrm{CI}: 0.63,0.78$; $\mathrm{I} 2=0 \%, \mathrm{p}=0.60)$ was found for postmenopausal women, but not for premenopausal women $\left(\mathrm{RR}=0.7695 \% \mathrm{CI}: 0.49,1.19\right.$; $\mathrm{I}^{2}$ $=16 \%, \mathrm{p}=0.27$. No differences were observed between ever-smokers and non-smokers, i.e., in both subgroups the risk was significantly reduced for the highest category of coffee consumption compared to lowest category $(\mathrm{RR}=0.78,95 \% \mathrm{CI}: 0.68,0.88$ for non-smokers, and $\mathrm{RR}=0.74,95 \% \mathrm{CI}: 0.57,0.98$ for ever-smokers, respectively, Table 2 ). Finally, the analysis of the highest versus the lowest category of coffee consumption according to body mass index (BMI) categories showed a significant decrease in the risk of endometrial cancer among the obese $(\mathrm{BMI}>30 \mathrm{~kg} / \mathrm{m} 2)$ women $(\mathrm{RR}=0.75,95 \% \mathrm{CI}: 0.63,0.88)$. 
Table 2. Subgroup and additional analyses of studies reporting risk of endometrial cancer for the highest versus lowest (reference) category coffee consumption (analyses based on 12 studies consisting of 10 databases).

\begin{tabular}{|c|c|c|c|c|}
\hline Subgroup/Additional analysis & No. of datasets & $\mathrm{RR}(95 \% \mathrm{Cl})$ & $1^{2}$ & $P_{\text {heterogeneity }}$ \\
\hline Total & 10 & $0.79(0.73,9.87)$ & $28 \%$ & 0.19 \\
\hline \multicolumn{5}{|l|}{ Geographical area } \\
\hline North America & 5 & $0.75(0.67,0.84)$ & $6 \%$ & 0.37 \\
\hline Europe & 4 & $0.84(0.74,0.94)$ & $29 \%$ & 0.24 \\
\hline Asia & 1 & $0.97(0.56,1.68)$ & NA & NA \\
\hline \multicolumn{5}{|l|}{ Menopausal status } \\
\hline Postmenopausal & 7 & $0.70(0.63,0.78)$ & $0 \%$ & 0.60 \\
\hline Premenopausal & 2 & $0.76(0.49,1.19)$ & $16 \%$ & 0.27 \\
\hline \multicolumn{5}{|l|}{ Coffee type } \\
\hline Caffeinated & 4 & $0.65(0.50,0.85)$ & $64 \%$ & 0.04 \\
\hline Decaffeinated & 4 & $0.76(0.62,0.93)$ & $0 \%$ & 0.72 \\
\hline \multicolumn{5}{|l|}{ BMI } \\
\hline$<25 \mathrm{~kg} / \mathrm{m} 2$ & 7 & $0.99(0.86,1.14)$ & $0 \%$ & 0.58 \\
\hline$>25 \mathrm{~kg} / \mathrm{m} 2$ & 7 & $0.79(0.61,1.01)$ & $66 \%$ & 0.004 \\
\hline$>30$ kg/m2 & 5 & $0.75(0.63,0.88)$ & $22 \%$ & 0.27 \\
\hline \multicolumn{5}{|l|}{ Smoking status } \\
\hline Never smoker & 8 & $0.78(0.68,0.88)$ & $7 \%$ & 0.38 \\
\hline Ever smoker (former/current) & 8 & $0.74(0.57,0.98)$ & $68 \%$ & 0.003 \\
\hline \multicolumn{5}{|l|}{ Adjusted for smoking } \\
\hline No & 0 & NA & NA & NA \\
\hline Yes & 10 & $0.79(0.73,9.87)$ & $28 \%$ & 0.19 \\
\hline \multicolumn{5}{|l|}{ Adjusted for BMI } \\
\hline No & 1 & $0.69(0.52,0.91)$ & NA & NA \\
\hline Yes & 9 & $0.80(0.74,0.88)$ & $27 \%$ & 0.20 \\
\hline \multicolumn{5}{|l|}{ Adjusted for education } \\
\hline No & 8 & $0.81(0.74,0.89)$ & $30 \%$ & 0.19 \\
\hline Yes & 2 & $0.68(0.53,0.87)$ & $0 \%$ & 0.80 \\
\hline \multicolumn{5}{|l|}{ Adjusted for alcohol intake } \\
\hline No & 8 & $0.77(0.71,0.84)$ & $0 \%$ & 0.56 \\
\hline Yes & 2 & $0.85(0.67,1.07)$ & $52 \%$ & 0.15 \\
\hline
\end{tabular}

Nine studies [16, 26, 28-30, 32, 34-36] were eligible for dose-response meta-analysis of prospective cohort studies on coffee consumption and endometrial cancer risk. Six studies [2631] provided risk estimates for postmenopausal women only. In both the non-linear and the linear dose-response meta-analyses, a significant association between coffee consumption and endometrial cancer risk was found (Figure 3 , Table 3 ). Compared to no coffee consumption, the pooled relative risks for endometrial cancer were: $0.95,95 \% \mathrm{CI}: 0.92,0.97$, for one cup/day; 0.90, 95\% CI: 0.85 , 0.94, for two cups/day; 0.85, 95\% CI: 0.78, 0.92, for three cups/day; 0.80, 95\% CI: $0.72,0.89$, for four cups/day; 0.76, 95\% CI: 0.67, 0.86, for five cups/day; $0.72,95 \%$ CI: 0.61, 0.84, for six cups/day; 0.68, 95\% CI: 0.57, 0.81, for seven cups/day. Two cohorts, NOWAC and VIP, were excluded from the main analysis, as part of theirs cases are included in the multicentre study EPIC. However, an alternative analysis was performed by including these cohorts and excluding the EPIC study, confirming the results of the main analysis (Supplementary Table S3). Finally, the association between coffee intake and endometrial cancer was stronger when taking into consideration postmenopausal women. 
Table 3. Dose-response meta-analysis of prospective cohort studies on coffee consumption and endometrial cancer risk.

\begin{tabular}{|c|c|c|c|c|c|c|c|c|c|c|c|c|}
\hline & \multirow{2}{*}{$\begin{array}{l}\text { No. of } \\
\text { datasets } \\
\text { (no. of } \\
\text { studies) }\end{array}$} & \multicolumn{8}{|c|}{ Coffee intake (cups/day) } & \multirow{2}{*}{$I^{2}(\%)$} & \multirow{2}{*}{$P_{\text {heterogeneit }}$} & \multirow{2}{*}{$\begin{array}{l}P_{\text {non- }} \\
\text { linearity }\end{array}$} \\
\hline & & 0 & 1 & 2 & 3 & 4 & 5 & 6 & 7 & & & \\
\hline \multicolumn{13}{|l|}{ Total analysis } \\
\hline Non-linear & $11(9)$ & Ref. & $\begin{array}{c}0.91 \\
(0.85,0.97)\end{array}$ & $\begin{array}{c}0.85 \\
(0.76,0.94)\end{array}$ & $\begin{array}{c}0.81 \\
(0.73,0.91)\end{array}$ & $\begin{array}{c}0.79 \\
(0.70,0.89)\end{array}$ & $\begin{array}{c}0.76 \\
(0.67,0.87)\end{array}$ & $\begin{array}{c}0.74 \\
(0.64,0.86)\end{array}$ & $\begin{array}{c}0.72 \\
(0.61,0.85)\end{array}$ & 30.98 & 0.09 & 0.09 \\
\hline Linear & $11(9)$ & Ref. & $\begin{array}{c}0.95 \\
(0.92,0.97)\end{array}$ & $\begin{array}{c}0.90 \\
(0.85,0.94)\end{array}$ & $\begin{array}{c}0.85 \\
(0.78,0.92)\end{array}$ & $\begin{array}{c}0.80 \\
(0.72,0.89)\end{array}$ & $\begin{array}{c}0.76 \\
(0.67,0.86)\end{array}$ & $\begin{array}{c}0.72 \\
(0.61,0.84)\end{array}$ & $\begin{array}{c}0.68 \\
(0.57,0.81)\end{array}$ & 59.21 & 0.01 & NA \\
\hline \multicolumn{13}{|c|}{ Postmenopausal } \\
\hline Non-linear & $7(6)$ & Ref. & $\begin{array}{c}0.92 \\
(0.83,1.01)\end{array}$ & $\begin{array}{c}0.85 \\
(0.73,0.99)\end{array}$ & $\begin{array}{c}0.80 \\
(0.69,0.92)\end{array}$ & $\begin{array}{c}0.75 \\
(0.65,0.87)\end{array}$ & $\begin{array}{c}0.71 \\
(0.61,0.83)\end{array}$ & $\begin{array}{c}0.67 \\
(0.56,0.79)\end{array}$ & $\begin{array}{c}0.63 \\
(0.52,0.76)\end{array}$ & 0 & 0.64 & 0.67 \\
\hline Linear & $7(6)$ & Ref. & $\begin{array}{c}0.93 \\
(0.91,0.95)\end{array}$ & $\begin{array}{c}0.87 \\
(0.83,0.91)\end{array}$ & $\begin{array}{c}0.81 \\
(0.76,0.87)\end{array}$ & $\begin{array}{c}0.76 \\
(0.69,0.83)\end{array}$ & $\begin{array}{c}0.71 \\
(0.63,0.79)\end{array}$ & $\begin{array}{c}0.66 \\
(0.58,0.76)\end{array}$ & $\begin{array}{c}0.62 \\
(0.53,0.72)\end{array}$ & 0 & 0.46 & NA \\
\hline
\end{tabular}
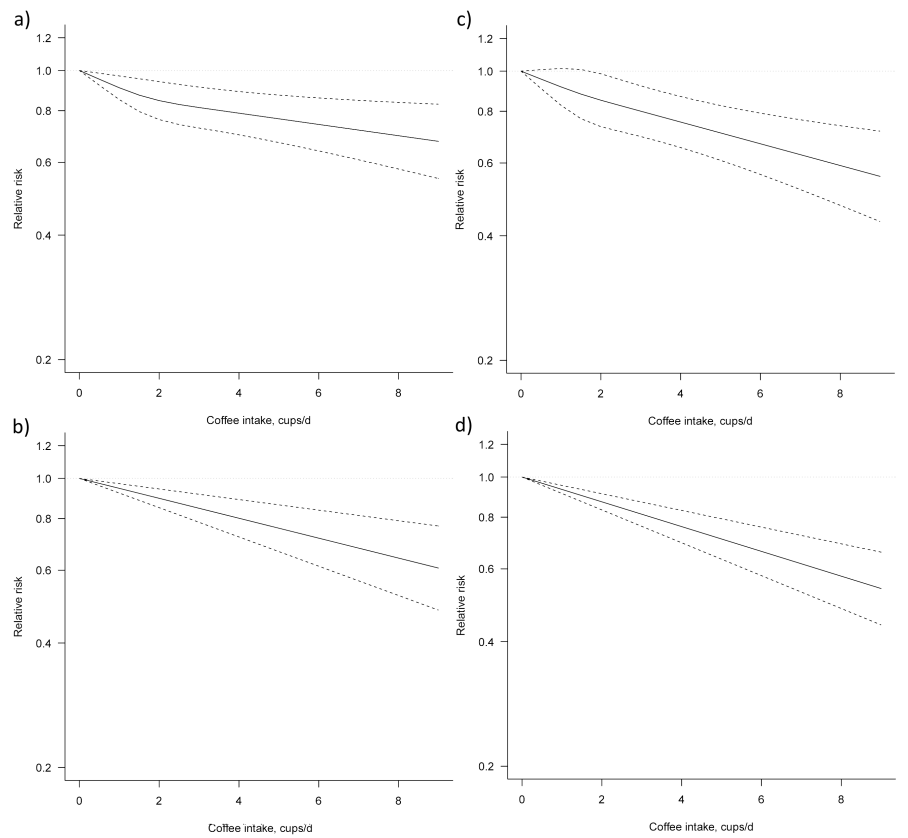

Figure 3. Dose-response association between coffee consumption and endometrial cancer risk a) non-linear, total analysis; b) linear, total analysis c) non-linear, postmenopausal; d) linear, postmenopausal. 


\section{Discussion}

The present meta-analysis, including 12 prospective cohort studies, showed that coffee consumption is associated with a lower risk of endometrial cancer; such association was stronger for postmenopausal endometrial cancer and in obese women (BMI > 30).

Various meta-analyses on the association of coffee consumption and endometrial cancer risk have been conducted so far: for instance, in 2011 Je and Giovannucci [14] documented an inverse dose-response association, with a geographical gradient (stronger association in Japan, followed by the USA and then Europe). Subgroup analyses were later published in 2015 by Yang and colleagues [16] and by Zhou and colleagues [15]: both groups limited their analyses to prospective studies and found a linear inverse association. The first research group found some evidence of heterogeneity among BMI subgroups (overweight women, with a BMI higher than 25 , showed a more pronounced inverse association than women with a lower BMI). The second group confirmed these results and pointed out a similar pattern for women without a history of hormone therapy, while documenting no differences with respect to study location, smoking status, and menopausal status. Compared to the previous literature, our results, especially on subgroup analyses for postmenopausal status and BMI (overweight vs obese), are in line with the reported observations, yet provide original findings.

Coffee constituents have been associated with several biological mechanisms related to carcinogenesis, both in vitro and in vivo. These mechanisms include: DNA methylation, oxidative damage, activation of proto-oncogenes and inactivation of onco-suppressor genes, loss of apoptosis and growth control, and induction of angiogenesis [37, 38]. Active coffee constituents that have been identified include not only caffeine (mainly known for its ability to increase blood pressure and for its psychostimulatory and diuretic properties) [39], but also polyphenols (e.g., chlorogenic acids, which produce catechins, caffeic, ferulic and coumaric acids), lipids in the form of diterpenes (e.g., cafestol and kahweol), melanoidins, and trigonelline $[40,41]$. There is evidence that dietary polyphenols might be associated with decreased mortality and cancer risk, and may be the mediators of the potential effects of coffee on cancer prevention $[42,43]$.

With particular referral to female reproductive cancers, several mechanisms have been proposed: for instance, caffeine and coffee intake have been positively associated to sex hormone-binding globulin (SHBG) in postmenopausal women [44]. SHBG is the major carrier of estrogens and testosterone, thus lowering the circulating levels of free hormones; the positive relationship between coffee or caffeine intake and SHBG has been proved in many studies [45, 46]. Another possible mechanism resulting in lower levels of circulating estrogens after coffee intake is through the inhibition of the enzyme converting androgens into estrogens, i.e., CYP19 or aromatase [44]. A low level of estrogens is considered a protective factor against endometrial cancers acting through the down-regulation of endometrial proliferation [45], and the inverse association between coffee or caffeine consumption and estrogens has been widely documented $[47,48]$. 
Additional effects of coffee and caffeine intake on hormonal functions have been seen in improved insulin sensitivity as a result of the stimulation of insulin-mediated uptake of glucose [49]. Coffee could therefore have a protective role against type 2 diabetes development: most epidemiological studies have documented an inverse association between the intake of caffeinated coffee, decaffeinated coffee, and caffeine and type 2 diabetes in a dose-response manner compared with no or infrequent coffee consumption [50]. In turn, type 2 diabetes has been associated with an increased risk of endometrial cancer, and more specifically with an increased risk of type 1 endometrioid endometrial adenocarcinoma [51]. In recent epidemiological studies, such risk has been associated not only with insulin resistance and diabetes, but also with the metabolic syndrome that is characterized by the coexistence of various factors, such as abdominal obesity, low levels of high density lipoprotein, elevated levels of triglycerides and low levels of density lipoprotein, hypertension, and insulin resistance [52, 53].

As already pointed out, we observed a stronger association between coffee consumption and endometrial cancer in women with high BMI (above 30) compared with women with a BMI of 25 or lower. Overweight and obesity have been associated with the development of cancers [54], and various mechanisms have been proposed, including: (i) chronic inflammation and oxidative stress; (ii) cross-talk between tumor cells and surrounding adipocytes; (iii) migration of adipose stromal cells; (iv) obesity-induced hypoxia; (v) genetic susceptibility; and (vi) immunological dysfunctions [55]. In several studies, coffee intake has been inversely associated with metabolic syndrome [56-66]. Metabolic risk factors, such as obesity, impaired glucose tolerance, dyslipidemia, and hypertension have been linked to elevated systemic inflammation and oxidative stress. Thus, impaired metabolism may induce inflammation and oxidative stress, which in turn may lead to carcinogenic transformation. Within these pathways, four main components have been identified: insulin, insulin-like growth factor-I, sex steroids, and adipokines, and coffee consumption has been associated, directly or indirectly, with most of them [55]. For instance, an in vitro study showed that exposure to coffee reduced the accumulation of lipids inhibiting adipocytic differentiation [67]. In animal models, coffee consumption has been related to changes in transcription factors and lipogenesis-related proteins, and, in epidemiological studies, decreased body weight and decreased visceral fat, in relation to coffee consumption, have been observed [68].

The present meta-analysis has some limitations. First, despite we provided insights on underrated factors potentially affecting the association between coffee consumption and endometrial cancer risk, other variables (such as the type of coffee seeds, the roasting method, and the type of preparation) remained largely unexplored. Second, we cannot rule out the possibility of changes in dietary habits (i.e., increased or decreased consumption of coffee) over time, leading to the risk of reverse causation in the event that an individual changed coffee intake due to a newly diagnosed medical condition. 


\section{Conclusions}

In conclusions, our findings suggest that increased coffee consumption is associated with decreased risk of endometrial cancer, especially in postmenopausal, obese women.

\section{Supplementary Materials}

The following are available online at www.mdpi.com/2072-6643/9/11/1223/s1. 


\section{References}

1. Word Health Oranganization. Available online: http://globocan.iarc.fr/Default.aspx (accessed on 4 November 2017).

2. Forouzanfar, M.H.; Alexander, L.; Anderson, H.R.; Bachman, V.F.; Biryukov, S.; Brauer, M.; Burneet, R.; Casey, D.; Coates, M.M.; Cohen, A.; et al. Global, regional, and national comparative risk assessment of 79 behavioural, environmental and occupational, and metabolic risks or clusters of risks, 1990-2013: A systematic analysis for the global burden of disease study 2013. Lancet 2016, 388, 2287-2323. [CrossRef] 3. Grosso, G.; Bella, F.; Godos, J.; Sciacca, S.; Del Rio, D.; Ray, S.; Galvano, F.; Giovannucci, E. Possible role of diet in cancer: Systematic review and multiple meta-analyses of dietary patterns, lifestyle factors, and cancer risk. Nut. Rev. 2017, 75, 405-419. [CrossRef] [PubMed]

4. Lim, S.S.; Vos, T.; Flaxman, A.D.; Danaei, G.; Shibuya, K.; Adair-Rohani, H.; AlMazroa, M.A.; Amann, M.; Anderson, H.R.; Andrews, K.G.; et al. A comparative risk assessment of burden of disease and injury attributable to 67 risk factors and risk factor clusters in 21 regions, 1990-2010: A systematic analysis for the global burden of disease study 2010. Lancet 2012, 380, 2224-2260. [CrossRef]

5. Grosso, G.; Godos, J.; Galvano, F.; Giovannucci, E.L. Coffee, caffeine, and health outcomes: An umbrella review. Annu. Rev. Nutr. 2017, 37, 131-156. [CrossRef] [PubMed]

6. Grosso, G.; Micek, A.; Godos, J.; Sciacca, S.; Pajak, A.; Martinez-Gonzalez, M.A.; Giovannucci, E.L.;

Galvano, F. Coffee consumption and risk of all-cause, cardiovascular, and cancer mortality in smokers and non-smokers: A dose-response meta-analysis. Eur. J. Epidemiol. 2016, 31, 1191-1205. [CrossRef] [PubMed]

7. Marventano, S.; Salomone, F.; Godos, J.; Pluchinotta, F.; Del Rio, D.; Mistretta, A.; Grosso, G. Coffee and tea consumption in relation with non-alcoholic fatty liver and metabolic syndrome: A systematic review and meta-analysis of observational studies. Clin. Nutr. 2016, 35, 1269-1281. [CrossRef] [PubMed] 8. Godos, J.; Micek, A.; Marranzano, M.; Salomone, F.; Rio, D.D.; Ray, S. Coffee consumption and risk of biliary tract cancers and liver cancer: A dose-response meta-analysis of prospective cohort studies. Nutrition 2017, 9, 950. [CrossRef] [PubMed]

9. Liu, H.; Hu, G.H.; Wang, X.C.; Huang, T.B.; Xu, L.; Lai, P.; Guo, Z.F.; Xu, Y.F. Coffee consumption and prostate cancer risk: A meta-analysis of cohort studies. Nutr. Cancer 2015, 67, 392-400. [CrossRef] [PubMed]

10. Ran, H.Q.; Wang, J.Z.; Sun, C.Q. Coffee consumption and pancreatic cancer risk: An update metaanalysis of cohort studies. Pak. J. Med. Sci. 2016, 32, 253-259. [CrossRef] [PubMed]

11. Gan, Y.; Wu, J.; Zhang, S.; Li, L.; Cao, S.; Mkandawire, N.; Ji, K.; Herath, C.; Gao, C.; Xu, H.; et al. Association of coffee consumption with risk of colorectal cancer: A meta-analysis of prospective cohort studies. Oncotarget 2016, 8, 18699. [CrossRef] [PubMed]

12. Caprioli, G.; Cortese, M.; Sagratini, G.; Vittori, S. The influence of different types of preparation (espresso and brew) on coffee aroma and main bioactive constituents. Int. J. Food Sci. Nutr. 2015, 66, 505-513. [CrossRef] [PubMed]

13. Godos, J.; Pluchinotta, F.R.; Marventano, S.; Buscemi, S.; Li Volti, G.; Galvano, F.; Grosso, G. Coffee components and cardiovascular risk: Beneficial and detrimental effects. Int. J. Food Sci. Nutr. 2014, 65, 925-936. [CrossRef] [PubMed]

14. Je, Y.; Giovannucci, E. Coffee consumption and risk of endometrial cancer: Findings from a large upto-date meta-analysis. Int. J. Cancer 2012, 131, 1700-1710. [CrossRef] [PubMed]

15. Zhou, Q.; Luo, M.L.; Li, H.; Li, M.; Zhou, J.G. Coffee consumption and risk of endometrial cancer: A dose-response meta-analysis of prospective cohort studies. Sci. Rep. 2015, 5, 13410. [CrossRef] [PubMed] 16. Yang, T.O.; Crowe, F.; Cairns, B.J.; Reeves, G.K.; Beral, V. Tea and coffee and risk of endometrial cancer: Cohort study and meta-analysis. Am. J. Clin. Nutr. 2015, 101, 570-578. [CrossRef] [PubMed] 
17. Federation, E.C. Coffee Consumption in Europe. Available online: https://www.ecfcoffee.org/index.php (accessed on 4 November 2017).

18. Grigg, D. The worlds of tea and coffee: Patterns of consumption. GeoJournal 2002, 57, 283-294. [CrossRef]

19. Wang, A.;Wang, S.; Zhu, C.; Huang, H.;Wu, L.;Wan, X.; Yang, X.; Zhang, H.; Miao, R.; He, L.; et al. Coffee and cancer risk: A meta-analysis of prospective observational studies. Sci. Rep. 2016, 6, 33711. [CrossRef] [PubMed]

20. Stroup, D.F.; Berlin, J.A.; Morton, S.C.; Olkin, I.; Williamson, G.D.; Rennie, D.; Moher, D.; Becker, B.J.; Sipe, T.A.; Thacker, S.B. Meta-analysis of observational studies in epidemiology: A proposal for reporting. Meta-analysis of observational studies in epidemiology (moose) group. JAMA 2000, 283, 20082012. [CrossRef] [PubMed]

21. Wells, G.A.; Shea, B.; O’Connell, D.; Peterson, J.; Welch, V.; Losos, M.; Tugwell, P. The NewcastleOttawa Scale (nos) for Assessing the Quality of Nonrandomised Studies in Meta-Analyses; Ottawa Health Research Institute: Ottawa, ON, Canada, 1999.

22. Greenland, S. Quantitative methods in the review of epidemiologic literature. Epidemiol. Rev. 1987, 9, 1-30. [CrossRef] [PubMed]

23. Greenland, S.; Longnecker, M.P. Methods for trend estimation from summarized dose-response data, with applications to meta-analysis. Am. J. Epidemiol. 1992, 135, 1301-1309. [CrossRef] [PubMed] 24. Orsini, N.B.R.; Greenland, S. Generalized least squares for trend estimation of summarized doseresponse data. Stata J. 2006, 6, 40-57.

25. Orsini, N.; Li, R.; Wolk, A.; Khudyakov, P.; Spiegelman, D. Meta-analysis for linear and nonlinear dose-response relations: Examples, an evaluation of approximations, and software. Am. J. Epidemiol. 2012, 175, 66-73. [CrossRef] [PubMed]

26. Friberg, E.; Orsini, N.; Mantzoros, C.S.; Wolk, A. Coffee drinking and risk of endometrial cancer-A population-based cohort study. Int. J. Cancer 2009, 125, 2413-2417. [CrossRef] [PubMed]

27. Gavrilyuk, O.; Braaten, T.; Skeie, G.;Weiderpass, E.; Dumeaux, V.; Lund, E. High coffee consumption and different brewing methods in relation to postmenopausal endometrial cancer risk in the Norwegian women and cancer study: A population-based prospective study. BMC Women's Health 2014, 14, 48. [CrossRef] [PubMed]

28. Giri, A.; Sturgeon, S.R.; Luisi, N.; Bertone-Johnson, E.; Balasubramanian, R.; Reeves, K.W.

Caffeinated coffee, decaffeinated coffee and endometrial cancer risk: A prospective cohort study among us postmenopausal women. Nutrition 2011, 3, 937-950. [CrossRef] [PubMed]

29. Gunter, M.J.; Schaub, J.A.; Xue, X.; Freedman, N.D.; Gaudet, M.M.; Rohan, T.E.; Hollenbeck, A.R.; Sinha, R. A prospective investigation of coffee drinking and endometrial cancer incidence. Int. J. Cancer 2012, 131, E530-E536. [CrossRef] [PubMed]

30. Hashibe, M.; Galeone, C.; Buys, S.S.; Gren, L.; Boffetta, P.; Zhang, Z.F.; La Vecchia, C. Coffee, tea, caffeine intake, and the risk of cancer in the plco cohort. Br. J. Cancer 2015, 113, 809-816. [CrossRef] [PubMed]

31. Je, Y.; Hankinson, S.E.; Tworoger, S.S.; De Vivo, I.; Giovannucci, E. A prospective cohort study of coffee consumption and risk of endometrial cancer over a 26-year follow-up. Cancer Epidemiol.

Biomark. Prev. 2011, 20, 2487-2495. [CrossRef] [PubMed]

32. Merritt, M.A.; Tzoulaki, I.; Tworoger, S.S.; De Vivo, I.; Hankinson, S.E.; Fernandes, J.; Tsilidis, K.K.; Weiderpass, E.; Tjonneland, A.; Petersen, K.E.; et al. Investigation of dietary factors and endometrial cancer risk using a nutrient-wide association study approach in the epic and nurses' health study (NHS) and NHSII. Cancer Epidemiol. Biomark. Prev. 2015, 24, 466-471. [CrossRef] [PubMed] 
33. Nilsson, L.M.; Johansson, I.; Lenner, P.; Lindahl, B.; Van Guelpen, B. Consumption of filtered and boiled coffee and the risk of incident cancer: A prospective cohort study. Cancer Causes Control 2010, 21, 1533-1544. [CrossRef] [PubMed]

34. Shimazu, T.; Inoue, M.; Sasazuki, S.; Iwasaki, M.; Kurahashi, N.; Yamaji, T.; Tsugane, S.; JPHC Study Group Members of the Japan Public Health Center-based Prospective Study. Coffee consumption and risk of endometrial cancer: A prospective study in Japan. Int. J. Cancer 2008, 123, 2406-2410. [CrossRef] [PubMed]

35. Uccella, S.; Mariani, A.; Wang, A.H.; Vierkant, R.A.; Cliby, W.A.; Robien, K.; Anderson, K.E.; Cerhan, J.R. Intake of coffee, caffeine and other methylxanthines and risk of Type I vs. Type II endometrial cancer. Br. J. Cancer 2013, 109, 1908-1913. [CrossRef] [PubMed] 36. Weiderpass, E.; Sandin, S.; Lof, M.; Oh, J.K.; Inoue, M.; Shimazu, T.; Tsugane, S.; Adami, H.O. Endometrial cancer in relation to coffee, tea, and caffeine consumption: A prospective cohort study among middle-aged women in Sweden. Nutr. Cancer 2014, 66, 1132-1143. [CrossRef] [PubMed] 37. Bohn, S.K.; Blomhoff, R.; Paur, I. Coffee and cancer risk, epidemiological evidence, and molecular mechanisms. Mol. Nutr. Res. 2014, 58, 915. [CrossRef] [PubMed]

38. Boettler, U.; Sommerfeld, K.; Volz, N.; Pahlke, G.; Teller, N.; Somoza, V.; Lang, R.; Hofmann, T.; Marko, D. Coffee constituents as modulators of Nrf2 nuclear translocation and ARE (EpRE)-dependent gene expression. J. Nutr. Biochem. 2011, 22, 426-440. [CrossRef] [PubMed]

39. Gaascht, F.; Dicato, M.; Diederich, M. Coffee provides a natural multitarget pharmacopeia against the hallmarks of cancer. Genes Nutr. 2015, 10, 51. [CrossRef] [PubMed]

40. Niseteo, T.; Komes, D.; Belš̌cak-Cvitanovi'c, A.; Horžíc, D.; Bude $c$, M. Bioactive composition and antioxidant potential of different commonly consumed coffee brews affected by their preparation technique and milk addition. Food Chem. 2012, 134, 1870-1877. [CrossRef] [PubMed]

41. Liang, N.; Kitts, D.D. Antioxidant property of coffee components: Assessment of methods that define mechanisms of action. Molecules 2014, 19, 19180. [CrossRef] [PubMed]

42. Grosso, G.; Godos, J.; Lamuela-Raventos, R.; Ray, S.; Micek, A.; Pajak, A.; Sciacca, S.; D’Orazio, N.;

Del Rio, D.; Galvano, F. A comprehensive meta-analysis on dietary flavonoid and lignan intake and cancer risk: Level of evidence and limitations. Mol. Nutr. Food Res. 2017, 61, 1600930. [CrossRef] [PubMed]

43. Grosso, G.; Micek, A.; Godos, J.; Pajak, A.; Sciacca, S.; Galvano, F.; Giovannucci, E.L. Dietary flavonoid and lignan intake and mortality in prospective cohort studies: Systematic review and doseresponse meta-analysis. Am. J. Epidemiol. 2017, 185, 1304-1316. [CrossRef] [PubMed]

44. Kotsopoulos, J.; Eliassen, A.H.; Missmer, S.A.; Hankinson, S.E.; Tworoger, S.S. Relationship between caffeine intake and plasma sex hormone concentrations in premenopausal and postmenopausal women. Cancer 2009, 115, 2765-2774. [CrossRef] [PubMed]

45. Ferrini, R.L.; Barrett-Connor, E. Caffeine intake and endogenous sex steroid levels in postmenopausal women. The rancho bernardo study. Am. J. Epidemiol. 1996, 144, 642-644. [CrossRef] [PubMed]

46. Nagata, C.; Kabuto, M.; Shimizu, H. Association of coffee, green tea, and caffeine intakes with serum concentrations of estradiol and sex hormone-binding globulin in premenopausal Japanese women. Nutr. Cancer 1998, 30, 21. [CrossRef] [PubMed]

47. Fung, T.T.; Schulze, M.B.; Hu, F.B.; Hankinson, S.E.; Holmes, M.D. A dietary pattern derived to correlate with estrogens and risk of postmenopausal breast cancer. Breast Cancer Res. Treat. 2012, 132, 1157. [CrossRef] [PubMed]

48. Sisti, J.S.; Hankinson, S.E.; Caporaso, N.E.; Gu, F.; Tamimi, R.M.; Rosner, B.; Xu, X.; Ziegler, R.; Eliassen, A.H. Caffeine, coffee, and tea intake and urinary estrogens and estrogen metabolites in premenopausal women. Cancer Epidemiol. Biomark. Prev. 2015, 24, 1174. [CrossRef] [PubMed] 
49. Akash, M.S.; Rehman, K.; Chen, S. Effects of coffee on type 2 diabetes mellitus. Nutrition 2014, 30, 755. [CrossRef] [PubMed]

50. Ortega, Á.; Berná, G.; Rojas, A.; Martín, F.; Soria, B. Gene-diet interactions in type 2 diabetes: The chicken and egg debate. Int. J. Mol. Sci. 2017, 18, 1188. [CrossRef] [PubMed]

51. Lees, B.; Leath, C.A. The impact of diabetes on gynecologic cancer: Current status and future directions. Curr. Obstet. Gynecol. Rep. 2015, 4, 234-239. [CrossRef] [PubMed]

52. Alicandro, G.; Tavani, A.; La Vecchia, C. Coffee and cancer risk: A summary overview. Eur. J. Cancer Prev. 2017, 26, 424-432. [CrossRef] [PubMed]

53. Stocks, T.; Bjorge, T.; Ulmer, H.; Manjer, J.; Haggstrom, C.; Nagel, G.; Engeland, A.; Johansen, D.; Hallmans, G.; Selmer, R.; et al. Metabolic risk score and cancer risk: Pooled analysis of seven cohorts. Int. J. Epidemiol. 2015, 44, 1353-1363. [CrossRef] [PubMed]

54. Renehan, A.G.; Tyson, M.; Egger, M.; Heller, R.F.; Zwahlen, M. Body-mass index and incidence of cancer: A systematic review and meta-analysis of prospective observational studies. Lancet 2008, 371, 569-578. [CrossRef]

55. De Pergola, G.; Silvestris, F. Obesity as a major risk factor for cancer. J. Obes. 2013, 2013, 291546. [CrossRef] [PubMed]

56. Dos Santos, P.R.; Ferrari, G.S.; Ferrari, C.K. Diet, sleep and metabolic syndrome among a legal amazon population, Brazil. Clin. Nutr. Res. 2015, 4, 41-45. [CrossRef] [PubMed]

57. Driessen, M.T.; Koppes, L.L.; Veldhuis, L.; Samoocha, D.; Twisk, J.W. Coffee consumption is not related to the metabolic syndrome at the age of 36 years: The amsterdam growth and health longitudinal study. Eur. J. Clin. Nutr. 2009, 63, 536-542. [CrossRef] [PubMed]

58. Chang, C.S.; Chang, Y.F.; Liu, P.Y.; Chen, C.Y.; Tsai, Y.S.; Wu, C.H. Smoking, habitual tea drinking and metabolic syndrome in elderly men living in rural community: The tianliao old people (TOP) study 02. PLoS ONE 2012, 7, e38874. [CrossRef] [PubMed]

59. Grosso, G.; Marventano, S.; Galvano, F.; Pajak, A.; Mistretta, A. Factors associated with metabolic syndrome in a mediterranean population: Role of caffeinated beverages. J. Epidemiol. 2014, 24, 327-333. [CrossRef] [PubMed]

60. Grosso, G.; Stepaniak, U.; Micek, A.; Topor-Madry, R.; Pikhart, H.; Szafraniec, K.; Pajak, A.

Association of daily coffee and tea consumption and metabolic syndrome: Results from the polish arm of the hapiee study. Eur. J. Nutr. 2015, 54, 1129-1137. [CrossRef] [PubMed]

61. Lutsey, P.L.; Steffen, L.M.; Stevens, J. Dietary intake and the development of the metabolic syndrome: The atherosclerosis risk in communities studies. Circulation 2008, 117, 754-761. [CrossRef] [PubMed]

62. Matsuura, H.; Mure, K.; Nishio, N.; Kitano, N.; Nagai, N.; Takeshita, T. Relationship between coffee consumption and prevalence of metabolic syndrome among Japanese civil servants. J. Epidemiol. 2012, 22, 160-166. [CrossRef] [PubMed]

63. Nordestgaard, A.T.; Thomsen, M.; Nordestgaard, B.G. Coffee intake and risk of obesity, metabolic syndrome and type 2 diabetes: A Mendelian randomization study. Int. J. Epidemiol. 2015, 44, 551-565. [CrossRef] [PubMed]

64. Takami, H.; Nakamoto, M.; Uemura, H.; Katsuura, S.; Yamaguchi, M.; Hiyoshi, M.; Sawachika, F.; Juta, T.; Arisawa, K. Inverse correlation between coffee consumption and prevalence of metabolic syndrome: Baseline survey of the japan multi-institutional collaborative cohort (J-micc) study in Tokushima, Japan. J. Epidemiol. 2013, 23, 12-20. [CrossRef] [PubMed]

65. Suliga, E.; Koziel, D.; Ciesla, E.; Rebak, D.; Gluszek, S. Coffee consumption and the occurrence and intensity of metabolic syndrome: A cross-sectional study. Int. J. Sci. Nutr. 2016, 68, 507-513. [CrossRef] [PubMed] 
66. Micek, A.; Grosso, G.; Polak, M.; Kozakiewicz, K.; Tykarski, A.; Puch Walczak, A.; Drygas, W.; Kwasniewska, M.; Pajak, A. Association between tea and coffee consumption and prevalence of metabolic syndrome in Poland-Results from the WOBASZ II study (2013-2014). Int. J. Food Sci. Nutr. 2017, 1-11. [CrossRef] [PubMed]

67. Aoyagi, R.; Funakoshi-Tago, M.; Fujiwara, Y.; Tamura, H. Coffee inhibits adipocyte differentiation via inactivation of ppar. Biol. Pharm. Bull. 2014, 37, 1820-1825. [CrossRef] [PubMed]

68. Kearney, J.M.; Kearney, M.J.; McElhone, S.; Gibney, M.J. Methods used to conduct the pan-

European Union survey on consumer attitudes to physical activity, body weight and health. Public Health Nutr. 1999, 2, 79-86. [CrossRef] [PubMed] 



\section{Coffee intake decreases risk of postmenopausal breast cancer: a dose-response meta-analysis on prospective cohort studies}

Published as:

Alessandra Lafranconi, Agnieszka Micek, Paolo De Paoli, Sabrina Bimonte, Paola Rossi, Vincenzo Quagliariello and Massimiliano Berretta (2018) Coffee Intake Decreases Risk of Postmenopausal Breast Cancer: A Dose-Response MetaAnalysis on Prospective Cohort Studies Nutrients, 10(2):112; doi:10.3390/nu10020112 [IF (2018): 2,36]

Acknowledgements:

This study has been supported by the "Ricerca Corrente of the Italian Ministry of Health 2016, Line 4-Solid Tumors, Translational research improves diagnosis \& care". The work of Alessandra Lafranconi is partially supported by a Jean Monnet Erasmus + grant (574376-EPP-1-2016-1-IT-EPPJMO-MODULE).

Author Contributions:

A.L. A.M. and M.B. conceived the study; A.L. wrote introduction and discussion in consultation with P.D.P, S.B., P.R., V.Q. and M.B.; A.M. carried out the statistical analysis and wrote methods and results.

Conflict of interest:

The authors declare no conflict of interest. 



\section{Abstract}

Aim: A dose-response meta-analysis was conducted in order to summarize the evidence from prospective cohort studies regarding the association between coffee intake and breast cancer risk.

Methods: A systematic search was performed in electronic databases up to March 2017 to identify relevant studies; risk estimates were retrieved from the studies, and linear and non-linear dose-response analysis modelled by restricted cubic splines was conducted. A stratified and subgroup analysis by menopausal and ER/PR receptor status, smoking status and BMI were performed in order to detect potential confounders.

Results: A total of 21 prospective studies were selected either for dose-response, the highest versus lowest category of consumption or subgroup analysis. The dose-response analysis of 13 prospective studies showed no significant association between coffee consumption and breast cancer risk in the non-linear model. However, an inverse relationship has been found when the analysis was restricted to post-menopausal women. Consumption of four cups of coffee per day was associated with a $10 \%$ reduction in postmenopausal cancer risk (RR $0.90 ; 95 \%$ CI 0.82 to 0.99). Subgroup analyses showed consistent results for all potential confounding factors examined.

Conclusions: Findings from this meta-analysis may support the hypothesis that coffee consumption is associated with decreased risk of postmenopausal breast cancer.

Keywords: coffee; caffeine; breast cancer; receptor; postmenopausal; dose-response; metaanalysis. 


\section{Introduction}

Breast cancer is the most frequently diagnosed cancer and among the leading causes of cancer death among females (1-3). Worldwide and European estimates of women with a diagnosis of breast cancer occurring in the last 5 years were over 6.2 and 1.8 million, respectively, in 2012 (4). Significant improvements in early diagnosis and treatment have led to decreased mortality in the last two decades $(5,6)$. However, evaluating potential risk factors and improving preventive actions is needed in order to decrease the global burden of such disease.

A recent summary of scientific literature provided insightful the evidence of the potential benefits of coffee on human health (7). Most of evidence relied on observational prospective cohort studies, suggesting that moderate-to-high coffee can be overall associated with lower risk of all-cause, cardiovascular and cancer mortality compared to lower consumption (8). These protective effects are likely to be mediated by coffee active compounds, including, but not limited to, coffee polyphenols, which have been shown to have anti-diabetic, anti-carcinogenic, anti-inflammatory and anti-obesity properties (9-11). Among others, coffee consumption has been hypothesized to affect the risk of female cancers (breast, endometrial and ovarian cancers), and particularity the risk of breast cancer in post-menopausal women. A recent analysis of dietary patterns of women participating in the Nurses' Health Study II pointed out that a low intake of green leafy vegetables, cruciferous vegetables and coffee during adolescence and early adulthood may increase the incidence of premenopausal breast cancer, thus posing the basis for further research on long-term associations and cumulative effects (12).

Previous quantitative evidence syntheses on breast cancer risk often reported contrasting results, either when assessing the risk estimates for extreme categories of consumption and in a doseresponse manner (13-17). For instance, the meta-analysis carried out by $\mathrm{Li}$ and colleagues, on 16 cohort and 10 case-control studies, found a borderline significant association (RR: 0.96; 95\% CI: 0.93-1.00) when comparing highest versus lowest coffee consumption; results limited to cohort studies were not significant. Interestingly, a significant inverse association between coffee drinking and breast cancer risk was documented in women without estrogen receptor (ERnegative subgroup) (18). Similarly, Jiang and colleagues analysed 20 case-control and 17 cohort studies, and reported a borderline association with breast cancer risk of the highest coffee consumption category compared to the lowest (RR: 0.97; 95\% CI: 0.93-1.00); yet, a significant inverse association was present in postmenopausal women and in women with BRCA1 mutations (the latter being highlighted as strong association) (19). Therefore, coffee consumption might have a protective role for specific subgroups of individuals (i.e., based on receptor and menopausal status) $(18,19)$; yet, some conclusions were drafted considering results of both case-control and prospective studies, while evidence should be evaluated based on the latter. Thus, the aim of this study was to update current evidence on the association between coffee consumption and risk of breast cancers, analysing results obtained from prospective studies only, in order to summarize the evidence and provide new insights on potential effect modification of putative confounding factors. 


\section{Methods}

We followed Meta-Analysis of Observational Studies in Epidemiology (MOOSE) protocols throughout preparing background, search strategy, methods and reporting the results, discussion, and conclusion of meta-analysis (Supplementary Table 1).

\section{Search strategy}

Articles were retrieved by searching two different electronic databases (PubMed (http://www.ncbi.nlm.nih.gov/pubmed/) and EMBASE (http://www.embase.com/) and were limited to publications in English language between the earliest available online indexing year and March 2017. The following search strategy based on the conjunction of the three terms: (i) coffee OR caffeine OR beverages AND (ii) breast AND (iii) cancer OR carcinoma OR neoplasm (Supplementary Table 2) was adopted. Titles and abstracts of all identified studies were independently reviewed by two authors. Based on recent guidelines proposed to draft the highest level of evidence in nutritional science (20), eligibility criteria for study inclusion in the metaanalysis were based on the following criteria: 1) a prospective design; 2) coffee consumption as the exposure of interest 3) incidence of breast cancer as the outcome; 4) the measure of association (relative risk or hazard ratio) with 95\% confidence interval provided for 3 or more quantitative categories of coffee consumption. Hand searching the reference lists of obtained manuscripts was also performed to find additional studies not previously detected. In the case of duplicated published cohorts, the one with the largest number of cases/entire cohort or with the longest follow-up for endpoint of interest was included.

\section{Data extraction}

Using a standardized extraction form, data were abstracted from all identified studies. The following information was obtained from each article: 1) first author name; 2) year of publication; 3) study cohort name; 4) country; 5) sex of participants; 6) age range of the study population at baseline; 7) categories of coffee consumption; 8) type of coffee; 9) follow-up period; 10) distribution of cases and person-years/number of participants, across categories of exposure; 11) relative risks or hazard ratios, with $95 \%$ CIs for all categories of exposure 13) covariates used in adjustments. Extraction of data was conducted independently by two authors. Discrepancies were resolved through a consensus discussion, The Newcastle-Ottawa Quality Assessment Scale was used to assess the quality of included studies (21).

\section{Statistical analysis}

For the purpose of this meta-analysis, relative risks (RRs) or hazard ratios (HRs) with 95\% confidence intervals (CIs) for all categories of coffee consumption were extracted based on the most fully adjusted models. Pooled effects were assessed by random-effect meta-analyses in which RRs and HRs were treated as equivalent measure of risk (22) and the term of the relative risk refer to both of them. Heterogeneity was assessed using $\mathrm{I}^{2}$ statistic and the Cochran's Q test. The $\mathrm{I}^{2}$ statistic represented the amount of total variation that could be attributed to heterogeneity and its values $\leq 25 \%, 25-50 \%, 50-75 \%$, and $>75 \%$ indicated no, small, moderate, and significant 
heterogeneity, respectively. The P values of $\mathrm{Q}$ test of less than 0.1 were accepted as statistically significant. The relationship between coffee consumption and risk of breast cancer was firstly determined by highest versus lowest analysis. The stability of the results was assessed through a sensitivity analysis in which one study at a time was excluded. Potential confounders or effect modifiers and sources of heterogeneity were verified in subgroup analysis and publication bias was tested visually by detecting asymmetry of funnel plots.

Based on retrieved data (amount of exposure, distributions of cases and person-years or number of participants, and RRs/HRs with 95\% CIs) for each category (at least three) of coffee consumption, a dose-response meta-analysis was performed. Within the studies, the mean or median intake, alternatively the midpoint of the range of intake of coffee consumption was assigned to the corresponding RR/HR with the 95\% CI. Right-unbounded highest categories of exposure were assumed to have the same width as the adjacent one. Both linear and non-linear dose-response relationship between coffee intake and risk of total and postmenopausal breast cancer was assessed by random-effect meta-analysis performed in two stages. In the first stage, the generalized least-squares (GLS) method reported by Greenland and Orsini was implemented and study-specific coefficients were calculated based on retrieved data across categories of coffee consumption and taking into account the intraclass (within study) correlation of RRs/HRs (23, 24). Non-linear dose-response analysis was modelled by restricted cubic splines with 3 knots at fixed percentiles $(25 \%, 50 \%$, and $75 \%)$ of the distribution (25). In the second step of the randomeffect meta-analysis summary statistics from each study were combined. The between-study variance in linear dose-response meta-analysis and the between-study covariance matrice in nonlinear dose-response meta-analysis was assessed by DerSimonian and Laird estimator or multivariate extension of the method of moments, respectively. P-value for non-linearity was calculated by testing the value of the coefficient of the second spline of zero. All analyses were performed with $\mathrm{R}$ software version 3.0.3, to conduct dose-response meta-analysis the package dosresmeta was used (Development Core Team, Vienna, Austria).

\section{Results}

\section{Study characteristics}

The systematic search identified 1,724 studies, of which 1,533 were excluded after reviewing the title, and 162 after reviewing the abstract (Figure 1). Of the 29 publications selected for evaluation of full-text article, 8 were excluded for the following reasons: 1) article did not provide risk with confidence intervals; 2) article did not have prospective design; 3) article provided data only on genetic polymorphism; 4) article did not provide data for general population.

For the meta-analysis on the association between coffee consumption and breast cancer risk 21 studies were eligible (26-46). Several cohorts, namely VIP, NOWAC, E3N and EPIC-NL (26, $29,40,42)$ were excluded from the main analysis, as part of theirs cases are included in the multicentre study EPIC (27). However, an alternative analysis was performed by including these cohorts and excluding EPIC study. Two articles were used only for subgroup analysis $(33,41)$. 
Studies eligible for the main analysis comprised 1,068,098 participants and 36,597 breast cancer cases. Selected characteristics of the studies included in the meta-analysis are described in Table 1. Eight studies provided relative risk for postmenopausal $(27,28,30,31,33,37,43,45)$ and for premenopausal status $(27,28,32,37,41,43,45,46)$. Seven studies were conducted in North America (28, 30-32, 34, 37, 46), 6 in Europe (27, 35, 36, 39, 43, 45), and 2 in Asia (38, 44). The follow-up in prospective cohort studies ranged from about 5 to 26 years.

Table 1. Selected characteristics of the studies included in the meta-analysis.

\begin{tabular}{|c|c|c|c|c|}
\hline $\begin{array}{c}\text { Author, } \\
\text { year }\end{array}$ & $\begin{array}{l}\text { Cohort name, } \\
\text { country }\end{array}$ & $\begin{array}{l}\text { Years of } \\
\text { study, } \\
\text { follow-up }\end{array}$ & $\begin{array}{c}\text { Cases; } \\
\text { total } \\
\text { population }\end{array}$ & Adjustments \\
\hline $\begin{array}{l}\text { Vatten, } \\
1990\end{array}$ & $\begin{array}{l}\text { National Health Screening } \\
\text { Service, Norway }\end{array}$ & $\begin{array}{l}\text { 1974-NR, } 12 \\
y \text { (mean) }\end{array}$ & $\begin{array}{c}155 \\
14,593\end{array}$ & Age. \\
\hline $\begin{array}{l}\text { Hoyer, } \\
1992\end{array}$ & $\begin{array}{l}\text { The Glostrup Population } \\
\text { Studies, Denmark }\end{array}$ & $\begin{array}{l}1964-1990 \\
26 y(\max )\end{array}$ & $51 ; 5,207$ & $\begin{array}{l}\text { Social class, age at menarche, menopause status, number of full-term pregnancies, } \\
\text { height, weight, BMI, alcohol, smoking. }\end{array}$ \\
\hline $\begin{array}{l}\text { Folsom, } \\
1993\end{array}$ & $\begin{array}{l}\text { lowa Women's Health Study, } \\
\text { USA }\end{array}$ & $\begin{array}{l}\text { 1986-1990, } \\
5 y\end{array}$ & $\begin{array}{c}580 ; \\
34,388\end{array}$ & $\begin{array}{l}\text { Age, waist/hip ratio, number of live births, age at first live birth, age at menarche, } \\
\text { FHBC, family history } \times \text { waist/hip ratio, and family history } \times \text { number of live births. }\end{array}$ \\
\hline $\begin{array}{l}\text { Key, } \\
1999\end{array}$ & $\begin{array}{l}\text { The Radiation Effects } \\
\text { Research Foundation's Life } \\
\text { Span Study, Japan }\end{array}$ & $\begin{array}{l}1969-1993 \\
24 \text { y }(\max )\end{array}$ & $\begin{array}{c}427 \\
34,759\end{array}$ & Age, calendar period, city, age at time of bombings, radiation dose. \\
\hline $\begin{array}{l}\text { Michels, } \\
2002\end{array}$ & $\begin{array}{l}\text { Swedish Mammography } \\
\text { Cohort, Sweden }\end{array}$ & $\begin{array}{l}\text { 1987-1997, } \\
9.5 y\end{array}$ & $\begin{array}{l}1,271 \\
59,036\end{array}$ & $\begin{array}{l}\text { Age, family history of breast cancer, height, BMI, education, parity, age at first birth, } \\
\text { alcohol consumption, total caloric intake. }\end{array}$ \\
\hline $\begin{array}{l}\text { Suzuki, } \\
2004\end{array}$ & Cohort I - Cohort II, Japan & $\begin{array}{l}\text { 1984-NR } \\
\text { Cohortl, 9y; } \\
\text { 1990-NR } \\
\text { Cohortll, } 7 \text { y }\end{array}$ & $\begin{array}{l}\text { Cohortl: } \\
\text { 103; 8,799; } \\
\text { Cohort II: } \\
119 ; \\
11,288\end{array}$ & $\begin{array}{l}\text { Age, types of health insurance, age at menarche, menopausal status, age at first birth, } \\
\text { parity, mother's history of breast cancer, smoking, alcohol drinking, BMI, consumption } \\
\text { frequencies of black tea. }\end{array}$ \\
\hline $\begin{array}{l}\text { Hirvonen, } \\
2006\end{array}$ & $\begin{array}{c}\text { Supplementation en } \\
\text { Vitamines et Mineraux } \\
\text { Antioxydants (SU.VI.MAX), } \\
\text { France }\end{array}$ & $\begin{array}{l}\text { 1994-2002, } \\
\text { 6.6 y } \\
\text { (median) }\end{array}$ & $95 ; 4,396$ & $\begin{array}{l}\text { Age, smoking, number of children, use of oral contraception, family history of breast } \\
\text { cancer, menopausal status. }\end{array}$ \\
\hline
\end{tabular}

Ganmaa, National Health Service I, 1976-2002， 5,272;

$2008 \quad$ USA 22 y $\quad 85,987$

Ishitani, 2008

Women's Health Study, USA

1992-2004, 1,188; $10 \mathrm{y}$ (avg)

38,432

\begin{tabular}{|c|c|c|c|}
\hline $\begin{array}{l}\text { Larsson, } \\
2009\end{array}$ & $\begin{array}{l}\text { Swedish Mammography } \\
\text { Cohort(SMC), Sweden }\end{array}$ & $\begin{array}{c}1987-2007, \\
17.4 y \\
\text { (mean) }\end{array}$ & $\begin{array}{l}2,952 \\
61,433\end{array}$ \\
\hline $\begin{array}{l}\text { Wilson, } \\
2009\end{array}$ & $\begin{array}{c}\text { National Health Service II, } \\
\text { USA }\end{array}$ & $\begin{array}{c}1991-2005, \\
14 y\end{array}$ & $\begin{array}{l}1,179 \\
90,628\end{array}$ \\
\hline $\begin{array}{l}\text { Bhoo-Pathy, } \\
2010\end{array}$ & $\begin{array}{l}\text { European Prospective } \\
\text { Investigation into Cancer } \\
\text { and Nutrition (EPIC-NL), }\end{array}$ & $\begin{array}{c}\text { 1993-2007, } \\
9.6 \text { y (avg) }\end{array}$ & $\begin{array}{c}681 \\
27,323\end{array}$ \\
\hline
\end{tabular}

Age months, smoking status, BMI, physical activity, height, alcohol intake, family history of breast cancer in mother or a sister, history of benign breast disease, menopausal status, age at menopause, use of hormone therapy, age at menarche, parity and age at first birth, weight change after 18 , duration of postmenopausal hormone use, tea intake.

Age, randomized treatment assignment, BMI, physical activity, total energy intake, alcohol intake, multivitamin use, age at menopause, age at menarche, age at first pregnancy lasting $\geq 6$ months, number of pregnancies lasting $\geq 6$ months, menopausal status, postmenopausal hormone use, prior hysterectomy, prior bilateral oophorectomy, smoking status, family history of breast cancer in mother or a sister, history of benign breast disease.

Age, education, BMI, height, parity, age at first birth, age at menarche, age at menopause, use of oral contraceptives, use of postmenopausal hormones, family history of breast cancer, and intakes of total energy, alcohol and tea.

$\mathrm{BMI}$, height, $\mathrm{OC}$ use, parity and age at first birth, age at menarche, family history of breast cancer, history of benign breast disease, smoking, physical activity, animal fat, glycemic load, alcohol and energy.

Age, smoking status, educational status, BMI, alcohol intake, energy intake, energyadjusted saturated fat intake, energy-adjusted fiber intake, tea intake, physical activity level, ever prior use of oral contraceptives, presence of hypercholesterolemia, family history of breast cancer, age at menarche, parity, and cohort. 


\begin{tabular}{|c|c|c|c|c|}
\hline $\begin{array}{l}\text { Boggs, } \\
2010\end{array}$ & $\begin{array}{c}\text { Black Women's Health } \\
\text { Study, USA }\end{array}$ & $\begin{array}{c}1995-2007 \\
12 y\end{array}$ & $\begin{array}{l}1,268 \\
52,062\end{array}$ & $\begin{array}{l}\text { education, geographic region, parity, age at first birth, oral contraceptive use, } \\
\text { menopausal status, age at menopause, female hormone use, vigorous activity, } \\
\text { smoking status, alcohol intake. }\end{array}$ \\
\hline $\begin{array}{l}\text { Nilsson, } \\
2010\end{array}$ & $\begin{array}{l}\text { Västerbotten Intervention } \\
\text { Programme (VIP), Sweden }\end{array}$ & $\begin{array}{c}1992-2007, \\
15 y(\max )\end{array}$ & $\begin{array}{c}587 \\
32,178\end{array}$ & Age, sex, BMI, smoking, education, recreational physical activity. \\
\hline $\begin{array}{l}\text { Fagherazzi, } \\
2011\end{array}$ & $\begin{array}{l}\text { Etude Epidémiologique } \\
\text { auprès de femmes de } \\
\text { l'Education Nationale (E3N), } \\
\text { France }\end{array}$ & $\begin{array}{l}\text { 1993-2005, } \\
11 \text { y } \\
\text { (median) }\end{array}$ & $\begin{array}{l}2,868 \\
67,703\end{array}$ & $\begin{array}{l}\text { Age, total energy intake, ever use of oral contraceptives, age at menarche, age at } \\
\text { menopause, number of children, age at first pregnancy, history of breast cancer in the } \\
\text { family and years of schooling, current use of postmenopausal hormone therapy (for } \\
\text { postmenopausal women only), personal history of benign breast disease, menopausal } \\
\text { status, BMI. }\end{array}$ \\
\hline $\begin{array}{l}\text { Gierach, } \\
2012\end{array}$ & $\begin{array}{l}\text { NIH-AARP Diet and Health } \\
\text { Cohort Study, USA }\end{array}$ & $\begin{array}{c}1995-2006, \\
9.8 \text { y (avg) }\end{array}$ & $\begin{array}{c}9,915 \\
198,404\end{array}$ & $\begin{array}{l}\text { Age, race/ethnicity, education, BMI, smoking status and dose, alcohol, proportion of } \\
\text { total energy from fat, age at first live birth, menopausal hormone therapy use, history } \\
\text { of breast biopsy, family history of breast cancer. }\end{array}$ \\
\hline & European Prospective & & & Age at menarche, ever use of oral contraceptives, age at first delivery, ever \\
\hline $\begin{array}{l}\text { Bhoo-Pathy, } \\
2015\end{array}$ & $\begin{array}{l}\text { Investigation into Cancer } \\
\text { and Nutrition (EPIC), } \\
\text { Multicenter }\end{array}$ & $\begin{array}{c}1992-2010 \\
11 \text { y (avg) }\end{array}$ & $\begin{array}{l}10,198 \\
335,060\end{array}$ & $\begin{array}{l}\text { breastfeeding, smoking status, educational level, physical activity level, alcohol intake, } \\
\text { height, weight, energy intake from fat source, energy intake from non-fat source, total } \\
\text { saturated fat intake, total fiber intake, ever-use of postmenopausal hormones. } \\
\text { Age, energy intake, height, BMI, education, oral contraceptive use, hormone }\end{array}$ \\
\hline $\begin{array}{l}\text { Harris, } \\
2015\end{array}$ & $\begin{array}{l}\text { Swedish Mammography } \\
\text { Cohort(SMC), Sweden }\end{array}$ & $\begin{array}{c}1987-2012 \\
15 y\end{array}$ & $\begin{array}{l}1,603 \\
37,004\end{array}$ & $\begin{array}{l}\text { replacement therapy use, age at menarche, age at menopause, family history of breast } \\
\text { cancer, history of benign breast disease, smoking status, physical activity, alcohol } \\
\text { intake. }\end{array}$ \\
\hline $\begin{array}{l}\text { Hashibe, } \\
2015\end{array}$ & $\begin{array}{l}\text { Prostate, Lung, Colorectal, } \\
\text { and Ovarian (PLCO) Cancer } \\
\text { Screening Trial, USA }\end{array}$ & $\begin{array}{c}1992-2011 \\
13 y \text { (max) }\end{array}$ & $\begin{array}{l}1,703 \\
50,563\end{array}$ & Age, sex, race, and education, drinking frequency. \\
\hline $\begin{array}{l}\text { Oh, } \\
2015\end{array}$ & $\begin{array}{l}\text { Swedish Women's Lifestyle } \\
\text { and Health study, Sweden }\end{array}$ & $\begin{array}{c}1991-2012, \\
11 \text { y (avg) }\end{array}$ & $\begin{array}{l}1,395 \\
42,099\end{array}$ & Age, BMI, duration of breastfeeding, alcohol consumption. \\
\hline $\begin{array}{l}\text { Lukic, } \\
2016\end{array}$ & $\begin{array}{l}\text { Norwegian Women and } \\
\text { Cancer study (NOWAC), } \\
\text { Norway }\end{array}$ & $\begin{array}{l}\text { 1991-2013, } \\
13.1 \text { y (avg) }\end{array}$ & $\begin{array}{l}3,277 \\
91,767\end{array}$ & $\begin{array}{l}\text { Menopausal status, smoking status, age at smoking initiation, number of pack-years, } \\
\text { exposure to cigarette smoke during childhood, duration of education, BMI, physical } \\
\text { activity level, alcohol consumption, number of children, age at first birth, ever use of } \\
\text { oral contraceptives, duration of oral contraceptive use, use of hormone replacement } \\
\text { therapy, maternal history of breast cancer, total energy intake, intake of fibers, intake of } \\
\text { processed meat, intake of red meat, height, participation in mammography screening. }\end{array}$ \\
\hline
\end{tabular}

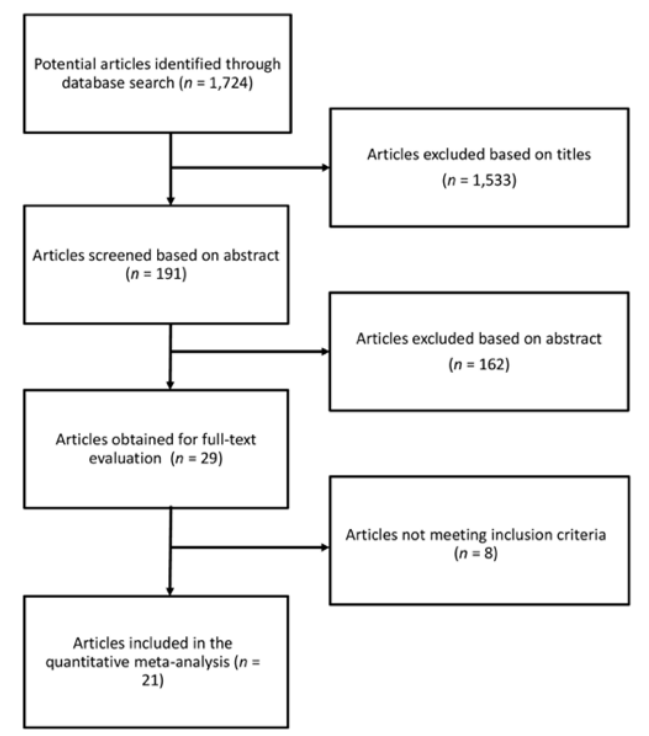

Figure 1. Flow chart of selection of studies reporting on the association between coffee consumption and breast cancer risk. 


\section{Summary relative risk for the high vs. lowest category of coffee consumption}

The summary RR of breast cancer for highest vs. lowest category of coffee consumption was $\mathrm{RR}=0.96,95 \%$ CI: 0.93, 1.00 with small heterogeneity $\mathrm{I}^{2}=7 \%, \mathrm{P}=0.37$ (Figure 2, Table 2); no publication bias was found after visual inspection of funnel plot (Supplementary Figure 1). Two studies $(36,38)$ were at higher risk of bias and provided very small heterogeneity to the overall analysis, despite no specific reasons have been identified; we may hypothesize that quality of the data was not optimal since the studies were not conducted specifically on coffee as variable of interest, but this is only speculative and no data can support this explanation. Since several cohorts (VIP, NOWAC, E3N, EPIC-NL) share the cases with EPIC multicentre study an alternative analysis by excluding EPIC study and including the others was performed. The summary RR of breast cancer for highest vs. lowest category of coffee consumption in alternative analysis was $\mathrm{RR}=0.96,95 \% \mathrm{CI}: 0.93,1.00$ with no evidence of heterogeneity $\mathrm{I}^{2}=$ $0 \%, \mathrm{P}=0.48$; indicating the stability of the results. In the stratified analysis we found a significant inverse association between coffee consumption and breast cancer risk among postmenopausal women $\left(\mathrm{RR}=0.92,95 \% \mathrm{CI}: 0.88,0.98\right.$ with no evidence of heterogeneity $\mathrm{I}^{2}=0 \%, \mathrm{P}=0.57$ ). Stratified analyses were carried out for receptor status and BMI: none of them showed a significant association between coffee intake and cancer risk; yet, similar point estimates and confidence intervals were found for the receptor-negative group and for the overweight and obese group. Interestingly, results were not influenced by coffee type (caffeinated versus decaffeinated), nor for time of follow-up. Adjusted analyses were carried out for smoking, alcohol intake, physical activity and education, without evidence of effect modification.

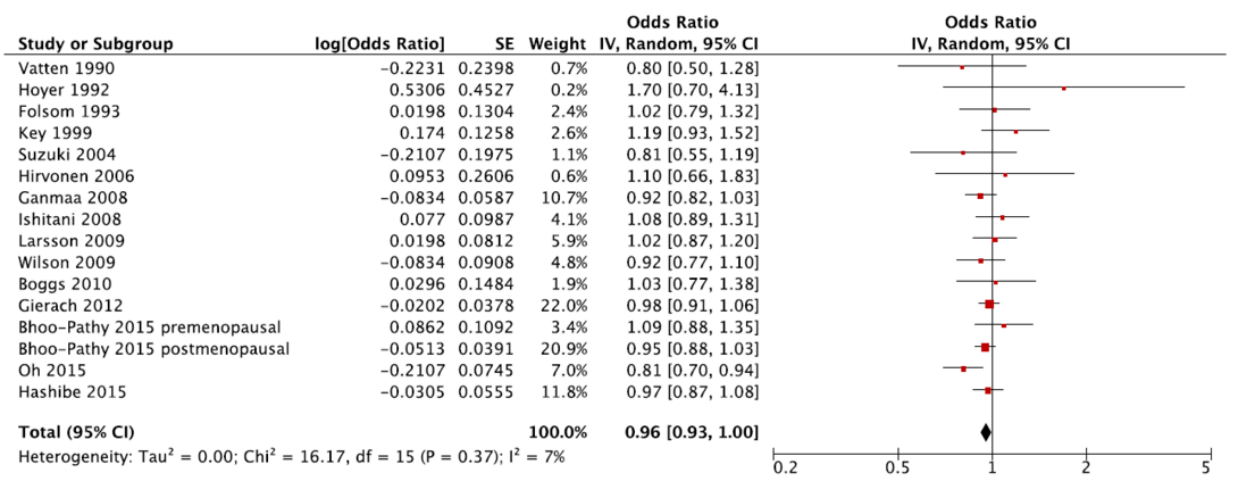

Figure 2. Forest plot of summary relative risks (RRs) of breast cancer for the bighest versus lowest (reference) category of coffee consumption. 
Table 2. Subgroup and additional analyses of studies reporting risk of breast cancer for the bighest versus lowest (reference) category coffee consumption.

\begin{tabular}{|c|c|c|c|c|}
\hline Subgroup & No. of datasets & $\mathrm{RR}(95 \% \mathrm{Cl})$ & $1^{2}$ & $P_{\text {heterogeneity }}$ \\
\hline Total & 16 & $0.96(0.93,1.00)$ & $7 \%$ & 0.37 \\
\hline (Alternative analysis) & 18 & $0.96(0.93,1.00)$ & $0 \%$ & 0.48 \\
\hline \multicolumn{5}{|l|}{ Geographical location } \\
\hline North America & 7 & $0.97(0.93,1.02)$ & $0 \%$ & 0.84 \\
\hline Europe & 7 & $0.95(0.87,1.05)$ & $36 \%$ & 0.15 \\
\hline Asia & 2 & $1.01(0.70,1.47)$ & $63 \%$ & 0.10 \\
\hline \multicolumn{5}{|l|}{ Menopausal status } \\
\hline Premenopausal & 8 & $0.98(0.89,1.07)$ & $0 \%$ & 0.46 \\
\hline Postmenopausal & 8 & $0.92(0.88,0.98)$ & $0 \%$ & 0.57 \\
\hline \multicolumn{5}{|l|}{ Receptor status } \\
\hline $\mathrm{ER}+/ \mathrm{PR}+$ & 5 & $0.97(0.89,1.07)$ & $0 \%$ & 0.40 \\
\hline ER+/PR- or ER-/PR+ & 5 & $0.98(0.82,1.17)$ & $0 \%$ & 0.60 \\
\hline ER-/PR- & 5 & $0.92(0.79,1.07)$ & $0 \%$ & 0.82 \\
\hline \multicolumn{5}{|l|}{ Coffee type } \\
\hline Caffeinated & 6 & $0.96(0.91,1.01)$ & $0 \%$ & 0.45 \\
\hline Decaffeinated & 6 & $0.97(0.90,1.04)$ & $0 \%$ & 0.67 \\
\hline \multicolumn{5}{|l|}{ BMI } \\
\hline$<25 \mathrm{~kg} / \mathrm{m} 2$ & 5 & $0.98(0.87,1.10)$ & $0 \%$ & 0.42 \\
\hline$\geq 25 \mathrm{~kg} / \mathrm{m} 2$ & 5 & $0.91(0.79,1.04)$ & $0 \%$ & 0.69 \\
\hline \multicolumn{5}{|l|}{ Duration of follow-up } \\
\hline$<10 y$ & 3 & $0.97(0.80,1.18)$ & $0 \%$ & 0.55 \\
\hline$\geq 10 y$ & 13 & $0.97(0.92,1.01)$ & $20 \%$ & 0.24 \\
\hline \multicolumn{5}{|l|}{ Adjustment for smoking } \\
\hline No & 7 & $0.95(0.86,1.05)$ & $41 \%$ & 0.12 \\
\hline Yes & 9 & $0.97(0.93,1.01)$ & $0 \%$ & 0.67 \\
\hline \multicolumn{5}{|c|}{ Adjustment for alcohol intake } \\
\hline No & 5 & $1.02(0.88,1.19)$ & $0 \%$ & 0.41 \\
\hline Yes & 11 & $0.96(0.92,1.00)$ & $13 \%$ & 0.32 \\
\hline \multicolumn{5}{|c|}{ Adjustment for physical activity } \\
\hline No & 10 & $0.97(0.90,1.04)$ & $27 \%$ & 0.20 \\
\hline Yes & 6 & $0.96(0.91,1.01)$ & $0 \%$ & 0.58 \\
\hline \multicolumn{5}{|l|}{ Adjustment for education } \\
\hline No & 10 & $0.95(0.87,1.04)$ & $32 \%$ & 0.16 \\
\hline Yes & 6 & $0.98(0.93,1.02)$ & $0 \%$ & 0.86 \\
\hline
\end{tabular}

\section{Dose-response meta-analysis}

Thirteen studies $(26,28,29,31,32,34,37-40,42,43,45)$ were eligible for dose-response metaanalysis of prospective cohort studies on coffee consumption and breast cancer risk. Six studies $(32,34,41-43,45)$ provided risk estimates for postmenopausal woman only. In linear doseresponse meta-analysis a significant association between coffee consumption and breast cancer risk was found (Figure 3, Table 3). Compared with no coffee consumption, the pooled relative risks for breast cancer were 0.99, 95\% CI: 0.98, 1.00 for one cup/day, 0.98, 95\% CI: 0.96, 0.99 for two cups/day, 0.97, 95\% CI: 0.94, 0.99 for three cups/day, 0.96, 95\% CI: 0.93, 0.99 for four cups/day, 0.95, 95\% CI: 0.91, 0.98 for five cups/day, 0.93, 95\% CI: 0.89, 0.98 for six cups/day and $0.92,95 \% \mathrm{CI}: 0.88,0.98$ for seven cups/day. When taking into account postmenopausal woman only, the association between coffee consumption and risk of breast cancer was stronger. 
a)

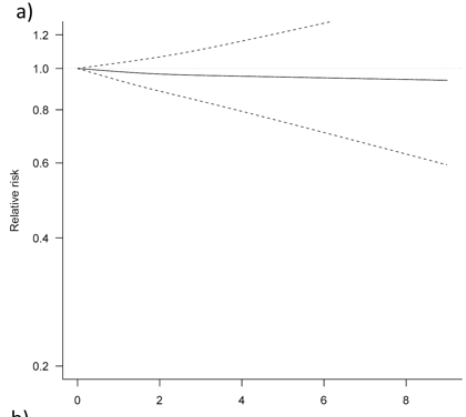

b)

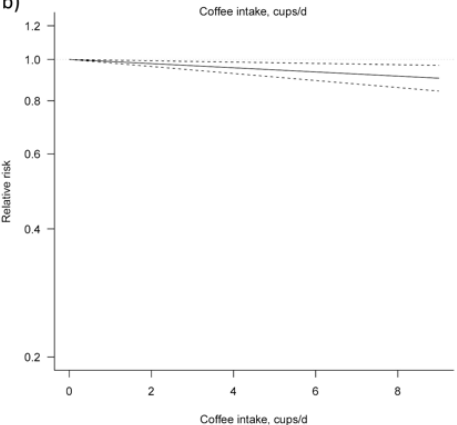

c)

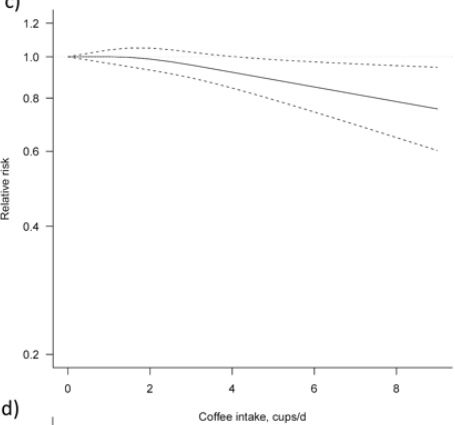

d)

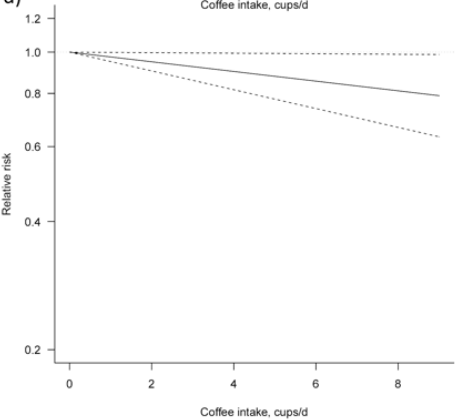

Figure 3. Dose-response association between coffee consumption and breast cancer risk. a) non-linear, total analysis; b) linear, total analysis; c) non-linear, postmenopausal; d) linear, postmenopausal. Solid lines represent relative risk, dashed lines represent $95 \%$ confidence intervals. 
Table 3. Dose-response meta-analysis of prospective cohort studies on coffee consumption and breast cancer risk.

\begin{tabular}{|c|c|c|c|c|c|c|c|c|c|c|c|c|}
\hline & \multirow{2}{*}{\multicolumn{2}{|c|}{$\begin{array}{l}\text { No. of } \\
\text { datasets } \\
\text { (no. of } \\
\text { studies) }\end{array}$}} & \multicolumn{7}{|c|}{ Coffee intake (cups/day) } & \multirow{2}{*}{$-1^{2}(\%)$} & \multirow{2}{*}{$P_{\text {heterogeneits }}$} & \multirow{2}{*}{$\begin{array}{l}P_{\text {non- }} \\
\text { ly }\end{array}$} \\
\hline & & & 1 & 2 & 3 & 4 & 5 & 6 & 7 & & & \\
\hline \multicolumn{13}{|l|}{ Total analysis } \\
\hline Non-linear & $\begin{array}{c}13 \\
(13)\end{array}$ & Ref. & $\begin{array}{c}0.98 \\
(0.94,1.03)\end{array}$ & $\begin{array}{c}0.97 \\
(0.88,1.06)\end{array}$ & $\begin{array}{c}0.96 \\
(0.84,1.11)\end{array}$ & $\begin{array}{c}0.96 \\
(0.79,1.16)\end{array}$ & $\begin{array}{c}0.95 \\
(0.75,1.22)\end{array}$ & $\begin{array}{c}0.95 \\
(0.71,1.28)\end{array}$ & $\begin{array}{c}0.95 \\
(0.67,1.34)\end{array}$ & - & 0.69 & 0.52 \\
\hline Linear & $\begin{array}{c}13 \\
(13)\end{array}$ & & $\begin{array}{c}0.99 \\
(0.98,1.00)\end{array}$ & $\begin{array}{c}0.98 \\
(0.96,0.99)\end{array}$ & $\begin{array}{c}0.97 \\
(0.94,0.99)\end{array}$ & $\begin{array}{c}0.96 \\
(0.93,0.99)\end{array}$ & $\begin{array}{c}0.95 \\
(0.91,0.98)\end{array}$ & $\begin{array}{c}0.93 \\
(0.89,0.98)\end{array}$ & $\begin{array}{c}0.92 \\
(0.88,0.98)\end{array}$ & - & 0.58 & NA \\
\hline \multicolumn{13}{|c|}{ Postmenopausal } \\
\hline Non-linear & $\begin{array}{c}6 \\
(6)\end{array}$ & Ref. & $\begin{array}{c}1.00 \\
(0.96,1.04)\end{array}$ & $\begin{array}{c}0.99 \\
(0.93,1.05)\end{array}$ & $\begin{array}{c}0.96 \\
(0.89,1.03)\end{array}$ & $\begin{array}{c}0.92 \\
(0.84,1.00)\end{array}$ & $\begin{array}{c}0.88 \\
(0.79,0.99)\end{array}$ & $\begin{array}{c}0.85 \\
(0.74,0.97)\end{array}$ & $\begin{array}{c}0.82 \\
(0.69,0.96)\end{array}$ & 0 & 0.71 & 0.14 \\
\hline Linear & $\begin{array}{c}6 \\
\text { (6) }\end{array}$ & Ref. & $\begin{array}{c}0.97 \\
(0.95,1.00)\end{array}$ & $\begin{array}{c}0.95 \\
(0.90,1.00)\end{array}$ & $\begin{array}{c}0.92 \\
(0.86,1.00)\end{array}$ & $\begin{array}{c}0.90 \\
(0.82,0.99)\end{array}$ & $\begin{array}{c}0.88 \\
(0.78,0.99)\end{array}$ & $\begin{array}{c}0.85 \\
(0.74,0.99)\end{array}$ & $\begin{array}{c}0.83 \\
(0.70,0.99)\end{array}$ & 39.6 & 0.14 & NA \\
\hline \multicolumn{13}{|c|}{$\mathrm{BMI}>25 \mathrm{~kg} / \mathrm{m} 2$} \\
\hline Non-linear & $\begin{array}{c}5 \\
(5)\end{array}$ & Ref. & $\begin{array}{c}0.98 \\
(0.91,1.06)\end{array}$ & $\begin{array}{c}0.97 \\
(0.86,1.10)\end{array}$ & $\begin{array}{c}0.97 \\
(0.84,1.12)\end{array}$ & $\begin{array}{c}0.97 \\
(0.82,1.14)\end{array}$ & $\begin{array}{c}0.97 \\
(0.80,1.18)\end{array}$ & $\begin{array}{c}0.97 \\
(0.76,1.24)\end{array}$ & $\begin{array}{c}0.97 \\
(0.72,1.30)\end{array}$ & 10.1 & 0.35 & 0,77 \\
\hline Linear & $\begin{array}{c}5 \\
(5)\end{array}$ & & $\begin{array}{c}0.99 \\
(0.96,1.02)\end{array}$ & $\begin{array}{c}0.98 \\
(0.92,1.05)\end{array}$ & $\begin{array}{c}0.97 \\
(0.88,1.08)\end{array}$ & $\begin{array}{c}0.96 \\
(0.84,1.10)\end{array}$ & $\begin{array}{c}0.95 \\
(0.81,1.13)\end{array}$ & $\begin{array}{c}0.95 \\
(0.77,1.16)\end{array}$ & $\begin{array}{c}0.94 \\
(0.74,1.19)\end{array}$ & 39 & 0.16 & \\
\hline \multicolumn{13}{|l|}{ ER-/PR- } \\
\hline Non-linear & $\begin{array}{c}5 \\
(4)\end{array}$ & Ref. & $\begin{array}{c}0.93 \\
(0.84,1.04)\end{array}$ & $\begin{array}{c}0.9 \\
(0.76,1.07)\end{array}$ & $\begin{array}{c}0.91 \\
(0.77,1.08)\end{array}$ & $\begin{array}{c}0.94 \\
(0.79,1.11)\end{array}$ & $\begin{array}{c}0.97 \\
(0.79,1.19)\end{array}$ & $\begin{array}{c}1.00 \\
(0.77,1.30)\end{array}$ & $\begin{array}{c}1.04 \\
(0.75,1.43)\end{array}$ & 0 & 0.88 & 0.25 \\
\hline Linear & $\begin{array}{c}5 \\
(4)\end{array}$ & Ref. & $\begin{array}{c}0.99 \\
(0.95,1.03)\end{array}$ & $\begin{array}{c}0.98 \\
(0.91,1.06)\end{array}$ & $\begin{array}{c}0.97 \\
(0.86,1.10)\end{array}$ & $\begin{array}{c}0.97 \\
(0.82,1.13)\end{array}$ & $\begin{array}{c}0.96 \\
(0.78,1.17)\end{array}$ & $\begin{array}{c}0.95 \\
(0.75,1.20)\end{array}$ & $\begin{array}{c}0.94 \\
(0.71,1.24)\end{array}$ & 66.3 & 0.43 & NA \\
\hline
\end{tabular}

\section{Discussion}

The present dose-response meta-analysis, which included 13 prospective studies and followed over 1 million people, did not show a significant association between coffee consumption and overall breast cancer risk in the non-linear model. However, an inverse relationship has been found when the analysis was restricted to post-menopausal women (RR 0.92, 95\% CI: 0.88$0.98)$.

The meta-analysis performed by $\mathrm{Li}$ and colleagues (18), on 16 cohort and 10 case-control studies, showed a borderline significant inverse association between coffee intake and the risk of breast cancer (RR: 0.96, CI95\%: 0.93-1.00 for highest versus lowest analysis; RR: 0.98, CI95\%: 0.971.00 for an increment of 2 cups per day). Statistical significance was reached only for those women without estrogen receptor (ER-negative, RR: 0.81, 95\% CI: 0.67-0.97)). In our study, such finding was not confirmed. The work carried out by Jiang and colleagues (19), which included 17 prospective and 20 case-control studies, found no significant association between coffee consumption and breast cancer risk (highest versus lowest analysis: RR: 0.98, CI95\% 0.951.02; dose-response analysis: RR: 0.98, 95\% CI: 0.92-1.05 for an increment of 2 cups per day). Such relationship became significant for post-menopausal women, with a stronger inverse relationship for those with BRCA1 mutation. Overall results are mostly confirmed in our metaanalysis, even though we included a higher number of individuals and performed alternative analyses to avoid overlap of cohorts. However, while our analysis confirmed a statistically 
significant relationship between coffee intake and breast cancer in post-menopausal women, we were not able to draw insights on the role of BRCA status (evidence derived from case-control studies, not eligible for our meta-analysis). Moreover, similarly to our study, the meta-analysis of Jiang and colleagues differentiated the analysis according to follow-up duration, and found similar results between studies with long $(>10)$ and short (<10 years) follow-up.

Several studies associated coffee consumption with health benefits, including decreased risk of cancers (e.g. colorectal, endometrial and prostate cancers) $(7,13,14)$. Several compounds have been considered responsible for such potential protective effects, including polyphenols (such as chlorogenic acids), diterpens (such as cafestol and kahweol), but also melanoidins (generated during the roasting process) and trigonelline (47-50). Data from in vitro and in vivo studies suggest that coffee could interfere with different stages of the cancerous process, including induction of DNA damage caused by pro-carcinogens and reactive oxygen species (ROS), activation of proto-oncogenes and inactivation of onco-suppressor genes, loss of apoptosis and growth control, induction of angiogenesis and consequent metastatic process (11).

Our study revealed significant results for post-menopausal women. Several mechanisms have been proposed to act specifically in the etiopathogenesis of female cancers: for instance, caffeine and coffee intake have been inversely associated with free estradiol levels in premenopausal women, either directly or indirectly (relationship mediated by the sex hormone-binding globulin - SHBG) (51-53). SHBG, which is the major carriers of sex-steroids, lowers the circulating free levels of estrogens, and the positive association between coffee intake and SHBG has been documented in post-menopausal women as well (54). Similarly, coffee has been associated with the inhibition of CYP19, or aromatase, the enzyme converting androgens into estrogens (51). Circulating estrogens are well-established risk factors for breast cancer (55).

Despite the complexity of the described mechanisms, it is crucial to understand the pathways through which coffee may decrease risk of cancer. Our finding, showing a similar association for caffeinated and decaffeinated coffee, may suggest a limited role of caffeine on breast cancer risk (the literature highlights the role of caffeine on neurotransmitters, therefore on neurological, cardiorespiratory and gastrointestinal diseases) (7). It is therefore more plausible that the action on carcinogenesis is mediated by antioxidants: due to coffee natural richness in dietary antioxidants and its wide consumption worldwide, such beverage is one of the major contributor to dietary antioxidant $(56,57)$. However, based on the observational nature of the studies involved in this research, we cannot rule out the possibility of existence of confounding factors or effect modifiers that can indirectly explain the potential benefits of coffee toward breast cancer risk. For instance, one of the stronger evidence regarding coffee consumption regards liver and, more generally, metabolic health (58). Several studies showed a better metabolic status occurring in individuals characterized by high consumption of coffee $(10,59-68)$. We found no difference in the relationship between coffee intake and breast cancer risk according to BMI; nevertheless, obesity is a well-recognized risk factor for breast cancer, and hormonal impairment consequent to excess body weight may be inversely associated with consumption of coffee (69, 70). The metabolic syndrome, also known as insulin resistance syndrome, is a multifactorial 
disease well related to breast cancer risk of incidence and recurrence $(71,72)$ with a crucial role in the activation of many endocrine and immune factors linked to breast cancer cell proliferation, survival and chemo-resistance. Among different nutritional approach aimed to revert metabolic syndrome in breast cancer patients, it was recently shown that consumption of coffee in adults up to three cups a day reduces the risk of type-2 diabetes, the metabolic syndrome as well as non alcoholic fatty liver disease (NAFLD) $(58,73)$. Several studies showed that the association is rather stronger with the overall metabolic status than with individual components of the syndrome $(74,75)$. A crucial endocrine role in breast cancer risk and progress may be related to low levels of adiponectin (having anti-cancer effect) and high levels of leptin (having insulin and IGF1-like effects in cancer cells) in the blood $(76,77)$; interestingly, in a cross-sectional study, it was demonstrated that coffee consumption has a significant positive associations with adiponectin and inverse associations with leptin as well as with the inflammatory marker high sensitivity C-reactive protein (hs-CRP) indicating interesting endocrine and metabolic effects of coffee consumption (78).

In our study we investigated the possible role of confounding factors in determining the association between coffee consumption and breast cancer risk. It has been reported that smoking status, education, physical activity and BMI, may cluster together with dietary choices that may affect cancer risk (i.e., consumption of meat, fruit and vegetable) (79). Besides BMI, for which some studies provided specific RRs and we were able to perform the aforementioned stratified risk analysis, in our study the results of studies grouped according to adjustment for specific variables, such as smoking status, education, and physical activity, did not weakened the results, rather they shortened CIs despite yet not significant, suggesting that better designed cohort studies properly adjusting for potential confounding factors may enhance the overall quality of comprehensive quantitative synthesis and leading to significant results toward lower risk of breast cancer associated with higher consumption of coffee.

Another indirect confounding effect may be related to alcohol consumption: alcohol is another known risk factor for breast cancer through the alteration of biological pathways associated to hormone levels, the production of carcinogens through metabolism of ethanol, and the inhibition of the one-carbon metabolism and nucleotide biosynthesis $(80,81)$. Some descriptive studies on beverage drinking patterns suggest that increased coffee/tea consumption might be associated with alcohol intake (82-87). However, our results showed that studies adjusting for alcohol intake provided lower risk estimates for the association between coffee and breast cancer risk, suggesting that adjustment for such lifestyle factors is crucial when exploring the potential effects of coffee on health. Coffee drinking has been associated with smoking habits, which in turn may exert detrimental effects on health (88); in contrast, coffee might be a part of an overall healthier dietary pattern, which in turn might be associated with lower risk of cancer due to a synergistic effect of several components rather than an individual food or beverage (89). More in-depth studies with further evaluation of genetic parameters are ongoing, but additional research is needed to conclude a causal relation between coffee consumption and risk of cancer. 
Besides the aforementioned limitations related to the original design of the studies included in this meta-analysis, the presented results should be considered in light of some other limitations. No data on methods of preparation have been provided in the studies, leading to possible heterogeneity of results due to differences in quantity and quality of bioactive compounds (90). Finally, due to the observational nature of the studies included in the meta-analysis we cannot exclude the possibility of recall bias and reverse causation.

\section{Conclusion}

In conclusions, overall we observed no significant association between coffee intake and breast cancer risk, but coffee consumption may represent a protective factor for post-menopausal breast cancer risk. Further evidences taking into account population subsets and specific strata are extremely needed to corroborate the retrieved associations.

\section{Supplementary Materials}

The following are available online at www.mdpi.com/link, Figure S1: Funnel plot and publication bias, Table S1: MOOSE protocol, Table S2: Search strategy. 


\section{References}

1. Boyle P, Levin B. World cancer report. IARC Press, Lyon, ISBN: 97892832042372008.

2. Ban KA, Godellas CV. Epidemiology of breast cancer. Surgical oncology clinics of North America. 2014;23(3):409-22. 10.1016/j.soc.2014.03.011

3. Tao Z, Shi A, Lu C, Song T, Zhang Z, Zhao J. Breast Cancer: Epidemiology and Etiology. Cell biochemistry and biophysics. 2015;72(2):333-8. 10.1007/s12013-014-0459-6

4. WHO. http://globocan.iarc.fr/Default.aspx [Available from: http://globocan.iarc.fr/Default.aspx.

5. Coleman MP, Quaresma M, Berrino F, Lutz JM, De Angelis R, Capocaccia R, et al. Cancer survival in five continents: a worldwide population-based study (CONCORD). The Lancet Oncology.

2008;9(8):730-56. 10.1016/s1470-2045(08)70179-7

6. Siegel R, Naishadham D, Jemal A. Cancer statistics, 2012. CA: a cancer journal for clinicians. 2012;62(1):10-29. 10.3322/caac.20138

7. Grosso G, Godos J, Galvano F, Giovannucci EL. Coffee, caffeine, and health outcomes: an umbrella review. Annual Review of Nutrition. 2017;37(1).

8. Grosso G, Micek A, Godos J, Sciacca S, Pajak A, Martinez-Gonzalez MA, et al. Coffee consumption and risk of all-cause, cardiovascular, and cancer mortality in smokers and non-smokers: a dose-response meta-analysis. Eur J Epidemiol. 2016;31(12):1191-205. 10.1007/s10654-016-0202-2

9. Tajik N, Tajik M, Mack I, Enck P. The potential effects of chlorogenic acid, the main phenolic components in coffee, on health: a comprehensive review of the literature. European Journal of Nutrition. 2017:1-30.

10. Godos J, Pluchinotta FR, Marventano S, Buscemi S, Li Volti G, Galvano F, et al. Coffee components and cardiovascular risk: beneficial and detrimental effects. International journal of food sciences and nutrition. 2014;65(8):925-36. 10.3109/09637486.2014.940287

11. Bohn SK, Blomhoff R, Paur I. Coffee and cancer risk, epidemiological evidence, and molecular mechanisms. Molecular nutrition \& food research. 2014;58(5):915-30. 10.1002/mnfr.201300526

12. Harris HR, Willett WC, Vaidya RL, Michels KB. An Adolescent and Early Adulthood Dietary Pattern Associated with Inflammation and the Incidence of Breast Cancer. Cancer Res. 2017;77(5):1179.

10.1158/0008-5472.CAN-16-2273 [doi]

13. Alicandro G, Tavani A, La Vecchia C. Coffee and cancer risk: a summary overview. EurJCancer Prev. 2017. 10.1097/CEJ.0000000000000341 [doi]

14. Malerba S, Turati F, Galeone C, Pelucchi C, Verga F, La Vecchia C, et al. A meta-analysis of prospective studies of coffee consumption and mortality for all causes, cancers and cardiovascular diseases. EurJEpidemiol. 2013;28(7):527. 10.1007/s10654-013-9834-7 [doi]

15. Je Y, Giovannucci E. Coffee consumption and risk of endometrial cancer: findings from a large upto-date meta-analysis. International journal of cancer. 2012;131(7):1700. 10.1002/ijc.27408 [doi]

16. Yang TO, Crowe F, Cairns BJ, Reeves GK, Beral V. Tea and coffee and risk of endometrial cancer: cohort study and meta-analysis. The American journal of clinical nutrition. 2015;101(3):570.

10.3945/ajcn.113.081836 [doi]

17. Braem MG, Onland-Moret NC, Schouten LJ, Tjonneland A, Hansen L, Dahm CC, et al. Coffee and tea consumption and the risk of ovarian cancer: a prospective cohort study and updated meta-analysis.

The American journal of clinical nutrition. 2012;95(5):1172. 10.3945/ajcn.111.026393 [doi]

18. Li XJ, Ren ZJ, Qin JW, Zhao JH, Tang JH, Ji MH, et al. Coffee consumption and risk of breast cancer: an up-to-date meta-analysis. PLoS One. 2013;8(1):e52681. 10.1371/journal.pone.0052681

19. Jiang W, Wu Y, Jiang X. Coffee and caffeine intake and breast cancer risk: an updated dose-response meta-analysis of 37 published studies. GynecolOncol. 2013;129(3):620. 10.1016/j.ygyno.2013.03.014 [doi] 
20. Degrees of evidence by the Joint WHO/FAO Expert Consultation.

http://www.who.int/nutrition/topics/5_population_nutrient/en/ - diet5.1.2 Accessed Novermber 2015. 21. Wells GA SB, O'Connell D, Peterson J, Welch V, Losos M, Tugwell P, editor The Newcastle-Ottawa Scale (NOS) for assessing the quality of nonrandomised studies in meta-analyses. Ottawa (Canada): Ottawa Health Research Institute; 1999.

22. Greenland S. Quantitative methods in the review of epidemiologic literature. Epidemiologic reviews. 1987;9:1-30.

23. Greenland S, Longnecker MP. Methods for trend estimation from summarized dose-response data, with applications to meta-analysis. American journal of epidemiology. 1992;135(11):1301-9.

24. Orsini N BR, Greenland S. Generalized least squares for trend estimation of summarized doseresponse data. Stata J. 2006;6:40-57.

25. Orsini N, Li R, Wolk A, Khudyakov P, Spiegelman D. Meta-analysis for linear and nonlinear doseresponse relations: examples, an evaluation of approximations, and software. American journal of epidemiology. 2012;175(1):66-73. 10.1093/aje/kwr265

26. Bhoo Pathy N, Peeters P, van Gils C, Beulens JW, van der Graaf Y, Bueno-de-Mesquita B, et al. Coffee and tea intake and risk of breast cancer. Breast cancer research and treatment. 2010;121(2):461-7. 10.1007/s10549-009-0583-y

27. Bhoo-Pathy N, Peeters PH, Uiterwaal CS, Bueno-de-Mesquita HB, Bulgiba AM, Bech BH, et al. Coffee and tea consumption and risk of pre- and postmenopausal breast cancer in the European Prospective Investigation into Cancer and Nutrition (EPIC) cohort study. Breast cancer research : BCR. 2015;17:15. 10.1186/s13058-015-0521-3

28. Boggs DA, Palmer JR, Stampfer MJ, Spiegelman D, Adams-Campbell LL, Rosenberg L. Tea and coffee intake in relation to risk of breast cancer in the Black Women's Health Study. Cancer Causes Control. 2010;21(11):1941-8. 10.1007/s10552-010-9622-6

29. Fagherazzi G, Touillaud MS, Boutron-Ruault MC, Clavel-Chapelon F, Romieu I. No association between coffee, tea or caffeine consumption and breast cancer risk in a prospective cohort study. Public health nutrition. 2011;14(7):1315-20. 10.1017/S1368980011000371

30. Folsom AR, McKenzie DR, Bisgard KM, Kushi LH, Sellers TA. No association between caffeine intake and postmenopausal breast cancer incidence in the Iowa Women's Health Study. American journal of epidemiology. 1993;138(6):380-3.

31. Ganmaa D, Willett WC, Li TY, Feskanich D, van Dam RM, Lopez-Garcia E, et al. Coffee, tea, caffeine and risk of breast cancer: a 22-year follow-up. International journal of cancer. 2008;122(9):20716. 10.1002/ijc. 23336

32. Gierach GL, Freedman ND, Andaya A, Hollenbeck AR, Park Y, Schatzkin A, et al. Coffee intake and breast cancer risk in the NIH-AARP diet and health study cohort. International journal of cancer.

2012;131(2):452-60. 10.1002/ijc.26372

33. Harris HR, Bergkvist L, Wolk A. An estrogen-associated dietary pattern and breast cancer risk in the Swedish Mammography Cohort. International journal of cancer. 2015;137(9):2149-54. 10.1002/ijc.29586 34. Hashibe M, Galeone C, Buys SS, Gren L, Boffetta P, Zhang ZF, et al. Coffee, tea, caffeine intake, and the risk of cancer in the PLCO cohort. British journal of cancer. 2015;113(5):809-16.

10.1038/bjc.2015.276

35. Hirvonen T, Mennen LI, de Bree A, Castetbon K, Galan P, Bertrais S, et al. Consumption of antioxidant-rich beverages and risk for breast cancer in French women. Annals of epidemiology. 2006;16(7):503-8. 10.1016/j.annepidem.2005.09.011

36. Hoyer AP, Engholm G. Serum lipids and breast cancer risk: a cohort study of 5,207 Danish women. Cancer Causes Control. 1992;3(5):403-8. 
37. Ishitani K, Lin J, Manson JE, Buring JE, Zhang SM. Caffeine consumption and the risk of breast cancer in a large prospective cohort of women. Archives of internal medicine. 2008;168(18):2022-31. 10.1001/archinte.168.18.2022

38. Key TJ, Sharp GB, Appleby PN, Beral V, Goodman MT, Soda M, et al. Soya foods and breast cancer risk: a prospective study in Hiroshima and Nagasaki, Japan. British journal of cancer. 1999;81(7):1248-56. 10.1038/sj.bjc.6690837

39. Larsson SC, Bergkvist L, Wolk A. Coffee and black tea consumption and risk of breast cancer by estrogen and progesterone receptor status in a Swedish cohort. Cancer Causes Control. 2009;20(10):203944. 10.1007/s10552-009-9396-x

40. Lukic M, Licaj I, Lund E, Skeie G, Weiderpass E, Braaten T. Coffee consumption and the risk of cancer in the Norwegian Women and Cancer (NOWAC) Study. Eur J Epidemiol. 2016;31(9):905-16. 10.1007/s10654-016-0142-x

41. Michels KB, Holmberg L, Bergkvist L, Wolk A. Coffee, tea, and caffeine consumption and breast cancer incidence in a cohort of Swedish women. Annals of epidemiology. 2002;12(1):21-6.

42. Nilsson LM, Johansson I, Lenner P, Lindahl B, Van Guelpen B. Consumption of filtered and boiled coffee and the risk of incident cancer: a prospective cohort study. Cancer Causes Control.

2010;21(10):1533-44. 10.1007/s10552-010-9582-x

43. Oh JK, Sandin S, Strom P, Lof M, Adami HO, Weiderpass E. Prospective study of breast cancer in relation to coffee, tea and caffeine in Sweden. International journal of cancer. 2015;137(8):1979-89. 10.1002/ijc. 29569

44. Suzuki Y, Tsubono Y, Nakaya N, Suzuki Y, Koizumi Y, Tsuji I. Green tea and the risk of breast cancer: pooled analysis of two prospective studies in Japan. British journal of cancer. 2004;90(7):1361-3. 10.1038/sj.bjc.6601652

45. Vatten LJ, Solvoll K, Loken EB. Coffee consumption and the risk of breast cancer. A prospective study of 14,593 Norwegian women. British journal of cancer. 1990;62(2):267-70.

46. Wilson KM, Mucci LA, Cho E, Hunter DJ, Chen WY, Willett WC. Dietary acrylamide intake and risk of premenopausal breast cancer. American journal of epidemiology. 2009;169(8):954-61.

10.1093/aje/kwn421

47. Bjorklund G, Chirumbolo S. Role of oxidative stress and antioxidants in daily nutrition and human health. Nutrition. 2017;33:311-21. 10.1016/j.nut.2016.07.018

48. Grosso G, Godos J, Lamuela-Raventos R, Ray S, Micek A, Pajak A, et al. A comprehensive metaanalysis on dietary flavonoid and lignan intake and cancer risk: Level of evidence and limitations.

Molecular nutrition \& food research. 2017;61(4). 10.1002/mnfr.201600930

49. Grosso G, Micek A, Godos J, Pajak A, Sciacca S, Galvano F, et al. Dietary Flavonoid and Lignan Intake and Mortality in Prospective Cohort Studies: Systematic Review and Dose-Response MetaAnalysis. American journal of epidemiology. 2017;185(12):1304-16. 10.1093/aje/kww207

50. Liang N, Kitts DD. Antioxidant property of coffee components: assessment of methods that define mechanisms of action. Molecules. 2014;19(11):19180-208. 10.3390/molecules191119180

51. Kotsopoulos J, Eliassen AH, Missmer SA, Hankinson SE, Tworoger SS. Relationship between caffeine intake and plasma sex hormone concentrations in premenopausal and postmenopausal women. Cancer. 2009;115(12):2765. 10.1002/cncr.24328 [doi]

52. Fung TT, Schulze MB, Hu FB, Hankinson SE, Holmes MD. A dietary pattern derived to correlate with estrogens and risk of postmenopausal breast cancer. Breast cancer research and treatment. 2012;132(3):1157. 10.1007/s10549-011-1942-z [doi] 
53. Sisti JS, Hankinson SE, Caporaso NE, Gu F, Tamimi RM, Rosner B, et al. Caffeine, coffee, and tea intake and urinary estrogens and estrogen metabolites in premenopausal women. Cancer epidemiology, biomarkers \& prevention : a publication of the American Association for Cancer Research, cosponsored by the American Society of Preventive Oncology. 2015;24(8):1174. 10.1158/1055-9965.EPI-15-0246 [doi] 54. Nagata C, Kabuto M, Shimizu H. Association of coffee, green tea, and caffeine intakes with serum concentrations of estradiol and sex hormone-binding globulin in premenopausal Japanese women.

NutrCancer. 1998;30(1):21. 10.1080/01635589809514635 [doi]

55. Chuffa LG, Lupi-Junior LA, Costa AB, Amorim JP, Seiva FR. The role of sex hormones and steroid receptors on female reproductive cancers. Steroids. 2017;118:93. S0039-128X(16)30199-4 [pii]

56. Federation EC. Coffee consumption in Europe [Available from: http://www.ecf-coffee.org/aboutcoffee/coffee-consumption-in-europe.

57. Palmioli A, Ciaramelli C, Tisi R, Spinelli M, De Sanctis G, Sacco E, et al. Natural Compounds in Cancer Prevention: Effects of Coffee Extracts and Their Main Polyphenolic Component, 5-O-

Caffeoylquinic Acid, on Oncogenic Ras Proteins. Chem Asian J. 2017. 10.1002/asia.201700844

58. Marventano S, Salomone F, Godos J, Pluchinotta F, Del Rio D, Mistretta A, et al. Coffee and tea consumption in relation with non-alcoholic fatty liver and metabolic syndrome: A systematic review and meta-analysis of observational studies. Clin Nutr. 2016;35(6):1269-81. 10.1016/j.clnu.2016.03.012

59. Lutsey PL, Steffen LM, Stevens J. Dietary intake and the development of the metabolic syndrome: the Atherosclerosis Risk in Communities study. Circulation. 2008;117(6):754-61.

10.1161/CIRCULATIONAHA.107.716159

60. Driessen MT, Koppes LL, Veldhuis L, Samoocha D, Twisk JW. Coffee consumption is not related to the metabolic syndrome at the age of 36 years: the Amsterdam Growth and Health Longitudinal Study. Eur J Clin Nutr. 2009;63(4):536-42. 10.1038/ejcn.2008.6

61. Chang CS, Chang YF, Liu PY, Chen CY, Tsai YS, Wu CH. Smoking, habitual tea drinking and metabolic syndrome in elderly men living in rural community: the Tianliao old people (TOP) study 02. PLoS One. 2012;7(6):e38874. 10.1371/journal.pone.0038874

62. Matsuura H, Mure K, Nishio N, Kitano N, Nagai N, Takeshita T. Relationship between coffee consumption and prevalence of metabolic syndrome among Japanese civil servants. J Epidemiol. 2012;22(2):160-6.

63. Takami H, Nakamoto M, Uemura H, Katsuura S, Yamaguchi M, Hiyoshi M, et al. Inverse correlation between coffee consumption and prevalence of metabolic syndrome: baseline survey of the Japan MultiInstitutional Collaborative Cohort (J-MICC) Study in Tokushima, Japan. J Epidemiol. 2013;23(1):12-20. 64. Dos Santos PR, Ferrari GS, Ferrari CK. Diet, sleep and metabolic syndrome among a legal Amazon population, Brazil. Clin Nutr Res. 2015;4(1):41-5. 10.7762/cnr.2015.4.1.41

65. Grosso G, Stepaniak U, Micek A, Topor-Madry R, Pikhart H, Szafraniec K, et al. Association of daily coffee and tea consumption and metabolic syndrome: results from the Polish arm of the HAPIEE study. Eur J Nutr. 2015;54(7):1129-37. 10.1007/s00394-014-0789-6

66. Nordestgaard AT, Thomsen M, Nordestgaard BG. Coffee intake and risk of obesity, metabolic syndrome and type 2 diabetes: a Mendelian randomization study. Int J Epidemiol. 2015;44(2):551-65. 10.1093/ije/dyv083

67. Suliga E, Koziel D, Ciesla E, Rebak D, Gluszek S. Coffee consumption and the occurrence and intensity of metabolic syndrome: a cross-sectional study. International journal of food sciences and nutrition. 2016:1-7. 10.1080/09637486.2016.1256381 
68. Micek A, Grosso G, Polak M, Kozakiewicz K, Tykarski A, Puch Walczak A, et al. Association between tea and coffee consumption and prevalence of metabolic syndrome in Poland - results from the WOBASZ II study (2013-2014). International journal of food sciences and nutrition. 2017:1-11. 10.1080/09637486.2017.1362690

69. Pan MH, Tung YC, Yang G, Li S, Ho CT. Molecular mechanisms of the anti-obesity effect of bioactive compounds in tea and coffee. Food Funct. 2016;7(11):4481-91. 10.1039/c6fo01168c

70. Santos RM, Lima DR. Coffee consumption, obesity and type 2 diabetes: a mini-review. Eur J Nutr. 2016;55(4):1345-58. 10.1007/s00394-016-1206-0

71. Chen Y, Wen YY, Li ZR, Luo DL, Zhang XH. The molecular mechanisms between metabolic syndrome and breast cancer. Biochem Biophys Res Commun. 2016;471(4):391-5.

10.1016/j.bbrc.2016.02.034

72. Feola A, Ricci S, Kouidhi S, Rizzo A, Penon A, Formisano P, et al. Multifaceted Breast Cancer: The Molecular Connection With Obesity. J Cell Physiol. 2017;232(1):69-77. 10.1002/jcp.25475

73. Baspinar B, Eskici G, Ozcelik AO. How coffee affects metabolic syndrome and its components. Food Funct. 2017;8(6):2089-101. 10.1039/c7fo00388a

74. Grosso G, Marventano S, Galvano F, Pajak A, Mistretta A. Factors associated with metabolic syndrome in a mediterranean population: role of caffeinated beverages. J Epidemiol. 2014;24(4):327-33. 75. Suliga E, Koziel D, Ciesla E, Rebak D, Gluszek S. Coffee consumption and the occurrence and intensity of metabolic syndrome: a cross-sectional study. International journal of food sciences and nutrition. 2017;68(4):507-13. 10.1080/09637486.2016.1256381

76. Saxena NK, Sharma D. Multifaceted leptin network: the molecular connection between obesity and breast cancer. J Mammary Gland Biol Neoplasia. 2013;18(3-4):309-20. 10.1007/s10911-013-9308-2 77. Quagliariello V, Rossetti S, Cavaliere C, Di Palo R, Lamantia E, Castaldo L, et al. Metabolic syndrome, endocrine disruptors and prostate cancer associations: biochemical and pathophysiological evidences. Oncotarget. 2017;8(18):30606-16. 10.18632/oncotarget.16725

78. Yamashita K, Yatsuya H, Muramatsu T, Toyoshima H, Murohara T, Tamakoshi K. Association of coffee consumption with serum adiponectin, leptin, inflammation and metabolic markers in Japanese workers: a cross-sectional study. Nutr Diabetes. 2012;2:e33. 10.1038/nutd.2012.6

79. Grosso G, Micek A, Godos J, Pajak A, Sciacca S, Galvano F, et al. Health risk factors associated with meat, fruit and vegetable consumption in cohort studies: A comprehensive meta-analysis. PLoS One.

2017;12(8):e0183787. 10.1371/journal.pone.0183787

80. Mourouti N, Kontogianni MD, Papavagelis C, Panagiotakos DB. Diet and breast cancer: a systematic review. International journal of food sciences and nutrition. 2015;66(1):1-42.

10.3109/09637486.2014.950207

81. Shield KD, Soerjomataram I, Rehm J. Alcohol Use and Breast Cancer: A Critical Review. Alcohol Clin Exp Res. 2016;40(6):1166-81. 10.1111/acer.13071

82. Sui Z, Zheng M, Zhang M, Rangan A. Water and Beverage Consumption: Analysis of the Australian 2011-2012 National Nutrition and Physical Activity Survey. Nutrients. 2016;8(11). 10.3390/nu8110678

83. Gibson S, Shirreffs SM. Beverage consumption habits "24/7" among British adults: association with total water intake and energy intake. Nutr J. 2013;12:9. 10.1186/1475-2891-12-9

84. Mistura L, D'Addezio L, Turrini A. Beverage Consumption Habits in Italian Population: Association with Total Water Intake and Energy Intake. Nutrients. 2016;8(11). 10.3390/nu8110674

85. Nissensohn M, Sanchez-Villegas A, Ortega RM, Aranceta-Bartrina J, Gil A, Gonzalez-Gross M, et al. Beverage Consumption Habits and Association with Total Water and Energy Intakes in the Spanish Population: Findings of the ANIBES Study. Nutrients. 2016;8(4):232. 10.3390/nu8040232 
86. Nissensohn M, Sanchez-Villegas A, Serra-Majem L. Beverage consumption habits amongst the Spanish population: association with total water and energy intake. Findings of the ANIBES study. Nutr Hosp. 2015;32 Suppl 2:10325. 10.3305/nh.2015.32.sup2.10325

87. Szabo de Edelenyi F, Druesne-Pecollo N, Arnault N, Gonzalez R, Buscail C, Galan P. Characteristics of Beverage Consumption Habits among a Large Sample of French Adults: Associations with Total Water and Energy Intakes. Nutrients. 2016;8(10). 10.3390/nu8100627

88. Grosso G, Micek A, Godos J, Pajak A, Sciacca S, Bes-Rastrollo M, et al. Long-Term Coffee Consumption Is Associated with Decreased Incidence of New-Onset Hypertension: A Dose-Response Meta-Analysis. Nutrients. 2017;9(8). 10.3390/nu9080890

89. Grosso G, Bella F, Godos J, Sciacca S, Del Rio D, Ray S, et al. Possible role of diet in cancer: systematic review and multiple meta-analyses of dietary patterns, lifestyle factors, and cancer risk. Nutrition reviews. 2017;75(6):405-19. 10.1093/nutrit/nux012

90. Caprioli G, Cortese M, Sagratini G, Vittori S. The influence of different types of preparation (espresso and brew) on coffee aroma and main bioactive constituents. International journal of food sciences and nutrition. 2015;66(5):505-13. 10.3109/09637486.2015.1064 



\section{Chapter 9}

General discussion 



\section{General summary}

One of the greatest challenges of the European Union $(\mathrm{EU})$ is to provide food and nutrition security, while dealing with environmental impacts of current patterns of food production, and ensuring that inequalities related to access to healthy food are minimized (1). Regional, national and local policies to facilitate universal access to safe and nutritious food, as well as a sustainable food supply, should be evaluated and, if effective (or cost-effective), implemented, at the right level (2).

The aim of the thesis has been threefold: firstly, to identify public health policies aimed at improving dietary habits in the European Union, while reducing health inequalities in the meantime; secondly, to examine current experiences in public health nutrition policies in Europe, focusing on the role of economic analyses in informing policymakers; thirdly, to assess synergies between health and environment when rethinking current patterns of food production and consumption, with the practical intention to determine which public health policies are low-hanging fruits and should therefore be implemented in the nearby future. Moreover, a case-study on coffee is presented, as an example of a nutrient which lays at the interplay of health, environment and social issues. The main findings of the thesis are presented in Figure 1.

\begin{tabular}{|c|c|c|c|c|c|}
\hline \multirow{2}{*}{$\begin{array}{l}\begin{array}{l}\text { Overarching } \\
\text { research question }\end{array} \\
\text { Content (including } \\
\text { the five research sub- } \\
\text { questions) }\end{array}$} & \multicolumn{5}{|c|}{$\begin{array}{l}\text { How such factors as equality-oriented approaches, economic analyses and systematic data } \\
\text { collection can contribute to informing food and nutrition policies in Europe, to improve public } \\
\text { health? }\end{array}$} \\
\hline & $\begin{array}{l}\text { Food and nutrition } \\
\text { policy in Europe: } \\
\text { How to address } \\
\text { nutrition-related } \\
\text { health inequalities? }\end{array}$ & $\begin{array}{l}\text { Food and nutrition } \\
\text { policy in Europe: } \\
\text { What is the role of } \\
\text { economic analyses } \\
\text { in evaluating food } \\
\text { and nutrition } \\
\text { policies? }\end{array}$ & $\begin{array}{l}\text { European nutrition } \\
\text { policy on healthy } \\
\text { and sustainable } \\
\text { diets: } \\
\text { What are the } \\
\text { practical } \\
\text { implications for } \\
\text { public health policy } \\
\text { makers when } \\
\text { considering health } \\
\text { and environment } \\
\text { simultaneously? }\end{array}$ & $\begin{array}{l}\text { Case study: } \\
\text { How systematic } \\
\text { collected data } \\
\text { inform our } \\
\text { knowledge on } \\
\text { chronic diseases, } \\
\text { using the case of } \\
\text { coffee in relation to } \\
\text { endometrial cancer? }\end{array}$ & $\begin{array}{l}\text { Case study: } \\
\text { How systematically } \\
\text { collected data } \\
\text { inform our } \\
\text { knowledge on } \\
\text { chronic diseases, } \\
\text { using the case of } \\
\text { coffee in relation to } \\
\text { breast cancer? }\end{array}$ \\
\hline Main findings & $\begin{array}{l}\text { There is a range of } \\
\text { policies to address } \\
\text { nutrition-related } \\
\text { health inequalities, } \\
\text { in the form of } \\
\text { universal } \\
\text { interventions (e.g. } \\
\text { school policies) or } \\
\text { targeted } \\
\text { interventions (e.g. } \\
\text { incentives or } \\
\text { subsidies). }\end{array}$ & $\begin{array}{l}\text { Few economic } \\
\text { evaluations have } \\
\text { been performed. } \\
\text { Researchers and } \\
\text { policymakers were } \\
\text { found to be } \\
\text { concerned by } \\
\text { implementation and } \\
\text { methodological } \\
\text { challenges, } \\
\text { respectively. }\end{array}$ & $\begin{array}{l}\text { Actions to } \\
\text { incorporate } \\
\text { sustainability into } \\
\text { food systems are } \\
\text { fragmented. } \\
\text { Sustainable dietary } \\
\text { guidelines might be } \\
\text { a valuable policy } \\
\text { option to exploit } \\
\text { health and } \\
\text { environmental } \\
\text { synergies. }\end{array}$ & $\begin{array}{l}\text { Increased coffee } \\
\text { consumption is } \\
\text { associated with } \\
\text { decreased risk of } \\
\text { endometrial cancer } \\
\text { in women, } \\
\text { regardless of their } \\
\text { menopausal status. }\end{array}$ & $\begin{array}{l}\text { Increased coffee } \\
\text { consumption is } \\
\text { associated with } \\
\text { decreased risk of } \\
\text { breast cancer in } \\
\text { post-menopausal } \\
\text { women. }\end{array}$ \\
\hline
\end{tabular}

Figure 1. Main findings of the thesis. Source: compiled by the author. 
In the following section, the main findings per chapter and per research question are summarized, followed by broader reflections on the EU role in public health nutrition and the scholarship's stance on the research topic. In a subsequent step, the way forward is discussed debating on the lessons learnt and delineating the perspectives for future research and policy. The limitations of this thesis are deliberated thoroughly in the last section. 


\section{Main findings of the thesis}

This thesis consists of four main parts, each addressing a specific structural block of the undertaken research study. Background information on public health nutrition in Europe corresponded to part one (Chapter 2 and 3), while the core of the thesis, constituted by health promotion, health protection and disease prevention actions in the field of nutrition, corresponded to part two, three and four, respectively (Chapter 4 to 8$)$.

Chapter 2 dealt with the burden of non-communicable diseases and related costs in the $\mathbf{E U}$, thus making the case for concerted action at the EU level in the field of public health nutrition. The chapter quantified the burden of disease attributable to dietary related risk factors in the EU, which amounted to about 16 million DALYs in 2017. Such burden was mostly caused by cardiovascular diseases; diabetes, cancers and chronic kidney disease were other frequent causes of diet-related deaths and disabilities. The economic costs related to non-communicable diseases in the EU were estimated, too: annual healthcare costs for chronic diseases were found to amount to 700 billion euro, and non-healthcare further increased the economic and social burden related to dietary risk factors. Given such estimates, the chapter highlights the importance of economic, social and environmental evaluations to address the question: "What are the impacts of the different policy options and who will be affected?"

Chapter 3 counterpoised the abundance of public health nutrition policy options with the lack of consensus on their expected impacts. The lack of consensus was particularly tangible on two specific policy options, namely simplified food labelling and fiscal instruments. The editorial closing question, "How do we raise nutritional standards?", is a tie between all the following chapters.

Chapter 4 investigated the unequal exposure to nutrition-related determinants in Europe and identified key nutritional policies to reduce inequalities in such exposure. The chapter aimed to summarize consolidated facts, on which the public health scientific community has already expressed a consensus; in order to capture the attention of policy-makers, the chapter had the form of a policy brief, and it should be intended as the consolidated scientific rationale for a political audience. Main sources were official documents and reports produced by governments, academics, and international organizations. Health inequalities were documented, both between and within countries, and measured using common indicators such as life expectancy at birth and standardized cause-specific mortalities; differences in several health determinants and behaviors (including differences in diets), and differences in health outcomes (e.g. obesity and chronic diseases) were reported, too. Finally, diet-related policies that target health inequalities were presented, in form of recommendations to be applied to the general population (school initiatives being only one example of universal interventions) or to the most vulnerable ones (for instances, in form of incentives or subsidies).

Chapter 5 further elaborated on public health nutritional policies, to assist the scientific and the decision-making communities in establishing what policies are good value for money. It explored facilitators and barriers in conducting and using economic analysis to inform 
decision makers in the field of public health nutrition, in the European Region. It consisted of a qualitative study (conventional content analysis), and data were collected through written openended interviews on 23 participants (13 from academia, 10 from policy), selected through purposive sampling. The analysis revealed a paucity of economic evaluations of health promotion policies and interventions; main barriers were represented by methodological challenges in performing economic evaluations and by implementation challenges in using economic evaluations in policy-making settings. Similarly, two categories of facilitators were found, the former linked to methodology, the latter linked to science-into-policy translations. Interestingly, researchers were more focused on implementation aspects, while policymakers were more concerned by methodological gaps.

Chapter 6 enlarged the field of discussion to environmental aspects, analyzing the impact of nutritional policies in Europe on health and environment simultaneously. An historical introduction elaborated on the transition from local farming to industrialized agriculture and describes the growing demand for diets deemed healthy (since the 1980s) and sustainable (since the 1990s). The literature review summarized evidence on current European diets and on costs and benefits in transitioning to healthy and sustainable diets: following a process of westernization, the direction of current dietary patterns seemed to be towards a common European dietary platform, with local and regional variations. Changes in eating environments (e.g. eating out and availability of fast food outlets) were documented, too. Costs to shift towards sustainable eating resided into higher monetary and non-monetary costs at the individual level (e.g. time and knowledge to prepare healthy and sustainable food), as well as into the societal costs related to implementation of policy options aimed at orienting peoples' choices. Benefits were identified as decreased social and economic burden of chronic diseases, and as lower environmental impacts, compared to actual dietary patterns. Finally, the review provided evidence-based policy recommendations: it pinpointed the limited and fragmented actions to incorporate sustainable aspects into food systems planning, and it identified sustainable dietary guidelines as the way forward in achieving dietary reforms, in the interests of improved nutrition and environmental protection.

Chapter 7 and chapter $\mathbf{8}$ are two systematic reviews and dose-response meta-analyses, which explored the relationship between coffee consumption and endometrial and breast cancer, thus representing a case study on systematic data collection and evidence generation in the field of nutrition. Eligible cohort studies were identified through PubMed and EMBASE databases, and data were extracted. The dose-response relationship and the risk of cancer for the highest versus the lowest categories of coffee consumption were assessed; moreover, subgroup analyses were carried out to control for potential confounders, such as menopausal status, smoking status, receptor positivity and BMI. The results, from 12 studies (endometrial cancer) and 21 studies (breast cancer), suggested that increased coffee consumption is associated with decreased risk of endometrial cancer (regardless of the menopausal status) and with decreased risk of breast cancer (evidence limited to postmenopausal women). 
Overall, this thesis resonates with previous literature, demonstrating that the burden of current dietary patterns and related chronic diseases is high and unequal $(3,4)$, and that effective policies can be either universal or specifically addressed to the poor $(5,6)$. In addition to socially-oriented policies, environmentally-oriented policies were analyzed and, in line with scholar evidence in the field, sustainable dietary guidelines have been identified as a desirable option $(7,8)$. Finally, this thesis found that, despite the abundancy of policies, there is little consensus on how to evaluate and implement these. Hence, in contrast to published literature, the findings support that barriers to economic evaluations in public health nutrition should be addressed comprehensively, evaluating simultaneously technical and implementational barriers $(9,10)$, to avoid shifting of responsibilities between researchers and policymakers.

Based on the summary of the main findings, the discussion moves now to broader reflections on public health nutrition in the EU context. Particularly, in relation to the assumed theoretical approach, EU efforts towards health promotion, disease prevention and management of noncommunicable diseases are here considered. 


\section{Revisiting public health nutrition in EU context \\ EU efforts towards health promotion, disease prevention and management of non-communicable diseases}

The current thesis highlights the huge social and economic burden related to nutrition and NCDs: in 2017, the EU dietary-related burden reached 16 million DALYs. In line with previous literature (11), the distribution of such burden was found to be highly unequal, following the social gradient in health that runs from top to bottom of the socioeconomic spectrum.

Most of the described policy options directed to reduce nutrition inequalities focused on obesity, which is the most described health outcome associated with dietary inequalities. Such strong emphasis on obesity, which characterized the first decade of the current century, may have its basis not only in scholarly research (12), but also in political will and deployed strategies and tools.

In May 2007, the European Commission established the first comprehensive action to address overweight and obesity across the member states, by adopting the "strategy on nutrition, overweight and obesity-related health issues" (13). The strategy highlighted the need of action at local, regional, national and European levels to reduce the risks associated with poor nutrition and limited physical exercise, while addressing the issue of inequalities across member states. Moreover, the strategy identified a range of Commission policies as cornerstone: food labelling, health and nutrition claims, school fruit scheme, school milk scheme, audiovisual media services directive are few examples. In concomitance with the publication of the Strategy, the "High-level group on nutrition and physical activity" was created, to strengthen the role of the governments in counteracting overweight and obesity, and to coordinate the work of the already established "EU platform for action on diet, physical activity and health" and their voluntary commitments towards better dietary standards (14).

In more recent years, in recognition of the current global epidemic of NCDs, the research and the policy communities singled out the growing importance of a holistic approach towards NCDs (15). Among others, the 2030 Sustainable Development Agenda signs a shift of focus, from overweight and obesity to NCDs (16).

In light of the Sustainable Development Agenda and of the third Programme for the Union's action in the field of health (2014-2020), in July 2018 the European Commission created the "steering group on health promotion, disease prevention and management of noncommunicable diseases" (17), to assist the Commission in taking its initiatives to address the challenges caused by chronic diseases. It should select best practices and assess the outcomes of their transfer and implementation in other context, thus fostering exchanges of relevant experiences, policies and practices between Member States.

With regards to nutrition and public health, the steering group has selected an initial set of policy interventions that will be implemented by multiple EU countries, and is selecting the next priority areas for the implementation of best practices. One of the support resources available for the steering group is the collection of the policy briefs published on the knowledge gateway 
on health promotion and disease prevention. Three policy briefs constitute part of the present thesis: "EU burden from non-communicable diseases and key risk factors" and "Cost of Non-Communicable Diseases in the EU" form Chapter 2, while "Health inequalities: dietary and physical activity-related determinants" corresponds to Chapter 4.

Few closing reflections link the present thesis with the current EU policy landscape with: first, it was found that public health nutrition policy options targeted to reduce health inequalities may have the form of universal interventions or interventions tailored to the most disadvantaged. Considering the intrinsic pan-governmental nature of the European Union, it is not surprising the EU interest is highly directed towards those universal interventions aimed to improve nutrition public health and reduce health inequalities simultaneously, for instance through school initiatives.

Second, the current research found that there is little consensus on how to perform economic evaluations of public health policies, thus hampering their use in policymaking. As already stated in the introduction, the European Commission Better Regulation Agenda is a first effort to compare systematically policy alternatives, in terms of effectiveness, efficiency, coherence and distributional effects. Despite tangible examples in which impact assessment has been an essential step in policymaking, such as the TFA case, the EU and its Member States are still far away from considering economic evaluations as integral part of their routine policymaking.

Third, environmentally-oriented nutritional policies, in the form of sustainable dietary guidelines, have been identified as a desirable option. The knowledge gateway, in its extensive sub-section on FBDG in Europe, moves forward the original definition of FBDG: beyond describing the common food groups, references to physical activity, overall diet and lifestyle habits, and environmental sustainability are also considered. The introduction of environmental aspects in a technical document, originally intended for public health stakeholders, together with the European Green Deal and its "Farm to Fork" strategy (18), should be read as positive signs towards alignment of health and environmental instances in the field of food systems. 


\section{Implications for research and policy}

The discussion now moves to implications for research and policy, highlighting future perspectives in three dimensions, which are the leading dimensions of the thesis: public health nutrition and inequalities; economic evaluations in public health nutrition; environmental aspects related to food systems. 


\section{Public health nutrition and inequalities: data generation to guide nutritional practice and policy}

The link between socio-economic status (SES) and health is well established, and the existence of health inequalities in Europe has been widely documented by the scientific community (3, 19).

Concordant is the perception of the policy community: according to the European Food and Nutrition Action Plan 2015-2020, "tackling avoidable inequalities in diet and achieving universal access across social gradients (age, gender, ethnicity, disability or socioeconomic position) will be necessary to achieve the best results and will support human capital and the economy in all Member States at a time of limited resources. Policies that have the effect of improving the availability, affordability and acceptability of healthy diets for the most vulnerable groups (thereby influencing the accessibility of healthy diets) can contribute to reducing their risks for disease and, in tandem with policies in other areas, may help to close the gap" (20).

In line with previous evidence $(21,22)$, the present work confirms the presence of a gradient in chronic diseases and obesity according to SES. A study carried out on 13 European states attributed to differences in SES over than $40 \%$ of obesity in women and more than $20 \%$ in men $(21,22)$. Among children, obesity and overweight were associated with low SES of their parents, especially of mothers (23).

The current thesis adds to the growing body of evidence on the link between the SES and chronic diseases $(22,24)$, which is at least partially mediated by an existing gradient in exposure to dietary risk factors (25). Among other socioeconomic determinants, the level of education was found to have a strong influence on household food choices, purchases and eating patterns. This relationship has been documented by other authors in various contexts, such as the purchases of fish, of fruit and vegetables, and of fats and cheese (26-30), both in adults and in children (31).

Despite the relative success of the European Union in avoiding the aggravation of health inequalities after the 2008 economic crisis, health inequalities persist and represent a public health priority (4). Some scholars argue that additional descriptive studies on inequality might not be needed: it is time to use the already produced measures of inequalities to pragmatically inform and guide public health practice and policy (32).

Research on policy options to reduce inequality is also abundant, with areas of consensus and discrepancy, as presented in Chapter 4 of the present dissertation.

Fiscal instruments, particularly those in the form of taxes, were found to be controversial, as they might widen inequalities if inappropriately applied. Our findings resonate with previous literature: for instance, some authors argue that, if not properly designed, a food tax has its highest burden on the poor, who are more likely to purchase foods of poor nutritional value (33) and spend a greater proportion of their incomes on food purchases than people of higher SES (34). The combination of taxes with subsidies could provide a fairer approach, by preventing the widening in health inequalities (35). Similarly, the EAT-Lancet Commission, which is in charge 
of constructing the first global benchmark diet capable of sustaining health and protecting the planet, remarked that pricing is crucial: healthy and sustainable diets are affordable in many countries, but a combination of higher income, nutritional assistance, and lower prices is still needed for those most vulnerable (36).

In the current thesis, the provision of information was also found to be a potential source of increased health inequalities. The observation is in line with the work of authors, who found that interventions aimed at increasing the provision of information, such as food labeling, could potentially increase health disparities, as they have a higher effect on people from a higher SES than on people from a lower status $(37,38)$. Food literacy, which is the idea of proficiency in food related skills and knowledge (critical knowledge on understanding food-related information, rather than functional knowledge, constituted by skills, abilities and choices) (39) has been repeatedly shown to be limited in the elderly, in people with low education, and in those financially deprived, where it concurs in producing impaired health status (40-42). In line with those researchers highlighting the need for food literacy programs focused on targeting specific subgroups characterized by the lowest food-literacy behaviors $(43,44)$, the current thesis found that user-friendly labeling to help customers make healthy food choices are related to reductions in health inequalities (45-48).

Our results show that initiatives aimed at changing the default and making healthy choice the easy choice have been associated to decreased inequalities. Scholarly evidence in the field span from reformulation initiatives to changes to the physical environment and advertising and marketing. Previous researcher in various European countries associates reformulation initiatives (in the form of mandatory bans or voluntary agreements with industry to limit the content of transfats, sugar and salt, without changes in price to consumers) to reduced inequalities in dietrelated behaviors (49-52). Similarly, changes to the physical environment to avoid food deserts and to guarantee access to supermarkets were found to address the currently observed health inequalities in diet-related behaviors $(53,54)$. While the literature on the effect on inequalities of reformulation policies and physical environment policies is in line with our findings, there is no conclusive evidence on advertising and marketing. If on one hand it is clear that residents in deprived areas are more exposed to ultra-processed food advertisement than those in wealthy areas $(55,56)$, and that children from poorer communities are more exposed to pervasive food marketing than children from wealthier neighborhoods (57-59), there are only few attempt to quantify the relationship between restriction in advertising and marketing and amelioration of health inequalities.

Finally, we found that universal interventions, for instance in the form of school interventions to promote healthy eating, are often successful in reducing health inequalities related to dietary behaviors. Similarly, various authors have shown that obesity and diet-related inequalities can be effectively reduced through school interventions in disadvantaged areas, especially if synergies with parents exist and if school interventions can embrace various component, such as nutrition and physical activity together (60-63). 
Despite an increasing body of evidence on public health nutritional policies aimed at reducing health inequalities (64), we still observe the deployment of strategies that are not effective enough in reducing health inequalities (65). As a scientific community, we should not stop our genuine interest in advancing tools to promote health equity across the European Union (66). 


\section{Economic evaluations in public health nutrition: data generation beyond cost-effectiveness to evaluate public health nutritional policies and further ameliorate current practices}

The impacts of nutrition-related diseases and disorders on the healthcare and social systems make nutrition an interesting area for economic analyses. The present thesis revealed an increasing body of evidence on economic evaluation studies conducted on interventions aimed at dietary improvements, especially in the field of food reformulation, which involves reducing the levels of fats, salt and sugar in processed foods. It is not surprising that most economic evidence in nutrition comes from reformulation initiatives: they are often pursued through a centralized, governmental action, in the form of legal limit or ban, with strong evidence needed to support their implementation.

Scholarly evidence in the field shows that reformulation interventions are cost-saving or costeffective, especially in regards to salt (67), while evidence on sugar and fats looks less conclusive $(68,69)$. Interestingly, most studies take quite a narrow healthcare perspective where only direct medical costs are included; few studies include a societal perspective where societal costs (e.g. social care and productivity-related losses) are also factored in. Very few studies, considered almost "exceptions", take a wider public sector perspective where costs incurred by government in order to implement the nutrition intervention are included, in the form of media advertising, loss of tax revenues, or food and vegetable food stamps for low-income consumers (67-69).

Such findings are in line with our research, which showed that the research community and the policy making community work in silos, are little aware of each other issues, and tend to narrow their focus rather than enlarging it.

Specifically, our results say that methodologies and guidelines originally developed for the economic evaluation of healthcare interventions are often not appropriate to the economic evaluation of nutrition interventions and two main issues were identified from a methodological point of view.

Definition and measurement of outcomes: our research found that the choice and definition of the outcome to report on may affect the validity of the economic analysis itself. Our results resonate with previous literature, which reiterates: (a) the inadequacy of health outcomes such as QALYs or DALYs to evaluate public health nutrition interventions, (b) the necessity to account for the so-called spillover effect, to evaluate the consequences of the intervention on the social environment and include unintended effects, and (c) the difficulty to attribute effects to specific interventions, as lifestyle interventions affect several diseases or risk factors simultaneously $(70,71)$.

Absence of adequate frameworks to guide PHEE: our research found that the need for carefully designed frameworks and methodologies suitable to public health nutrition is high. Previous evidence on the field highlighted the need to identify inter-sectoral costs and consequences: productivity changes or price changes (for example in the case of nutrient taxes or marketing restrictions), and their impact on the food industry and consumers should be 
considered as integral part of a public health economic evaluation (72, 73). Moreover, other authors underline that equity aspects are hardly incorporated in economic evaluation of public health interventions (74), especially in the field of nutritional policies and interventions (75). Taken together, all these observations are coherent in stating that better tools are a condition sine qua non to achieve more meaningful influence of economic evaluations on policy-making (76).

Two final thoughts, elaborated during the JRC workshop "Public Health and Nutrition Economics: the numbers behind prevention?" (77), are here presented. The workshop involved most of the interviewed participants in the qualitative research presented in Chapter 5, and the following closing messages should be read in parallel to the identified facilitators to the use of economic evaluations in public health nutrition interventions.

First, the effect of public health interventions has to be assessed through rigorous monitoring of interventions, so that their effectiveness is clear and the data can be used for further economic evaluations. Ramp up surveillance efforts at different levels should be implemented, too: for example, a research infrastructure should be in place to create and maintain reliable data registries.

Second, for further development of the field, we should share and disseminate know-how and create platforms and spaces to promote and expand the community of practice, moving beyond the silo approach encountered and described in the current thesis. Enablers such as toolkits, manuals and online platforms are strengthened if they have a political mandate behind them, and if a multidisciplinary and inclusive approach is taken.

In conclusion, with sound economic evaluations of public health interventions, which produce ranking and priority actions, decision making could be effectively informed and directed towards enhancement of population health, while minimizing costs simultaneously. 


\section{Environmental aspects related to food systems: data generation on sustainable guidelines and sustainability in all policies}

Dietary choices have an effect on human health and on environment, too. Visible examples of such impact include threats to climate, biodiversity and ecosystem resilience. While substantial improvements were made over the past decades, concern has been expressed that health agencies, at regional and national level, have not included sustainability as an integral part of multi-sectoral food policy (78).

To create the scientific context for the current debate on how to address environmental issues in the context of food policy, an extensive literature review has been conducted and the main results are presented in Chapter 6 and in the report "Sustainable and healthy eating", published by the Food and Nutrition Section of EUPHA (European Public Health Association).

In line with previous literature, the current thesis states that environmental and health effects are often concordant: many food items classified as healthy, whose consumption is recommended by most dietary guidelines (i.e. fruit and vegetables, grains and pulses) have also a restrained environmental impact, while food items whose consumption should be limited (meat and highly processed foods) have a higher environmental impact (79-83).

Moreover, it was found that compliance with healthy eating guidelines leads to lower energy demands and a decrease in GHGEs, largely due to a lesser reliance on livestock-based food products $(84,85)$. When reducing the consumption of livestock-based food products, the beneficial effects on environment are not limited to climate: less arable land and grassland is needed for animal feed production; moreover, vegetable protein production requires much less farmland per unit of protein produced than does animal protein production $(86,87)$.

Yet, as found by many scholars, even healthy food can have negative and often hidden consequences for the environment if not properly monitored (88-90), and vice versa $(91,92)$. A clear example belonging to the first category is represented by added sugar, whose environmental impact is trivial, contrarily to its health impact (93). A typical example of the second category, where differences in health impacts are negligible while differences in environmental impacts are burdensome, is the consumption of imported seafood rather than local seafood $(94,95)$.

When enlarging the focus from GHGEs to other environmental effects, such as for example land use, water use, biodiversity, pollution $(96,97)$, coffee is a good example to examine: its exposure has been related to reduced incidence of type 2 diabetes mellitus, obesity, cardiovascular disease and some type of cancers (98-102), as discussed in Chapters 7 and 8 ; its environmental impact is felt across all life cycle steps, from coffee growing (in tropical and equatorial areas) through to its distribution to consumers (whose two thirds live in the United States and in the European Union), consumption and disposal (103). Due to climate change, growing conditions for coffee crops are changing, and crops are moving to new areas, with an unknown cumulative environmental effect, which is nevertheless supposed to impact on water, 
wildlife, pollinator interaction, carbon storage and nature conservation, on national to global scales (104).

In light of the above considerations, since the contribution of healthy diets does not produce enough reductions in GHGEs and in environmental impacts in general, the present thesis is an additional piece of evidence (105) calling for the inclusion of environmental sustainability recommendations into dietary guidelines.

Food Based Dietary Guidelines (FBDG) are science-based recommendations in the form of guidelines for healthy eating, primarily intended for consumers. To date, very few countries have included sustainability in their FBDG (8): in Europe, Sweden and Germany have been pioneering the practice. Other European countries have official or quasi-official FBDG addressing environmental aspects, for instance with a reference to buying seasonal and regional produce $(106,107)$, or to choosing sustainably sourced fish (108). Yet, despite convincing evidence of the very considerable impact that food systems and human diets exert on public and planetary health, concerted dietary guidelines that include sustainable aspects are lacking in Europe.

Further research should be based on continued interdisciplinary collaboration to advance dietary guidance that promotes sustainable nutrition (109), to avoid dangerous unwanted effects either on human health or on the environment.

Moreover, the sustainability in all policies (SiAP) strategy goal, which suggests that healthy environments are pivotal in ensuring health and development, provides a clear remand to the idea of "health in all policies" (HiAP). Born in 2006, when the Finnish presidency of the EU first used the term, and sprouted from the importance of social determinants of health, HiAP is now a core principle in all public policy making (110). The current thesis, together with the scholar debate on sustainable and healthy nutrition, reinforces the need of the recently coined term, SiAP, and hopefully will contribute to its success. 


\section{Limitations}

Apart from the limitations of each study of the present thesis, which are discussed extensively within each chapter, there are broader limitations regarding the scope of this research. Such limitations are content-related limitations or methodological limitations.

In regard of the content-related limitations, the broadness and the cross-disciplinary nature of the topic are the main inherent limitations of this thesis. When the research started, in 2015, the review of inequities in health between and within countries across the 53 Member States of the WHO European Region had just been published (22). Meanwhile, the EUPHA President called for a greater alignment of healthy and sustainability messages on diet and nutrition, and commissioned a report to the Food \& Nutrition Section (78). In the same months, the JRC hosted a debate on economic evaluations in the area of public health nutrition, addressing gaps and barriers, and suggesting ways forward (77). In view of such a broad landscape, the approach taken in this research reflects one particular framing of the research questions and proposed solutions, which is influenced by the author's expertise and chosen framework.

The cross-disciplinary nature of the current thesis is openly addressed through the use of three different perspectives, namely the health policy perspective, the economic perspective and the data and information perspective. Although differentiated, such perspectives are not exhaustive: the selection of the analyzed perspectives stemmed from the author's individual competences and choices, which inherently limits the scope of the assessment and the proposed solutions.

With regards to methods, some authors could argue that different methodologies from the adopted ones could have been applied to each session. Particularly, the use of editorials, scoping reviews and policy briefs could be felt unusual or even inappropriate. Nevertheless, the importance of the topic required communication tools; tools as editorials, scoping reviews and policy briefs were used to target a specific audience, and to capture the attention of policymakers at the EU level.

Moreover, it should be noticed that the variety of applied methods in this thesis underlines the multiple research foci of the thesis itself. Qualitative analysis (content analysis) was deemed most suitable method to explore expert perceptions on the use of economic analyses to evaluate public health nutrition interventions, and to identify facilitators and barriers in the implementation of such analyses. Quantitative approaches (systematic reviews and metaanalyses) were applied for epidemiological public health nutrition research within this thesis' data and information perspective.

The chosen framework was based on the core Essential Public Health Operators (EPHOs) established by the WHO. Other frameworks could have been used, such as, for instance, the one adopted by the Joint Programming Initiative 'A healthy diet for a healthy life' (JPI HDHL). The JPI HDHL, which is a scientific and voluntary partnership between Member States and Associated Countries of the EU, aimed at addressing major societal challenges, is structured into three key interacting research areas: determinants of diet and physical activity (including a sound understanding of effective policies for improving public health); diet and food production 
(including actions targeted at food stakeholders, from farmers to consumers); diet-related chronic diseases (including prevention of diet-related chronic diseases, such as cancers). The choice of the structure adopted by the JPI HDHL would have been supported by authors demanding for a more specific focus on diet and nutrition. Yet, the EPHOs framework looks the best fit for public health scholars, interested in promoting health, preventing diseases and fostering supportive environments for healthy lifestyles.

In general, the breadth and cross-disciplinary dimension of the research topic posed difficulties. This thesis did not provide an all-in-one solution; yet, it constitutes a comprehensive set of actions for improving public health nutrition in Europe, considering the role of economic evaluations of policy options, their impact on inequalities, and enlarging the discussion to environmental aspects and to the need of systematic data collection and integrated approaches. 


\section{Conclusion}

This thesis has stated the public health policies in the field of food and nutrition fall short in creating healthy and sustainable living conditions for all, and therefore in preventing avoidable health burden from noncommunicable diseases (which is maximum for people at the lower hand of the socio-economic spectrum) and avoidable environment burden from the current pattern of food production and consumption. Moreover, the research found that public health policy options are only occasionally evaluated from a cost-effective perspective before their implementation, due to not only technical difficulties (perceived by policy-makers), but also to lack of political interest and commitment (perceived by researchers).

Despite the many efforts deployed over the last few years, at both EU and Member States levels (Better Regulation Agenda, European Green Deal with Farm to Fork Strategy, country implementation of Sustainable Dietary Guidelines, local implementation of School Schemes, just to name few), currently there is no culture to assess, compare and evaluate public health nutrition policy options under the multiple facets they should be examined through, such as effectiveness and cost-effectiveness, redistribution effects, and environmental impacts. Considering the EU predominant role in the field of climate change and environmental health, as well as the social roots of the EU itself, both EU and Member States should promote a better policymaking, to create healthy and sustainable living conditions for all EU citizens. 


\section{References}

1. Zurek M, Hebinck A, Leip A, Vervoort J, Kuiper M, Garrone M, et al. Assessing sustainable food and nutrition security of the EU food system—an integrated approach. Sustainability. 2018;10(11):4271.

2. Capacci S, Mazzocchi M, Shankar B, Brambila Macias J, Verbeke W, Pérez-Cueto FJA, et al. Policies to promote healthy eating in Europe: a structured review of policies and their effectiveness. Nutrition Reviews. 2012;70(3):188-200.

3. Marmot M. The Health Gap: The Challenge of an Unequal World: the argument. International journal of epidemiology. 2017;46(4):1312-8.

4. Mackenbach JP, Valverde JR, Artnik B, Bopp M, Brønnum-Hansen H, Deboosere P, et al. Trends in health inequalities in 27 European countries. Proceedings of the National Academy of Sciences of the United States of America. 2018;115(25):6440-5.

5. Health WHOEMCoCODaPAf, Europe WHOROf. Comparative analysis of nutrition policies in the WHO European Region : a comparative analysis of nutrition policies and plans of action in WHO European Region, May 2006. 2006.

6. Europe WHO. Obesity and inequities - Guidance for addressing inequities in overweight and obesity. 7. Lang T, Mason P. Sustainable diet policy development: implications of multi-criteria and other approaches, 2008-2017. Proc Nutr Soc. 2018;77(3):331-46.

8. Fischer CG, Garnett T. Plates, pyramids and planets - Developments in national healthy and sustainable dietary guidelines: a state of play assessment. Food and Agriculture Organization of the United nations and Food Climate Research Network (FCRN), University of Oxford.; 20162016.

9. Lenoir-Wijnkoop I, Dapoigny M, Dubois D, van Ganse E, Gutierrez-Ibarluzea I, Hutton J, et al. Nutrition economics - characterising the economic and health impact of nutrition. The British journal of nutrition. 2011;105(1):157-66.

10. Weatherly H, Drummond M, Claxton K, Cookson R, Ferguson B, Godfrey C, et al. Methods for assessing the cost-effectiveness of public health interventions: key challenges and recommendations. Health policy (Amsterdam, Netherlands). 2009;93(2-3):85-92.

11. Collaborators GRF. Global, regional, and national comparative risk assessment of 84 behavioural, environmental and occupational, and metabolic risks or clusters of risks for 195 countries and territories, 1990-2017: a systematic analysis for the Global Burden of Disease Study 2017. Lancet.

2018;392(10159):1923-94.

12. Friedman JM. Obesity in the new millennium. Nature. 2000;404(6778):632-4.

13. White Paper on A Strategy for Europe on Nutrition, Overweight and Obesity related health issues \{SEC(2007) 706\} \{SEC(2007) 707\} / Internal Document.

14. Diet, Physical Activity and Health: A European Plaftorm for Action (2005)

https://ec.europa.eu/health/ph_determinants/life_style/nutrition/platform/docs/platform_charter.pdf. Accessed on: January 2020.

15. Egger G, Dixon J. Beyond obesity and lifestyle: a review of 21 st century chronic disease determinants. BioMed research international. 2014;2014:731685-.

16. United Nations General A. Transforming our world: the 2030 Agenda for Sustainable Development: Sustainable Development Knowledge Platform. 2015.

17. Commission Decision of 17.7.2018 setting up a Commission expert group "Steering Group on Health Promotion, Disease Prevention and Management of Non-Communicable Diseases" and repealing the Decision setting up a Commission expert group on rare diseases and the Decision establishing a Commission expert group on Cancer Control. 
18. Communication From The Commission To The European Parliament, The European Council, The Council, The European Economic And Social Committee And The Committee Of The Regions. The European Green Deal COM/2019/640 final.

19. Marmot M. Health in an unequal world: social circumstances, biology and disease. Clinical medicine (London, England). 2006;6(6):559-72.

20. WHO. European Food and Nutrition Action Plan 2015-2020. 2014.

21. Robertson LaKftEC. Obesity and socio-economic groups in Europe: evidence review and implications for action.

22. WHO. Review of social determinants and the health divide in the WHO European Region ISBN 9789289000307

http://www.euro.who.int/en/publications/abstracts/review-of-social-determinants-and-the-healthdivide-in-the-who-european-region.-final-report

23. Europe WHOROf. Growing up unequal. HBSC 2016 study (2013/2014 survey). 20162016.

24. Lago S, Cantarero D, Rivera B, Pascual M, Blázquez-Fernández C, Casal B, et al. Socioeconomic status, health inequalities and non-communicable diseases: a systematic review. Zeitschrift fur Gesundheitswissenschaften = Journal of public health. 2018;26(1):1-14.

25. Piccinelli C, Carna P, Stringhini S, Sebastiani G, Demaria M, Marra M, et al. The contribution of behavioural and metabolic risk factors to socioeconomic inequalities in mortality: the Italian Longitudinal Study. Int J Public Health. 2018;63(3):325-35.

26. Elmadfa I. European Nutrition and Health Report 2009: Karger Medical and Scientific Publishers; 2009 2009/01/01/. 426 p.

27. Sanchez-Villegas A, Martínez JA, Prättälä R, Toledo E, Roos G, Martínez-González MA. A systematic review of socioeconomic differences in food habits in Europe: consumption of cheese and milk. European Journal of Clinical Nutrition. 2003;57(8):917-29.

28. López-Azpiazu I, Sánchez-Villegas A, Johansson L, Petkeviciene J, Prättälä R, Martínez-González MA, et al. Disparities in food habits in Europe: systematic review of educational and occupational differences in the intake of fat. Journal of Human Nutrition and Dietetics. 2003;16(5):349-64.

29. Mullie P, Clarys P, Hulens M, Vansant G. Dietary patterns and socioeconomic position. European Journal of Clinical Nutrition. 2010;64(3):231-8.

30. Rodrigues SSP, Caraher M, Trichopoulou A, de Almeida MDV. Portuguese households' diet quality (adherence to Mediterranean food pattern and compliance with WHO population dietary goals): trends, regional disparities and socioeconomic determinants. European Journal of Clinical Nutrition. 2008;62(11):1263-72.

31. Fernández-Alvira JM, Bammann K, Pala V, Krogh V, Barba G, Eiben G, et al. Country-specific dietary patterns and associations with socioeconomic status in European children: the IDEFICS study. European Journal of Clinical Nutrition. 2014;68(7):811-21.

32. Newton JN. Counting early deaths due to socioeconomic inequality. Lancet Public Health. 2020;5(1):e6-e7.

33. Darmon N, Drewnowski A. Contribution of food prices and diet cost to socioeconomic disparities in diet quality and health: a systematic review and analysis. Nutrition reviews. 2015;73(10):643-60.

34. Loring B, Robertson A. Obesity and inequities. Guidance for addressing inequities in overweight and obesity: World Health Organization; 20142014.

35. World Health O. Using price policies to promote healthier diets (2015)2015 2015.

36. Hirvonen K, Bai Y, Headey D, Masters WA. Affordability of the EAT-Lancet reference diet: a global analysis. Lancet Glob Health. 2020;8(1):e59-e66. 
37. Afshin A, Penalvo J, Del Gobbo L, Kashaf M, Micha R, Morrish K, et al. CVD Prevention Through Policy: a Review of Mass Media, Food/Menu Labeling, Taxation/Subsidies, Built Environment, School Procurement, Worksite Wellness, and Marketing Standards to Improve Diet. Curr Cardiol Rep.

2015;17(11):98.

38. Afshin A, Micha R, Khatibzadeh S, Schmidt LA, Mozaffarian D. Dietary Policies to Reduce NonCommunicable Diseases. In: Brown GW, Yamey G, Wamala S, editors. The Handbook of Global Health Policy: John Wiley \& Sons, Ltd; 2014. p. 175-93.

39. Truman E, Lane D, Elliott C. Defining food literacy: A scoping review. Appetite. 2017;116:365-71. 40. Palumbo R, Adinolfi P, Annarumma C, Catinello G, Tonelli M, Troiano E, et al. Unravelling the food literacy puzzle: Evidence from Italy. Food Policy. 2019;83:104-15.

41. Truman E, Elliott C. Barriers to Food Literacy: A Conceptual Model to Explore Factors Inhibiting Proficiency. Journal of Nutrition Education and Behavior. 2019;51(1):107-11.

42. Begley A, Paynter E, Butcher LM, Dhaliwal SS. Examining the Association between Food Literacy and Food Insecurity. Nutrients. 2019;11(2).

43. Begley A, Butcher LM, Bobongie V, Dhaliwal SS. Identifying Participants Who Would Benefit the Most from an Adult Food-literacy Program. Int J Environ Res Public Health. 2019;16(7).

44. McGowan L, Pot GK, Stephen AM, Lavelle F, Spence M, Raats M, et al. The influence of sociodemographic, psychological and knowledge-related variables alongside perceived cooking and food skills abilities in the prediction of diet quality in adults: a nationally representative cross-sectional study. The international journal of behavioral nutrition and physical activity. 2016;13(1):111-

45. Sadana R, Blas E. What Can Public Health Programs Do to Improve Health Equity? Public Health Reports. 2013;128(6_suppl3):12-20.

46. Egnell M, Ducrot P, Touvier M, Alles B, Hercberg S, Kesse-Guyot E, et al. Objective understanding of Nutri-Score Front-Of-Package nutrition label according to individual characteristics of subjects: Comparisons with other format labels. PLoS One. 2018;13(8):e0202095.

47. Pettigrew S, Talati Z, Miller C, Dixon H, Kelly B, Ball K. The types and aspects of front-of-pack food labelling schemes preferred by adults and children. Appetite. 2017;109:115-23.

48. Ducrot P, Mejean C, Julia C, Kesse-Guyot E, Touvier M, Fezeu LK, et al. Objective Understanding of Front-of-Package Nutrition Labels among Nutritionally At-Risk Individuals. Nutrients. 2015;7(8):7106-25.

49. Allen K, Pearson-Stuttard J, Hooton W, Diggle P, Capewell S, O'Flaherty M. Potential of trans fats policies to reduce socioeconomic inequalities in mortality from coronary heart disease in England: cost effectiveness modelling study. Bmj. 2015;351:h4583.

50. Leroy P, Requillart V, Soler LG, Enderli G. An assessment of the potential health impacts of food reformulation. Eur J Clin Nutr. 2016;70(6):694-9.

51. Pearson-Stuttard J, Hooton W, Critchley J, Capewell S, Collins M, Mason H, et al. Cost-effectiveness analysis of eliminating industrial and all trans fats in England and Wales: modelling study. J Public Health (Oxf). 2017;39(3):574-82.

52. Hutchinson J, Rippin HL, Jewell J, Breda JJ, Cade JE. Comparison of high and low trans-fatty acid consumers: analyses of UK National Diet and Nutrition Surveys before and after product reformulation. Public Health Nutr. 2018;21(3):465-79.

53. Burgoine T, Mackenbach JD, Lakerveld J, Forouhi NG, Griffin SJ, Brage S, et al. Interplay of Socioeconomic Status and Supermarket Distance Is Associated with Excess Obesity Risk: A UK CrossSectional Study. International journal of environmental research and public health. 2017;14(11):1290. 
54. Lewis LB, Galloway-Gilliam L, Flynn G, Nomachi J, Keener LC, Sloane DC. Transforming the Urban Food Desert From the Grassroots Up: A Model for Community Change. Family \& Community Health. 2011;34:S92-S101.

55. Fagerberg P, Langlet B, Oravsky A, Sandborg J, Lof M, Ioakimidis I. Ultra-processed food advertisements dominate the food advertising landscape in two Stockholm areas with low vs high socioeconomic status. Is it time for regulatory action? BMC Public Health. 2019;19(1):1717.

56. Adams J, Ganiti E, White M. Socio-economic differences in outdoor food advertising in a city in Northern England. Public Health Nutr. 2011;14(6):945-50.

57. Boyland EJ, Nolan S, Kelly B, Tudur-Smith C, Jones A, Halford JCG, et al. Advertising as a cue to consume: a systematic review and meta-analysis of the effects of acute exposure to unhealthy food and nonalcoholic beverage advertising on intake in children and adults1,2. The American Journal of Clinical Nutrition. 2016;103(2):519-33.

58. Jenkin G, Madhvani N, Signal L, Bowers S. A systematic review of persuasive marketing techniques to promote food to children on television. Obesity Reviews. 2014;15(4):281-93.

59. Velazquez CE, Black JL, Potvin Kent M. Food and Beverage Marketing in Schools: A Review of the Evidence. Int J Environ Res Public Health. 2017;14(9).

60. Luybli M, Schmillen H, Sotos-Prieto M. School-Based Interventions in Low Socioeconomic Settings to Reduce Obesity Outcomes among Preschoolers: A Scoping Review. Nutrients. 2019;11(7).

61. Pearce A, Dundas R, Whitehead M, Taylor-Robinson D. Pathways to inequalities in child health. Arch Dis Child. 2019;104(10):998-1003.

62. Bickham DS, Hswen Y, Slaby RG, Rich M. A Preliminary Evaluation of a School-Based Media Education and Reduction Intervention. J Prim Prev. 2018;39(3):229-45.

63. Mackenbach JD, Nelissen KGM, Dijkstra SC, Poelman MP, Daams JG, Leijssen JB, et al. A Systematic Review on Socioeconomic Differences in the Association between the Food Environment and Dietary Behaviors. Nutrients. 2019;11(9):2215.

64. Evans CEL. Sugars and health: a review of current evidence and future policy. Proc Nutr Soc. 2017;76(3):400-7.

65. Hu Y, van Lenthe FJ, Judge K, Lahelma E, Costa G, de Gelder R, et al. Did the English strategy reduce inequalities in health? A difference-in-difference analysis comparing England with three other European countries. BMC Public Health. 2016;16(1):865.

66. Santana P, Freitas A, Stefanik I, Costa C, Oliveira M, Rodrigues TC, et al. Advancing tools to promote health equity across European Union regions: the EURO-HEALTHY project. Health Res Policy Syst. 2020;18(1):18.

67. Cobiac LJ, Veerman L, Vos T. The role of cost-effectiveness analysis in developing nutrition policy. Annual Review of Nutrition. 2013;33:373-93.

68. Federici C, Detzel P, Petracca F, Dainelli L, Fattore G. The impact of food reformulation on nutrient intakes and health, a systematic review of modelling studies. BMC Nutrition. 2019;5(1):2.

69. Fattore G, Ferre F, Meregaglia M, Fattore E, Agostoni C. Critical review of economic evaluation studies of interventions promoting low-fat diets. Nutr Rev. 2014;72(11):691-706.

70. Gyles CL, Lenoir-Wijnkoop I, Carlberg JG, Senanayake V, Gutierrez-Ibarluzea I, Poley MJ, et al. Health economics and nutrition: a review of published evidence. Nutrition reviews. 2012;70(12):693-708. 71. Szucs TD, Stoffel AW. Nutrition and health-Why payors should get involved. Nutrition. 2016;32(5):615-6.

72. Collins B, Kypridemos C, Pearson-Stuttard J, Huang Y, Bandosz P, Wilde P, et al. FDA Sodium Reduction Targets and the Food Industry: Are There Incentives to Reformulate? Microsimulation CostEffectiveness Analysis. Milbank Q. 2019;97(3):858-80. 
73. Donaldson C, Birch S, Gafni A. The distribution problem in economic evaluation: income and the valuation of costs and consequences of health care programmes. Health Econ. 2002;11(1):55-70.

74. Poley MJ. Nutrition and health technology assessment: when two worlds meet. Frontiers in Pharmacology. 2015;6(232).

75. Zorbas C, Grigsby-Duffy L, Backholer K. Getting the Price Right: How Nutrition and Obesity Prevention Strategies Address Food and Beverage Pricing Within High-Income Countries. Curr Nutr Rep. 2020;9(1):42-53.

76. Gutiérrez-Ibarluzea I, Arana-Arri E. Nutrition, a health technology that deserves increasing interest among HTA doers. A systematic review. Frontiers in Pharmacology. 2015;6(156).

77. Lafranconi A, Wollgast J, Caldeira S. Public health and nutrition economics: the numbers behind prevention (2017)

https://ec.europa.eu/jrc/sites/jrcsh/files/phe_ws_report_020517_online.pdf

78. EUPHA Food and Nutrition Working group. Healthy and Sustainable Diets for European Countries.

Report of a Working Group.

https://eupha.org/repository/advocacy/EUPHA_report_on_healthy_and_sustainable_diets_20-052017.pdf

79. Alsaffar AA. Sustainable diets: The interaction between food industry, nutrition, health and the environment. Food Science and Technology International = Ciencia Y Tecnologia De Los Alimentos Internacional. 2016;22(2):102-11.

80. Donzelli A, Lafranconi A. Effects of low-carbohydrate and low-fat diets. Ann Intern Med.

2015;162(5):391-2.

81. Ruini LF, Ciati R, Pratesi CA, Marino M, Principato L, Vannuzzi E. Working toward healthy and sustainable diets: the "Double Pyramid Model" developed by the Barilla Center for Food and Nutrition to raise awareness about the environmental and nutritional impact of foods. Nutrition and

Environmental Sustainability. 2015;2:9.

82. Dernini S, Berry EM, Serra-Majem L, La Vecchia C, Capone R, Medina FX, et al. Med Diet 4.0: the Mediterranean diet with four sustainable benefits. Public Health Nutrition. 2016:1-9.

83. Grosso G, Fresán U, Bes-Rastrollo M, Marventano S, Galvano F. Environmental Impact of Dietary Choices: Role of the Mediterranean and Other Dietary Patterns in an Italian Cohort. Int J Environ Res Public Health. 2020;17(5).

84. Springmann M, Godfray HCJ, Rayner M, Scarborough P. Analysis and valuation of the health and climate change cobenefits of dietary change. Proceedings of the National Academy of Sciences. 2016;113(15):4146-51.

85. Clonan A, Wilson P, Swift JA, Leibovici DG, Holdsworth M. Red and processed meat consumption and purchasing behaviours and attitudes: impacts for human health, animal welfare and environmental sustainability. Public Health Nutrition. 2015;18(13):2446-56.

86. Fazeni K, Steinmüller H. Impact of changes in diet on the availability of land, energy demand, and greenhouse gas emissions of agriculture. Energy, Sustainability and Society. 2011;1(1):6.

87. Aleksandrowicz L, Green R, Joy EJM, Smith P, Haines A. The Impacts of Dietary Change on Greenhouse Gas Emissions, Land Use, Water Use, and Health: A Systematic Review. PLOS ONE. 2016;11(11):e0165797.

88. Downs SM, Fanzo J. Is a Cardio-Protective Diet Sustainable? A Review of the Synergies and Tensions Between Foods That Promote the Health of the Heart and the Planet. Current Nutrition Reports. 2015;4(4):313-22.

89. Macdiarmid JI. Is a healthy diet an environmentally sustainable diet? Proceedings of the Nutrition Society. 2013;72(01):13-20. 
90. Perignon M, Vieux F, Soler LG, Masset G, Darmon N. Improving diet sustainability through evolution of food choices: review of epidemiological studies on the environmental impact of diets. Nutr Rev. 2017;75(1):2-17.

91. Payne CLR, Scarborough P, Cobiac L. Do low-carbon-emission diets lead to higher nutritional quality and positive health outcomes? A systematic review of the literature. Public Health Nutrition.

2016;19(14):2654-61.

92. González-García S, Esteve-Llorens X, Moreira MT, Feijoo G. Carbon footprint and nutritional quality of different human dietary choices. Sci Total Environ. 2018;644:77-94.

93. Clark MA, Springmann M, Hill J, Tilman D. Multiple health and environmental impacts of foods. Proc Natl Acad Sci U S A. 2019;116(46):23357-62.

94. Guillen J, Natale F, Carvalho N, Casey J, Hofherr J, Druon JN, et al. Global seafood consumption footprint. Ambio. 2019;48(2):111-22.

95. Jennings S, Smith ADM, Fulton EA, Smith DC. The ecosystem approach to fisheries: management at the dynamic interface between biodiversity conservation and sustainable use. Annals of the New York Academy of Sciences. 2014;1322(1):48-60.

96. Hallström E, Carlsson-Kanyama A, Börjesson P, editors. Effect of dietary change on greenhouse gas emissions and land use demand - the state of knowledge in 2014. 9th International Conference on Life Cycle Assessment in the Agri-Food Sector (LCA Food 2014); 2014 2014. San Francisco, California, USA: American Center for Life Cycle Assessment.

97. Tilman D, Clark M. Global diets link environmental sustainability and human health. Nature. 2014;515(7528):518-22.

98. Gökcen BB, Şanlier N. Coffee consumption and disease correlations. Crit Rev Food Sci Nutr. 2019;59(2):336-48.

99. Lafranconi A, Micek A, De Paoli P, Bimonte S, Rossi P, Quagliariello V, et al. Coffee Intake Decreases Risk of Postmenopausal Breast Cancer: A Dose-Response Meta-Analysis on Prospective Cohort Studies. Nutrients. 2018;10(2).

100. Lafranconi A, Micek A, Galvano F, Rossetti S, Del Pup L, Berretta M, et al. Coffee Decreases the Risk of Endometrial Cancer: A Dose-Response Meta-Analysis of Prospective Cohort Studies. Nutrients. 2017;9(11).

101. Micek A, Godos J, Lafranconi A, Marranzano M, Pajak A. Caffeinated and decaffeinated coffee consumption and melanoma risk: a dose-response meta-analysis of prospective cohort studies. Int J Food Sci Nutr. 2018;69(4):417-26.

102. Caini S, Masala G, Saieva C, Kvaskoff M, Savoye I, Sacerdote C, et al. Coffee, tea and melanoma risk: findings from the European Prospective Investigation into Cancer and Nutrition. International Journal of Cancer. 2017;140(10):2246-55.

103. Roberta S. Life cycle assessment applied to coffee production: Investigating environmental impacts to aid decision making for improvements at company level. Journal of Food, Agriculture and Environment. 2003;1(2):295-300.

104. Hannah L, Roehrdanz PR, K C KB, Fraser EDG, Donatti CI, Saenz L, et al. The environmental consequences of climate-driven agricultural frontiers. PLoS One. 2020;15(2):e0228305.

105. Horgan GW, Perrin A, Whybrow S, Macdiarmid JI. Achieving dietary recommendations and reducing greenhouse gas emissions: modelling diets to minimise the change from current intakes. International Journal of Behavioral Nutrition and Physical Activity. 2016;13:46.

106. Swiss Nutrition Society in collaboration with Federal Food Safety and Veterinary Office Swiss Food Pyramid

http://www.sge-ssn.ch/media/sge_pyramid_E_basic_20161.pdf 
107. Public Health Authority of the Slovak Republic. Ten rules of a healthy plate - 2016 http://www.uvzsr.sk/en/docs/info/Letak_Zdravy_tanier_EN.pdf.

108. Public Health England. Eatwell Guide - The most recent model, the Eatwell Guide, 2016 https://www.nhs.uk/Livewell/Goodfood/Documents/The-Eatwell-Guide-2016.pdf.

109. Blackstone NT, Conrad Z. Comparing the Recommended Eating Patterns of the EAT-Lancet Commission and Dietary Guidelines for Americans: Implications for Sustainable Nutrition. Curr Dev Nutr. 2020;4(3):nzaa015.

110. Melkas T. Health in all policies as a priority in Finnish health policy: A case study on national health policy development. Scandinavian Journal of Public Health. 2013;41(11_suppl):3-28.

All links contained in this reference section have been checked on 3 September, 2020 



\section{Relevance for society}

In Europe, 2 people out of 3 die because of chronic diseases, mainly in the form of cardiovascular diseases and cancers. Chronic diseases are deeply related to our choices and lifestyles, for example in the field nutrition: from salt and sugar to vegetables and fish, from fast food to soft drinks, it all has an impact on our body which goes far beyond the meal experience.

People choices on food and nutrition, in turn, are influenced by the environment in which we live, that is shaped by social and cultural norms and values, as well by policies and regulations.

Policies and regulations may be analyzed, for instance measuring their costs and their effects, to produce evidence to establish what is their value and whether should be seen as good practice, for implementation in other settings.

Therefore, aim of my thesis is to assess: How different sources of evidence contribute to European policy making in the field of food and nutrition?

\section{Relevance for policy makers}

Policy makers are well aware of the burden of chronic diseases, in both social and economic terms, and are concerned by the deteriorating nutrition standards observed in the most developed settings. Yet, the current set of policies, at national and at European level, is not fully equipped to deal with the health challenges posed by modern food and nutrition habits.

Policymakers have a wide variety of evidence available: systematic analyses, economic evaluations, analyses of distributional effects, just to name few.

With these observations in mind, my goal has been threefold. First, I approached the current European food and nutrition policy landscape in a systematic way, through environmental lenses, to identify policies that are good for human health and for the environment, too. I found that sustainable dietary guidelines are a low hanging fruit, in the field of nutritional policies with a good impact on environment, too.

Moreover, I assessed whether economic analyses can help policy-makers in identifying and implementing those policies which are good value for money. Particularly, I looked at facilitators and barriers in the use of economic analyses in policymaking, to enable a wider use of economic analyses than the status quo. I found that policymakers and researchers have very different views about barriers, the former pointing out the technical difficulties, the latter blaming a consensusdriven way of action.

Third, the scientific community believes that equal societies are healthy societies, and shies away from policies that widen health inequalities. Taking this into consideration, I examined the policy landscape with a focus on distributional effects, to make sure that the policies identified 
as "best buys" are also those with a beneficial effect on the most disadvantaged ones. I found that reformulation initiatives, with costs bared by the industry, and initiatives aimed at changing the default options might work best in reducing health inequalities at the population level; school interventions were found to be effective in inequalities reduction, too.

\section{Relevance for researchers}

To obtain robust and well-rounded results, I carried out my project with the use of a wide variety of methodological tools, including: literature reviews, policy briefs and content analysis.

Literature reviews are useful to scrutinize the existing scholarly evidence in the studied field, and to identify gaps in research, conflicting data, and open questions. For such reasons, it was chosen for the assessment of the state of art of public health nutritional policies with respect to environment, in Europe. Sustainable dietary guidelines were identified as the way forward, and further research is needed to investigate the long-term effects of the implementation of such guidelines.

Similarly, policy briefs contain concise summary of particular issues; moreover, they contain policy options and recommendations, and have an intrinsic sense of urgency, too. In the present thesis, policy briefs were used to describe: the burden of disease related to the current European dietary patterns; the economic costs of chronic diseases in Europe; the existing healthinequalities in nutrition-related determinants in Europe. While research documenting the health divide in Europe is abundant, there is rather a paucity of evidence on effective policies in reducing such health divide. In public health nutrition, numerous options are viable, especially in the form of universal interventions, in the form of school-based initiatives, reformulation initiatives, and policies aimed at changing our food environment.

On the contrary, content analysis is often use to explore and describe complex phenomena, on which the existing literature is not so abundant to allow for secondary research. In the current dissertation, written interviews were performed to experts, from academia and policymaking settings, in the field of public health nutrition as well as in the field of health economics, with the aim to gain further insights on facilitators and barriers to economic analyses of public health policies, especially in the context of public health nutrition. The research found important asymmetries in documenting perceived gaps and barriers, and argues in favor of the implementation of economic analyses in decision-making settings, despite their technical limitations.

Finally, I presented a case study on coffee, whose health effects on chronic diseases are still controversial. Laying at the interplay of social, economic and environmental aspects, coffee looked like an ideal food to investigate. Our results showed that moderate regular consumption of coffee might be beneficial in preventing certain form of endometrial and breast cancers.

\section{Dissemination}

The creation and dissemination of my findings has been very much facilitated by the Jean Monnet Module "Development for health: the EU role on health explained to students 
of health-related professions", for which I acted as Coordinator, at University of MilanoBicocca, years 2016-2019.

The Module was structured on three parallel tiers: the first tier consisted of lectures in the field of environmental health (1st year), nutrition (2nd year) and public health (3rd year), whose concepts were delivered by frontal lectures, non-formal learning sessions and practical activities. About one hundred medical students attended the Module in the three years.

The second tier focused on research: open data and data collected in literature through systematic searches were analyzed, to address societal questions; results of the present thesis were presented at the European Health Forums Gastein (years 2016, 2017) and at the European Public Health Conferences (years 2017, 2018).

The third tier aimed at fostering connections between the Module participants and the external environment (research organizations, NGOs and civil society). Among others, it's worth mentioning the collaboration with the Italian Consumer Health Association Altroconsumo, which worked in a mutual way of exchange: the students participated to workshops organized by Altroconsumo / BEUC and found opportunities to engage with the civil society. On the other hand, I was invited to share some of my results to high-school teachers, in the frame of a lifelong learning programme organized by Altroconsumo itself and our Region, Lombardy.

A dedicated website supported the dissemination of educational materials and key documents, including published open access papers and in-house produced visual material (power points, posters and videos).

Other than the Jean Monnet Module related activities, some results of the present dissertation were transferred into further projects and public health reports, published by the EUPHA and the JRC.

\section{Innovation}

The innovation aspect of the present dissertation can be well argumented through two different lines of thoughts.

First, the scientific rationale is per se innovative: while academic research might not go beyond academia itself, this work goes far beyond the technical aspects, to equip decision-makers in the field of public health nutrition with strong evidence in favor of comprehensive, equality-driven, and cost-effective policy options.

Second, the dissemination aspect is innovative, too: in Italian academic settings, especially where the course of study is extremely technical (e.g. medicine and healthcare professions), students have often proved to be willing to study and discuss health policies, but often do not have the means to do so. This dissertation, whose findings have been produced and disseminated during the aforementioned Jean Monnet Module, proved to be a useful starting point to facilitate a notion-rich debate in public health among students of medicine and healthcare professions. 

The reduction of the burden of diet-related non-communicable diseases, whose highest impact is felt by those people laying at the lowest segment of the socio-economic spectrum, and the sustainability of our food systems are among the key challenges of the European Union. Regional, national and local policies to facilitate universal access to safe and nutritious food, as well as a sustainable food supply, are the most important tools to meet the challenges and should therefore be evaluated and, if effective and economically savvy, should be implemented, at the right level.

The aim of the thesis has been threefold: first, to identify public health nutrition policies with a positive effect in reducing health inequalities. Second, to examine current experiences in economic evaluations of public health nutrition policies. Third, to assess synergies between health and environment in order to reshape current patterns of food production and consumption. Moreover, given its effects on health, environment and social justice, a case-study on coffee is presented.

Considering the breadth and the complexity of the topic, the studies in this dissertation are grouped in three core parts, corresponding to the three essential operators in public health (i.e. promotion, protection, prevention): unequal distribution of dietary-related health determinants, policies to address redistribution effects and economic evaluation of public health nutrition policies compose the first part, health promotion. The second part, health protection, consists of the analysis of environmental impacts of current patterns of food production and consumption, to identify policy options that co-optimize health and environmental benefits. Two studies on the relationship between coffee consumption and women cancers constitute part three, disease prevention.

The dissertation opens with an introductory overview on the burden of non-communicable diseases and related costs in the EU, and on the abundance (yet not consensual in terms of expected impacts) of public health nutrition policy options to improve our current food environment.

In Part I, a policy brief is presented, to document existing levels of health inequalities, both between and within countries, and to propose diet-related policies that target such gaps: universal interventions, such as school schemes, reformulation initiatives and policies aimed at changing the default options, were found to be particularly effective in reducing health inequalities. Moreover, facilitators and barriers to economic analyses of public health policies are evaluated through a content analysis, and were found to be different between policymakers and researchers: the former are most concerned with technical difficulties, the latter believe that evidence has little power in steering and influencing policymaking. 
In Part II, environmental aspects are taking into consideration, in addition to the already examined health and economic arguments. A scoping review provides evidence-based policy recommendations: in the current limited and fragmented panorama of actions to incorporate sustainability into food systems, sustainable dietary guidelines are identified as the way forward to achieve health and environmental benefits simultaneously.

In Part III, a case study is discussed: the performed systematic reviews and meta-analyses showed that coffee, whose consumption has been suggested to improve metabolic health and to decrease the risk of mortality, is associated with decreased risk of endometrial cancer in women, regardless of their menopausal status, and with decreased risk of endometrial cancer in post-menopausal women.

Taken together, this thesis highlights the high and unequal burden of chronic diseases, related to our current dietary patterns. It calls for effective redistributive public health nutrition policies, especially in universal forms, and for environmentally-oriented policies, such as sustainable dietary guidelines. Finally, it underlines that there is little consensus on how public health nutrition policies should be evaluated and implemented; it recommends that technical and implementation barriers to economic evaluation are comprehensively addressed, to avoid shifting responsibilities between researchers and policy makers. 


\section{Sommario}

L'elevato impatto delle malattie croniche legate all'alimentazione, che affligge soprattutto coloro che si trovano nel segmento più basso dello spettro socio-economico, e la sostenibilità dei nostri sistemi alimentari sono tra le sfide chiave dell'Unione Europea . Le politiche sovra-nazionali, nazionali e locali per facilitare l'accesso universale a cibo sicuro e nutriente, nonché un approvvigionamento alimentare sostenibile, sono gli strumenti più importanti per affrontare tali sfide; queste azioni politiche dovrebbero quindi essere costantemente valutate e, se ritenuti efficaci ed economicamente ragionevoli, dovrebbero essere attuate, al giusto livello.

Lo scopo della tesi è stato triplice: primo, identificare le politiche nutrizionali di salute pubblica con un effetto positivo nella riduzione delle disuguaglianze di salute. In secondo luogo, esaminare le attuali esperienze nelle valutazioni economiche delle politiche nutrizionali per la salute pubblica. Terzo, valutare le sinergie tra salute e ambiente al fine di rimodellare gli attuali modelli di produzione e consumo di cibo. Inoltre, visti i suoi effetti su salute, ambiente e giustizia sociale, viene presentato un caso di studio sul caffè.

Considerando l'ampiezza e la complessità dell'argomento, gli studi di questa dissertazione sono raggruppati in tre parti, corrispondenti ai tre operatori essenziali nella salute pubblica (cioè promozione, protezione, prevenzione). In particolare, l'analisi della distribuzione diseguale dei determinanti di salute legati all'alimentazione, delle politiche nutrizionali aventi effetti sulle diseguaglianze e la valutazione economica di tali politiche compongono la prima parte, incentrata sulla promozione della salute. La seconda parte, che corrisponde alla prevenzione o tutela della salute, consiste nell'analisi degli impatti ambientali degli attuali modelli di produzione e consumo di cibo, per identificare le opzioni politiche che co-ottimizzano i benefici per la salute e l'ambiente. Due studi sulla relazione tra consumo di caffè e tumori delle donne costituiscono la terza parte, la prevenzione delle malattie.

La dissertazione si apre con una panoramica introduttiva sull'impatto delle malattie croniche e relativi costi economici nell'UE, e sull'abbondanza (ancora non consensuale in termini di impatti attesi) di opzioni di politica nutrizionale per la salute pubblica, per migliorare il nostro attuale ambiente alimentare.

Nella Parte I, viene presentato un documento programmatico, per documentare i livelli esistenti di disuguaglianze sanitarie, sia tra i Paesi che all'interno di essi, e per proporre politiche relative all'alimentazione che colmino tali divari: interventi universali (come progetti rivolti alle scuole, e iniziative di riformulazione alimentare) e politiche mirate a modificare l'ambiente alimentare in cui siamo immersi si sono rivelati particolarmente efficace nel ridurre le disuguaglianze di salute. Inoltre, i facilitatori e le barriere all'analisi economica delle politiche di salute pubblica sono stati valutati attraverso un'analisi del contenuto. Si è osservato che, mentre i responsabili politici percepiscono come principale barriera all'attuazione di analisi economiche di politiche pubbliche le difficoltà tecniche delle analisi stesse, i ricercatori credono invece che le analisi abbiano di fatto scarso potere nel guidare e influenzare il processo decisionale. 
Nella Parte II vengono presi in considerazione gli aspetti ambientali, oltre agli argomenti sanitari ed economici già esaminati. Una revisione narrativa fornisce raccomandazioni politiche basate sull'evidenza: nell'attuale panorama di azioni limitate e frammentate volte ad incorporare la sostenibilità nei sistemi alimentari, è strategico focalizzarsi sulla creazione di linee guida nazionali per una alimentazione che sia non solamente sana, ma anche sostenibile.

Nella Parte III, viene discusso un caso di studio. Le revisioni sistematiche e le meta-analisi effettuate hanno mostrato che il caffè, il cui consumo è stato storicamente associato a migliori outcome metabolici e ad un ridotto rischio di mortalità, è risultato correlato ad un minor rischio di cancro dell'endometrio nelle donne, indipendentemente dal loro stato menopausale, e ad un ridotto rischio di cancro dell'endometrio nelle donne in post-menopausa.

In conclusione, questa tesi evidenzia l'impatto, elevato e diseguale, delle malattie croniche legate ai nostri attuali modelli alimentari. Identifica la necessità di politiche di nutrizione per la salute pubblica che siano efficaci nel ridurre le ineguaglianze (soprattutto quando applicate in forma di politiche universali) e di politiche orientate all'ambiente (come le linee guida per una alimentazione sana e sostenibile, redatte a livello nazionale). Infine, sottolinea che c'è poco consenso su come valutare e attuare le politiche nutrizionali per la salute pubblica; consiglia quindi di affrontare gli ostacoli tecnici e attuativi alle valutazioni economiche delle politiche sanitarie in modo completo e simultaneo, per evitare lo spostamento di responsabilità tra ricercatori e responsabili politici. 


\section{Samenvatting}

De verlaging van voedingsgerelateerde, niet-overdraagbare ziekten, waarvan de mensen uit het laagste segment van het sociaaleconomische spectrum de meeste last ondervinden, en de duurzaamheid van onze voedselsystemen behoren tot de belangrijkste uitdagingen van de Europese Unie. Regionaal, nationaal en lokaal beleid om universele toegang tot veilig en voedzaam voedsel te vergemakkelijken, evenals een duurzame voedselvoorziening, zijn de belangrijkste middelen om die uitdagingen aan te gaan en zouden daarom moeten worden geëvalueerd en, indien effectief en economisch verantwoord, op het juiste niveau moeten worden geïmplementeerd.

Het doel van het proefschrift is drieledig: ten eerste om het volksgezondsheidbeleid inzake voeding te identificeren waarbij een positief effect optreedt bij het verminderen van ongelijkheid op gezondheidsgebied. Ten tweede, de bestaande ervaringen in economische evaluaties van het volksgezondheidsbeleid inzake voeding te onderzoeken. Ten derde, om de synergie tussen gezondheid en milieu te beoordelen teneinde de huidige patronen van voedselproductie en consumptie om te vormen. Bovendien wordt, gezien de effecten op gezondheid, milieu en sociale rechtvaardigheid, een gevalsstudie over koffie gepresenteerd.

Gezien de breedte en de complexiteit van het onderwerp, zijn de studies in dit proefschrift gegroepeerd in drie hoofdgroepen, die overeenkomen met de drie essentiële actoren in de volksgezondheid (d.w.z. promotie, bescherming, preventie): ongelijke verdeling van voedingsgerelateerde gezondheidsdeterminanten, beleid om herverdelingseffecten aan te pakken en economische evaluatie van het voedingsbeleid in het kader van volksgezondheid vormen het eerste deel: gezondheidsbevordering. Het tweede deel, gezondheidsbescherming, bestaat uit een analyse van milieu-effecten van de huidige patronen van voedselproductie en consumptie, om beleidsopties te kunnen identificeren die de gezondheids- en milieuvoordelen samen optimaliseren. Twee onderzoeken naar de relatie tussen koffieconsumptie en kanker bij vrouwen vormen deel drie: ziektepreventie.

Het proefschrift begint met een inleidend overzicht van de last van niet-overdraagbare ziekten en daaraan gerelateerde kosten in de EU, en de overvloed (edoch zonder consensus in termen van verwachte effecten) aan beleidsmogelijkheden voor wat betreft volksgezondheidsbeleid inzake voeding om onze huidige voedselomgeving te verbeteren.

In deel I wordt een beleidsnota gepresenteerd om de bestaande niveaus in kaart te brengen van ongelijkheden op gezondheidsgebied, zowel tussen als binnen landen, en om voedingserelateerd beleid voor te stellen dat gericht is op zo'n kloof: universele interventies, zoals regelingen voor scholen, herformuleringsinitiatieven en beleid gericht op verandering van de standaardopties, bleken bijzonder effectief te zijn bij het verkleinen van verschillen op gezondheidsgebied. Voorts zijn facilitatoren en belemmeringen voor economische analyses van volksgezondheidsbeleid geëvalueerd door middel van een inhoudsanalyse; er bleken verschillen te zijn tussen beleidsmakers en onderzoekers: de eerste groep is het meest bezorgd over technische 
problemen, de laatste groep is van mening dat bewijs weinig kracht heeft om de beleidsvorming te sturen en te beïnvloeden.

In deel II wordt, naast de reeds bestaande milieu-aspecten, ook rekening gehouden met reeds onderzochte gezondheids- en economische argumenten. Een scoping review geeft evidencebased beleidsaanbevelingen: in het huidige beperkte en gefragmenteerde panorama van te nemen acties om duurzaamheid in voedselsystemen te integreren, worden duurzame voedingsrichtlijnen gezien als de manier waarop zowel gezondheids- als milieuvoordelen te behalen zijn.

In deel III wordt een case study besproken: de uitgevoerde systematische reviews en metaanalyses lieten zien dat koffie, waarvan werd aangenomen dat deze de metabolische gezondheid zou verbeteren en het risico op sterfte te verminderen, in verband wordt gebracht met een verminderd risico op baarmoederslijmvlieskanker bij vrouwen, ongeacht hun menopauzale status, alsmede een verminderd risico op baarmoederslijmvlieskanker na de menopauze.

Alles bij elkaar belicht dit proefschrift de hoge en ongelijk verdeelde last van chronische ziekten, gerelateerd aan onze huidige voedingspatronen. Het vraagt om een doeltreffend volksgezondsheidbeleid inzake voeding, vooral in universele vormen, en om milieugericht beleid, zoals duurzame voedingsrichtlijnen.

Ten slotte wordt benadrukt dat er weinig consensus bestaat over de manier waarop volksgezondheidsbeleid inzake voeding geëvalueerd en geïmplementeerd moet worden en wordt er geadviseerd om technische en implementatiebelemmeringen voor economische evaluaties uitvoerig aan te pakken en ook om grenzen aan te geven zodat verschuiving van verantwoordelijkheden tussen onderzoekers en beleidsmakers wordt voorkomen. 


\section{List of abbreviations}

BAU: Business As Usual

BMI: Body Mass Index

BRCA: Breast Related Cancer Antigens

CBA: Cost-Benefit Analysis

CDC: Centers for Disease Control and Prevention

CEA: Cost-Effectiveness Analysis

CI: Confidence Interval

CRP: C-Reactive Protein

CUA: Cost-Utility Analysis

CVD: Cardio-Vascular Disease

DALYs: Disability-Adjusted Life Years

EC: European Commission

ECHI: European Core Health Indicator

EPHOs: Essential Public Health Operations

EU: European Union

EUPHA: European Public Health Association

FACCE JPI: Joint Programming Initiative on Agriculture, Food Security and Climate Change

FAO: Food and Agriculture Organization

FAOSTAT: Food and Agriculture Organization Corporate Statistical Database

FBDG: Food Based Dietary Guidelines

FEAD: Fund for European Aid to the Most Deprived

GBD: Global Burden of Disease

GDP: Gross Domestic Product

GHGEs: Green House Gas Emissions

GHGs: Green House Gases

GIS: Geographic Information System

GLS: Generalized Least-Squares

HAV: Hepatitis A Virus

HBP: High Blood Pressure 
HDHL JPI: Joint Programming Initiative on Healthy Diet for Healthy Life HiAP: Health in All Policies

HR: Hazard Ratio

IA: Impact Assessment

IHD: Ischaemic Heart Disease

IMHE: Institute for Health Metrics and Evaluation

ISCED: International Standard Classification of Education

JRC: Joint Research Centre of the European Union

MOOSE: Meta-Analysis of Observational Studies in Epidemiology

NAFLD: Non Alcoholic Fatty Liver Disease

NCDs: Non-Communicable Diseases

OECD: Organization for Economic Co-operation and Development

PHEE: Public Health Economic Evaluation

PHEIAC: Public Health Evaluation and Impact Assessment Consortium

PUFAs: Poly-Unsaturated Fatty Acids

QALYs: Quality-Adjusted Life Years

RR: Relative Risk

SES: Socio-Economic Status

SGD: Sustainable Development Goals

SHBG: Sex Hormone Binding Globulin

SiAP: Sustainability in All Policies

SSBs: Sugar-Sweetened Beverages

TFA: Trans-Fatty Acids

TFEU: Treaty on the Functioning of the European Union

UN: United Nations

WHO: World Health Organization

YLDs: Years of Life with Disabilities

YLLs: Years of Life Lost 


\section{Acknowledgments}

During my $\mathrm{PhD}$ journey, I have had the opportunity to learn and grow both as a researcher and as an individual. This endeavor could not have possible been accomplished without the valuable effort and support of many people to whom I wish to extend my gratitude and sincerest thanks.

First and foremost, I am truly grateful to my promotor, Prof. Katarzyna Czabanowska, who inspired me from the very first moment. During 2013 EPH Conference, I participated to a EUPHA workshop where Katarzyna was walking us down the impervious streets of European Funds for Public Health. The following year, I would have scheduled a mentoring session with her, to get further insight to her topic. And, as a consequence to her expert advices, I was able to gain the 2016-19 Jean Monnet Professorship. The 2017 Salzburg leadership training, where we had the occasion to sit down and sketch the years ahead, represented another milestone towards the achievement of my PhD. In the past few years, she has constantly pushed me to challenge my limits, without ever doubting of my capabilities and success: it felt terrific!

During 2015 EPH Conference, I met Prof. S . Back then, I wouldn't have imagined the importance of her supervision, guidance and critical reflections. Many were the calls challenged by time zones. Many more the insights and the lessons learned. Thank you very much for your commitment and for sharing your expertise!

Special thanks to Prof. D. Helmut Brand, whom I met the first time in Bad Hofgastein, in fall 2014. Back then, I was attending my first EHFG as Young Gasteiner and Helmut's welcoming words, marked by the slogan "Your success is our success!" still sound fresh and clear in my heart. You were right, dear Helmut, and far beyond Gastain Valley: my $\mathrm{PhD}$ is our success!

In that spirit, I would like to convey my thanks and appreciation to the members of the assessment committee for their time reading critically through this dissertation and taking the effort to discuss it with me during the defense. I would also like to give sincere gratitude to the co-authors of the papers here collected. Special thanks to Anita Creusen who has always given her administrative and practical support.

Lastly, but definitely most importantly, I would like to thank my family and friends. I wish to express my grateful and heartfelt thanks to my beloved husband and daughter, Lorenzo and Lucia, for always supporting me, and my family of origin, for providing me the time, peace and tranquility for writing, while taking care of Lucia.

I owe my sincerest thanks and appreciation to Eva, Agnieszka, Vladimir, Giuseppe, Mattia, Christoph and Su-Mia for piloting my drafts, helping out with practical advices and supporting me in any possible way.

Thank you! Grazie! Bedankt! 



\section{Curriculum Vitae}

Alessandra Lafranconi was born on 23 April 1985 in Desio, Milan, Italy. She studied Medicine at the University of Milano Bicocca, where she obtained her MD in 2010, with a thesis on "Environmental effects on hospital admissions and drug consumptions for cardio-respiratory illnesses: analyses on multiple samples from Lombardy" (Italian). Alessandra holds a Master of Science Degree in Environmental and Public Health, Cyprus University in association with the Harvard TH Chan School of Public Health (Master thesis: "Understanding costs and benefits of physical activity interventions: the case of cardiovascular health in EURO-A sub-region"). After her MSc (2011), Alessandra moved back to Italy to obtain the MD National Certification (2012) and to enroll in the Residency Course of Public Health, at the University of Milano Bicocca, where she discussed her thesis "Diet and Physical Activity: From Evidence to Economic Evaluation and Policy Development" in 2017.

Alessandra started her professional career as stagier at the World Health Organization (WHO), Department of Environmental Health (2010), where she was assigned to translational research in public health, in the field of climate change. For six years, from 2012 to 2018, she has been working as researcher and public health practitioner at local, national and international level, with policy, scientific, and science to policy roles. She carried out numerous projects on health promotion, disease prevention and health protection. Thanks to her expertise in public health nutrition, she was assigned few consultancy positions from governmental bodies and civil society bodies, namely: WHO, European Commission, Lombardy Region, Altroconsumo. In 2016, she spent one full year as visiting scientist at the Joint Research Centre, the inhouse research centre of the European Union.

Meanwhile, in 2016, Alessandra started her PhD trajectory as external candidate at the CAPHRI school of Maastricht University, Department of International Health. The focus of her PhD has been public health nutrition policymaking and its multiple facets in Europe. Throughout her $\mathrm{PhD}$ track, Alessandra has taken on various teaching roles in the field of public health, mainly at the University of Milano Bicocca, where she held a three-year Jean Monnet Professorship to develop and teach public health modules through European lenses (food and nutrition, 201617; environmental health, 2017-18; healthcare and public health, 2018-19). Moreover, from 2014 to 2019, Alessandra served the EUPHA Food and Nutrition Section as section active member.

In May 2018, intrigued by its result-oriented approach, Alessandra moved to the pharmaceutical sector, with the role of Medical Advisor Urology - Gastroenterology - Pediatrics, at Ferring Pharmaceuticals, Italian Affiliate. In June 2020, she was promoted to a leading position, and since then she has been coordinating the Italian Medical Team, while being the single point of contact between University of Milano Bicocca and Ferring Pharmaceuticals. 



\section{List of publications}

\section{Full text publications}

Lafranconi A, Meusel V, Caldeira S, Babich S, Czabanowska K, Facilitators and barriers to the use of economic evaluations in nutrition and public health, South Eastern European Journal of Public Health, 2020, doi.org/10.4119/seejph-3271

Berretta M, Micek A, Lafranconi A, Rossetti S, Di Francia R, De Paoli P, Rossi P, Facchini G "Coffee consumption is not associated with ovarian cancer risk: A dose-response meta-analysis of prospective cohort studies”, Oncotarget, 2018, doi: 10.18632/oncotarget.24829

Lafranconi A, Micek A, De Paoli P, Bimonte S, Rossi P, Quagliariello V, Berretta M “Coffee Intake Decreases Risk of Postmenopausal Breast Cancer: A Dose-Response Meta-Analysis on Prospective Cohort Studies”, Nutrients, 2018, doi: 10.3390/nu10020112

Lafranconi A, Micek A, Galvano F, Rossetti S, Del Pup L, Beretta M, Facchini G “Coffee decreases risk of endometrial cancer: a dose-response meta-analysis of prospective cohort studies", Nutrients, 2017, doi:10.3390/nu9111223

Lafranconi A, Pylkkanen L, Deandrea S, Bramesfeld A, Lerna D, Neamtiu L, Saz Parkinson Z, Posso M, Rigau D, Sola I, Alonso Coello P, Martínez Zapata MJ "Intensive follow-up for women with breast cancer: review of clinical, economic and patient's preference domains through evidence to decision framework", Health and Quality of Life Outcomes, 2017, doi: 10.1186/s12955-017-0779-5

Lafranconi A, Birt C “ 'Du bist was du isst'—challenges in European nutrition policy”, European Journal of Public Health, 2017, doi: 10.1093/eurpub/ckx162

Micek A, Godos J, Lafranconi A, Marranzano M, Pajak A “Caffeinated and decaffeinated coffee consumption and melanoma risk: a dose-response meta-analysis of prospective cohort studies", International Journal of Food Sciences and Nutrition, 2017, doi: 10.1080/09637486.2017.1373752

Prosperini A, Berrada H, Ruiz MJ, Caloni F, Coccini T, Spicer LJ, Perego MC, Lafranconi A "A Review of the Mycotoxin Enniatin B" Front Public Health, 201, doi: 10.3389/fpubh.2017.00304 


\section{Other relevant publications}

Lafranconi A, Ray S, Grosso G, "Public health nutrition: assessing evidence to determine policy and practice" Front Public Health, 2019, doi: 10.3389/fpubh.2019.00021

Lafranconi A, Wollgast J, Caldeira S, "Public health and nutrition economics: the numbers behind prevention”. Ispra, 2017

Lafranconi A, Rieger K, “Teaching Public Health through EU lenses”, Going International, 2017, Vol. 2

EUPHA Food and Nutrition Section. "Healthy and Sustainable Diets for European Countries. Report of a Working Group. EUPHA”. Utrecht, 2017

Lafranconi A, Rieger K, Ivankovic D, Vasiliu A, Cianci F, Czabanowska K, “Addressing gaps and needs in public health leadership academic courses in the European Region”, Eurohealth, 2016, Vol. 22, pp 10-13

Lafranconi A, "Food \& nutrition: from numbers to policies", in Sironi VA "Le declinazioni del cibo. Nutrizione, salute, cultura ”, Editori Laterza, 2016, ISBN 978-8858123355

Lafranconi A, Gomes BL, Stankunas M, Babich SM, Rethmeier K; Czabanowska K, "Medical leadership: from inspiration to education", Comment on Horton, The Lancet, 2015, Vol. 386, No 10003, pp 1531-1532

Lafranconi A, Birt C, "How best to use the EXPO momentum to improve our food environment?”, European Journal of Public Health, 2015, Vol. 25, No 5, pp 751-752

Association of Schools of Public Health in the European Region (ASPHER) 2018, Foldspang A et al., ASPHER's European List of Core Competences for the Public Health Professional, Scandinavian Journal of Public Health 2018. 2018 Nov;46(23_suppl):1-52 (Acknowledgments, Nutrition Advisory Expert Group) 


\section{Conference presentations}

Lafranconi A, "The EUPHA report on Healthy and Sustainable Diets: How the report was developed, and its recommendations", 11 th EPH Conference, Ljubljana, 2018

Lafranconi A, Rangelov N, "Methods and Findings" in "Healthy and Sustainable Diets for European Countries”, 10 $10^{\text {th }}$ EPH Conference, European Journal of Public Health, 2017, Vol 27 (suppl 3), p 238

Lafranconi A, Cesana GC, "Cost-effectiveness of physical activity interventions in four European countries", 10 $10^{\text {th }}$ EPH Conference, European Journal of Public Health, 2017, Vol 27 (suppl 3), p 96

Lafranconi A, Czabanowska K, Caldeira S, Cesana GC, "Facilitators and barriers in economic evaluations of nutrition interventions and policies", $10^{\text {th }} \mathrm{EPH}$ Conference, European Journal of Public Health, 2017, Vol 27 (suppl 3), p 512

Lafranconi A, Czabanowska K, Cesana GC, "Physical activity as part of the Mediterranean style: cost-effectiveness evaluations in four European countries", Mediterranean Diet \& Health, Halkidiki, 2017 (Forum Prize)

Lafranconi A, Caldeira S, Czabanowska K, "Facilitators and barriers to the use of economic evaluations in nutrition and public health", Young Forum Gastein - EHFG, Bad Hofgastein, 2017

Lafranconi A, Wollgast J, Caldeira S, "Nutrition \& Physical Activity Inequalities in the EU”, Young Forum Gastein - EHFG, Bad Hofgastein, 2016 (Forum Prize)

Rieger K, Lafranconi A, Gomes B, Ploeg L, Halfmann S, Zurriaga Carda R, "The EU Policies and

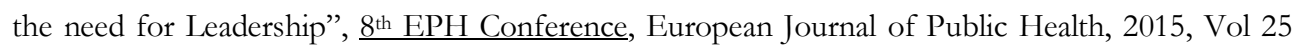
(suppl 3), p 252

Lafranconi A, Evans JS, Cesana GC, "Physical Activity Interventions: Costs, Benefits \& Why Should We Care", 7th EPH Conference - ASPHER Forum, Glasgow, 2014 (Forum prize)

Lafranconi A, Conti S, Donghi E, Cazzato N, Ferraroli A, Cesana GC, Gattinoni A, "A five yearassessment of children nutritional status in a district of Northern Italy: the impact of season", 7 th EPH Conference, European Journal of Public Health, 2014, Vol 4 (suppl 2), p 296

Lafranconi A, Evans JS, Cesana GC, "Understanding costs and benefits of physical activity interventions: the case of cardiovascular health in EURO-A sub-region", CPHA Conference, Toronto, 2014

Lafranconi A, Evans JS, Cesana GC, "How well do we understand costs and benefits of physical activity programs and campaigns?", 5 th EPH Conference, European Journal of Public Health, 2012, Vol 22, pp 15-16 
